$$
\begin{gathered}
\text { MASTER } \\
\text { NEGATIVE } \\
\text { NO. 92-80754-2 }
\end{gathered}
$$




\section{MICROFILMED 1992 \\ COLUMBIA UNIVERSITY LIBRARIES/NEW YORK}

as part of the
"Foundations of Western Civilization Preservation Project"

Funded by the
NATIONAL ENDOWMENT FOR THE HUMANITIES

Reproductions may not be made without permission from Columbia University Library 


\section{COPYRIGHT STATEMENT}

The copyright law of the United States -- Title 17, United States Code -- concerns the making of photocopies or other reproductions of copyrighted material...

Columbia University Library reserves the right to refuse to accept a copy order if, in its judgement, fulfillment of the order would involve violation of the copyright law. 
AUTHOR:

HERBERT, SOLOMON

TITLE:

THE FIRST

PRINCIPLES

OF EVOLUTION . . .

PLACE:

LONDON

DATE:

1913 


\section{COLUMBIA UNIVERSITY LIBRARIES \\ PRESERVATION DEPARTMENT}

\section{BIBLIOGRAPHIC MICROFORM TARGET}

\section{Original Material as Filmed - Existing Bibliographic Record}

Original Material as filmed-Existing Bibliographic Record

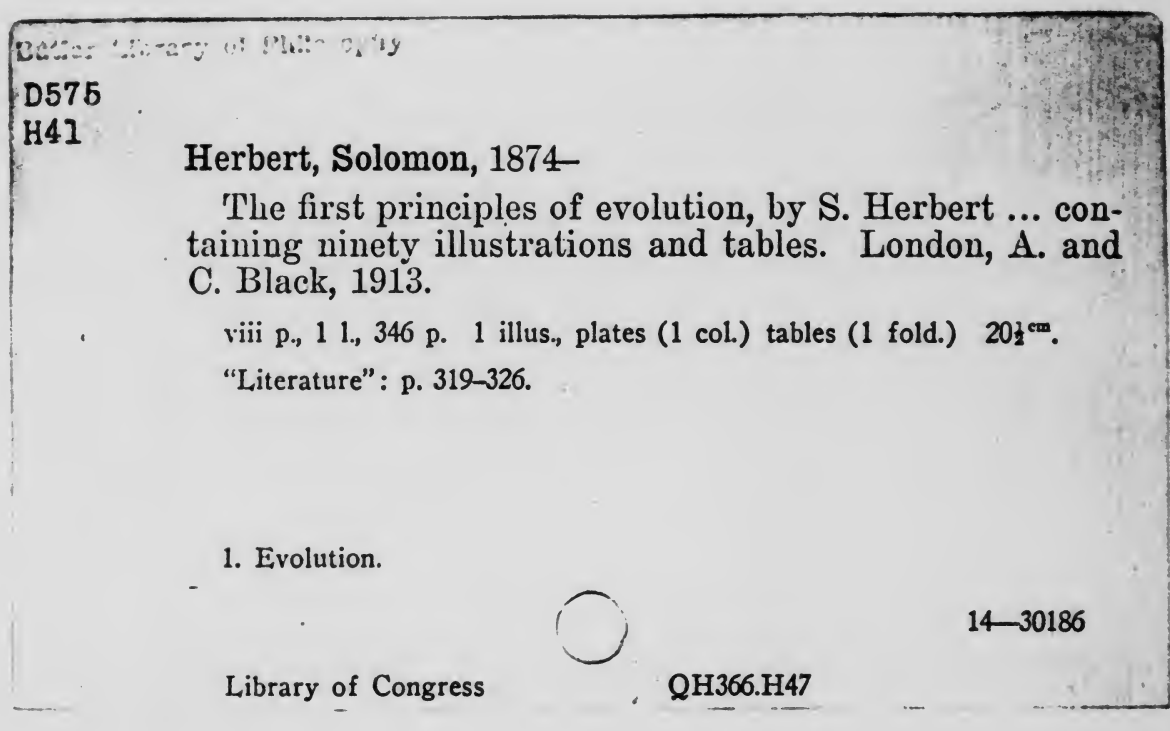

Restrictions on Use:

TECHNICAL MICROFORM DATA

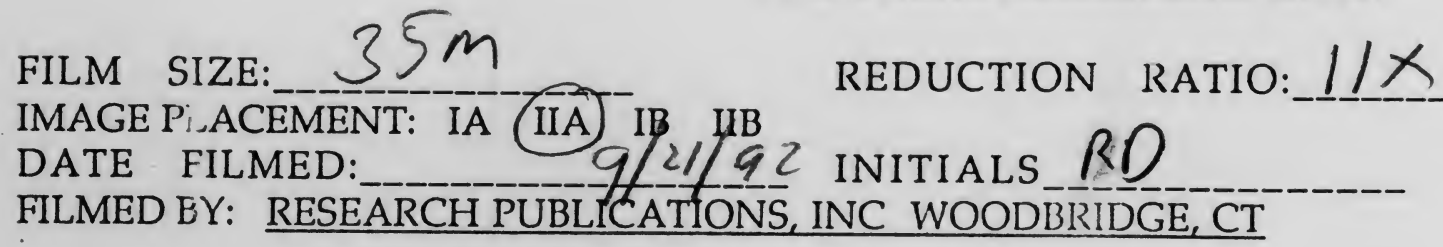




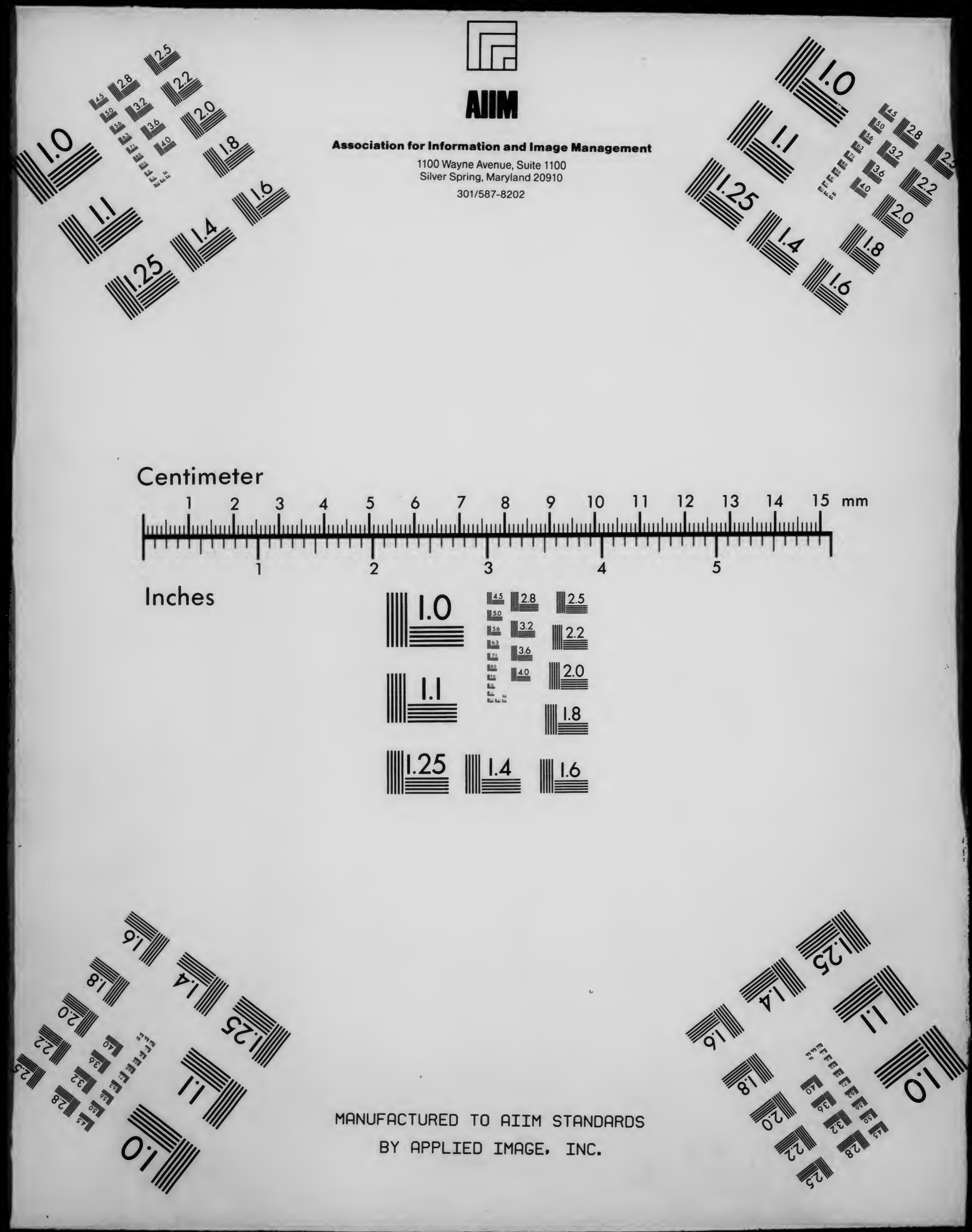




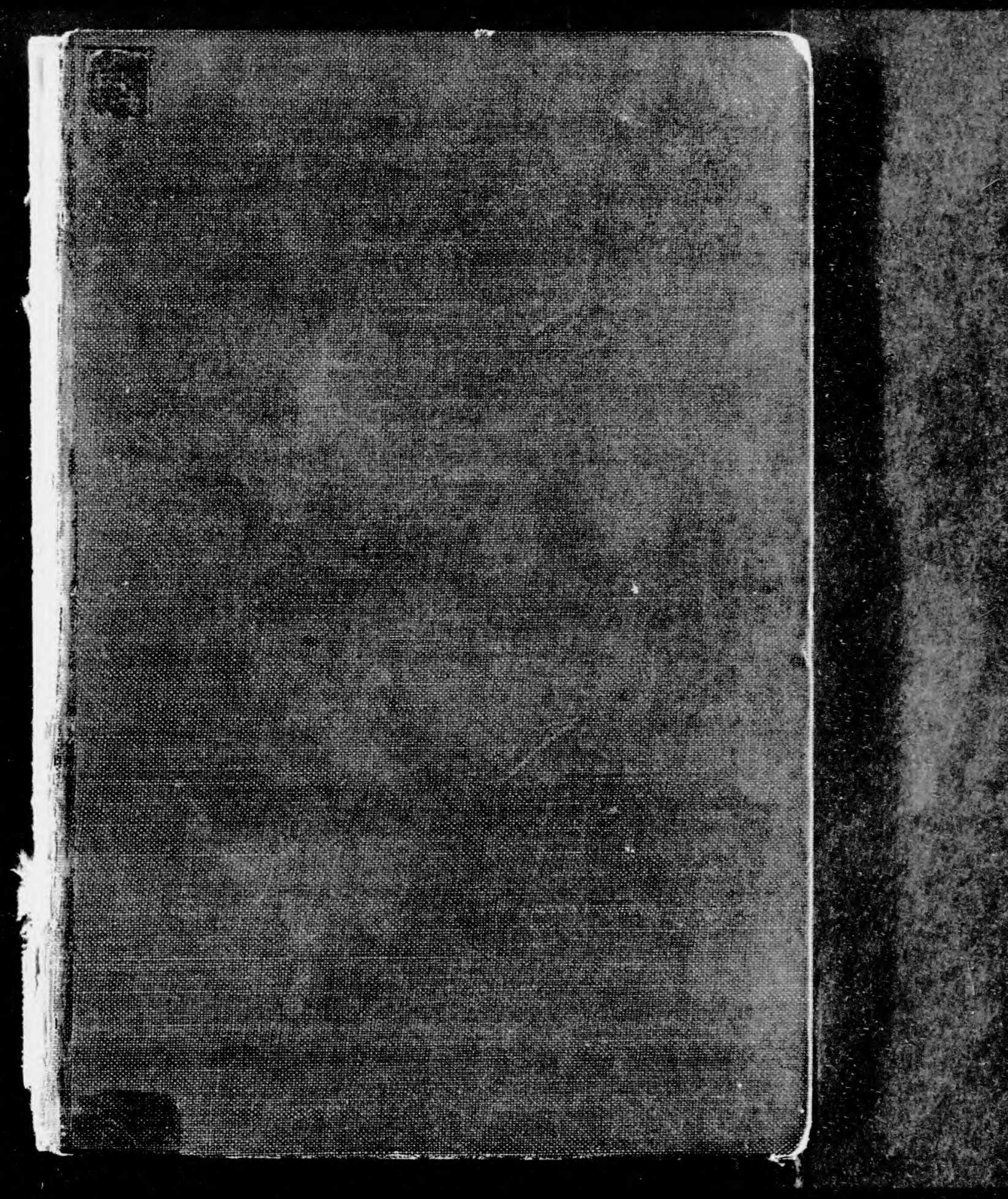




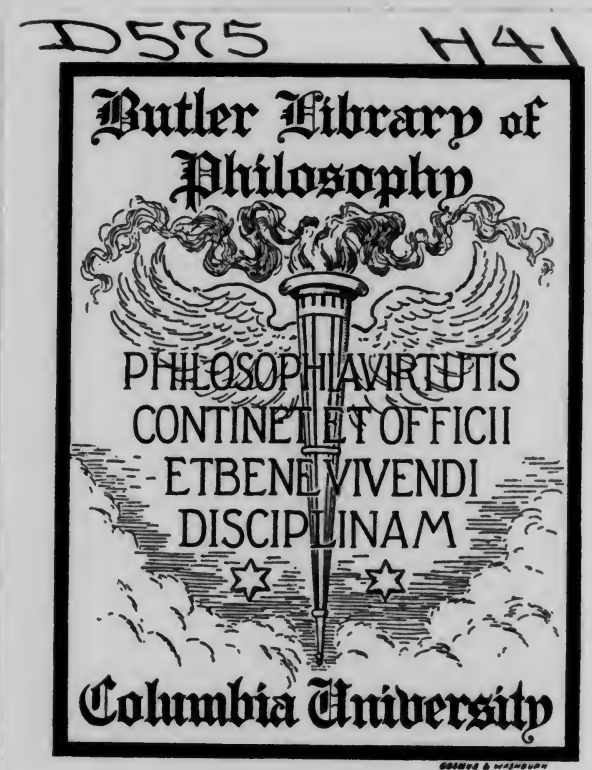




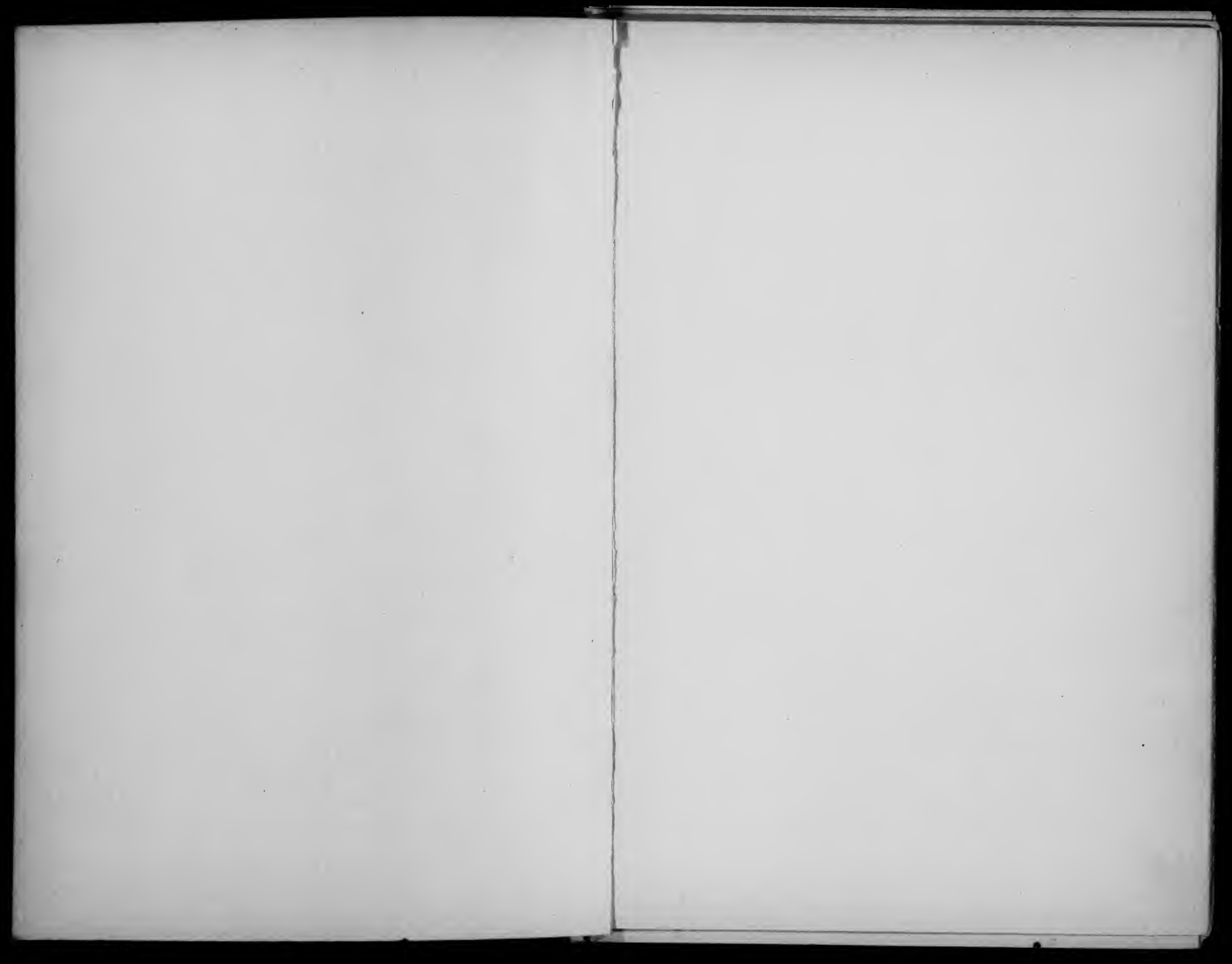


THE FIRST PRINCIPLES OF EVOLUTION 


\section{THE FIRST PRINCIPLES OF \\ EVOLUTION}

THE FIRST PRINCIPLES HEREDITY

CONTAINING 75 Diagrams AND ILLUStrations Large Crown 8vo., cloth Price 5 s. net (by post 5s. 4 d.)

"Dr. Herbert has produced a book which we think will be widely read and int al. wicen tudents very usefully. The text is clearly written, without any superfluous wordiness, and conveniently divided into sections. The diagrams and illustrations adopted from various sources have been judiciously chosen, and do much to throw beginuers, and the printing and pase are very pleasant."-Manchester Guardian.

PUBLISHED BY
A. AND C. BL.ACK 4 SOHO SQUARE. LONDON, W.

\section{AGENTS}

AMERTCA . . . . THE MACMILLAN COMPANY

AUBTRALARIA . . . OXFORD UNIVERSITY PRESS

CANADA . . . . . THE MACMILLAN COMPANY OF CANADA L.TD.
ST, MARTIN'S HOUSB, 70 BOND STRERT, TURONTO

WDL . . . . . MACMILLAN \& COMPANY, LTD.
BY

\section{S. HERBERT}

M.D. (VIENNA), M.R.C.S. (ENGL.), L.R.C.P. (LOND.) AUTHOR OF "THE FIRST PRINCIPLES OF HEREDITY"

CONTAINING NINETY ILLUSTRATIONS AND TABLES

\section{LONDON}

ADAM AND CHARLES BLACK I913 


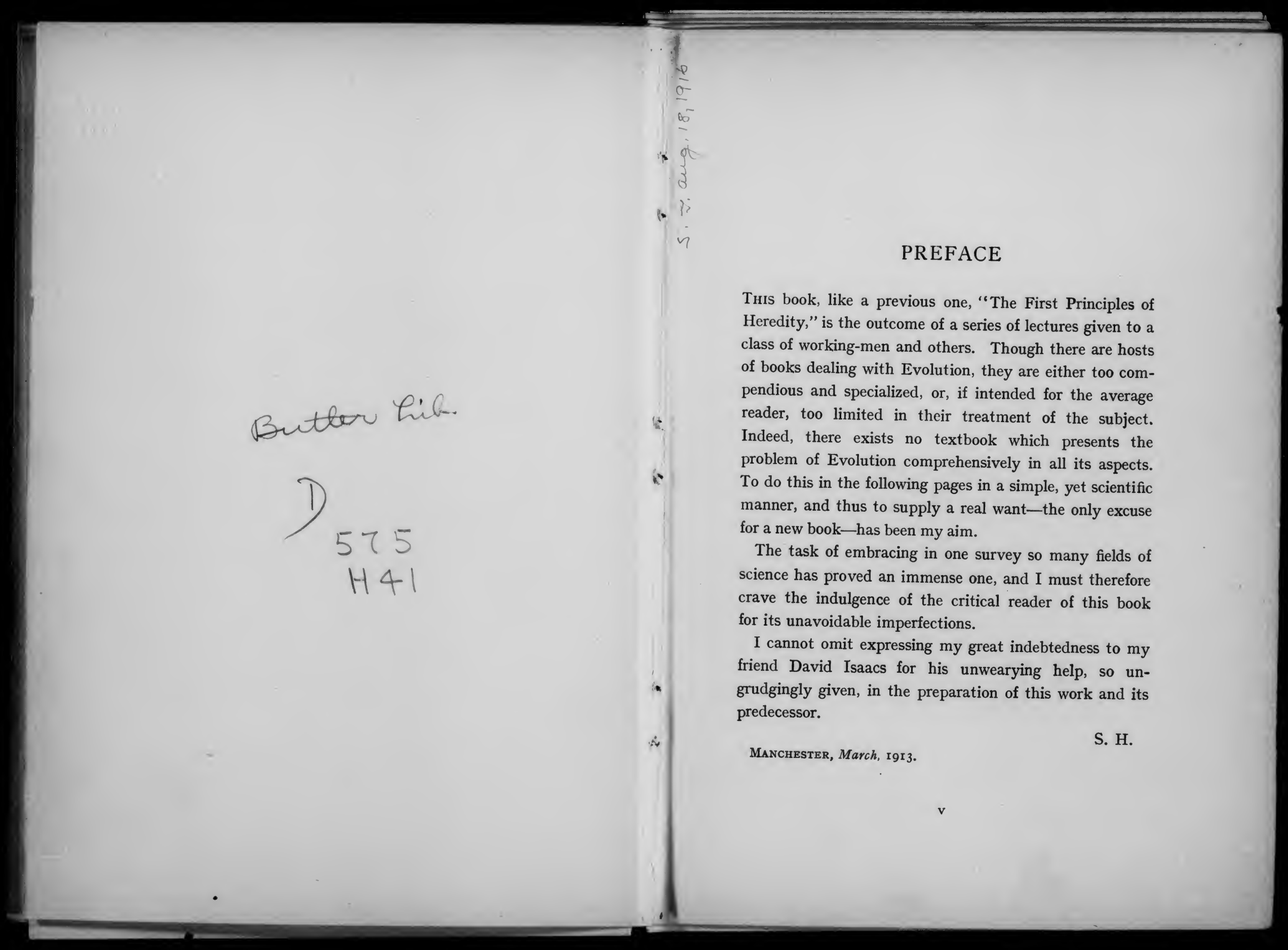




\section{CONTENTS}

INTRODUCTION

CHAPTER I. EVOLUTION IN GENERAL

SECTION I.-INORGANIC EVOLUTION

Chapter II. THE EVOlution OF Matter - - 7

I. COSMIC EVOLUTion

2. GEOLOGICAL EVOLUTION

3. ATOMIC EVOLUTION

4. EVOLUTION OF LIFE

SECTION II.-ORGANIC EVOLUTION

PART I.-THE FACTS OF EVOLUTION

Chapter III. MORPHOL.OGY

I. HOMOLOGOUS STRUCTURES

2. RUDIMENTARY STRUCTURES

3. VESTIGIAL STRUCTURES IN MAN

Chapter IV. EMBRYOLOGY

I. EMBRYOGENY

2. THE BIOGENETIC LAW

Chapter V. Classification

Chapter Vi. PAL EONTOLOGY

Chapter VII. GEOGRAPHICAL DISTRIBUTION 
PART II.-THEORIES OF EVOLUTION Chapter VIII. THEORIES OF EVOLUTION - - POT I. HISTORICAL - - $\quad-c^{-} \cdot-$ IO7

2. LAMARCKISM -

3. DARWINISM -

A. NATURAL SELECTION

ADAPTATIONS

(a) PLANT STRUCTURES

(b) ANIMAL COLOURATION

(c) INSTINCTS -

(d) HUMAN FACULTY -

(e) DEGENERATION

B. SEXUAL SELECTION

4. DIFFICULTIES OF THE THEORIES

A. NEO-LAMARCKISM

B. NEO-DARWINISM

$-178$

URAL SELECTION - 190

(a) PANMixia

(b) INTRA-SELECTION

(c) Germinal SELECTiON

(d) COINCIDENT SELECTIO

(e) ISOLATION -

III

-117
$-\quad 117$

124

- 125

-131
$-\quad 152$

- 157

159

- 163

- 172

-175
$-\quad 178$

Chapter IX. THEORIES OF EVOLUTION-Continued - 205

1. HETEROGENESIS

ORTHOGENESIS

(a) MECHANISTIC THEORIES

(b) VITALISTIC THEORIES -

3. CONCLUSION

SECTION III.-SUPERORGANIC EVOLUTION

Chapter X. Social evolution -

I. MENTAL EVOLUTION .

(a) BEHAVIOUR OF LOWER ORGANISMS - - 227

(b) INSTINCT

(d) REASON

\section{CONTENTS}

Chapter X. SOCIAL EVOLUTION-Continued

2. MORAL EVOLUTION - $\quad$ - $\quad$ - $\quad$ - 247

(a) ANIMAL ORIGINS -

(b) HUMAN DEVELOPMENTS

3. EVOLUTION OF MAN - - - -

4. EVOLUTION OF SOCIETY - - - - - 271

(a) THE PATRIARCHAL THEORY - - 272

(b) THE MATRIARCHAL THEORY - $\quad 274$

(c) THE MONOGAMOUS THEORY - - 278

B. THE STATE - - - - - 280

- 280

- 284

C. RELIGION - $\quad$ - $\quad$ -

(a) ANIMisM - $\quad$ - $\quad$ - $\quad$\begin{tabular}{ll}
289 \\
\hline
\end{tabular}

(b) OTHER THEORIES - - - $\quad 293$

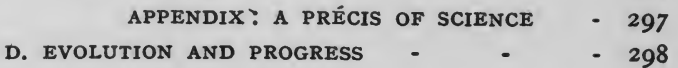

CONCLUSION

Chapter XI. THE FORMULA OF EVOlution - - 305

I. EVOLUTION -

2. DISSOLUTION - $\quad$ - $\quad$ - $\quad$ - $\quad$ - 313

Chapter XII. THE PHILOSOPHY OF CHANGE - - 316

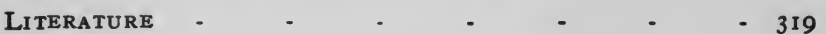

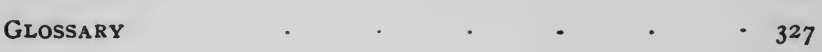

INDEX • $\quad \cdot \quad \cdot \quad \cdot \quad \cdot \quad \cdot \quad \cdot 337$ 


\title{
THE FIRST PRINCIPLES OF EVOLUTION
}

\author{
I N T RODUCT I O N
}

CHAPTER I

EVOLUTION IN GENERAL

THERE is perhaps nothing more significant of our age than the change which has taken place in our conception of the universe. The old notion of eternal unchangeableness, with occasional upheavals-the static view-has given way to the newer idea of progressive development in nature. way to the newer idea of progresive develop this new interGradually, within the last half-century, this new interpretation, which regards all things from the evolutionary or dynamic point of view, has extended from one field of human inquiry to another, creating everywhere fresh interests, giving novel aspects to old problems-nay, interests, giving novel aspect colouring and transforming the whole purpose and meaning of modern life. At last we seem to be on the threshold of nature's long-kept secret. After ages of darkness, the first gleam of a deeper understanding of her intentions has dawned upon us. Showing as it does the small beginnings daf of all things, their gradual transformation, step by step, towards higher stages of perfection, this new philosophy has opened out to us new possibilities, new visions and aspirations. It takes in with one grand sweep all the phenomena of existence, and stands as the embodiment of a new ideal which cannot fail to widen our outlook upon life. 


\section{THE FIRST PRINCIPLES OF EVOLUTION}

For this end it is necessary not only that we should know a few isolated facts of evolution, but that we should digest and thoroughly understand its principle ; in short, we must learn to think in terms of evolution.

But what is evolution?

Though the doctrine has been before the world for over fifty years, and has become an accepted fact of science, the general public still has only a very hazy notion of it and all it involves. It is often thought to imply nothing more than the belief in "the descent of man from monkey"; or sometimes people somewhat better informed will go so far as to connect it with the theory of the Origin of Species, propounded by Darwin. As usual, the popular fancy has seized on the most outstanding feature of the doctrine of evolution. We must make clear from the outset that evolution, properly understood, is neither the one nor the other of these theories, but rather includes, as we shall presently see, immeasurably more than both.

As we term the growth of the individual his development, so we call the development of the cosmos from a simple primitive state to complex and higher states its evolution. The unending process of evolution is a universal phenomenon, a fact of nature, for which an explanation is attempted in the various theories of evolution. Evolution and the theory of evolution are accordingly not identical terms, the first being a process of nature, the second a hypothesis or theory, formulated to explain this process.

That the universe is not static, but is, on the contrary, undergoing a continual change, is a truth which had already dawned on the ancient Greeks. "Flux or movement," said Heraclitus, " is the all-pervading law of things." After the passing of the dark Middle Ages, the idea of the gradual transformation of all the forms of life found expression here and there, but without gaining any wide pression here and there, but without gaining any wide that we find the principle of evolution established on a scientific basis. Erasmus Darwin, Lamarck, and others had made ineffectual attempts towards a solution of the problem ; but it was Charles Darwin who, in his book on the "Origin of Species," at one stroke not only offered an acceptable theory of the transmutation of species, but firmly established the fundamental principle of evolution. Since that time the world has become more and more convinced of the correctness of that principle; though, as we shall see later, this can by no means be said of the special theory which Darwin advanced as an explanation of organic evolution-a vital point which has already been alluded to, and which has to be carefully borne in mind by the reader.

For Darwinism, or the theory of evolution as propounded by Darwin, refers only to organic evolution-i.e. to the evolution of plants and animals. His epoch-making book, which appeared in I859, explains, as the title indicates, the "Origin of Species by Means of Natural Selection." It must therefore be understood that Darwinism is not identical with evolution, but is a theory -and a theory of organic evolution only. Still less can evolution theory of organic evolution only. Still less can evolution
be taken to be synonymous with the descent of man from the ape ; for the descent of the species man from the lower animals is only a particular case of the origin of species. Evolution in the fullest sense covers a much wider field ; it is coterminous with the whole range of cosmic phenomena. It holds good not less of the great stars, millions of miles away, than of the tiny microbes barely discernible under the highest magnifying power. By its light we are enabled to decipher the ancient history of suns and planets, of our earth, and all it contains: we can explain the onward path of all things existent, and to a certain extent foretell their further progress.

To have discovered a unifying principle of such farreaching application, covering such various phenomena, to have given us the grand conception of a world-embracing evolution, is the great achievement of Herbert Spencer. 
Not only was he the first independently to adopt the evolutionary principle as a means for the solution of various problems of matter and mind, actually anticipating Darwin's discovery by a few years-a fact very little known by the general public-but he gradually elaborated a complete theory of evolution, comprising in one great formula the theory of evolution, comprising in "Tirst Princip the law of all existence. Dealing in his "First Principles"
(Ist edition, I862) with the general aspect of the problem of evolution, he completed the tremendous task of working out all the successive sections of his great "Synthetic Philosophy" in full, applying the "master-key of evolution " in turn to the phenomena of life, the problems of society, and last, but not least, to the fundaments of ethics. "Indeed, this last part of the task it is," he writes, " to which I regard all preceding parts as subsidiary." "To find for the principles of right and wrong a scientific basis" is, he declares, his ultimate aim.

And here we are face to face with the profound importance of the results flowing from the scheme of evolu tionary doctrine. Giving us a unifying principle for the totality of manifestations, and recognizing the constant transformation of all things, spiritual as well as material, through a never-ending series to higher and more material, through a never-ending series to higher and mor perfect states, it is specially suited to deepen our inmost sense of life, making us tolerant towards the past and hopeful of the future.

\section{SEC'TION I}

\section{INORGANIC EVOLUTION}

NATURE is one and indivisible. She knows nothing of the categories we are wont to make in order to render her understandable to ourselves in parts. We are apt to overlook this truth when we apply ourselves to the study of any definite range of phenomena ; we so easily forget the connections which exist between the different manifestathese distinctions are of our own making-they are abstractions se-ving the useful purpose of defining the separate parts of our human knowledge. Of this unity in diversity science has at last become fully conscious, ever since the theory of evolution opened out to us the since the th bility of combining under one principle all natural phenomena, which had appeared until then as so many fragmentary records of an inscrutable whole. The hitherto isolated facts of nature have become, thanks to Herbert Spencer, comprehensible from one common point of view. He applied, as already mentioned, this new central idea of He applied, as already mentioned, this new central idea of
progressive development to all phases of existence; and in the exposition of the succeeding pages we shall have to follow largely the masterly account of his doctrine laid down in his " Synthetic Philosophy."

It is customary to divide the whole realm of nature into two great parts : the inorganic and the organic. The former comprises all lifeless things, as stones, rocks, planets, suns, etc. ; the latter contains the living beings with more 


\section{THE FIRST PRINCIPLES OF EVOLUTION}

or less differentiated parts (organs), from the lowest plants to the highest animals, including man. In addition to the facts presented by organic bodies taken singly, there are certain other phenomena, such as constitute the social life of a community, which are the result of the aggregation of a number of organisms. These phenomena were called by Herbert Spencer " superorganic." In dealing, then, with evolution, we shall treat it in three separate sectionsnamely, (I) inorganic, (2) organic, and (3) superorganic evolution.

\section{CHAPTER II}

THE EVOLUTION OF MATTER

BEFORE entering into the subject proper of inorganic evolution, we must remark that whatever we may be able to find out about the evolution of matter, we must take its somehow-existence for granted. Evolution only traces back the transformation of matter through its various stages ; it does not at all pronounce as to an original creation of matter out of nothing.*

Starting, then, with the world-stuff as given, we shall
the discuss (I) the evolution of the universe, or cosmic evolution; (2) the evolution of the earth, or geological evolution; (3) the evolution of the chemical elements, or atomic evolution; and (4) the evolution of organic forms from inorganic matter, or the evolution of life.

\section{Cosmic Evolution}

It has ever been the natural tendency of man to assign to himself a unique position in the scheme of creation, which he is but slowly being forced to abandon by the hard facts of science. To the ancients the earth, the abode of man, was the centre of the universe, and around it the sun, stars, and planets moved in their courses. This idea prevailed until deep into the Middle Ages. It was only in the sixteenth century that Copernicus finally overthrew the old Ptolemæan geocentric system by showing that the movements of the heavenly bodies could be accounted for much more plausibly by assuming the earth, in common with the other planets, to revolve round the sun as a fixed

* We shall see later on that the evolution of matter out of electrical units is the latest subject of speculation. 
centre. About a century later Kepler discovered the famous law of motion, according to which the paths or orbits described by the planets around the sun are not orbits described by the planets around the sun are no heliocentric theory of the solar system, then, posits mighty central sun $(866,000$ miles in diameter), and round it, coursing at various distances of millions of miles, the planets, all many times smaller than the sun each accompanied in turn by one or more satellites, whic move round their primaries according to the same law of motion. But this solar system of ours is, as is well known only a very small portion of the entire visible universe. For, as will appear later, the sun is nothing but a star, and For, as will appear to the the sun is nothing but a star, and millions of stars, the nearest of them many billions of miles away from our sun, each star having, in all probability, mightier and vaster systems than our own. These, including the passing comets and shooting stars, were concluaring the passing comet sidered to form the whole contents of the heavenly spheres, until at the end of the eighteenth century Sir Willian Herschel, by his extensive observations on nebulæ, showed them to be an integral part of the cosmic system, thereby opening a new outlook into the constitution of the universe. Tening a nin before his time, it was he who, by a systematic study of the nebulæ, was enabled to bring them into line with the other stellar phenomena ; indeed, he first gave scientific evidence, by means of his improved telescopic methods, of hypothesis which had already been advanced before him on hypothes which had already been advanced merely theortical philosopher Kant and by the great French mathematician and astronomer Laplace. This Kant-Laplacean theory, which is generally known as the " nebular hypothesis," we shall now deal with more in detail. (a) The Nebular Hypothesis.

It is a somewhat startling fact in the history of evolution to find that the first successful attempt of applying the principle of progressive development in nature was made with regard to celestial bodies which are million and millions of miles away. The nebular theory first suggested by Kant in 1755 , and afterwards worked out more fully by Laplace in 1796, has been amply confirmed by later scientific researches, and still holds the foremost place as an explanation of the origin of the solar system.

According to Laplace, the matter which now constitutes our solar system-i.e., the sun, planets, and their satellites -was once, æons ago, a vast mass of intensely heated gas, extending beyond the confines of the orbit of the outermost planet, Neptune, a radius of nearly three thousand million miles. This rarefied " fire-mist," millions of times more tenuous than air, was, in fact, at that time nothing else than a nebula, such as can be observed by the thousand else than a nebula, such as can be observed by the thousand
in the heavens with our improved telescopes. If there was any doubt left as to the true nature of such a nebula, the marvellous advancement of astrophysics has been able to set that at rest. For by means of spectrum analysis the constitution of the heavenly bodies coursing at such enormous distances can be analyzed as certainly as if we had them in our chemical laboratories.

It is a well-known fact that sunlight, when passed through a prism, is spread out into a beautiful coloured band or spectrum, exhibiting all the colours of the rainbow from red on one side through orange, yellow, green and blue to violet on the other. When suitably examined, this continuous spectrum of the sun can be seen to be crossed by a great number of dark lines, constant in position and relative intensity, which were first detected by Fraunhofer in the beginning of the nineteenth century, and are since known as "Fraunhofer lines." Kirchhoff was first able, in 1859, to give the meaning of these lines. He 


\section{THE FIRST PRINCIPLES OF EVOLUTION}

centre. About a century later Kepler discovered the famous law of motion, according to which the paths or orbits described by the planets around the sun are not orbits described but ellipses. The circles, as was previous sols heliocentric theory of the solar syles in diameter), and mighty central sun $(866,000$ miles in diameter), and round it, coursing at various distances of millions of miles, the planets, all many times smaller than the sun, each the planets in its turn by one or more satellites, whic accompanied in same law of move round their pris system of ours is, as is well known, motion. But this solar syste of only a very emall portion of the entire visible universe For, as will appear later, the sun is nothing but a star, and there are known to the astronomers at least a there are known the nearest of them many billions of miles millions of star having, in all probability, away from our sun, each star than own. These, inmightier and vaster systems than our own. These, including the passing comets and shooting stars, were considered to form the whole contents of the heavenly spheres, sidered to form end the eighteenth century Sir William until at the end of thive observations on nebulæ, showed Herschel, by his extens part of the cosmic system, thereby them to be an integral part of the cosmic system, thereby opening a new outlook into the constitution of the universe. Though faint luminosities in the heavens had been observec before his time, it was he who, by a systematic study of the before his time, it was to bring them into line with the other nebulæ, was enabled to bring he first gave scientific evidence, stellar phenomena; indeed, hed telescopic methods, of a by means of his improved telescopic methods, of a hypothesis which had already been advanced before him on merely theoretical grounds, independently by the German mhilosopher Kant and by the great French mathematician philosopher Kant Laplace. This Kant-Laplacean theory, and ast we " nebular hypothesis," we shall now deal with more in detail. (a) The Nebular Hypothesis.

It is a somewhat startling fact in the history of evolution to find that the first successful attempt of applying the principle of progressive development in nature was the principle of pro millions ref and millions of miles away. The nebular theory first suggested by Kant in $\mathbf{1 7 5 5}$, and afterwards worked out more fully by Laplace in 1796, has been amply confirmed by later scientific researches, and still holds the foremost by later scientific of

According to Laplace, the matter which now constitutes our solar system-i.e., the sun, planets, and their satellites -was once, aons ago, a vast mass of intensely heated gas, extending beyond the confines of the orbit of the outermext three thousand most planet, Neptune " fire-mist," millions of times million miles. This rarefied "fire-mist, "millions of times more tenuous than air, was, in fact, at that time nothing else than a nebula, such as can be observed by the thousand in the heavens with our improved telescopes. If there was in the heavens withe nature of such a nebula, the any doubt left as to the able to 作 set that at rest. For by means of spectrum analysis the constitution of the heavenly bodies coursing at such enormous distances can be analyzed as certainly as if we had them in our chemical laboratories.

It is a well-known fact that sunlight, when passed It is a well-known fact that sured
through a prism, is spread out into a beautiful coloured band or spectrum, exhibiting all the colours of the rainbow from red on one side through orange, yellow, green and blue to violet on the other. When suitably examined, this continuous spectrum of the sun can be seen to be this continuous spectruber of dark lines, constant in posicrossed by a great number of dark lines, cont detected tion and relative intensity, which were first detected by Fraunhofer in the beginning of the nineteenth century, and are since known as "Fraunhofer lines." Kirchhoff was first are in 1859 , to give the meaning of these lines. He 
IO THE FIRST PRINCIPLES OF EVOLUTION

how that light emitted from any given chemical element showed that light emitted fromce, when examined through made gaseous by incandescement of various prisms and a spectroscope (an arrang lines on a dark backgroundlenses), gave bright coloured lin. sectrum-each element the discontinuous bright-line - spectrumtheing chareterized by a definite set of lines, which were being charectertain groups of Fraunhofer found to correspond sun spectrum; indeed, the dark lines in the continuous in lines in the sun spectrum ind the sun. The lines appear various chemical substances in the sun. There surrounding dark, because the hot, vaporous atmosphere surrounding dark, bectives a bright-line spectrum, the sun, which by identical rays coming absorbs-i.e., extinguish central body of the sun. from the still hotter We are therefore enabled to distant by the kind any given body, however far distant, by the kind of any givm it gives. A discontinuous bright-line spectrum spectrum in gas; a continuous spectrum indicates an incates an incandescent solid or liquid without lines indicates an inder high pressure); while the body (or a gaseous body us the absorption spectrum, and addition of dark lines gives the absorptiour around a central indicates an atmosphere of cooler vapour around for the heated body. Distinctive groups of lines stand

separate elements constituting such Huggins first demonIt was in 1864 that Sir Willam the nebulæ by showing strated the real gaseous nature of the lines being those that they give a bright-line spectrum, the lines be found on of hydrogen, helium, and another gas, not yet " of hydr and provisionally called "nebulium." Such our earthe ant flat and rotating in the same direction nebula, spread out fiat assumed to have been the origin as the solar system, is as cooling would take place in this of our planetary world. As cooling wation of heat into space intensely hot, vast mass by the radiation of hit in the nebula would gradually contract, and its outermost the nould in consequence detach themselves equatorial parts similar to the rings seen in the plane as a separate ring, similar a further stage this ring would cool and

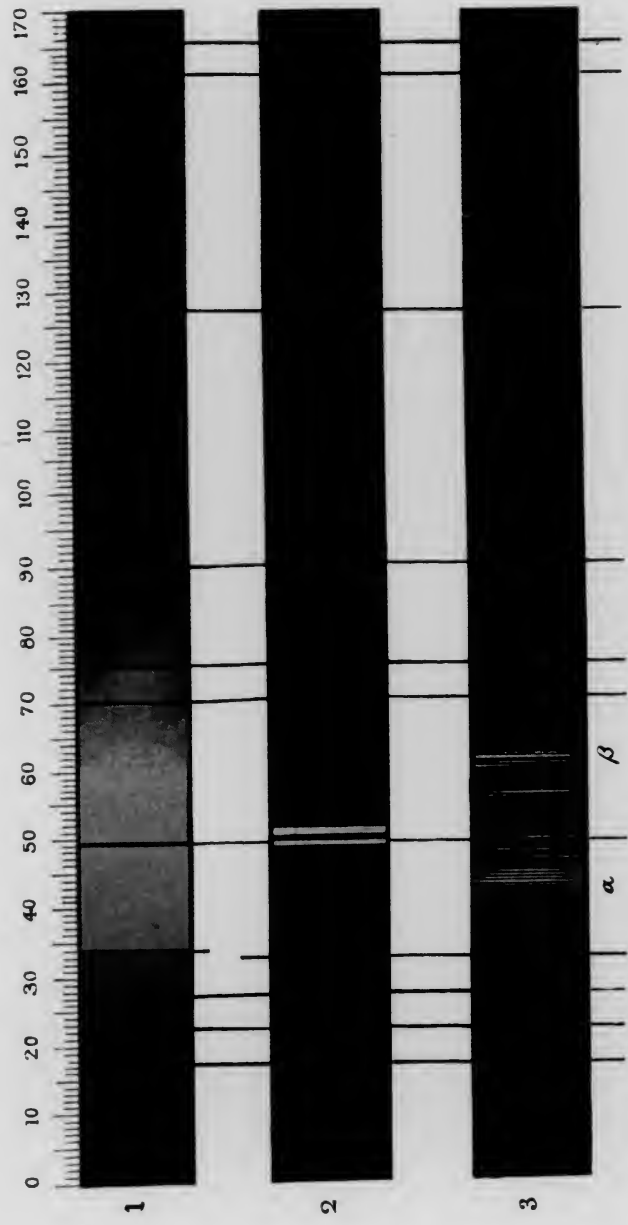


condense into a liquid or solid. As the cooling would not go con uniformly in all parts of the ring, it would break up and tend to agregate into a globular mass, forming a planet. tend to aggregate into a gly reeat itself successively in This process would not only repertion of the main parent mass, thus leading to the formainin the different planets coursing roun body as a sun, but the planets themselves, being fiery balls, would throw off their own satellites in a similar manner.* would throw sun and all its This theory of the original nebula accounts in attendant bodies out of one orignea most simple and satisfactory manner for a host of phe nomena exhibited by the solar system. It explains the facts : (I) That the sun and larger planets are much hotter act than the earthe of a body the longer attending satellites is in motion of the planets and their atten the same direction; (3) that the rotation of these difs in bodies, including that of the sun, on their own axis is in boction; (4) that the orbits of these different the same same plane; (5) that the earth, bodies are nearly in the flattened at both being originally a rotating fluid mass, etc.

poles and bulged out at the equator, etc. late indeed, the Further proof has been forthcoming of late; indeed, the whole science of stellar evolution may be said to have resulted from the application of this fruitful hypothesis resulted from the alæ been found in all stages of developNot only have nebulæ been ment from the diffuse nebula in Orion greater and greater condensation to planetary nebula, which appear like bright discs, but the stars themselve give evidence of their birth from these nebular masses give evidence of their indeed, there are no whity spectroscopically stars can of glow of nebulosity, while secording to their age. be arranged in a continuous series according to their age.

According to the newest theory, by Professor G. H. Darwin, the - According to the newed in this manner, but broke off, as it were, moon has not been formed in this action, after the earth had become from the earth as a res. 
As stars take their origin from a hot incandescent gas which is gradually cooling down and condensing, we should naturally find that stars in the earlier stages would be hotter than those of a more advanced type. The hottest stars are white. With gradual cooling down the colour of the stars changes to orange, yellow, and finally red, just as a heated iron cools from a white heat through yellow to red with the decrease of temperature. Furthermore, in the immense heat prevailing in these glowing stars, all substances are vaporized and broken up into their constituent elements; nay, the elements themselves, as will appear later, are dissociated-i.e., split up into their more primitive units. It follows that the earlier the evolutionary stage of a star, the more primitive will be its constituents and the simpler its spectrum.

The classification of stars is by no means simple, and has not been definitely settled. But on the whole four stages can be distinguished. We have, firstly, the earliest stars, like those of the Trapezium in the Orion nebula, which seem intimately connected with the surrounding nebular mass, and have the most primitive spectrum, showing only the helium and hydrogen lines. After these come the white or bluish-white stars, like Sirius, which give the lines of hydrogen, and in addition, faint lines of iron, sodium, magnesium, etc. At first the shrinking of the stars which takes place, more than counterbalances the loss of heat due to radiation, so that in the beginning the stars grow hotter instead of cooler. But ultimately a stage is reached when cooling of the outermost parts goes on rapidly enough to lead to their condensation. These stars show, in consequence, an orange or yellow colour, their spectrum giving faint hydrogen lines, while the metallic lines become more pronounced. (Our sun, which, as we have said before, is nothing but a star seen from a relatively short distance, belongs to this class.) Finally, we have the red stars in the declining age, showing a very complex spectrum.

The appearance of the planets, too, depends, as already 


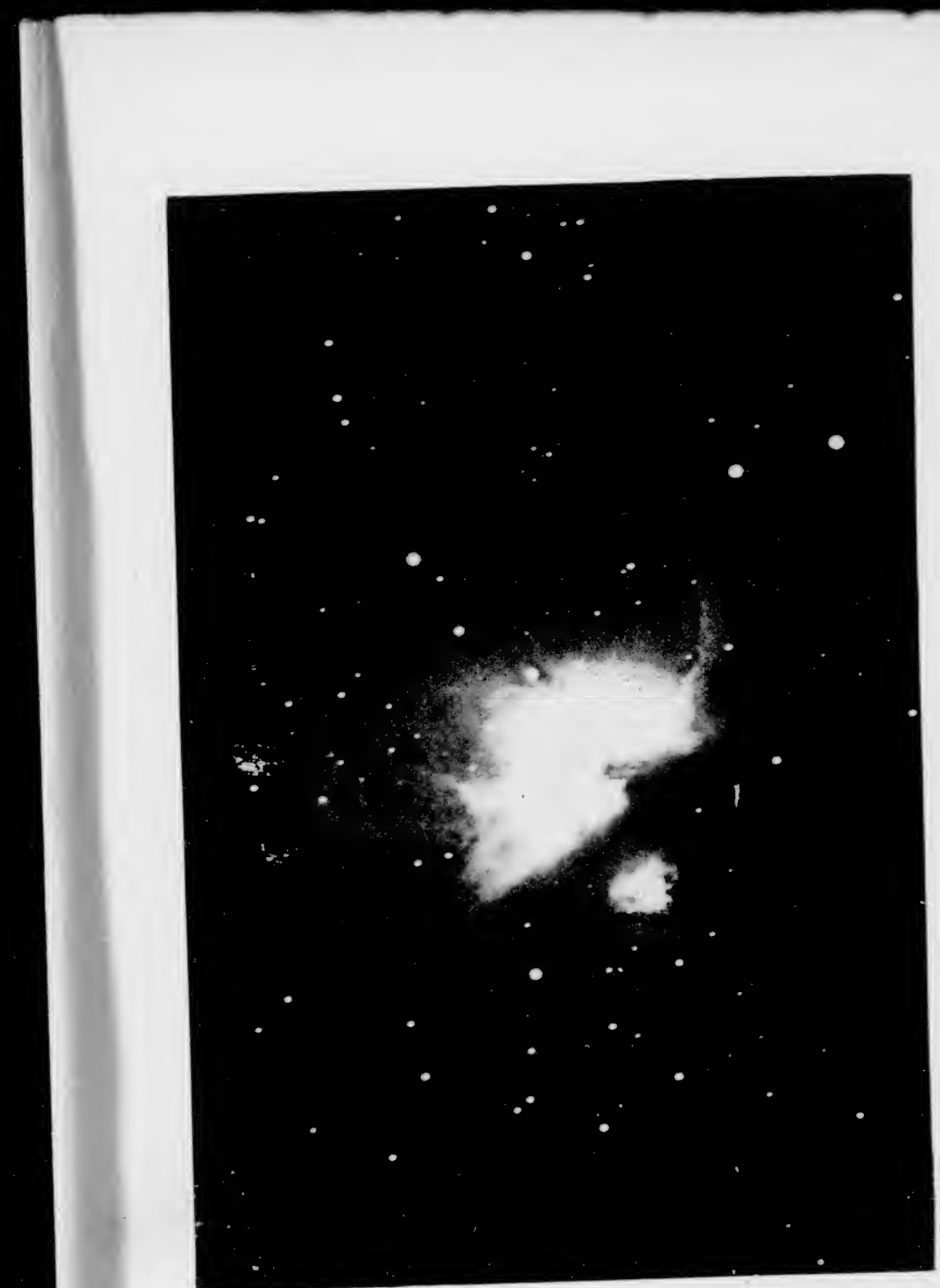

Fig. 2.-Diffuse Nebula in Orion (WV. H. Pickeringa). (From "Prob!ems in Astrothlysics," by dsilics.11. Clickt) 


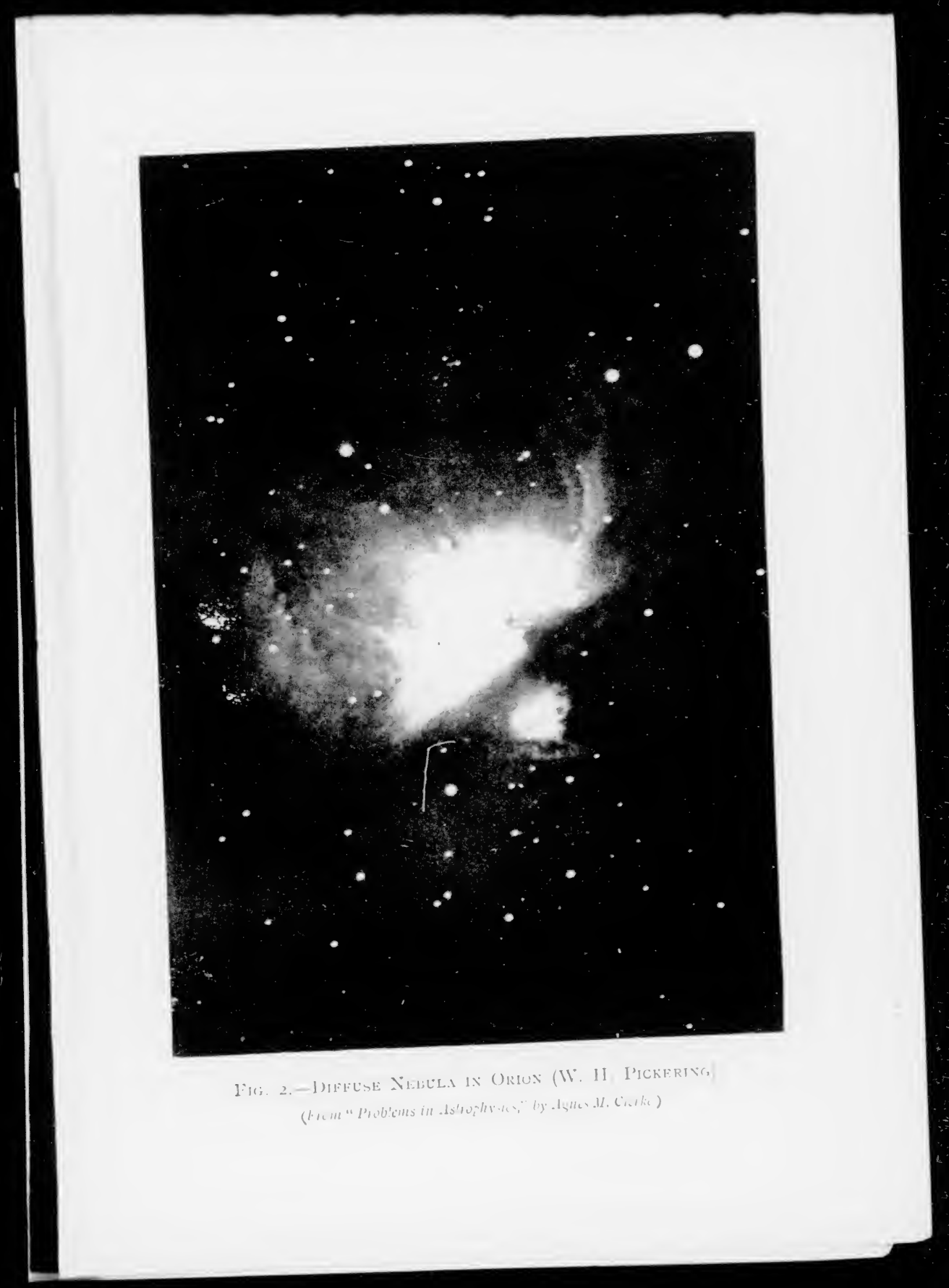


mentioned, on the stage of their development. We know mentioncd, on the stage of their devely down to have sufficiently cooled down to have a solid crust and a cool atmosphere, which made the evolution of organic life possible; while the much larger planet Jupiter is still a glowing ball surrounded by an plantely hot, vaporous envelope. The moon, on the intensely hot, other hand, much smaller than both these planets, has long since cooled down completely, and is now barren and atmosphereless.

The ultimate question arises: Whence these nebulæ? The can only surmise. The generally accepted idea is that We can only the collision of two mighty celestial bodies. sure the collision of two mighty celestial bodies. The heat generated by their tremendous impact would be sufficient to dissipate both of them into thin vapour forming the substance of a new nebula.

It must be added finally that the large nebulæ usually It must have not given rise to such a small system as observed have not given rise they represent rather a system of such systems.

Though, as we have seen, the nebular hypothesis brings into one harmonious scheme many phenomena of cosmic evolution, still, many facts have been forthcoming which evolution sthe shal only mention the principal ones:

only mention the principal ones : I. The formation of coherent rings has been doubted, because, acco the outermost portions would separate particle by particle.

particle by particle. 2. According to Professor $F$. R. Moultorial into a spheroid to form together of the ring material into a spheroid to

a planet meets with great mechanical disnculties. 3. If the plase has shown, rotate in the opposite direcas Professor Frimaries.

tion to that of their primaries.

4. While the satellites accompanying the earth, Mars and Jupiter, and eight of the satellites of Saturn, revolve, in accordance with the theory, in the same direction as their planets, the satellites of Uranus and Neptune, and 
If THE FIRST PRINCIPLES OF EVOLUTION

the newly discovered ninth satellite of Saturn, revolve in the opposite direction.

5. The planes of the orbits of the four satellites of Uranus are almost perpendicular to the plane of the planet's orbit.

6. According to the nebular theory, the loss of heat 6. According to the a conleads to contraction, and in of the planets. It follows stantly accelerated rotation of the planets. It follows from this that, as the satellites are thrown off at an early stage of the planet's existence, the time taken for a revolution of the satellite round its primary should be longe than the time of rotation of the primary round its own axis than the the revolves in less but Phobos, one of the satellites of

than a third of the time of the planet's rotation.* 7. Serious dynamical objections, too technical to
disced

8. Finally, and this is perhaps the weightiest argument 8. Finally against the theory, no nuth hing formation being Saturn. the only heavenly body with ring formation being Saturn. On the contrary, the discoveries of Professor Keeler have shown that out of nearly a hundred and twenty thousan nebulæ now recorded, by far the greater number are spiral in form, a fact with which we shall deal presently.

It would appear, then, that grave difficulties stand in It would appear, then, that grave difficulties stand in as propounded by Kant and Laplace; indeed, as has jus been mentioned, it does not take account at all of the majority of nebulæ, which, with the modern powerful instruments, have been found to exhibit a typical spiral structure. Professors Th. C. Chamberlin and F. R. Moulton have advanced a new hypothesis as to the origin of our solar system more in accordance with modern knowledge. To this we now turn.

* This objection has been met by Professor G. H. Darwin, who explains the difference as due to tidal retardation of the rotation of Mars. (b) The Planetesimal Hypothesis.

The starting-point of the solar system, according to this theory, is a spiral nebula, which is, as has just been said, the most common type observed. Such a nebula, as Fig. 3 well illustrates, shows a distinct central mass around which are coiled two long arms, which give the impression of having been produced by rotation of the whole mass, though sufficient time has not yet elapsed for proving such rotatory movement by actual observation. On the arms " knots" or partial concentrations of matter can be distinguished. The whole spiral is more or less flat, lying when seen edgewise, in one plane. The spectrum lying, when seen edsering that we have to deal, not with a finely dispersed gas, but with either liquid or, more probably, solid bodies. There seems to be no doubt that we have in these nebulæ aggregates of coll holies revolving round a common central medium. These bodies have been called "planetoids" or "planetesimals," on account of their resemblance to the planets, the theory of their origin and further evolution being the Planetesimal Theory.

It would appear, then, that we have in such a spiral nebula the rough outline of a planetary system, in which the process of further development is a relatively simple one. The knots forming the nuclei of the future planets, and coursing in their orbits around the central body, angres larger and larger masses, the os planets gathering up at the same time the remnants of nebulous matter, while the central body remains the controlling sun. It follows from this that the planets are at no time of their life-history entirely gaseous, but rather cool, solid bodies, including a greater or smaller amount of gaseous matter.

gaseous mal in As to the origin of the spiral nebula, effect of the tidal 
action of two more or less spheroidal nebulæ on each other. Given two such rotating bodies approaching near to each other without colliding, the effect of the mutual attraction on such loosely aggregated bodies would be an elongation of the main masses, the formation of bulging parts at the two opposite poles, and the final disruption of these protuberances into long streamer-like arms, which, on account of the rotatory movement of the whole mass, would tend to coil closer and closer round the central body. These coils would cool down through rapid radiation, and condense at various points into knots, forming finely divided solids and planetoids.

According to Chamberlin, the gaseous nebulæ have nothing to do with the evolution of our planetary system, though they may be connected with the origin of the stars. We are thus left face to face with two theories of cosmic evolution, which cannot be reconciled with each other ; nor does either of them fit in at present with all the observed facts of astronomy.

\section{(c) The Meteoritic Hypothesis.}

There .ird theory in the field, propounded by Sir N. Lockyer, and supported by Professor G. H. Darwin, which we must briefly mention for the sake of completeness, though it has found little recognition among scientists. According to this hypothesis, the original cosmic material consists of meteorites. "Nebulæ are really swarms of meteorites in the celestial space. The meteorites are sparse, and the collisions among them bring about a rise of temperature sufficient to render luminous some of their chief constituents." The meteorites swarm indiscriminately in all directions, and with widely different velocities. But Chamberlin has argued that if this is so, they must soon be vapourized; and therewith this theory would merge into the gaseous one of Laplace. Furthermore, the main evidence of Lockyer, based on the appearance of a certain characteristic line in the nebular spectrum, and attributed 


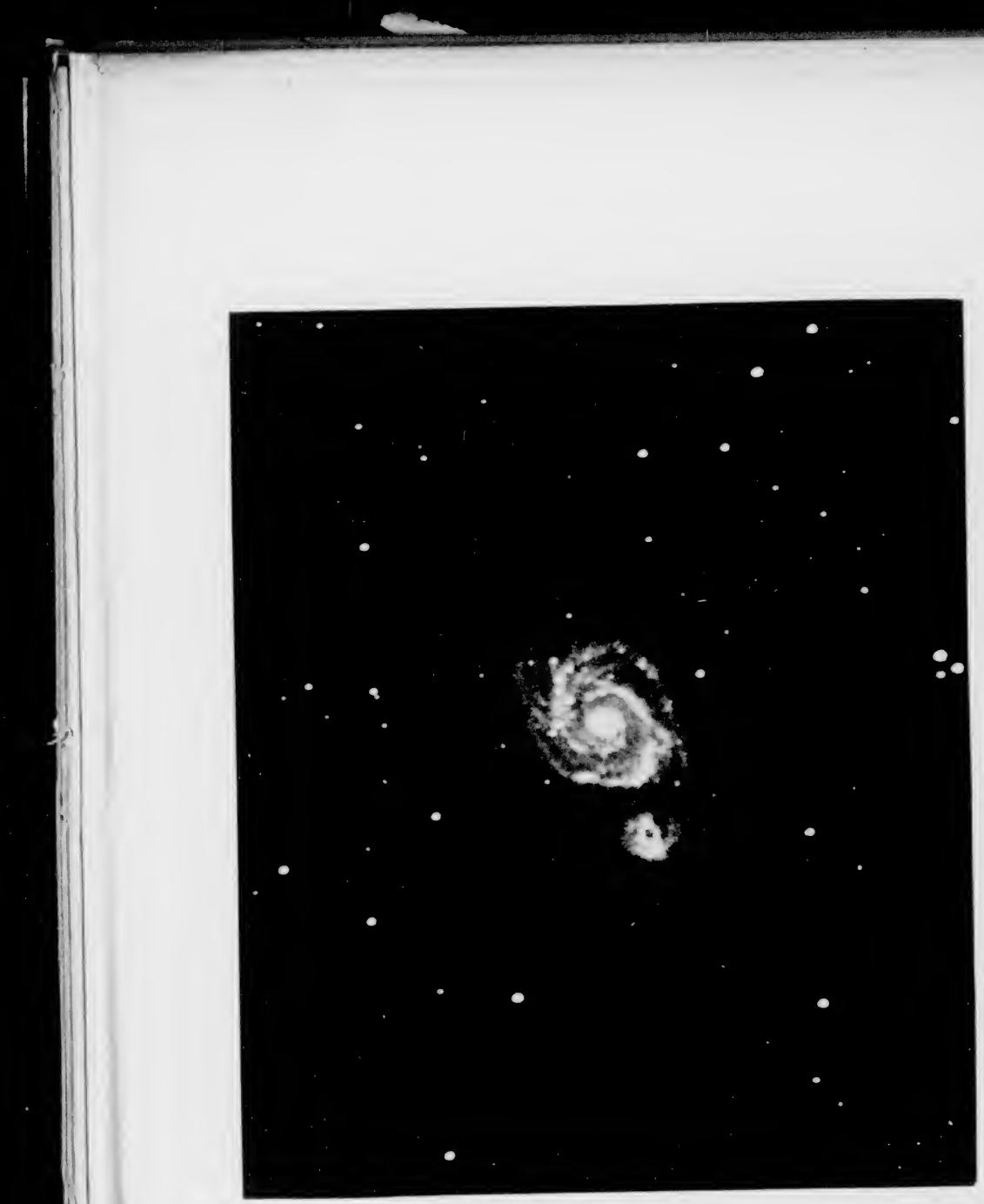

Fig. 3.-Spiral Nebula (taken by Mr. W. E. Wilson, March 6, 1897). (From "Problems in Astrophysics," by Agnes.1. Clerke.) 


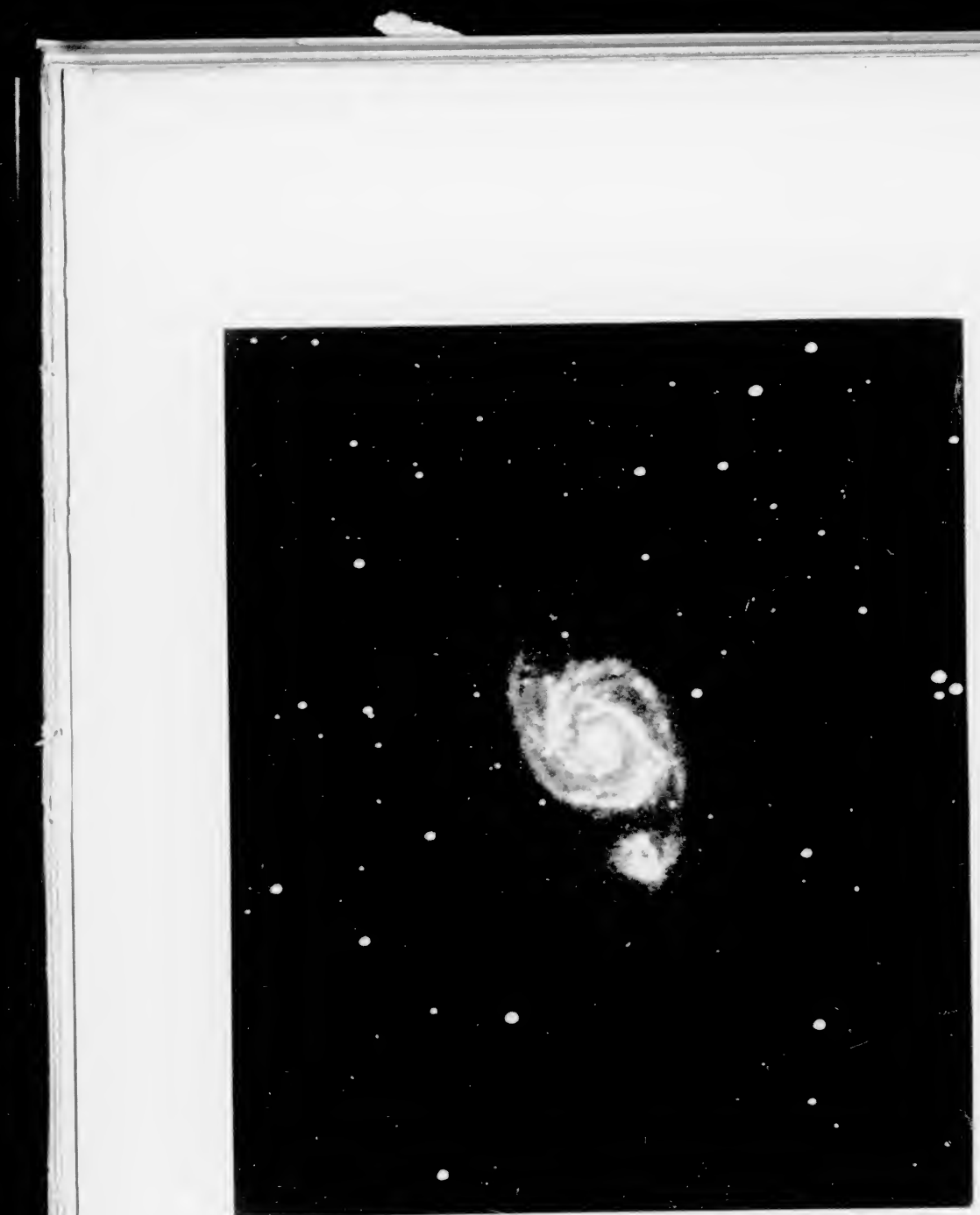

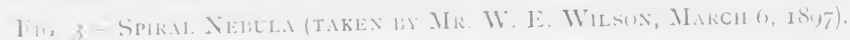

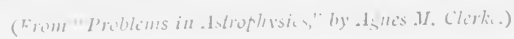


by him to magnesium oxide, has broken down, as this line is now generally interpreted as due to nebulium, a gas peculiar to nebulæ, and not yet found on our earth.

We must point out here, in order to avoid misunderWe inability to formulate at present one standing, that the in in thoroughgoing theory in explanation of stellar evolution, does not militate in the least against the evolution of the cosmos as a fact. The proofs of the latter are entirely independent of any theory that may be propounded to explain any particular method of evolution. We have explat henenena seen that the harmony of the observed heavenly phenomena fits in well with a general scheme of cosmic evolution; and the time may not be far off when all these phenomena will be brought into one comprehensive whole.

2. Geological Evolution.

The most primitive idea of the earth was that of a vast extended flat disc, with the expanse of the heavens stretch. ing over it like a mighty dome. This gave way in very ing the earth eared in space, the sun and stars coursing round it in their regular paths. The next stage was reached when, as has already been pointed out in the first part of this chapter, the centre of the whole system was transferred from the earth to the sun. Of course, was transferred from the geological history no possible there was at this period of geological history no thought of a continuous development of the earth. The most fanciful notions prevailed. The biblical theory of creation held sway in place of scientific research. Fossils were looked upon as "sports of Nature," and the belief in which once overtook the earth and all its unerse and there the its inhabitants was general. Though here and there the truth was guessed at-thus, among others, the famous painter Leonardo da Vinci recognized fossils to be the buried remains of once-existing animals, and Steno of Padua (I669) deduced from the marine deposits of Tuscany the (1669) deduced from the marine deposits of Tuscany 
I8 THE FIRST PRINCIPLES OF EVOLUTION

successive configurations of that district-it was not unti the end of the eighteenth century that the Scotch geologist Hutton (I788) promulgated the first coherent theory of co was the first to explain the geological formations. He was the first to explain the former changes of the earth's crust by means of natura forces only. According to him, "all past changes have been brought about by the slow agency of existing causes." Unfortunately his work met with great opposition for Unfortunately his werk me me eligious theory of the formation of the rocks, attributing their origin to igneous action only (vulcanism), in contradistinction to the so-called "Neptunists," who, led by the German geologist Werner, supposed all existing rocks to be " due to a chemical preci The true founder of modern geology is Charles Lyell, who in his "Principles of Geology" (Ist edition, 1830) elaborated all the natural means now recognized as factors in earthsculpture. The wearing down of the high land by the action of the rain and the atmosphere, the erosion of valleys by streams, the encroachment of the waves upon the seashore, and the deposition of the resulting débris either upon lowlands or within the sea as sedimentary strata ; further, the activity of volcanoes and underground waters :-in fact, the uniform action in all past ages of the same agencies as can now be studied, determines, according to modern geological science, the ultimate features of the face of the earth. Not catastrophism, but slow and orderly development, reigns in geological phenomena as in all other realms ment, regns ingeological phement ell, it is true, recognized neither beginning nor end in the earth's history ; but since then the new evolutionary ideas in conjunction with recent astronomical discoveries have enabled us to trace the earth's progress in a continuous line from its first beginnings up to the latest stages of the present time. Of these the early stages are in the nature of the case largely hypothetical, while the later geological formations of the earth have been worked out with more definiteness and accuracy. (a) The Hypothetical Stages.

We have scen that, according to the theory of cosmic evolution, the earth was born from a primeval nebula, and revolves, with its sister planets, around the central sun. We have further seen that in course of time the planets pass through various phases, starting as shining white-hot globes, and cooling down gradually to dull, non-luminous bodies receiving their light from the central sun. Now, we must assume the earth to have passed through all these successive stages. Originating as a great fiery ball, our globe, in whirling round its own axis, assumed its present shape, being flattened at the two poles and bulged out at the equator. On account of the enormous heat, all the substances making up the planet would be vapourized, the compound bodies being dissociated into their constituent elements. Gradually, as cooling took place through the radiation of heat into space, a molten mass would result the heavier metals, like iron, etc., gravitating towards the centre, the lighter towards the surface, while the lightest elements would form a vast atmosphere around it laden with the waters of the future oceans and heavy with carbonic acid $\left(\mathrm{CO}_{2}\right)$. The moon was thrown off, according to Professor G. H. Darwin, by a tidal wave, from the earth, while it was still in this plastic condition, which is reckoned to have taken place about fifty-six to fifty-seven million years ago.

With the further fall of temperature, the planet tended to consolidate. It is still a moot point in science where solidification first started. The opinion most widely held assumes the interior of the earth to be an intensely hot, partly gaseous, partly fluid mass ; though it must be understood that at the enormous pressure which prevails at this depth such a mass would behave practically like a rigid body. According to this view, the surface of the globe congealed first, forming a comparatively thin shell, which gradually extended towards the centre. Lord Kelvin, on 
2) THE FIRST PRINCIPLES OF EVOLUTION

the other hand, argued that with the high pressure at the the othe hane consolidated first. It must me not be imagined, however, that the primitive crust was smooth and uniform. Floating on a sea of fluid rock, and exposed to mighty tidal waves and strong atmospheric and exposed to mighty tit was repeatedly broken up into currents from above, it wa acquired stability only after many successive corrugations.

The first permanent configuration assumed by the earth, according to Professor J. H. Jeans, was pear-shaped (as if the earth the lik the equator was not circular, but oval, ; the equator was not the broader end corresponding to the middle of the African continent, while the stalked end formed an island-assumed to have once been in existence in the midst of the Pacific Ocean. With a further fall of temperature, the steam suspended in the atmosphere liquefied and settled on the suspended in the atmosphere liquefed and settled on the uneven surface of the land, thus giving rise to the first oceans, which consisted of boiling water. The original shape of the earth determined the primary distribution of land and sea, the latter accumulating mainly round the neck of the pear, forming a broad girdle of water round the globe corresponding to the present Pacific Ocean.* As the concorresponding to the present Pacific Ocean.* As the con-
densation going on in the overlying atmosphere must have been irregular, areas of high pressure and low pressure ensued, with the result that the thin crust was correspondingly depressed or raised. The solid earth became "dimpled and embossed," the water gathering in the hollows. But the very distribution of land and water would lead to a further differentiation of land and sea level. For the enormous weight of the oceans, exerting a steady downward pressure, would increase the oceanic depression, while, on the other hand, the release of pressure over the land area, produced by the withdrawal of the dense, heavy, watery atmosphere above it, would tend to

* Later on the land hemisphere collapsed at the two sides, which $*$ Later on the land hemisphere collapsed at the two sides, which
led to the formation of the Atlantic and Indian Oceans respectively. expand and elevate the crust. It must be understood, however, that the early formation of continents has nothing to do with the upheaval of gigantic mountain-ranges, which appear at a much later period of the earth's history. We pear at a much later peris accessible parts of the earth, the threefold zone of matter encircling our globe- " the lithosphere, or girdle of rock the hydrosphere, or belt of water; and the atmosphere, or mantle of air "- - the latter still dense and heavy, because (a) for the growth of the carboniferous forests, and all that
went otherwise into the formation of the rocks.

The further stages of the geological record consist, henceforth, mainly in the alternate process of wearing down the land surface and building up new rocks out of the detritus. Weathering, stream and coast erosion, etc. gradually disintegrate the rock substance, which is carried into the sea, and laid down at the bottom of it as sedimentary beds. These in their turn, after having been cons bined pressure of ocean and superimposed strata, emerge bined pressure of ocean and superimposed strata, emerge only to be worn down again in order to form new strata; until by constant repetition of this process the whole structure of the successive geological formations has been built up.

Before we enter upon this part of our subject we must point out that the hypothetical stages outlined above are by no means free from doubt. There are difficulties in the way of their acceptance, which we can only mention briefly. If the original earth crust furnished the material briefly. If the original earth crust furnished the material for the successive sedimentary rocks, it should form the tions. But, as the latest discoveries seem to indicate, the erlic well with such an assumption. They are rather igneous rocks, interposed generally between the stratified rocks 


\section{THE FIRST PRINCIPLES OF EVOLUTION}

and the supposed original crust, which is nowhere accessible. We should have to assume that after the formation of the primitive crust a prolonged era of widespread volcanic action ensued, completely burying the crust under a mass of poured-out lava. Such eruptive activity on a grand scale, however, could only take place if a great deal of the gases and steam, supposed to have been forced out into the atmosphere by the fiery-hot globe, was retained within it for a long time, to be given off gradually in volcanic explosions. Besides, a dense, heavy atmosphere, overcharged with steam and carbonic acid, and acting, as it were, as a warm blanket to the earth, is hardly consistent with the existence of organic life-forms, such as are known to have abounded in the very earliest geological times. At least their organization does not warrant our postulating fundamentally different atmospheric and thermal conditions for them.

According to the planetesimal theory, which was based by Chamberlin largely on geological considerations, the early phases of the earth would read rather differently. We would have firstly the nuclear stage, at which the globe, small as yet, is not able to hold an atmosphere, the light gases, not being attracted sufficiently by gravitation, flying off into space.* By gradual accretion an atmospheric envelope was gathered round the globe, partly by accumulation of the surrounding nebular masses, partly by extrusion of the gases occluded in the nucleus itself. The gases ultimately condensed and led to the appearance of water, which first accumulated within the lithosphere, because saturation ensued there most quickly. Gradually the water oozed out to the surface to form oceans. Violent extrusion of gas and steam would at the same time bring about a stage of vulcanism, and therewith lead to the formation of the oldest geological strata of igneous rocks.

* The atmosphereless stage is thus seen to precede the later stages, in contradistinction to the usual theory which ascribes the want of an atmosphere (as, e.g., of the moon) to the absorption of it
in the declining age of the orb.
GEOLOGICAL EVOLUTION

From thence the further geological stages are the same according to both cosmic theories.

(b) The Knoren Geological Stages.

The known geological strata which form the supercrust of the earth can be arranged into five great divisions, each being subdivided into systems, etc. (see Table, Fig. 4).

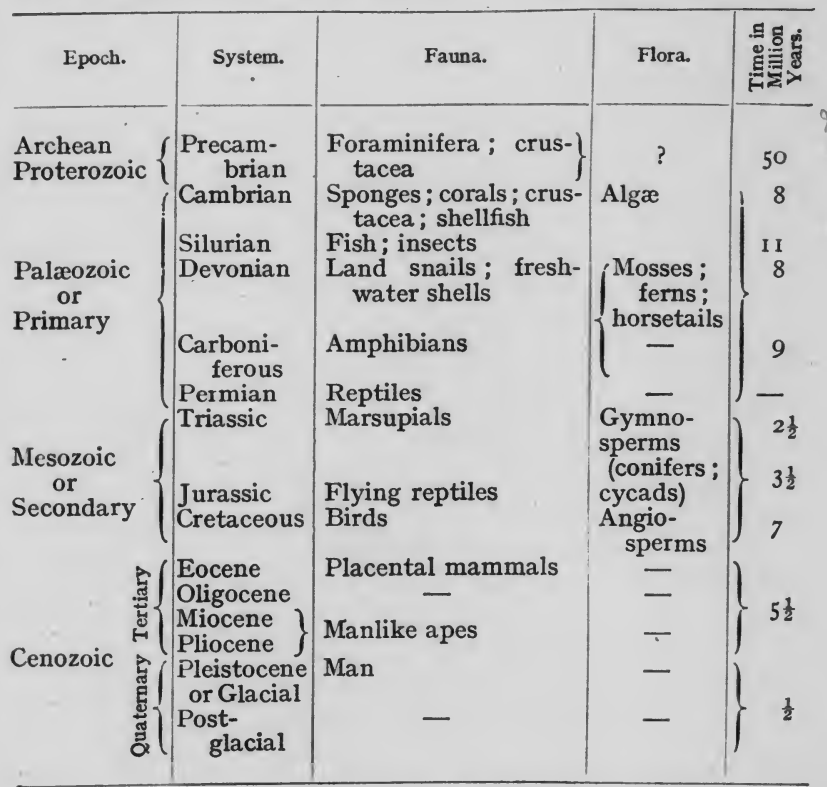

Fig. 4. -Table of Geological Periods with Successive APPEARANCE OF TYPICAL LIFE-FORMS. (Modified from $E$. Clodd.)

As these beds were superimposed upon each other in course of time, their position still gives us, on the whole, the order of their origin, the lowest being the oldest, the uppermost the newest stratum. Very often, however, the whole series 
24 THE FIRST PRINCIPLES OF EVOLUTION

has been upturned and disturbed by violent upheavals and distortions. But whatever may be the actual position of a given stratum, its place in the earth's history can be detergiven sossils it contains. William Smith mined by the kind of fossils it contains. William Smith, about a century ago, was the first to show that each geological period has its own characteristic organic remains, by which its chronological position can be ascertained. Later palæontological researches, based on the theory of Later palzon an actual succession of prowhich assumes an actual succession of pro-

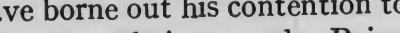
the full, his method having been greatly improved. ' Being here concerned only with a general view of the earth's history, we shall merely indicate briefly the course of the events.

We have already noted that the most ancient geological formation is the Archæan, which consists chiefly of rocks of igneous origin, while the later divisions are mainly made up of sedimentary strata. The Archæan land, most probably sparsly clothed with primitive vegetation, was bly sparsely clothed with primitive vetation, was gradually worn down by weathering and the encroaching sea ; and its vast detritus, accumulating for ages reckoned to exceed all the other geological periods together, went to form the sedimentary rocks of the Proterozoic era. The oldest definite fossils yet found belong to the latter stage, oldest definite fosils yet found belong to the latter stage, and, though occurring very sparsely, they are of a rathe advanced type, representing the crusters, thus indicating that life must have been in existence for a very long time previously in order to be able to attain to such high previously in order to be able to attain to such high organization. The Archan and Proterozoc "Prmations are often classed together under the term of "Precambrian," coming as they do before the Cambrian system, the firs which, by its abundance of preserved fossils, allows us more precise knowledge. The story of all successive stages is the precise knowledge. The story of all succes sedimentary same-a heaving up of the deposits, their gradual denudation, and the building up out of their detritus of the next geological stage.

At the beginning of the Cambrian period we find the
GEOLOGICAL EVOLUTION

distribution of land and sea settled in its main outline very much as at present: a large, low-lying mass of land stretching across the northern hemisphere of the globe, covering, according to some accounts, a great part of what is now the North Atlantic Ocean. No mouritains existed as yet, for these were slowly uplifted during later periods. The Cambrian Sea abounded in a rich variety of animal life, from the lowest Protozoa, sponges, etc., up to the crusters and molluscs, the most prominent class being a kind of cruster. Only doubtful fossils of plants have been found, though no doubt many must have existed at that time.

During the next stage, the Silurian system, the sea stood over a large part of the continents, only once more to withdraw slowly from the land at the close of the period. The prominent feature of this stage is the appearance of the first air-breathing animals, the insects, while its end witnessed the advent of the earliest type of fishes. Of plants, algæ mainly have been recovered. The climate during the last two periods must have been, judging from the wide distribution of the marine fauna, uniformly waim all over the globe.

The following system, the Devonian, is known in England chiefly as the age of " Old Red Sandstone." The sea inundated the greater part of Europe, leading there to marine deposits, while in England vast inland lakes were formed, where the accumulating sediments were transformed into rocks, of which red sandstone, so prevalent on the Devon coast, is the most characteristic. This period yields the first confident traces of terrestrial life, the earliest land animal preserved being the snail. A primeval vegetation of giant clubmosses, ferns, and horsetails, covered the of giant

The immense development of the carboniferous forests of the next period is well known. Enormous fern-trees, huge mosses, and mighty horsetails flourished in the vast swamps of the Carboniferous age, the remains of which now furnish the coal-seams all over the world. There were 
26 THE FIRST PRINCIPLES OF EVOLUTION

only few terrestrial animals, of which the most interesting are the earliest types of amphibians. The luxuriant veretation, favoured by a very moist and warm climate, largely absorbed the excess of carbon dioxide $\left(\mathrm{CO}_{2}\right)$ of the atmosphere, though, according to Chamberlin, the evidence of the superabundance of $\mathrm{CO}_{2}$ during the Carboniferous age is by no means unequivocal. Whatever carbonic acid was needed for vegetal growth was, according to him, supplied from volcanic and cosmic sources. Into this period falls the first beginning of mountain-formation, for it was then that the so-called Palæozoic Alps, remnants of which can be seen to-day in the Vosges, Black Forest, Harz, and Sudetes Mountains, began their development. The Ural Mountains, too seem to date from the same time. The main cause of the formation of mountain-chains is generally considered to be the contraction of the earth due to secular cooling. The shrinkage of the interior of the globe causes the crust to crumple into huge folds, which rise over the continents and sink at the bottom of the sea. For not only does the great weight of the superimposed sediments, accumulating for millions of years, tend to crush the oceanic segments downwards, but it would, according to Professor Sollas, thrust up the adjoining land by lateral pressure.

During the Permian period the uplifting of mountains went on apace. In America the Appalachian mountainrange arose, while large tracts of land emerged in the southern hemisphere, which bridged over the sea between Africa and South America on the one hand, and between India and Australia on the other, but have since disappeared again. The characteristic feature of this time is the general decrease of temperature, and the first indication of definite climatic zones and seasons. This has been ascribed to various causes, partly to the depletion of carbonic acid, which acts like a thermal blanket, partly to the reduction of humidity by the restriction of the oceanic area, etc. One thing is certain, that though traces of glacial action
GEOLOGICAL EVOLUTION

have been found as far back as the Cambrian times, the Permian period is distinguished by the first authentic Iceage, the causes of which we shall discuss later. This period, too, saw the rise of the first primitive reptiles.

It is unnecessary for our purpose to follow the whole series of successive strata by describing the essential characteristics of each. We shall confine ourselves to the main facts, which prove of general interest from the evolutionary point of view. The second great era, following upon the Palæozoic era, is the Mesozoic, which is divided into the Triassic, Jurassic, and Cretaceous systems. During the first period the sea overspread the greater part of Europe, which then again had a semi-tropical climate. The greatest significance is attached to the appearance of the lowest non-placental mammals, and the first flowering plants, represented by the conifers and cycads. The Jurassic age saw the origin of the first forerunners of the birds, evolving from the flying reptiles, which abounded during the Secondary epoch. Mountain-building, too, now started in full vigour, slowly giving rise during the next stages to the Rocky Mountains and Andes in America, and the Pyrenees and Alps in Europe. The third epoch, the Cretaceous, takes its name from the vast beds of chalk which were formed out of the shell-remains of lowly minute organisms swarming in the ocean which covered the whole of Southern Europe. True birds and the advent of true flowering plants characterize the life of this geological series.

The Tertiary era, which is divided by geologists into the Eocene, Oligocene, Miocene, and Pliocene epochs, is distinguished by a revival of great volcanic activity, which had ceased during the past ages. The configuration of the continents assumed its present shape, the great mountain-ranges, the Alps and the Himalayas, being finally reared, while the land which had connected North America with Europe and South America with Africa and Asia ultimately disappeared. The climate, temperate during 


\section{THE FIRST PRINCIPLES OF EVOLUTION}

the Eocene period, became tropical during the Oligocene to only to grow cold again, and finally to end in what is as the great Ice-age of the Pleistocene period. The evolution of the animal species reached its crucial point in the development of the ape-man (Pithecanthropus erectus), the developm to the appearance of man himself.

The Quaternary era was ushered in by the great Ice-age, time when not only the poles and the high mountainsummits were covered by mighty ice-fields, but when a great mantle of ice, extending over 6 to 8 million square great mantle of ice, extender in thickness, reached down miles, and up to I0,000 feet in North Europe. Signs of over half North America and North Europe. Signs of glaciation have been found as far south as the Thames and the Danube, and on the top of mountains even in tropical regions. There is sufficient evidence to show that ther regions. There is suficient was not one ice invasion only, but that six separate at intervals, only to advance again. Six separate suc invasions, with interglacial intervals, have been made out in America and Europe. As to the cause of the glacia period, with its alternate arctic and temperate climates, period, with its alternate arctic and bought forward. Repeated various explanations have been brought forward. Repeated ssion of the glaciated regions have been adduced, but such periodical oscillations of great continents within comparatively brief periods seem to be improbable. Atmospheric conditions, connected with the depletion of Atmospheric condion of the carbonic acid of the atmosphere, the interruption of oceanic currents, etc., are also scarcely able to account for the periodicity of the glacial phenomena. According to the astronomical hypothesis of James Croll, the regular recurrence of glacial periods is due to the variations of the earth's orbit, which produces at definite long intervals exceptionally short summers and long winters. Though perhaps the most widely accepted theory, this has by no means remained uncontroverted, so that at the present time we are still left in doubt as to the real cause or causes of the Ice-age.

Finally, the Postglacial or Human period embraces the

\section{GEOLOGICAL EVOLUTION}

stages of human development from prehistoric times of the Stone-age through the Bronze and Iron ages to our own historical period ; upon which stages, however, we do not need to enlarge here, as they more properly belong to archæology than geology.

In concluding this subject it will perhaps be advisable to give an indication of the time evolved in the past periods of geological evolution. The computation arrived at is founded partly on geological, partly on physicoastromical arguments. As to the latter, Lord Kelvin calculated from the rate of secular cooling of the globe, based on the known rate of increase of heat towards the earth's centre, that superficial congelation of the globe must have taken place between 20 and 40 million years ago while the age of the sun, according to the same authority, lies between the limits of 100 and 500 million years. Now, since Darwin postulated for the evolution of species a much greater length of time, there has long been a serious discrepancy between biological needs and physical calculation. The though the rate of denudation can be approximately reckoned out-it would, for instance, take about 7 million years for the European land-complex to be carried piecemeal into the sea-yet as the time that elapsed between the several geological strata is beyond our calculation, no definite figures can be given which are at all useful. Indeed, the figures given in the Table, Fig. 4, indicate more the relative duration of each period than its actual age. Lately Professor J. Joly estimated the age of the earth by the quantity of salt contained in the ocean. As the sea-water was originally precipitated on to the earth from the atmosphere, it contained no salts. These were carried into the sea by the rivers, which dissolved the saline constituents out of the rocks they traversed. Professor Joly arrived at a probable age of our globe of 90 to 100 million years. The deadlock the one hand, and physicists on the other, as regards 
30 THE FIRST PRINCIPLES OF EVOLUTION

geological time, and which at one time threatened to prove a very serious obstacle to the acceptance of the gradual evolution of species, has now at last been fortunately solved in favour of evolution. Since radium, which is one of the constituents of the earth and most probably of the sun, is known to be a great liberator of cosmic energy, producing it by its own disintegration, as we shall see in the next section, the source of energy available is now no longe restricted to the contraction of the cosmic bodies. According to G. H. Darwin, we may safely multiply the time given by I relvin by a number between ten or twenty. It would appear, then, that evolution has at its disposal any time it may require for the origin of species. It is now roughly put at about Ioo million years, while the date of the great Ice-age lies anywhere between 60,000 and 300,000 , or more years.

3. Aтомic Evolution.

Ever since John Dalton, in 1803 , formulated the atomic theory, the permanence and fixity of the chemical elements has been an accepted axiom of science. He showed that the elements combine with each other in certain unalterable proportions ; and also that, if several compounds are formed by the same elements, the relative weights of any one element entering into such combinations are simple multiples of each other. If, as Dalton assumed, matter is made up of ultimate atoms which cannot further be subdivided, then the atoms uniting with each other to form chemical compounds can only combine in whole numbers. As each atom of a given chemical element has its own definite atomic weight, the law of chemical combination, as enunciated above, follows as a matter of course. But while the fundamental basis of this theory remains unshaken, facts have gradually accumulated which tend to show that atoms are by no means the indivisible units they were originally held to be. (a) The Periodic Law.

In determining the relative weights of the atoms, taking hydrogen as unity $=\mathrm{I}$, it was found that many of the elements have atomic weights expressible by whole or very nearly whole numbers: thus the atomic weight of carbon is I2, that of nitrogen I4, etc. This suggested to Prout as early as I8I5 the idea that the heavier elements were nothing but condensations of hydrogen atoms, each element being made up of a certain number of such a tomsviz., I2 or I4, etc.- - according to the atomic weight of the viz., I2 or I4, etc.- - according to the atomic weight of the
element. But more precise work soon revealed the fallacy of this assumption, as it was definitely ascertained that the atomic weights of the majority of the elements are certainly not whole numbers.

Of more value was the discovery of Döbereiner, who found that certain elements had a very great resemblance to each other, forming little groups of triads which showed strongly correlated chemical properties. Such groups are, e.g. calcium, strontium, barium, or chlorine, bromine, iodine, etc. The interesting fact is that the atomic weight of the middle element of any one triad is the mean of the combined atomic weights of the first and third elements of the group.

The next important step was taken by John Newlands, who in 1863 showed that the elements, if arranged in order of their atomic weight from the lowest to the highest, fall naturally into a number of series, the elements which occupy the same place in each series forming a natural group, and being chemically closely related to each other. This law, which was independently worked out in full by Mendéeff which was independently worked out in full by Mendeeff significance lies in the fact that it shows the properties of the elements to be in some wise dependent on their atomic that each such related group, as it were forms a natural family of elements, this curious kinship seemed best explainable by assuming that the similarity 
32 THE FIRST PRINCIPLES OF EVOLUTION

of the related elements was due to an underlying unity in their composition. What this common factor was, chemistry was unable to tell. But other sciences gradually opened out new methods of inquiry, revealing hitherto unknown phenomena, which have brought this great fundamental problem of matter much nearer a solution.

(b) The Dissociation of Elements.

New evidence in favour of the view that the eighty-odd clements known at present are but different aggregations of one primordial substance, was furnished by the advance of the study of spectrum analysis. Sir Norman Lockyer, by his extensive researches on the spectroscopic behaviour of the elements under the most varying conditions, was able to carry the theory of the dissociation of the elements one step further. We have seen in the section on cosmic evolution that each element, when suitably examined through a spectroscope, exhibits a characteristic spectrum of its own, by which it is readily distinguishable from any other element. It was soon found, however, that the idea " one element-one spectrum " was by no means correct, for " certain elementary substances, when differently treated, furnish two kinds of spectra of quite a different character, not having any line or band in common." Lockyer was able to show by the application of various degrees of heat that the spectrum of a given element changes with the intensity of the temperature employed. Not only this, but, applying the same reasoning to the sun and the stars, he found corresponding changes in the spectroscopic appearance of the elements according to the temperature prevailing in the celestial bodies-temperatures which far exceed any attainable by artificial means, and which thus provide a natural means for the dissociation of the elements. As the temperature of the stars can be determined by the extension of their spectra into the ultraviolet-the hottest stars having the longest spectrum, the coldest the shortest-Lockyer was enabled to arrange the

\section{ATOMIC EVOLUTION}

stars into a series according to their temperature, and to compare their respective spectra with each other. As a result, he discovered that the gaseous stars, which are the hottest, have the simplest spectrum, showing only the lines of hydrogen, helium, and asterium (the latter a gas unknown as yet on earth). In the next order of stars, those of medium temperature, the gases (except hydrogen) begin to die out, while the lines of the metals appear, characteristic of the high temperature of the electric spark As these are totally different from the metallic lines at low temperature, the suggestion occurred to connect these simplified metallic spectra with an elemental state different from that of the ordinary metals. Lockyer therefore called these substances "proto-metals," since they form the stage before the real metals. For the ordinary metallic lines appear in the stars of the lowest grade of temperature, the gases (with the exception of hydrogen once more) having disappeared. It would seem, then, that with an increase of temperature a progressive disintegration of the elements takes place. Or, putting it the other way, as the stars gradually cool down, there are given the conditions for the successive births of the chemical elements. The for the successive births of the chemical elements. The ing of the temperature, more and more of the known substances make their appearance. Furthermore, as a general rule, the lightest elements appear first, then the proto-metals; the heaviest and most complex coming latest. proto-metals; the heaviest and most complex coming latest. tion that the elements, as observed by the chemist, consist of units which vary in number with the degree of the complexity of the atom.

There are many other phenomena of spectrum analysis

There are many other phenomena of spectrum analysis
tending to strengthen this hypothesis, of which we shall only give a few. Thus it is known that the so-called ironvapour in the sun is in rapid motion. But the up-rush and down-rush of the incandescent gas are not registered by all 
34 THE FIRST PRINCIPLES OF EVOLUTION

not dealing with iron itself, but with primitive forms of matter contained in iron," which are represented by different sets of spectroscopic lines. Other corroborative facts in favour of the dissociation theory are the possibility of sorting out the apparently haphazard arrangement of the multitude of spectroscopic lines into a number of harmonious series, each of which must be assumed to stand for a different set of vibrating particles of the atom in question : also the splitting up of yttria by Sir William Crookes in I883 into at least five components, each giving a distinct spectrum of its own.

But it must be admitted that, while there is no doubt of the facts, scientific opinion has been slow to accept the interpretation advanced by Lockyer. There are weighty objections, and the question of the ultimate constitution of the atom would have had to remain in abeyance once more, had not a new knowledge arisen-the science of radio-activity-which put the compound nature of the so-called elements finally beyond doubt.

\section{(c) Radio-Activity.}

Radio-activity is a property of matter which was first discovered by Henri Becquerel in the element uranium in I896, whilst he was studying the action of $\mathrm{X}$ rays and phosphorescent bodies. Uranium occurs in the minera pitchblende. Monsieur and Madame Curie, experimenting with the latter, found that it is four times more radio-active than uranium itself. This led them to the conclusion that there must be a substance in pitchblende many times more radio-active than uranium. They succeeded in isolating two such elements, which were named by them" polonium " and " radium." Radium was discovered in 1898 , and its discovery has well-nigh revolutionized the fundamental ideas of science.

What, then, is radio-activity ? It is nothing else than disintegration of the atom going on spontaneously before our very eyes.
ATOMIC EVOLUTION

If two poles of an electric current are fused into a sealed glass bulb from which the air has been exhausted to a very high degree of vacuum (the Crookes Tube, see Fig. 5), and an electric discharge is passed through the tube, rays are given off from the negative pole or cathode. These cathode rays were studied in detail by Sir William Crookes, who declared them to be " radiant matter," or " matter in the fourth state," thus anticipating in a remarkable degree the modern theory of matter. These rays were shown to travel in straight lines, producing vivid phosphorescence wherever

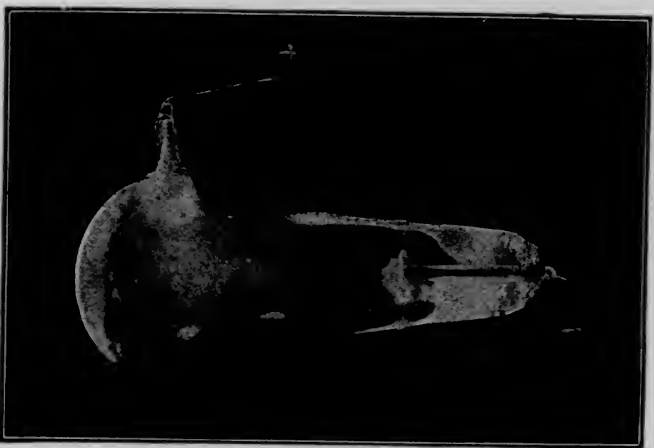

Fig. 5.-Crookes Tube in Action. ,+ Positive pole. -, nega tive pole. (From "The New Knowledge," by R. K. Duncan.)

they strike the glass. They are charged with negative electricity, and are deviated from their path by a strong magnet. They are capable of penetrating through solid bodies, and generate the $\mathrm{X}$ rays. In fact, the cathode rays are, as Crookes had already pointed out, particles of matter projected with great velocity from the negative pole. The same corpuscles are found in burning gases, in glowing metals, and in incandescent carbon, which act as conductors of electricity. Indeed, these corpuscles are identical with the electrons, which, according to the modern electrical 


\section{THE FIRST PRINCIPLES OF EVOLUTION}

theory, are the carriers of electricity, and which must be present wherever electric phenomena take place. These very same rays are given off by radio-active substances, the radio-active phenomena being due to the emission of rays from such substances as radium, uranium, thorium, rays from such substances as radord demonstrated three actinium, etc. Professor Rutherford demonstrated three $\operatorname{him} \alpha, \beta$, and $\gamma$ rays.

The $\beta$ rays have all the characteristics of the corpuscles just described; in fact, they are nothing but negative lectrons shot out from radio-active substances with a much higher velocity than the cathode rays, attaining nearly the speed of light.* They cause phosphorescence in certain substances, affect a photographic plate in the dark, discharge electrified bodies, penetrate through opaque matter, etc. The mass of a corpuscle has been determined to be a thousand times smaller than that of a hydrogen atom, which is the lightest element existing.

The $a$ rays are also particles of matter ; their speed is much lèss than that of the $\beta$ rays, their velocity being only I 2,000 miles per second. The weight of an a particle is four times as much as that of hydrogen-i.e., its atomic weight is 4 . Now, helium, which was discovered by Lockyer in the sun in 1868 , and was found by Ramsay in I 895 on our earth, has the same atomic weight. In fact, as Ramsay and Soddy showed in 1903 , the $\alpha$ rays are swarms of helium atoms constantly expelled with great velocity from radium and other radio-active substances. In contradistinction to the $\beta$ rays, which are negatively electric, they carry a positive electric charge. They cause phosphorescence, are but feebly penetrating, and are only with difficulty deviated by a magnet.

The $\gamma$ rays are always associated with the $\beta$ rays, and are most probably produced by them. They are

* Velocity of light equals 186,000 miles per second; speed of shooting stars, 20 to 40 miles per second ; swiftest rifle-bullet, abou $\frac{1}{2}$ mile per second. identical, according to some authorities, with the $\mathrm{X}$ rays. Little as yet is known about their nature; they are not corpuscles, but most likely waves set up in the ether.

Now, the remarkable feature of the production of these rays lies in the fact that we have here before us an actual splitting up of a radium atom into several components. The disintegration of elements, from being a mere theory, has become an established fact of science. Not only this, but a successive series of changes has been made out in the radio-active substances, leading step by step from one element to another, and thus exhibiting a real transmutation of matter. The dream of the a real transmutation of matter. The dream of the become true, though not exactly in the manner they had anticipated.

If radium bromide is dissolved in water, a gas escapes which is intensely radio-active, and has been called by Professor Rutherford the " emanation." While the atomic weight of radium is 226 , that of the emanation is 222 ; in other words, emanation is an atom of radium minus an atom of helium. But this emanation in its turn decomposes spontaneously. It has the property of causing objects spontaneously. It has the property of causing objects brought into its immediate neighbourhood to become radio-
active. This "induced radio-activity" is due to the deposition of an invisible film of radio-active substances. This " active deposit" of radium is non-gaseous, and represents the successive steps in the disintegration of the represents the successive steps in the disintegration of the emanation. For by the repeated emission of rays a series of new substances is formed, each changing into the next; resty rective Some of the substances are very fleeting, while Radium $F$, which has an atomic weight of $2 \mathrm{ro}$, has been found to be identical with the previously discovered element polonium. Finally, by the emission of a further $a$ particle, the atom of polonium 


\section{THE FIRST PRINCIPLES OF EVOLUTION}

changes into Radium G, which has an atomic weight of 206, and is in all probability identical with the well-known element lead, though its identity has not yet been finally settled.

But the question arises : If radium continually transforms itself in the manner described, how is it that there is any radium left in the world? However great the store may have been in past times, it must, one would think, have disappeared by constant decay. Now, radium emanation decays too, but we know that it is continuously reproduced by radium at exactly the same rate as it decomposes, so that by means of this "radio-active equilibrium" the amount of emanation present in radium at any given time is always constant. If the same holds good for radium, there must be a parent substance which produces radium as fast as the latter disappears. This source of radium was discovered by a train of reasoning which we can only just outline here. Not all the atoms of a given mass of radium break up simultaneously,* but only a certain number, which is proportionate to the number present, so that it would take a certain definite time before the whole mass of radium had undergone disintegration. Now, it has been found that half of the total mass of radium disintegrates in 1,300 years, another half of what is left-i.e., a quarter-in the next 1,300 years, and so on, until practically the whole mass has disappeared. In the same way the time (T) for emanation to lose half its radio-activity has been found to be 3.8 days. As both radium and emanation change at a given rate, the latter much faster than the former, there will always exist a certain proportionate amount of emanation to radium, which is a definite fixed quantity dependent on the relative rates of change of the two bodies. Now, radium is always found associated with uranium in constant proportions, $I$ part of radium * It must be understood, though, that the disintegration of each individual atom takes place instantaneously by a sort of small explosion.

\section{ATOMIC EVOLUTION}

to 3 million parts of uranium. This means that if uranium is the parent of radium, it must change more slowly than radium, its duration of life being three million times longer than that of radium. In fact, uranium is radio-active, as we have already learnt, but very much less so than radium. It emits $\alpha$ rays and changes into a substance called " uranium X." The further stages have not all been elucidated as yet, but we know that the ultimate result of these changes is the element radium. The im-

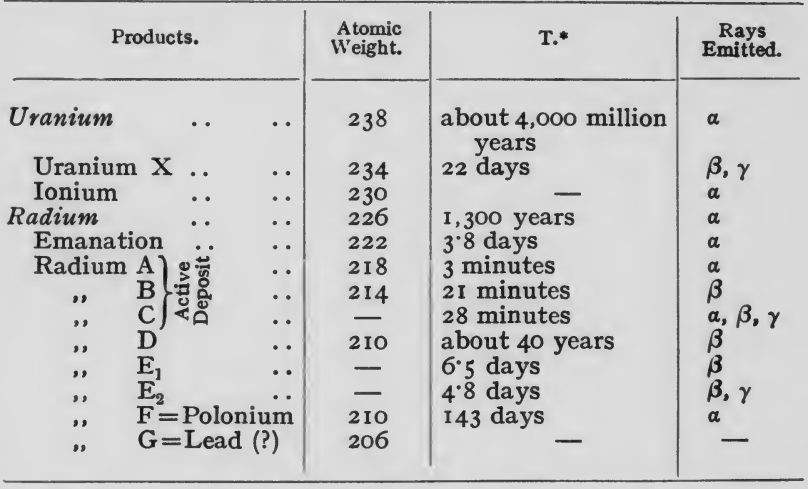

Fig. 6.-Uranium, Radium, and their Degradation RADIUM, AND
PRODUCTS.

(Modified from A. W. Stevoart.)

mediate parent-form of radium, the last product of the disintegration of uranium, has been named "ionium." We have, then, a complete series of transformations from uranium through radium and polonium to lead. The whole series as known is given in the above table (Fig. 6), with the atomic weights, the time of disintegration, and the character of the emitted rays.

Similar series can be made out for other radio-active elements.

* $\mathrm{T}=$ time taken for each radio-active substance to lose half its activity. 


\section{THE FIRST PRINCIPLES OF EVOLUTION}

We have arrived at a most interesting and significant point of our inquiry. We have seen that some radioactive elements change very slowly, others more rapidly while some are so transient that they exist only for a few minutes or it may be, days. Now, we have found that the minutes or, it may be, days. Now, we have found that the quantity of any given element depends on its rate of decay, so that those elements that change rapidly have only a very brief existence, while those which change less quickly, like radium, accumulate in small quantities compared with slowly changing elements like uranium. There is, then, as in the Professor Soddy says: "Probably for every stable atom many unstable ones are being formed. But only the stable forms can accumulate in quantity, and become known to us s ordinary chemical elements." Further, the fact that some common, will find its explanation in the greater stability of the latter, which, changing excessively slowly, are able to accumulate in great abundance. Nay more, the latest researches have shown radio-activity to be a common property of the most various clay, etc. Indeed, it has been assumed that all the elements are radio-active to a certain degree, the difference in the phenomena lying only in the rate of disintegration. This is so slow in the most common elements as to be hardly appreciable by our ordinary methods of investigation.

The transformation of the atom, then, is an established fact of science. The elements are compound bodies, constituted of units which are expelled with explosive force, producing by this process of disintegration the phenomena of radio-activity.

(d) The Electronic Theory of Matter.

Do we know anything about the ultimate constitution of the atoms ? Here we are on the field of theory, of speculation only. The latest and most widely accepted hypothesis is that of Sir J. J. Thomson, who posits the electron

\section{ATOMIC EVOLUTION}

$4 \mathrm{I}$

as the unit of matter. According to him, the electrons are the ultimate elements out of which all atoms are built up, their different properties being dependent on the number and arrangement of the electrons within the atom. Each atom is, according to this view, an agglomeration of negative electrons (identical, as we have seen, with the $\beta$ rays or corpuscles), which are perfectly balanced by a surrounding sphere of positive electrons. Such a collection of negative electrons, in order to be in stable equilibrium with the
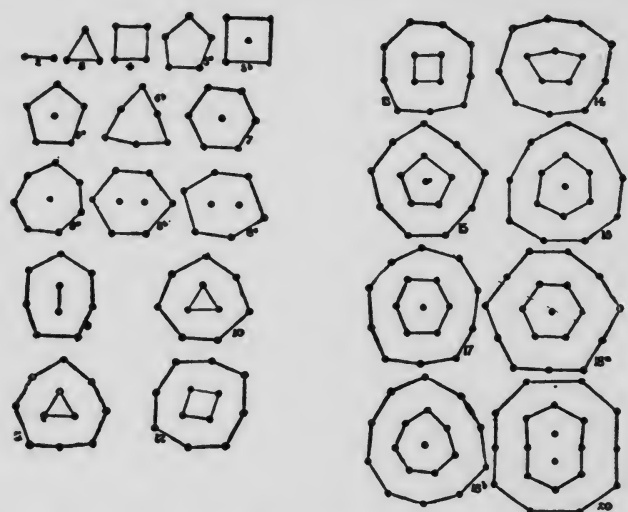

Fig. 7.-Free-Floating Magnets. (After Professor Mayer.) (Erom "The New Knovoledge," by R. K. Duncan )

positive sphere surrounding it, must arrange themselves, as Thomson has shown by mathematical calculation, into definite groups, according to the number of units involved.* First a small central group is formed, around which additional groups are successively built up, corresponding with the increase of units. Fig. 7 represents the configuration of such groups, according to Professor Mayer,

* The corpuscles are not in a state of rest, but are in constant motion, describing circular paths round the centre of the sphere and forming, as it were, a miniature cosmos. 
as shown by a working model of freely floating magnets in stable equilibrium. It must be understood, however, that the corpuscles, instead of grouping themselves in circles, form in reality concentric spheres in three dimensions. Sir J. J. Thomson has worked out the different arrangements for a successive number of corpuscles, of which a few are given in the following table (Fig. 8). We see that, starting with five units as a group, the same group recurs with an additional outer group of ten, when we have fifteen corpuscles; while a third group of fifteen units is added on reaching thirty corpuscles, and so on, with an additional number of units. Herein lies the explanation of the periodic law, with its serial formation. The appearance of the same primary groups at certain intervals accounts for the

\begin{tabular}{lrrrrrr} 
Number of corpuscles : & 5 & 10 & 15 & 20 & 25 & 30 \\
\hline Number in successive rings : & 5 & 2 & 5 & 1 & 3 & 5 \\
& & 8 & 10 & 7 & 9 & 10 \\
& 12 & 13 & 15
\end{tabular}

Fig. 8.-Arpangement of Corpuscles. (After Sir J. J. Thomson.)

periodical recurrence of similar elements, resemblance in group formation of corpuscles implying similarity of atomic constitution and chemical behaviour of the elements.

As to the ultimate nature of the electrons themselves, we can here only touch lightly upon the subject. What the positive electrons are, has not been determined as yet. They are only known as attached to the atom, to which they give a positive electric charge. Thus an $a$ particle is an atom of helium plus a positive electric charge. The negative electron or corpuscle has an independent existence of its own. It has, as previously said, a mass which is equal to $\frac{1}{1000}$ of that of a hydrogen atom. It consists of a unit of negative electricity moving rapidly through the ether, thereby carrying along with itself a certain portion of the surrounding ether, which is the larger the greater the speed of the moving electrical unit. The amount of this " bound " ether represents the whole mass of the corpuscle; the electrical unit itself (being a vortex or eddy in the ether) is assumed to have no mass of its own. The ether is not conceived to be imponderable, as hitherto held, but to possess a certain mass, its atomic weight being, according to Mendéeff, nearly one-millionth of that of hydrogen. We have, then, according to this theory, the new formation of matter (the atom) out of non-matter (negative electricity) by the intermediary agency of the ether.

The process of inorganic evolution sketched in the previous parts is thus seen to be complete, embracing as it does the first origin of matter, its gradual elaboration into elements, and the building up out of them of the mighty bodies which are known to us as nebulæ, stars, and planets.

\section{Evolution of Life.}

The development of living organisms out of inorganic matter was a common belief amongst the ancients. Spontaneous generation (generatio aquivoca) was held to be a fact by Aristotle, who taught that animals, such as worms, insects, and even fishes, could originate from mud. This idea only gradually gave way in the seventeenth century to the sounder doctrine of Harvey, the discoverer of the circulation of the blood, who established the truth, so far as the higher animals were concerned, that all living beings spring from eggs (omne vivum ex ovo). But when, with the invention of the microscope, the lowest one-celled organisms were discovered, the theory of abiogenesis (the origin of the living out of the non-living) once more came into vogue, and was freely upheld for infusoria, bacteria and other micro-organisms. It was only in the last century that this view was finally proved to be untenable, for Pasteur and Koch showed that, if proper precautions are taken to exclude the germs ever present in the air, no organisms arise except from pre-existing parent forms. Still, while biogenesis, or the origin of the living from the 


\section{THE FIRST PRINCIPLES OF EVOLUTION}

living, is thus accepted as the rule for all organisms, there remains the wider question: Whence the first living beings ? The answer to this problem depends on the view we take of life as such in contra-distinction to what is generally called matter.

\section{(a) Matter and Life.}

There is a school of thought which is wont to make a sharp contrast between the organic and inorganic, and which has insisted on the existence of an insurpassable gulf between the phenomena of life and of what is called " dead " matter. The Vitalists of the eighteenth century, as the NeoVitalists of our present time (Sir Oliver Lodge, Hans Driesch, etc.), maintain that, while life is bound up with matter, there is a special vital principle which, being superadded to and animating the physical frame, makes life possible. Monism, on the contrary, holds that all cosmic phenomena, including those of life, are manifestations of the self-same underlying entity, whatever philosophers may hold that to be.

Those who uphold a mechanistic theory of life (Professor Verworn and others) claim that there is no fundamental difference between living and non-living matter. The distinctions we make for the purpose of convenience do not when closely analyzed, hold good in nature. For the sake of comparison we must take the lowest organized lifeforms which represent the elemental units of all higher forms. Further, an organism should not be contrasted with a crystal, as it usually is, but with a substance which has, like the cell-protoplasm, a semifluid consistency, being in the colloid state. No absolute difference in structure can be established between living and lifeless substance, either in shape, complexity, or organization. A simple amœba has no definite shape nor special organs, while its complexity is only one of degree. The test of genetic derivation is also not thoroughgoing; for the lowest organisms multiply by mere fission, as a drop of oil would separate. The division between physical and physiological function is not quite distinctive either ; for the resemblance between an engine fed by fuel giving out power and the human machine is very close indeed. There remains the chemical difference. It used to be the main argument of the vitalists in favour of a special life-force that organic products could not be built up except by the living body Indeed, the term " organic compounds " in chemistry had reference to the fact that they were believed to be formed only in and by living organisms. But as early as 1828 Wöhler succeeded in producing urea, an organic waste product, by chemical synthesis, and since then a great number of organic compounds have been manufactured artificially; so that this once so essential distinction of organic and inorganic substances has been completely abolished. Furthermore, it has been found that no elements enter into the composition of organisms which are not to be found in inorganic nature also. The contrast between such chemical bodies is only one of degree, the organic compounds being on the whole far more complex in constitution. But while thus a natural kinship existsbetween the inorganic and organic series, there are certain chemical compounds which are distinctive of the organism, for they are only to be found associated with the function of life, and never occur in inorganic nature. These are the proteids, the carbohydrates, and the fats. The proteids are never absent in any organism. It would be rash, however, to base on this fact alone a fundamental distinction between life and matter, and to call in a new principle of a vital agency to explain phenomena connected with the action of proteids, while no such special principle is deemed necessary to account for the action of the less complex, inorganic compounds. There are some scientists, however, who, though not professed vitalists, would demur to some of these conclusions. According to Professor J. A. Thomson, the living organism is " a self-stoking, self-repairing, selfpreservative, self-adjusting, self-increasing, self-reproducing engine," and " it profits by experience," which no machine 


\section{THE FIRST PRINCIPLES OF EVOLUTION}

can do. For the vitalists the process of life, though connected with physical processes, is a phenomenon sui generis and cannot be explained by mechanical principles.

Now, it may be true that the phenomena of life cannot at present, and perhaps never will, be satisfactorily explained in physico-chemical terms, just as little as we can describe chemical action in terms of radio-activity. Each time we
come upon a higher synthesis of matter we have to take combination. But though a account of special vital principle has been clearly, vitalism for the phenomena of life, it has never been clearly, Mitchell has put it: "We have to scale the walls, open the windows, and explore the castle, before crying out that it is so marvellous that it must contain ghosts."

\section{(b) The Origin of Life.}

Applying, then, the foregoing facts to the problem of the rigin of life, we cannot but come to the conclusion that there must be a unity of development in all nature. Seeing that there is evolution in the inorganic sphere at the beginning of the cosmic process, and that there is evolution of the organic world at the latter end of it, the principle of the unification of causes would lead us to search for the origin of life on similar lines. Indeed, primordial archebiosis, or an initial derivation of protoplasm from nonliving particles, by a series of steps, is, as Huxley already pointed out, an unavoidable postulate of science. A number of transition stages must be posited, because the lowest known organisms are highly complex beings, while the earliest living things must, according to Haeckel, be assumed to have been nothing but " completely homoseners, structureless, formless lumps of proteid" for this reason that all pronouncements as to the artificial generation of living organisms in the laboratory must be regarded with the utmost caution, because, so long as the exact chemical composition of proteid is not even
THE EVOLUTION OF LIFE

known, the production of living protoplasm is not likely to succeed.

It is at the present stage of our knowledge perhaps little

profitable to attach much value to speculations with regard to the exact process of the evolution of life. We shall merely mention the four most prominent hypotheses, remarking that they serve only as hints of what might have happened.

It has been suggested by Lord Kelvin and also by Helmholtz that life may have come to our earth from other cosmic bodies. Though the possibility of such an occurrence cannot be totally denied, it only puts off the rea solution of the question. For either life has been in existence from eternity-i.e., has never been originatedsupposition we can, after the foregoing, hardly entertain or it has been originated somewhere out of something. And it is just this problem that we have set out to solve.

Professor Preyer rather reverses the problem and maintains that lifeless matter has been derived from the living substance, the former having been separated out like slack from the originally molten mass of the earth's body. But on this supposition the intensely hot molten globe, with its powerful molecular movement, would have to be looked upon as living, which is an unwarranted extension of the term " life."

Perhaps the most plausible hypotheses are those advanced by Haeckel and Pflüger respectively. According to the first, life had its origin in the primeval sea. There are several facts which speak in favour of this supposition. The earliest known organisms are inhabitants of the water, of which origin traces are still to be found in the human species, according to Charles Darwin, in the lunar periodic function of woman. If we take the elements constitut-

- On the vitalistic view of life it would still have to be assumed that the vital element is related somehow or other to the inorganic framework. It would lead us too far to enter here into the details of these theories, which carry us into the field of metaphysics. We would refer the reader to Professor W. McDougall's book on "Body and Mind" (I9I I). 


\section{THE FIRST PRINCIPLES OF EVOLUTION}

ing sea water and air, we find a curious resemblance to the composition of proteid, both being made up mainly of the elements carbon, oxygen, hydrogen, nitrogen, and sulphur. Strange to say, these are also the first elements originating in the process of inorganic evolution, being the elements which appear in the hottest stars. In fact, Pflïger's theory would put the origin of life back to the incandescent stage of our globe. He found in the behaviour of living proteid the most striking resemblances to cyanogen compounds (compounds of the cyanogen group, $\mathrm{CN}$ ), and concludes that, as cyanogen arises in an incandescent heat, a synthesis of the constituents of proteid must have taken place at fire-heat.

It has become clear that life must be looked upon as the last stage of a series of consecutive changes which go right back to the origin of the starry worlds. Organic evolution, which is concerned with the development of life-forms on our globe, occupies only a relatively very small point in the line of evolution viewed as a whole. It acquires such an enormous importance for us, only because man is the final outcome of this evolutionary process, and this conclusion vitally affects our whole outlook of life, our moral standards, and practical endeavours.

\section{SECTION II}

\section{ORGANIC EVOLUTION}

THERE still exists a very widespread confusion as to the exact import of evolution. To the average layman, Evolution and Darwinism are, as pointed out in the first chapter, convertible terms. The reasons are perhaps not far to seek. Up to the appearance of Darwin's " Origin of Species" the prevailing belief was in the immutability of spec_es, in accordance with the biblical tradition. Though attempts had previously been made to substitute for the attempts had previously been made to substitute for the
story of creation a theory of progressive development of organisms, they failed to gain acceptance. It was only when Darwin, by his masterly marshalling of an abundance of carefully collected facts, showed how the origin of species could be conceived to have actually taken place by means could be conceived to have actually taken place by means
of Natural Selection, that the world accepted evolution as of Natural Selection, that the world accepted evolution as
a fact. Indeed, the fight between Evolutionists and AntiEvolutionists turned in the beginning exclusively upon the question whether the transformation of species advocated by Darwin for all living beings, including man, was true or by Darwin for all living beings, including man, was true or not. It is Darwin's merit to have established evolution as
an irrefutable fact of science. "There is, however," as an irrefutable fact of science. " There is, however," as the fact of evolution and the manner of it, or between the evidence of evolution as having taken place somehow, and the evidence of the causes which have been concerned in the the evidence of the causes which have been concerned in the independent of any theory which may be brought forward to explain them. "Even if it be fully proved," says 
Romanes, "that the causes which they" (the biologists) " have hitherto discovered, or suggested, are inadequate to account for all the facts of organic nature, this would to account for all the facts of organic nature, this would
in no wise logically compel them to vacate their theory of evolution in favour of the theory of creation." For the sake of clearness, we are therefore following Romanes' example by dealing in the first part of this section with the facts of evolution, and in the second part with the theories of evolution.

\section{PART I.-THE FACTS OF EVOLUTION}

IT has just been said that the truth of the evolutionary principle rests solely on the array of facts which can be brought forward in its support. There are hosts of such facts, which find their most ready interpretation in the hypothesis of the transmutation of species by progressive evolution, while the only other alternative theory, that of evolution, while the only other alternative theory, that of
special creation, offers us no explanation whatever. Now, the value of any scientific theory depends on its power to correlate various seemingly disconnected phenomena and bring them under one harmonious view. The wider the application of such a working principle, the more assured we are of its correctness as a law of nature. It is just on these grounds that evolution has come to be regarded as a fundamental axiom of human knowledge, while the oldfashioned creation theory has gradually been abandoned in every field of scientific inquiry. The statement that the world has been created as it is once for all by a supernatural act, is not only contrary to the ascertainable facts-for it can be proved that all things are subject to progressive change-but the creation theory, as it stands, does not even attempt to account for such facts; it simply refers them back to an inscrutable act of creation. Numberless phenomena have become known, mainly through new researches stimuhave become known, mainly through new researches stimu-
lated by Darwin's evolution theory, which are only explainable by the principle of evolution, and we shall in the following pages give a selection from the truly overwhelming mass of material, arranged according to the subject-matter into-(I) Morphology, (2) Embryology (3) Classification, (4) Palæontology, and (5) Geographical Distribution 


\section{CHAPTER III}

MORPHOLOGY

AccoRDING to the evolution theory, all higher organisms have descended from the lower by a process of transmutation. As the surrounding conditions changed, animals and plants, by adapting themselves to the new environment were gradually transformed, and gave rise to new species. This progressive developme origination of manifold new types from a common ancestor substitutes therefore for the fixity of species a constantly changing flux of the organic world, the different classes o organisms being linked to each other by a natural kinship which is the closer the more recent the divergence from the original stock. This bond of union is first and foremost expressed in the morphological traits of the related species. For as the related animals (or plants) are descended from the same ancestral type, they must possess on the whole the same anatomical structure and organization, more or less modified in each individual case according to the lifehabits of the organism. It is this fundamental identity of structure that we mean when we speak of the "unity of type " in a given class of organisms, while the different parts and organs which are built on the same general plan in the various species are said to be homologous. In contradistinction, analogous organs are such as fulfil the same physiological function without possessing the same anatomical structure, as, e.g., the wing of a butterfly and that of a bird, which, though both serving for flight, are constructed each in a totally different manner.

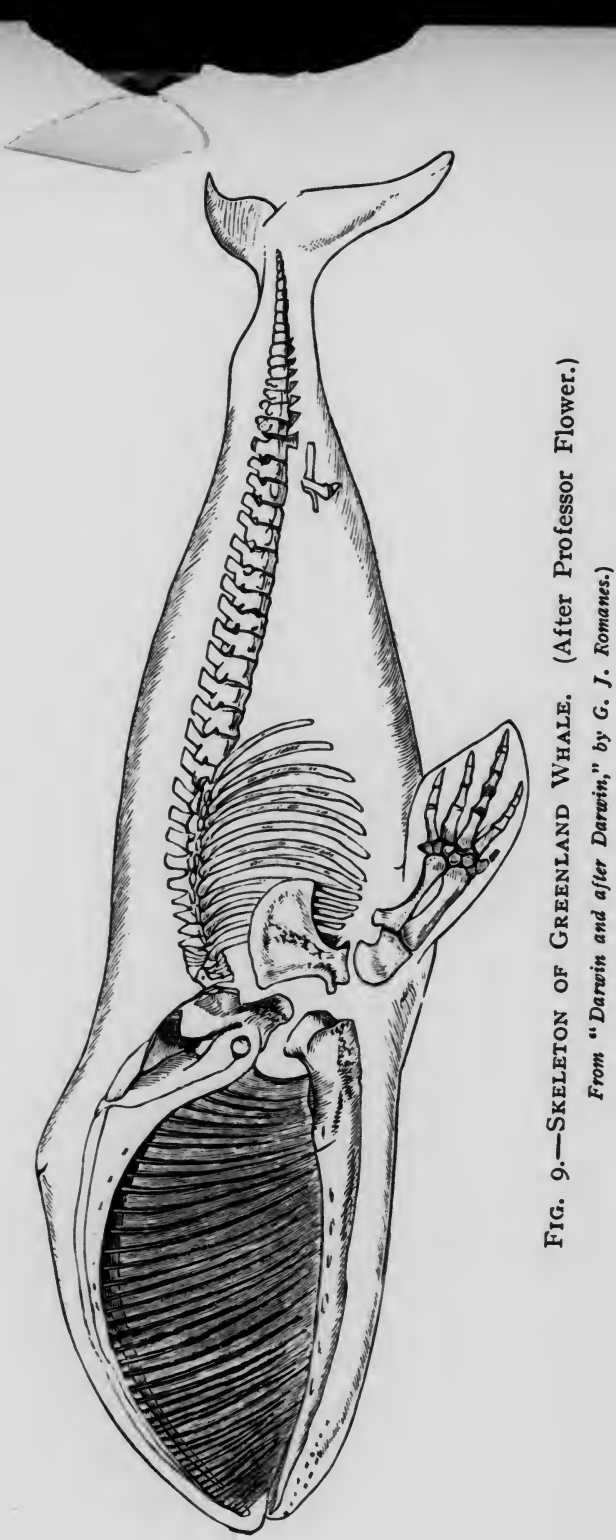


54 THE FIRST PRINCIPLES OF EVOLUTION

\section{Homologous Structures.}

Homologous structures, then, offer the most striking evidence for the transformation of species, remaining totally inexplainable on the creation theory. There is no conceivable reason, on the latter theory, why the paddle of the whale should be built on exactly the same

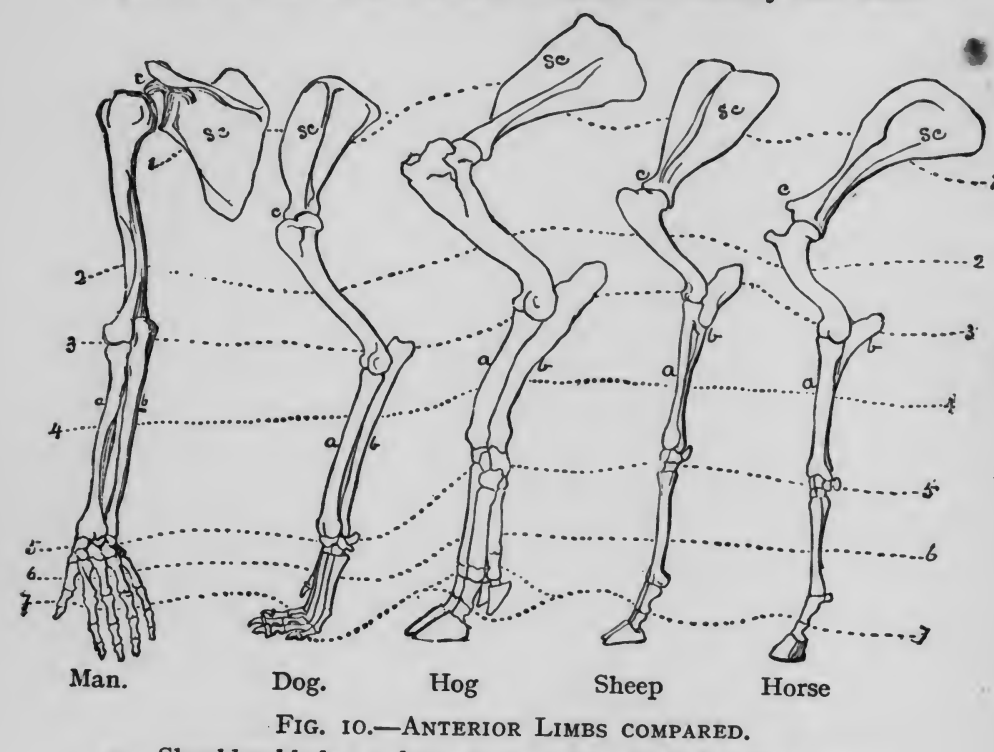

sc., Shoulder-blade; 2 , bone of upper arm; $a b$, bones of forearm; , bones of wrist; 6 , bones of hand ; 7 , bones of fingers. (From "Darwin and after Darwin," by G. J. Romanes.)

pattern as the forefoot of a quadruped, and why this in its turn should be identical bone for bone with the arm of a man. Nor does it offer any explanation why the wings of the extinct flying reptiles and of the modern birds and bats should all be arranged according to the same homologous design-that of a mammalian limb. If we compare the

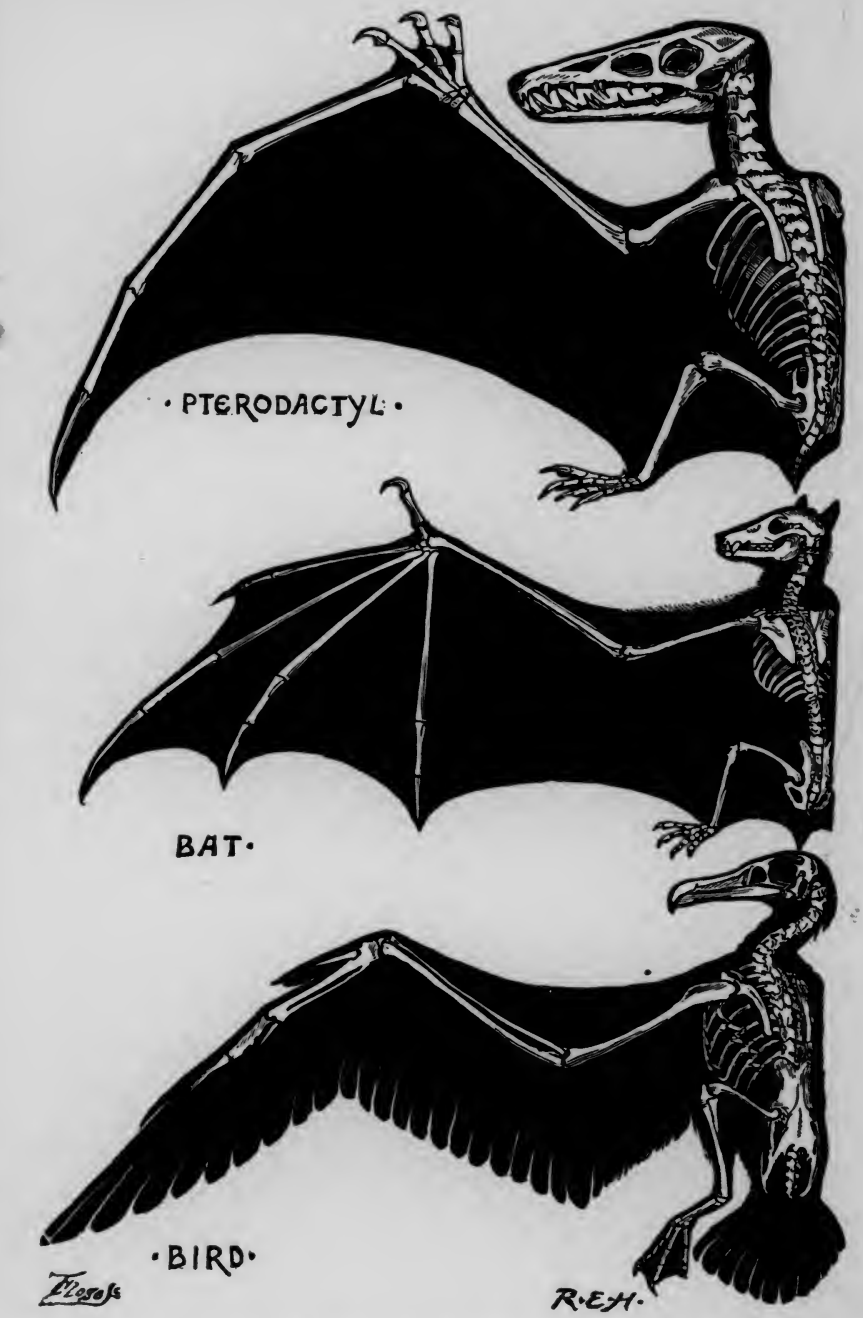

Iig. II.-Wing of RePtile, MAMMAL, AND BiRd COMPARED. (From "Darwin and after Darwin," by G. J. Romanes.) 
figures $(9$, Io, and II) we see that all these organs, be they paddle wing foot, or arm, consist of the same bones, parir several purposes. What, the the exists a real relationship between these different structures, each being

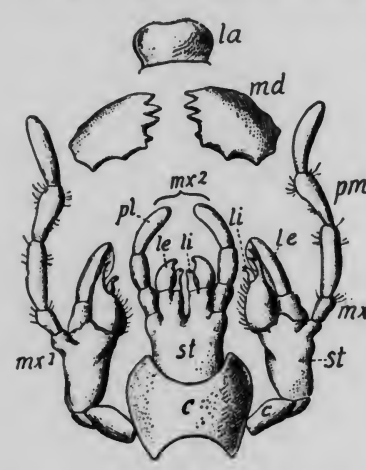

Fig. 12. - Mouth - Parts or $\begin{array}{ll}\text { COCKROACH } & \text { (Periplaneta } \\ \text { Orientalis) } & \text { (After R. }\end{array}$ Hertwig.)

a, Upper lip $m a$, mandibles : $m x^{1}$, first maxillæ with $c$, ternal lobe ; le, external lobe ; pm, maxillary palp maxillæ with similar detailed parts.

$$
\begin{aligned}
& \text { (From "The Evolution Theory," } \\
& \text { by A. Weismann.) }
\end{aligned}
$$

ransformed and adapted to ts special function, in the whale for swimming, in the bird for flying, etc. ? Indeed, that this is the true explanation will appear at once, if we remember that all these animals belong to the same reat class of vertebrata, whose skeleton is built according to a uniform type. Descent from a common ancestor, and progressive development on divergent lines, of each species, account in the most natural manner for these otherwise so strange nd mysterious coincidences. A similar case of transformation of the same parts into the most varied appliances is that of the mouthorgans of insects. Who would suspect that the jaws of a

beetle, the tongue of a bee, and the long proboscis of a butterfly, are identical structures? ? Ket this is so. All three are, as can be seen from Figs. 12, 13, and 14, built out of the same original parts, being modifications of the mouth-organs of some primitive insects.

Further evidence of the same kind is furnished by what Darwin has called "serial homologies." Many animals divided into a series of segments, each segment being fitted out originally with identical organs. Now, such homologous structures are often transformed in different

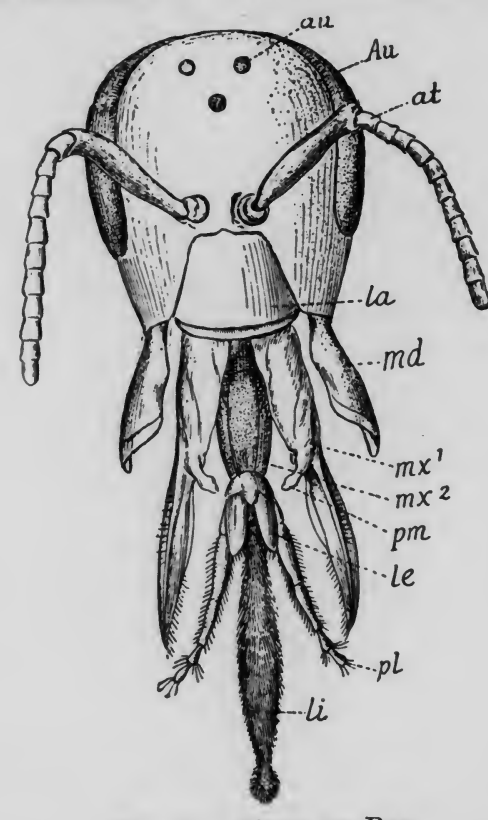

Fig. 13.-HEAd of BEE.

$A u$, Compound eyes ; $a u$, ocelli ; at, antennæ; la, upper lip ; $m d$, mandibles ; $m x^{1}$, first maxillæ, with $p m$, rudimentary maxillary palp ; $m x^{2}$, second maxillæ, with internal lobes (ii), fused tl ("

(From "The Evolution Theory," by A. Weismann.)

parts of the body according to the special needs of the organism. Thus we find in man the upper and lower limbs, though serving such different purposes, built on the same plan (Fig. I5), both being adaptive modifications of the 


\section{THE FIRST PRINCIPLES OF EVOLUTION}

typical mammalian limb. In crusters the complex jaws tyd lore is a constant and log anth-parts and relation between the number on the creation theory, all the number of remaining legs. On the creation theory, all these facts remain inexplainable, except perhaps on the supposition that unity of plan was implied in the purposeful sut it would seem that, if intended, such unity has not been carried out with much consistency; for we find homologous structures, though designed for the

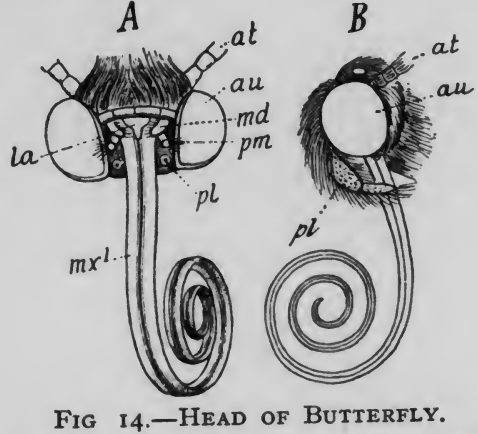

Fig 14.-HeAd OF ButTerfiy.

Seen from in front: $a u$, Eyes; $l a$, upper lip ; $m d$, rudiments o mandibles; $p m$, rudimentary maxillary palps; $m x^{1}$, firs maxillæ modified into suctorial proboscis; $p l$, palps of second (aving.)

(From "The Evolution Theory," by A. Weismann.)

same purpose, adapted in the most varied ways. We need for instance, only compare the forms of wings illustrated in Fig. II in order to see how differently the object of fligh in the wings of the various vertebrate animals. According to the evolution theory, this would be only natural, as each species developed on its own lines.

In plants we find serial homology in the several whorls of the flower-sepals, petals, stamens, and pistils-all being metamorphosed leaves, of which there is evidence in the occasional transformation of one into the other.

\section{Rudimentary Structures.}

We have seen how the forefoot of the whale has been transformed into a paddle. But the whole body of this animal has undergone a corresponding adaptation to its
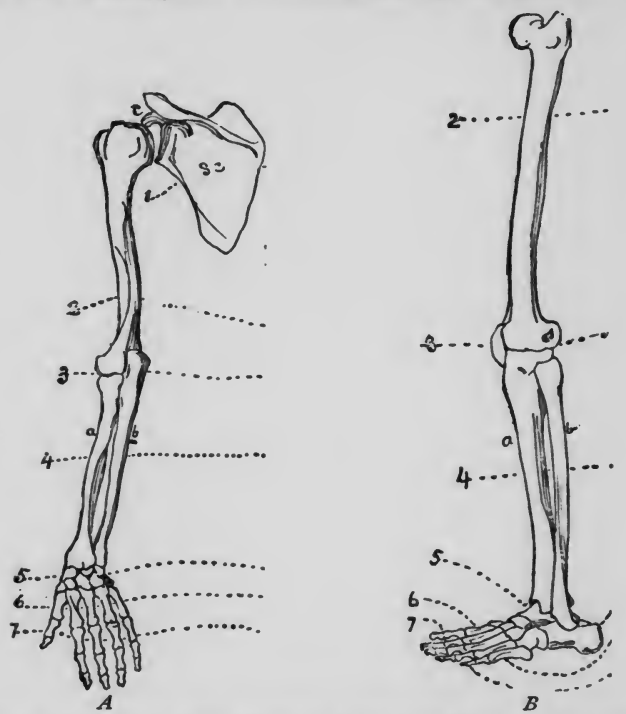

Fig. 15.-UPPER AND LOWER LIMB OF MAN COMPARED.

$A$, Upper limb ; $B$, lower limb. The corresponding bones are in dicated by the same number.

(From "Darwin and after Danwin," by G. J. Romanes.)

aquatic mode of life by becoming spindle-shaped with a fish-like tail. This has been achieved by a reduction of the hind-limbs, of which only rudiments are left, hidden underneath the skin. The process can be followed in the seals, where the limbs are seen to be in an intermediate state, the dwindling not having gone quite so far (Fig. I6). 


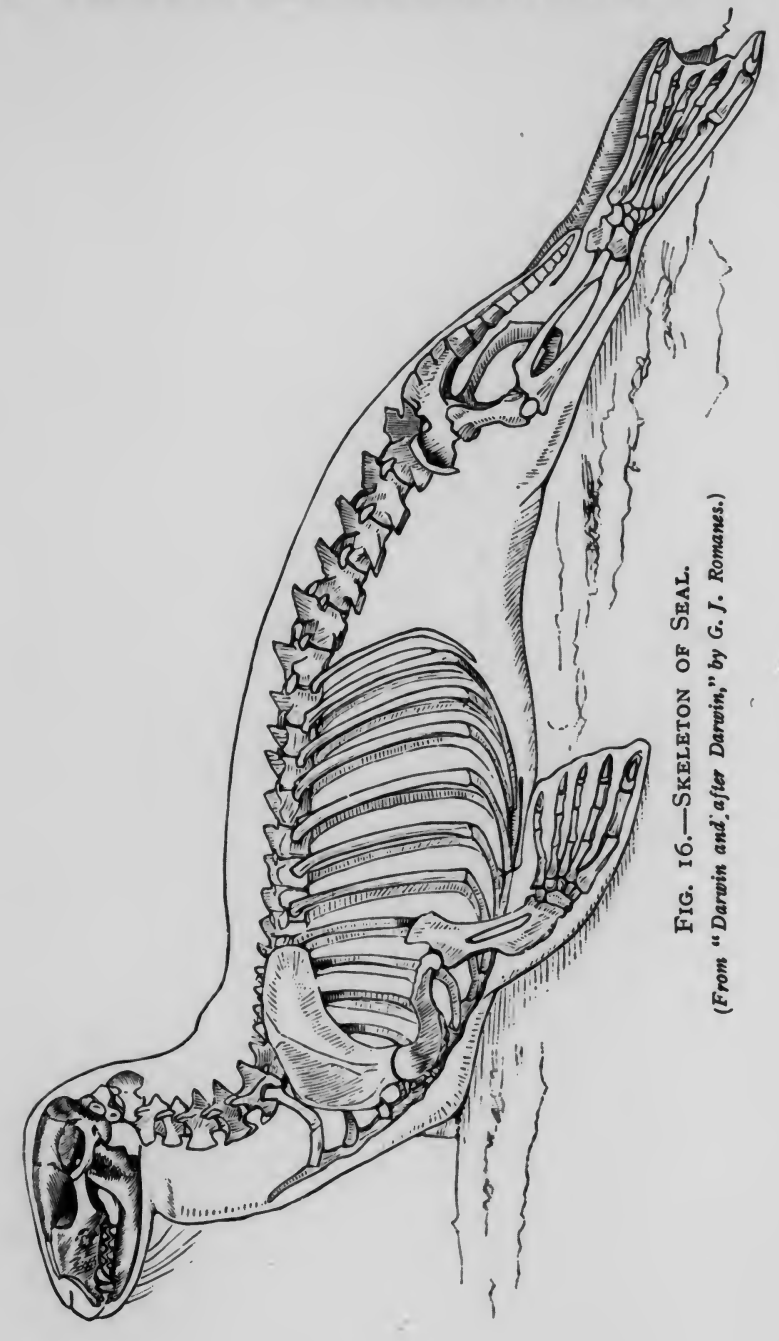

Rudimentary organs are of very frequent occurrence. The creation theory is unable to account for them on any rational basis, while they are most easily explained on the theory of descent with modification. For, according to this hypothesis, organs which through changed conditions this hypothesis, organs which through changed conditions
of life have become useless, are apt to dwindle away gradually, because they no longer fulfil any vital function. In fact, survival of such vestigial structures is the best indication of the actual change in progress in living

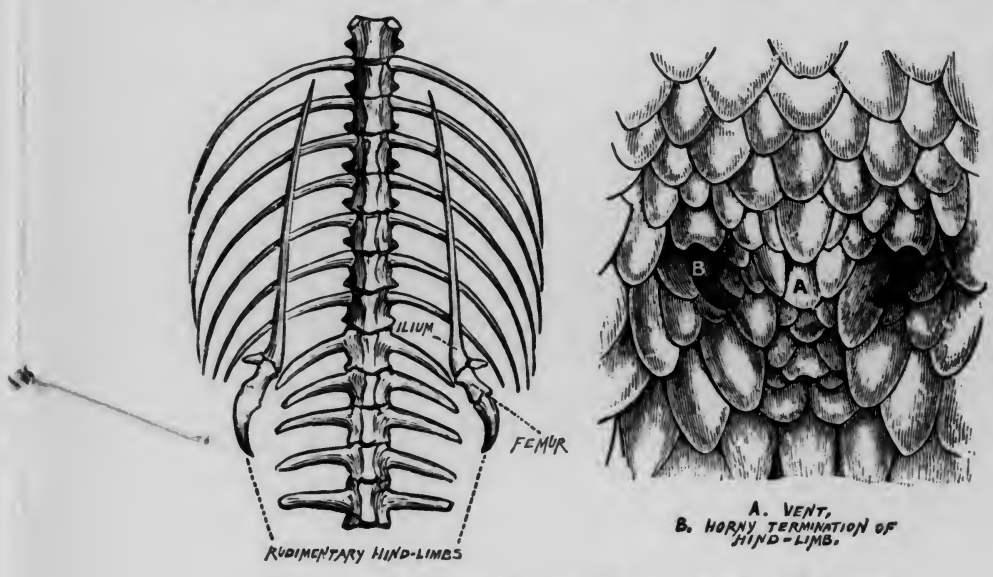

Fig. 17.-Rudimentary Hind-Limbs of Python. (From "Daroin and after Darwin" by G. J. Romanes)

organisms. Thus, while the long, lithe bodies of the snakes show in most of the species no trace of limbs, the occurrence show in most hind-limbs in the python is plain evidence of their original descent from limbed ancestors, the reptiles (see Fig. I7).

The process of atrophy can be well observed in the wings of birds. Darwin has shown that in the domesticated duck which flies very little, the wings are reduced relatively to the legs in comparison with the corresponding limbs of the 


\section{THE FIRST PRINCIPLES OF EVOLUTION}

wild duck. In the ostrich, which never flies, the wings wild in the Apteryx of New Zealand the wing has practically disappeared.

If any further proof of the morphological transformation of species through changed conditions were needed, we tion one-animals. have it in the wingless insects and blind cave-animals. Beetles living on oceanic storm-swept islands run great risk
of being carried out to sea during their flight. We find,

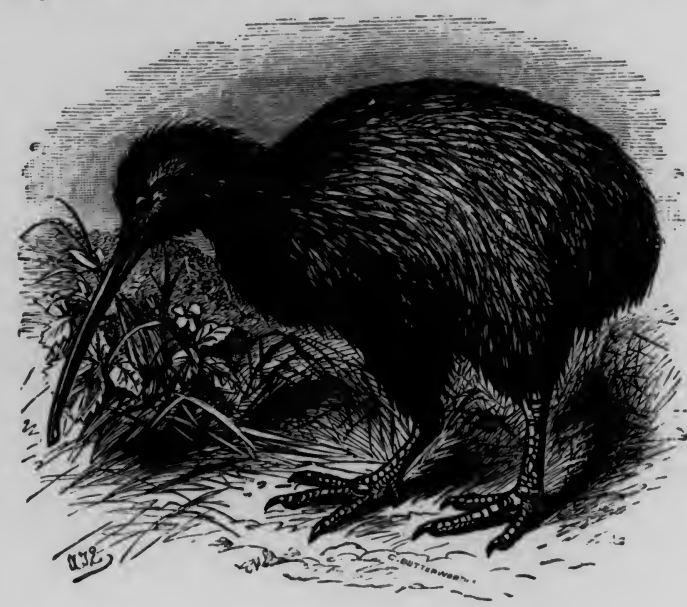

Fig. 18.-APTERYX

(From "Dictionary of Birds," by A. Newtom.)

therefore, that a great number of beetles inhabiting Madeira therefe, that a great and other islands are incapable of the beetles are mostly related to wings. As in these cases the beetles are loss of the wings those of the neighbouring ad an adication due can only be interpreted as an their mode of life. The to the peculiar circumstances of their mode of life. The same applies to the loss of sight in cave-animals which have been shut up for generations in natural caves without the access of light. Such animals as fishes, crabs, tritons, etc. have eyes which are in various stages of atrophy. That they were not specially created for subterranean life, but they were not specially created for subterranean life, but have changed since their introduction into the caves, follows
from the fact that they are in all cases closely allied to the natural species inhabiting the district.

3. Vestigal Structures in Man.

Darwin has shown in his "Descent of Man" that man has to be looked upon as in all essentials an animal, being the last outcome of a long succession of evolutionary stage

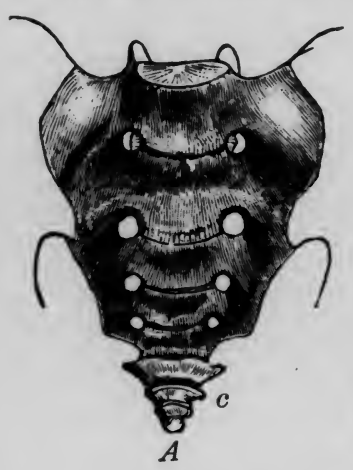
of the animal world. Not only is there a general resemblance beand his next of kin the

4 Sacrum of Man, with Coccygeal Bones $(c)$; $B$, Outline of HUMAN EMBRYo wrTh EXTERNAL TAIL (c). $a u$, Ear ; $v u$, anterior limb; $t f$, posterior limb. (Erom "Daroin and after Derain" by G. J. Romanes.)

anthropoid apes, but numerous links have remained, giving ample evidence of his animal ancestry. The anatomist Wiedersheim has enumerated as many as 180 of such rudimentary structures, which do not serve any useful purpose in man, and can only be interpreted as vestiges of his animal descent.

There are many animals, like the horse, which can move their skin and ears by means of special muscles to ward of 
64 THE FIRST PRINCIPLES OF EVOLUTION

flies, etc Rudiments of such muscles are preserved in human beings, though most people have lost the power of

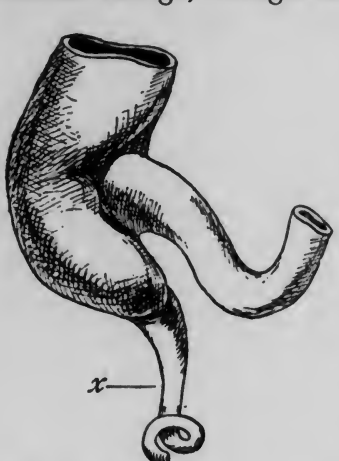

Fig. 20.-VERMIFORM APPEN DIX (MARKED $x$ )

(From "Evolution and Animal Life"
by Jordan and Kellog, published

using them. The tail, which most lower animals possess, has disappeared in man, but a remnant of it can still be found underneath the skin in the coccygeal bones, which the coccygeal bones, which form the caudal end of the
sacrum in man. The muscles belonging to the once movable tail are still traceable in a very rudimentary condition. That these parts are really vestigial structures, having dwindled down from their former larger proportions, finds corroboration in the fact that corroboration in the fact that stage of its development still possesses a conspicuous external tail (Fig. I9). Another rudiment is the vermiform appendix (Fig. 20), a small blind

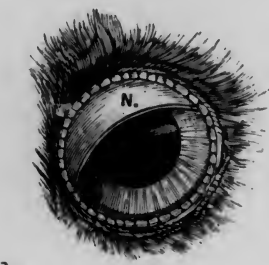

JwL

Fig. 21.-Eye of Owe and Man compaped. $N$, Nictitating membrane. (From "Darwin and after Darwin," by G. J. Romanes.)

process leading from the large intestine, which, serving an appropriate function in vegetable-feeding animals, has survived as a useless structure in man, and is at times even a source of danger, because not infrequently it is subject to severe inflammation through the lodgment in it of fruitto severe inflammation through the lodgment in it of fruit-
stones, etc. The semilunar fold to be observed at the inner

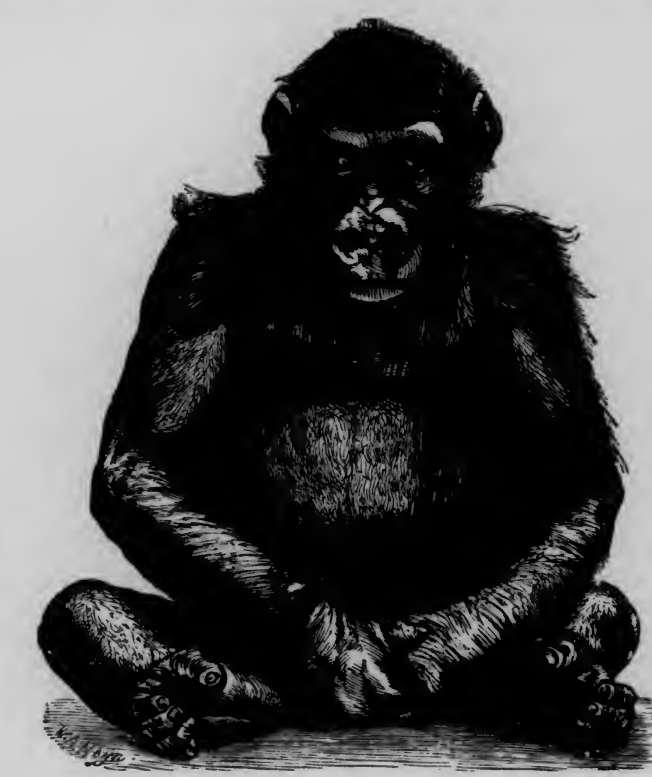

Fig. 22.-Young Gorilla. (After Hartman.) (From "Danwin and after Darwin," by G. J. Romanes.)

side of the human eye is all that is left of the nictitating membrane of the birds, which serves them as an active third eyelid (see Fig. 2I).

Of other peculiarities of man which point to his close relationship with the apes, we shall only give three more. Monkeys leading an arboreal life, swinging from tree to tree, have inwardly curved feet, with prehensile great toes; 


\section{THE FIRST PRINCIPLES OF EVOLUTION}

well adapted for grasping branches. Now, young children possess very mobile toes, the great toe being frequently used in the manner of a thumb, and they can often be seen taking up a similar attitude to that of monkeys, curving legs and feet inwards (cf. Figs. 22 and 23). The same reason must be assigned for the fact that the human infant

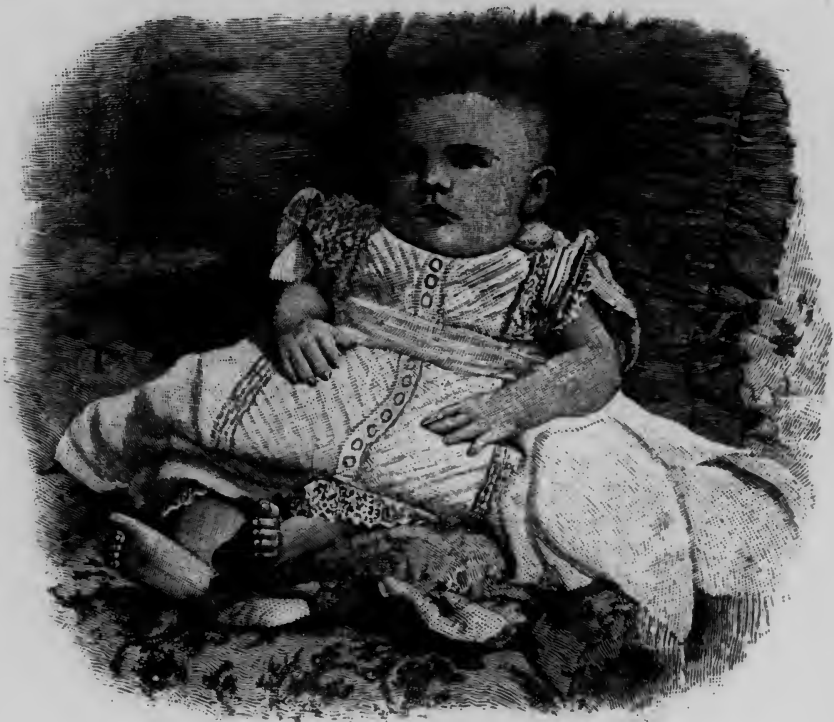

Fig. 23.-Young ChILD. (From "Darwin and after Darwin," by G. J. Romanes.)

possesses extraordinary grasping power in its hands, being able to support its whole weight by them (Fig. 24). This power was a life-saving necessity for the young monkey in the woods, but is in man merely a useless survival. Finally we mention as an interesting document of man's primeval origin a curious feature of the external

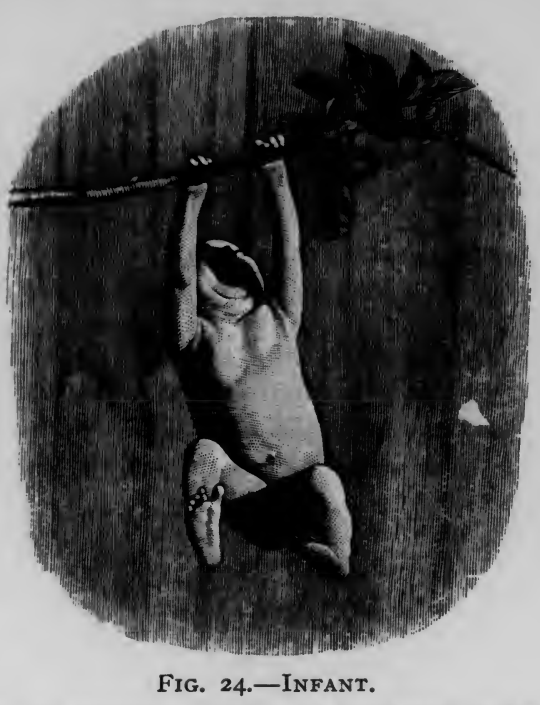

Three weeks old, supporting itself by its hands with strikingly simizn

(From "Darwin and after Darwin," by G. J. Romanes.)
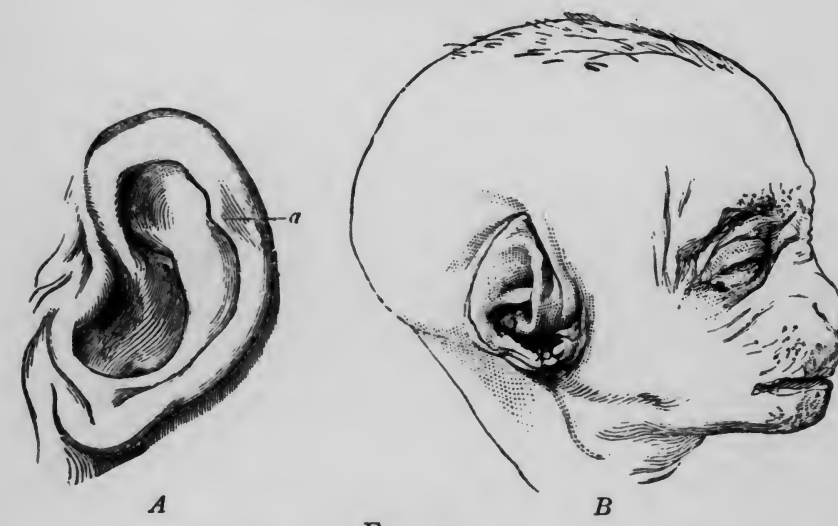

Fig. 25.

$A$, Ear of man with projecting point $(a) ; B$, fœetus of an orang. (From "Darwin and aflee Darwin," by G. J. Romanes) 


\section{THE FIRST PRINCIPLES OF EVOLUTION}

ear, which is very prominent in some persons. The ears of the lower animals are pointed, and the embryo of the apes still shows this peculiarity in a marked manner. Later in the development of the human species, the oute rim of the ear curves inward upon itself, when the rudiment of the point can often be distinctly traced as a little projection of the rim, giving thus plain evidence of man's animal descent (Fig. 25).

\section{CHAPTER IV}

EMBRYOLOGY

WE have seen in the previous chapter how morphological We hecies form an indication traits common of are so altered in their adult state, through adaptive modifications to new surroundings, that this relationship cannot casily be recognized. A clue to the original condition of easily be recognizd in their earler passes during its embryonic development through a succession of changes, which correspond roughly to the various cesson the ancestral species. stages attained during the evelution of the profer , propounded first by Professo Ernst Haeckel and called by him the "biogenetic law," is generally formulated: "The life-history of the individua is a condensed résumé of the life-history of its ancestral is a con ". or more briefly: "The Ontogeny (development species"; or more briefly: "The Ontogeny (devep of the individual) is a short recapitulation of the Phylogeny (development of the race)." This law not only explains satisfactorily why all higher organisms, starting from a single cell, pass during their embryogeny through a sucson forms, but also why the cession of more and more complex for embryonic condition of an organ often preserves an ancestra form which is different from that of the adult state.

Before entering, however, into the details of this law, we must give a short general outline of the process of embryonic development. 


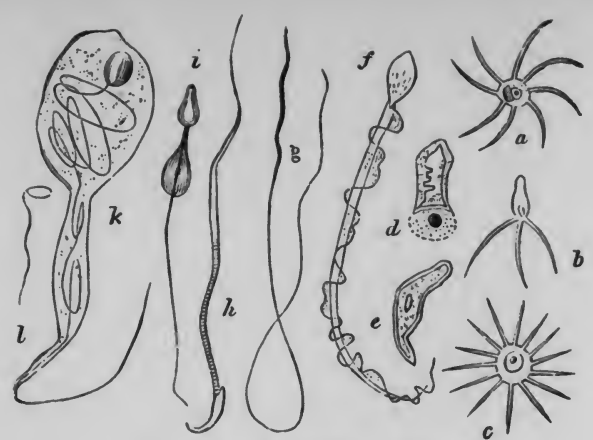

Fig. 26.-SpermatozoA. $a$, Crayfish ; $b$, lobster ; $c$, crab ; $d$, ascarid ; $e$, water-flea (Moina) ; sponge.

(From "The Evolution of Sex," by Geddes and Thomson.)

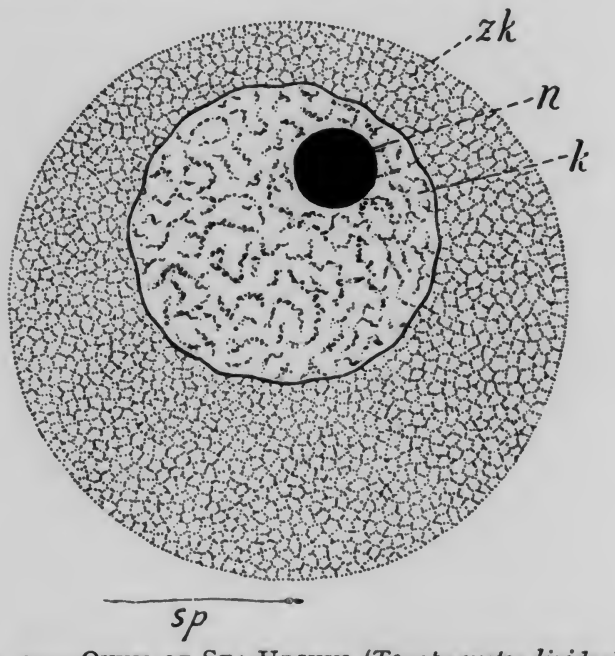

Fig. 27.-Ovum of SEA-URCHIN (Toxopneustes lividus).

$z k$, Cell-body ; $k$, nucleus; $n$, nucleolus. Below the ovum the spermatozoon
magnification.

(From "The Evolution Theory," by A. Weismann.)

\section{EMBRYOGENY}

Every animal and plant starts its existence as a single cell. This primitive mother-cell, as we shall see presently, gradually gives rise by repeated divisions to the body of the organism, which thus is nothing but an orderly arrangement of living cells. The mother-cell itself in all doublesexed species is the product of the union of the two sexcells, the male and female germs, which in the process of fertilization are brought together to form the new indi-

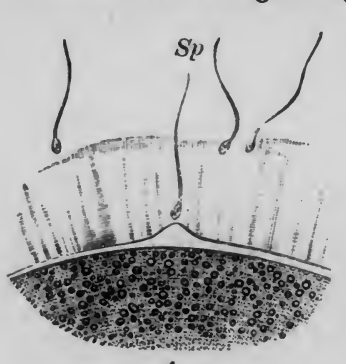
vidual. The male germ is called the "sperm-cell" or "spermatozoon" (Fig. 26);

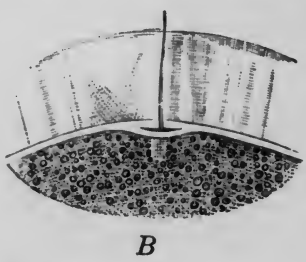

$B$

$A$, Part of the ovum with spermatozoa $(S p)$ on surface; $B$, one spermatozoon entering the ovum.

(From "Textbook of Zoology" by Carl Claus)

the female, the " egg-cell " or " ovum" (Fig. 27). Both are real cells of microscopic dimensions, with a cell-body, mem brane, nucleus, etc. In the process of fertilization one of the small active spermatozoa penetrates the much larger mature ovum (Fig 28) ; the contents of the two cells commingle; the nuclei, which are the bearers of the hereditary qualities, coalesce; and the new mother-cell is formed, which thus comes to unite in itself the characteristics of both parent organisms.

The next stages of embryonic development are fundamentally alike in all multicellular animals. The primitive 
mother-cell, after a complicated process of division of its nucleus, splits into two daughter-cells; these in the same manner into four granddaughter cells, and so forth, until a solid ball of cells is formed, in appearance very
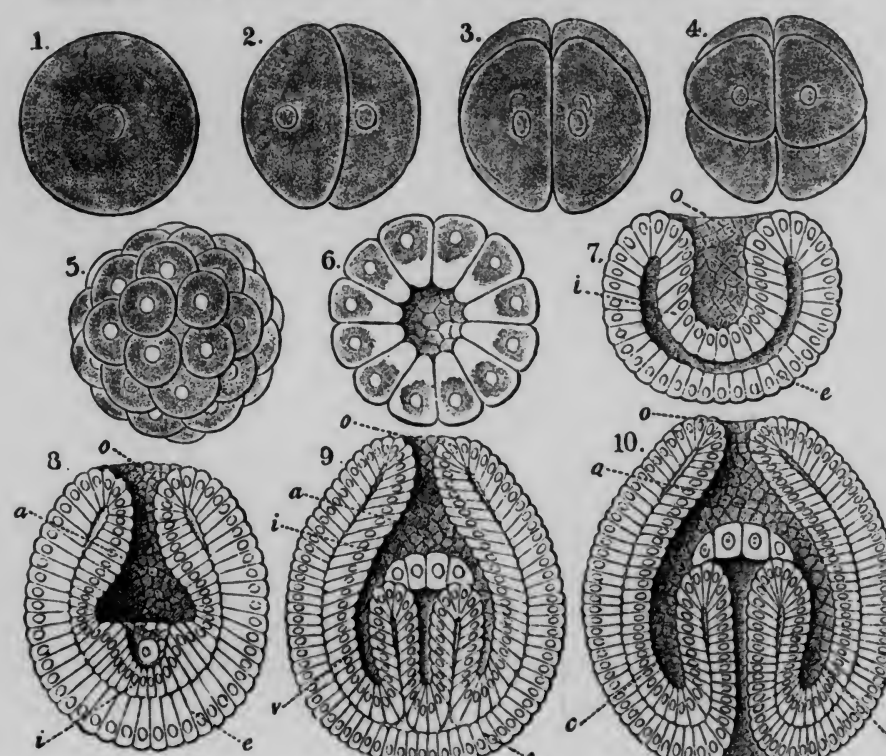

30]
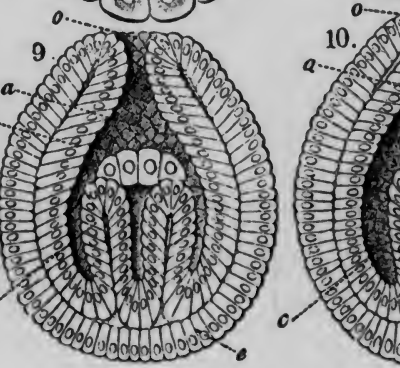

Fig. 29.-EMbryogeny of SAgitta.

I to 4 , Primitive mother-cell with successive divisions; 5 , morula , blastula, 7 and 8 , gastrula; 9 and 10, coelomula, $e$, ectoderm $i$, entoderm, 0 , prits ; $c$, colom cavity. I to 5 , Full views

6 to 10 , sections of embryos.

(From "Natural History of,Creation," by Ermst Haecked.

\section{Author and Publisher.).
B. By kind permission of the}

much like a mulberry, and therefore called a " morula." This morula undergoes further changes. Its central cells liquefy, so that instead of a solid ball we now get a hollow sphere, composed of a single layer of cells, and called a
" blastula" From this blastula arises the next stage, the "blusta, which consists of an outer layer of cells (the

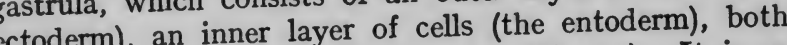
ectoderm), an inner layer of cells (the (Fig. 29). It is as if the blastula had been doubled in upon itself like a the dill these stages are, with regard tollow in all multicellular to their general plan, identical in all multicellular animals they differ in the various classes of animals only in the precise arrangement of the cells, which depends on the amount and distribution of the nutritive substance originally contained within the ovum.

In the further transformation of the gastrula a division of the primitive mouth cavity takes place by the growth of two folds (cœlom folds) which start from the dorsa side of the embryo, and gradually side of the embryo, and gradually elongate, to meet at the ventral two folds the original mouth cavity is divided into three parts: the middle part becomes the gut cavity middle part become the gut cavity of the animal, while the two side cavities represent the two body

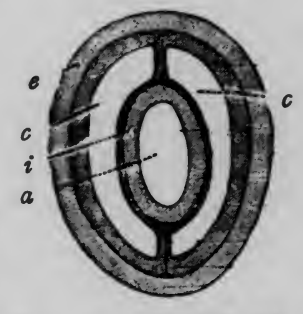
Hertwig.)
Fig. 30.- Section OF A Ectoderm or outer toderm or inner lining of gut; $a$, gut-cavity; $c$,
coelom or body cavities. or cœlom cavities of the fully deThe Evolution of Man,"
by E. Haechel.) veloped organism. We have here- higher animals, which with reached the archety two long tubes, the outer tube thus consists essentially of forming the body covering and the inner tube forming the gut cavity. Between the gut and the outer covering lie the two side cavities, separated from each other right along the back and front (Fig. 30). The development of the the back and front (Fig. 30 ). The is essentially similar later and final stages of this in process, and cheme by additional foldings, etc. 


\section{THE FIRST PRINCIPLES OF EVOLUTION}

2. The Biogenetic Law.

According to the biogenetic law, the development of each individual multicellular animal by means of these successive embryonic stages is due to the fact that the multicellular animals themselves were originally derived from single-celled organisms, which, during the course of evolution through the ages, assumed one by one the

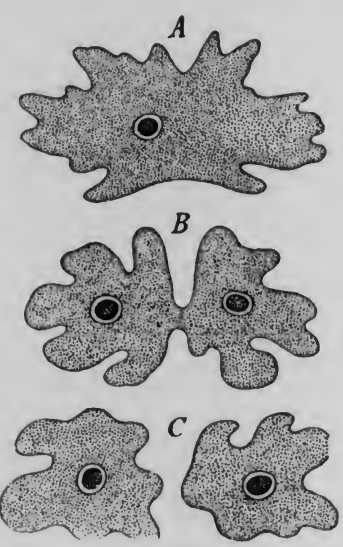

FIG, 31-AмевB DIVIDING (From "The Evolution Theory," by
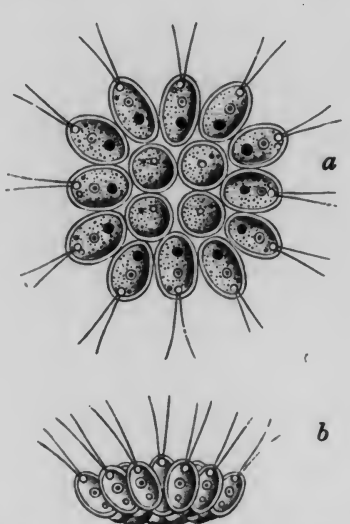

Fig. 32.-Cell Colony of Gonium. $a$, View from above; $b$, side view. From "Textbook of Zoology," by Carl Claus.

different body structures described above. As the lowest organisms became more and more complex by the addition of new stages, so the offspring, which each time had to start its own development over again from a single cell, had to pass through the same successive transformations. According to this theory, there ought, therefore, to exist a parallelism between the development of the individual and the evolutionary stages of its ancestral species. We find, in fact, that the lowest species of the animal kingdom correspond in a large degree to the embryonic stages sketched above. We have at the bottom f the amœbas, infusorians, of the step is (F. 3I). The next step is exemplified by some of the amœbinas, flagellates, etc. which after division do not separate, but cohere togethe and form a cell colony (Fig. 32). Further progress is indicated by the type of animals which, like the Mago-
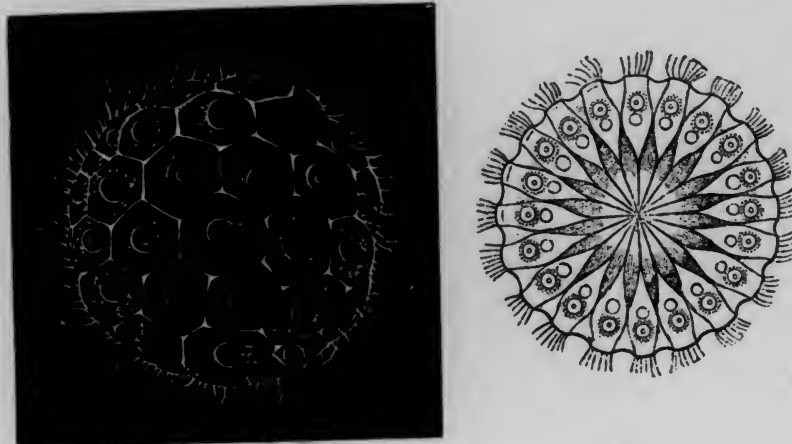

Fig. 33.-Magosphera Planula.

$A$ Seen from above ; $B$, transverse section. (From "The Natural History of Creation," by Errnst Haeckel. By kind permission
of the A A Athor and Publisher.)

sphara planula of Haeckel, the Volvocineæ, etc., form a hollow sphere of cells, but so loosely connected that, when the carry on a separate existence (Fig. 33). The gastræa type is represented by some of the lower cœlenterata, as sponges, etc., which consist essentially of two layers of cells, with a primitive mouth cavity (see Fig. 34 ) ; while all the higher prype of animals, however complex in structure, are built types of animals, however complex in structure, are built upon the archetypal plan of the cœlomula, possessing an inner gut cavity, two side cavities, and an outer covering 


\section{THE FIRST PRINCIPLES OF EVOLUTION}

of skin. The adult form of the lowest vertebrate, the lancelet or Amphioxus, still shows very clearly this primitive type (Fig. 35)
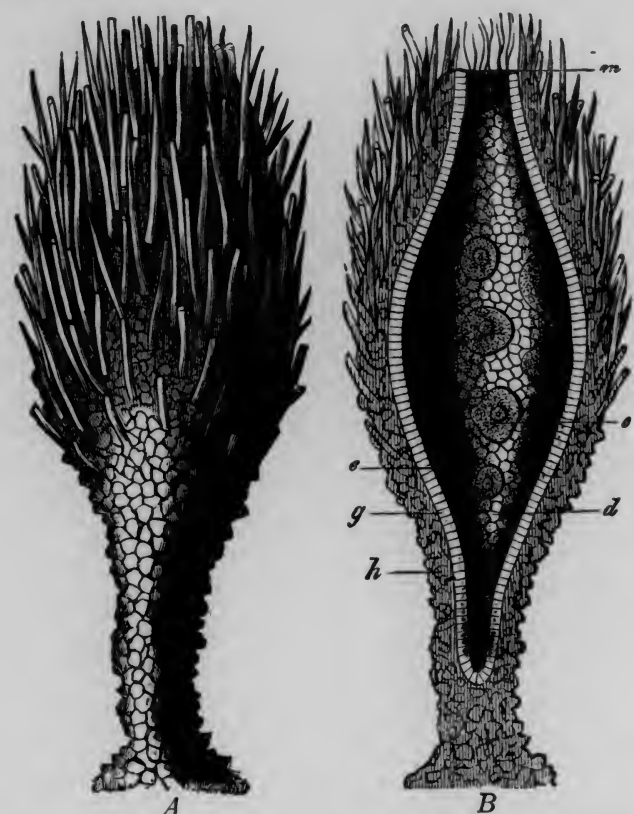

Fig 34-Trophysema Primordiale. (After Haeckel.)

$A$, External view of the animal attached by its foot to seaweed. $B$, longitudinal section. $h$, Ectoderm (incrusted with grains of large size, $e) ; d$, gut-cavity with mouth $(m)$

(From "Darwin and after Darwin," by G. J. Romanes.)

So far, we have shown the biogenetic law in its application to the most general features of animal develoption to the most gepresenting the lowest, i.e., earliest stages of animal evolution, they are common to all animals; for,
EMBRYOLOGY

as we have said, the embryonic development each time repeats the previous ancestral stages. But the same rule holds good for the later stages. Thus the highest vertebrata, including man, pass during their embryonic development through a embryonic development through a
series of transformations which represent roughly the evolutionary stages of the lower vertebrate ancestry. ancestry. As the successively higher forms were evolved by the addition of new features (sometimes by the loss of old ones), so the embryonic development was modified accordingly. Fig. 36 remodified accordingly. Fig. 36 rein the development of some of the vertebrate animals, from fish upward to man. We see that in the earliest of these stages there is hardly any difference to be found in a all the embryos, while in a somewhat later stage all the mammals still appear practically identical. Such resemblances can only be explained on the supposition that there were in Fig. 35. - Amphioxus Lanceolatus. (After Haeckel.)

$h$, skin (ectoderm); $d$, gut (do, dorsal wall; $d u$, ventral wall of gut); $m g$, stomach (anterior part of gut); $o$ ch, $m$ 2, spinal marrow; $k$, gills; $a$, anus.

(From "Danvin and after Darwin," by G. J.
Romanes.)

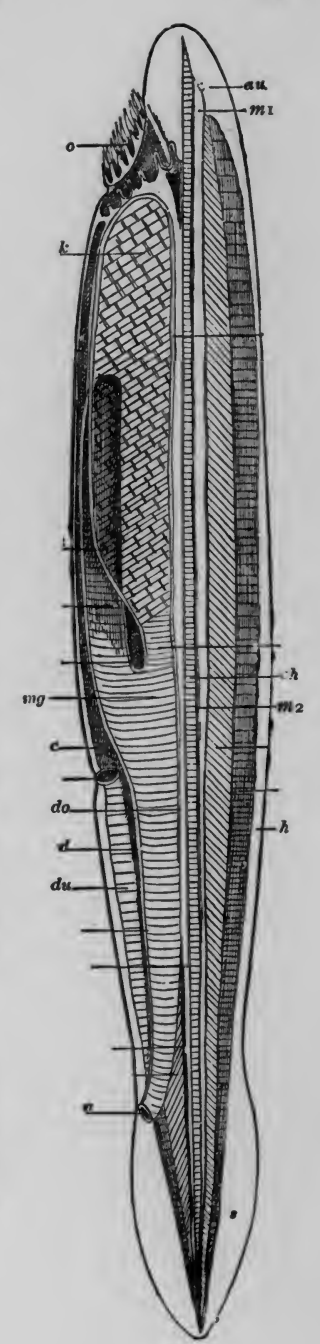




\section{THE FIRST PRINCIPLES OF EVOLUTION}

the evolutionary line of man fish-like and lower mammalian ancestors.

It is important, however, to guard against a misinterpretation of the biogenetic law. We have said that the embryo of any given higher species passes through the various evolutionary phases of its own ancestry : but this various evolutionary phases of its own ancestry ; but this is not to be understood in the sense that all ancestral form are seriatim repeated in full. Thus, for instance, the human embryo is not, as popular fancy s:ill has it, at one time a fish, then a dog, etc. ; but all that can be asserted is that it posseses at a development certain traits it possesses at a given period of development certain traits which are characteristic of the fishes, later those of the lower mammalian type, and so on. Thus gill arches and gill slits can be seen in all the embryos of the first series in Fig. 36 ; but while they are retained by the fishes right throu disto other words, we cannot refer each embryonic stage to a previous ancestral adult form, but must rather look for a parallelism between organs and sets of organs. A comparison of the embryonic forms of both related species rather than that of the adult forms, gives us the clue to their organic relationship. We must further understand that the ontogeny is only a condensed and foreshortened recapitulation of the phylogeny. This is due to the fact that, as new varieties appear and have to be taken up into the embryogeny, readjustments become necessary between the various ontogenetic stages. Also, the rôle a given organ plays during the embryogeny depends, of course, on its ultimate state of perfection; new and important organs will in the development naturally crowd out dwindling organs which are in the process of elimination. A selection of old transmitted forms, such arrangement prevailing as will best lead towards the final adult type.

A further factor occurs which tends to distort the simple

* Remnants of the gill slits are sometimes found as an abnormality in adult human beings. petition of the ancestral series. New embryonic stages epetion may be interpolated which havession of new adaptacestral inheritance, but are the expression of new tions of the species during the embryonic period. Haeckel called "cenogeny" this process of new formations during callotion embryo called "palingeny." For inof the old forms looked upon a stance, the pupa of a butterfly must be looked upon as a cenogenetic stage, for the pupa itself could not exist as an independent organism. The marvellous transformation of a crawling caterpillar with biting jaws into a winged butterfly crawling caterpillar with nectar from flowers, was evidently which lives by sucking nectar from the interpolation of too complex to be achieved without the interpolation of this pupa stage. Other forms there are, again, where the embryonic development is modified cenogenetically, in embryonic embryo order to meet certain ne itself. Thus Fritz Muller showed, according to a young forms of the crustacea, though built according to a certain prototype, are more or less modified according to their habits of life; and Lord Avebury has de

mething similar for the larvæ of somertant fact that, as We must point out, fo individual the old stages are naturally pushed back further and further in the embryogeny.

We can now see clearly why, as we stated at the beginning of this chapter certain affinities can be traced in the of this che completely lost in the adult We We shall conclude with some addition in the human ternal tail of man is still discernible in the human embryo (Fig. I9) ; rudimentary teeth are found in the embryo of the whale, though they never break through the jaw, and are replaced in the adult animal by whalebone. The and ar salamander atra), young of a certain land sall possess, before they are born, which breathes by lungs, still possess, before the are born, complete external gills. The markings in the young of some birds are often atavistic, i.e., revert back to the wild 


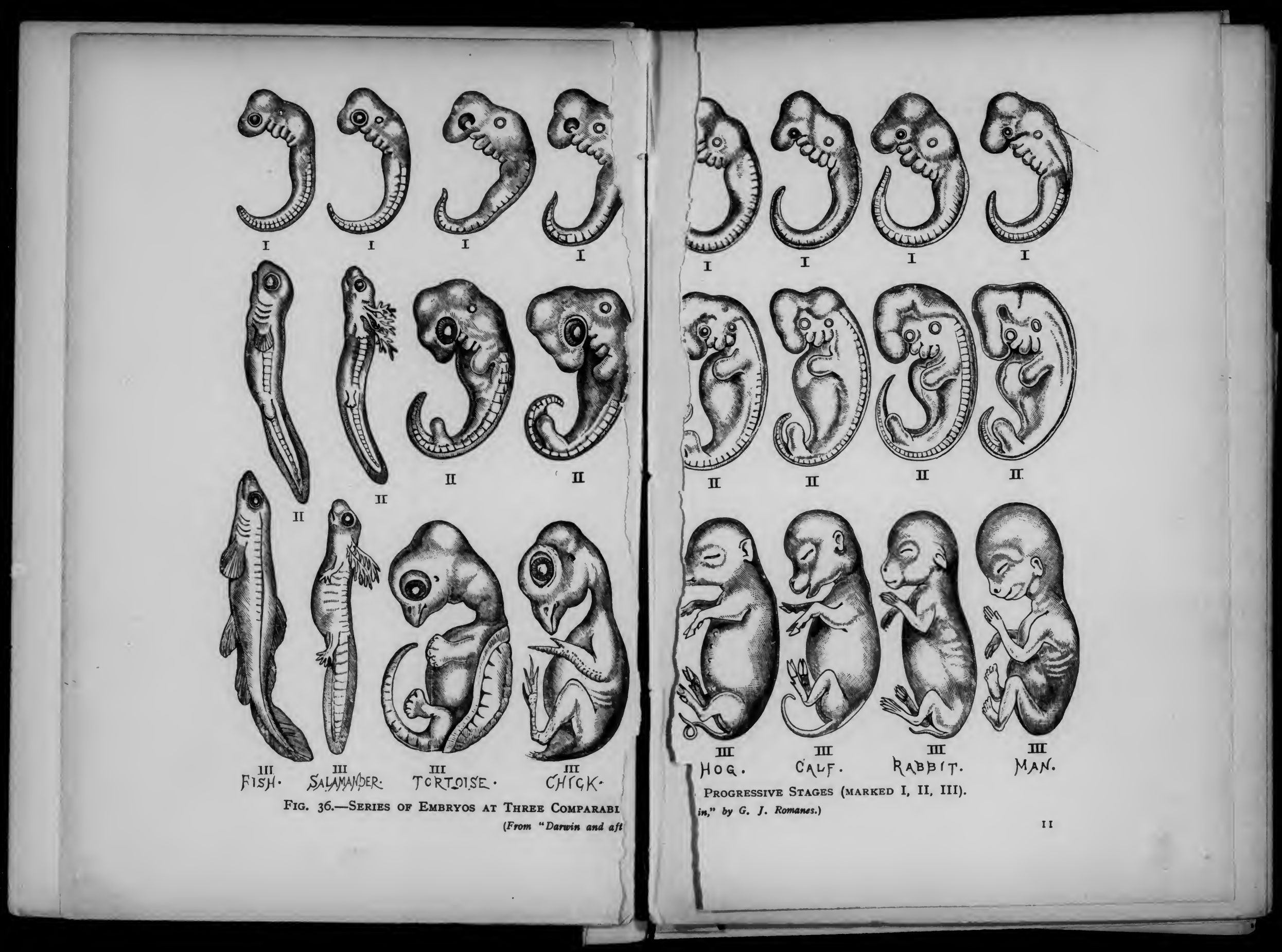


ancestral type of the species; while the adults have the own characteristic plumage, and so on.

Altogether, the new science of comparative embryology has thrown a flood of light on many hitherto unexplainabl has thrown a degree to th phenomena, and has contributed in solution of the intricate family relationships which exist between all natural species. To this problem we now turn our attention.

\section{CHAPTER V}

CLASSIFICATION

MAN, in order to gain knowledge of the natural objects MaN, in around him, tristinction is The of made throughout Nature, that of inorganic and organic while all organisms are once more separated into two large kingdoms-animals and plants. In early times the further classification proceeded on very simple methods. further classifcation pres were used distinguishing the Striking external featuras whe plants were smaller groups of organic beings. Thus, plants were divided, according to this primitive classification still extant in the Bible, into grasses, herbs, and trees; whil animals were distinguished according to their abodes into air, water, and land animals. The earliest scientific into air, water made by Aristotle (fourth attempt at classificationiched for the first time the great century B.c.), who established for the first time the great distinction between backboned (vertebrate) and backboneless (invertebrate) animals; though he erroneously held the latter to be bloodless, and named them accordingly. No further important step was made until Linnæus, in the No further important eighteenth century, arranged all animals into six great classes-mammals, birds, amphibians, fishes, insects, an worms, which latter class included all the organisms now recognized as lower than worms.

Slowly, with the advance of scientific knowledge and the remparison, recognition of interible. The a more detailed classifater defined and new ones were. various groups were better defined and new ones were added, as the distinctions, especi 
PLANTS.

Division I. Cryptogams (flowerless plants).

Subdivision I. Gymnospores (naked spores). Class I. Algr

Class 2. Fungi.

Class 3. Lichens.

Subdivision II. Angiospores (enclosed spores).

Class I. Mosses

Class 2. Ferns.

Class 3. Horsetails.

Division II. Phanerogams (flowering plants). Subdivision I. Gymnosperms (naked seeds).

Class I. Cycads.

Class 2. Conifers (pines, etc.)

Subdivision II. Angiosperms (enclosed seeds).

Class I. Monocotyledons (one seed-lobe). Grasses, sedges, palms, etc.

Class 2. Dicotyledons (two seed-lobes). Trees, shrubs, etc.

\section{ANIMALS.}

Division I. Invertebrates (without backbone).

Class I. Protozoa (one-celled).

Amœbæ, infusorians, etc.

Class 2. Colenterata.

Sponges, corals, polyps, etc.

Class 3. Echinodermata.

$$
\text { Starfish, etc. }
$$

Class 4. Worms.

Class 5. Arthropoda.

$$
\text { Crabs, spiders, insects, etc. }
$$

Class 6. Molluscs.

Oysters, snails, cuttlefish, etc.

Division II. Vertebrates (with backbone).

Class I. Fishes.

Class 2. Amphibia.$$
\text { Frogs, etc. }
$$

ANIMALS-Division II. Vertebrates (with backbone)-continued. Class 3. Reptiles.

Class 4. Birds.

Serpents, lizards, etc.

Class 5. Mammals (suckling the young).

Family I. Aplacentals (bringing forth immature young)

Order I. Monotremata (one-vented). Duckbill, ant-eater, etc.

Order 2. Marsupials (pouched).

Kangaroo, opossum, etc.

Family 2. Placentals (bringing forth mature young). Order I. Edentates.

$$
\text { Sloths, etc. }
$$

Order 2. Whales.

Order 3. Ungulates.

$$
\begin{aligned}
& \text { Genus I. Suidæ (pigs). } \\
& \text { Genus 2. Equidæ (horses). } \\
& \text { Species 1. Equus caballus } \\
& \text { Species 2. E. asinus (ass). } \\
& \text { (hpecies 3. E. zebra (zebra). }
\end{aligned}
$$

Genus 3. Bovidæ (cattle, sheep, etc.)

Order 4. Rodents.

Order 5. Carnivora (beasts of prey)

Genus I. Felidæ (cats).

Species I. Felis leo (lion)

Species 2. F. ligris (tiger).

Genus 2. Canidæ (dogs).

Species I. Canis familiaris

Species $C$ (dog).

Species 2. C. vulpus (fox) Species 3. C. lupus (wolf) Genus 3. Ursidæ (bears)

Order 6. Insect-eaters.

Order 7. Bats.

Order 8. Primates.

Apes and man.

AND ANimals (ABBREviated). 
organisms, became more and more accurate. Thus the present arrangement of classes was reached, each class being divided and subdivided into smaller and smaller groups, as families, orders, genera, and, lastly, species, which are the smallest aggregate units of similar individuals (see Table, Fig. 37, which gives the most important divisions and subdivisions of plants and animals).

Such a linear arrangement of the plant and animal world is, however, as we shall see presently, too narrow in its conception. It does not express at all the intricate cross-relationship which exists between the different organic types. Cuvier, by his discoveries in palæontology, and Von Baer, by his studies in comparative embryology, were led to adopt a new and more correct method of classification, that of diverging branches from a common centre. In this way a great tree of mutual affinities was gradually elaborated, which, in its more general ramifications, is given in Fig. 38. Such an arrangement not only applies to the great divisions of the animal and plant kingdoms, but also, as Haeckel has worked out in detail, to the smaller groups and subgroups.

What does this tree of life, as it has aptly been called, actually signify? We must clearly understand that all classification is merely a human device; the divisions are, as Spencer has said, "subjective conceptions, which have no absolute demarcations in nature corresponding to them." This is not only true of the larger divisions, as is evident from the fact that they have been constantly modified with the progress of science, but also of the lowest unit group of individuals - the species. The species, as now understood from an evolutionary point of view, is not a fixed entity, "a thought of the Creator," as Agassiz still expressed it; but is, as much as the higher taxonomic divisions, a human conception, which varies as our knowledge increases. There exist, in fact, transitional forms between species, which thus often shade into each other. This is, indeed, the central idea of the whole theory of 


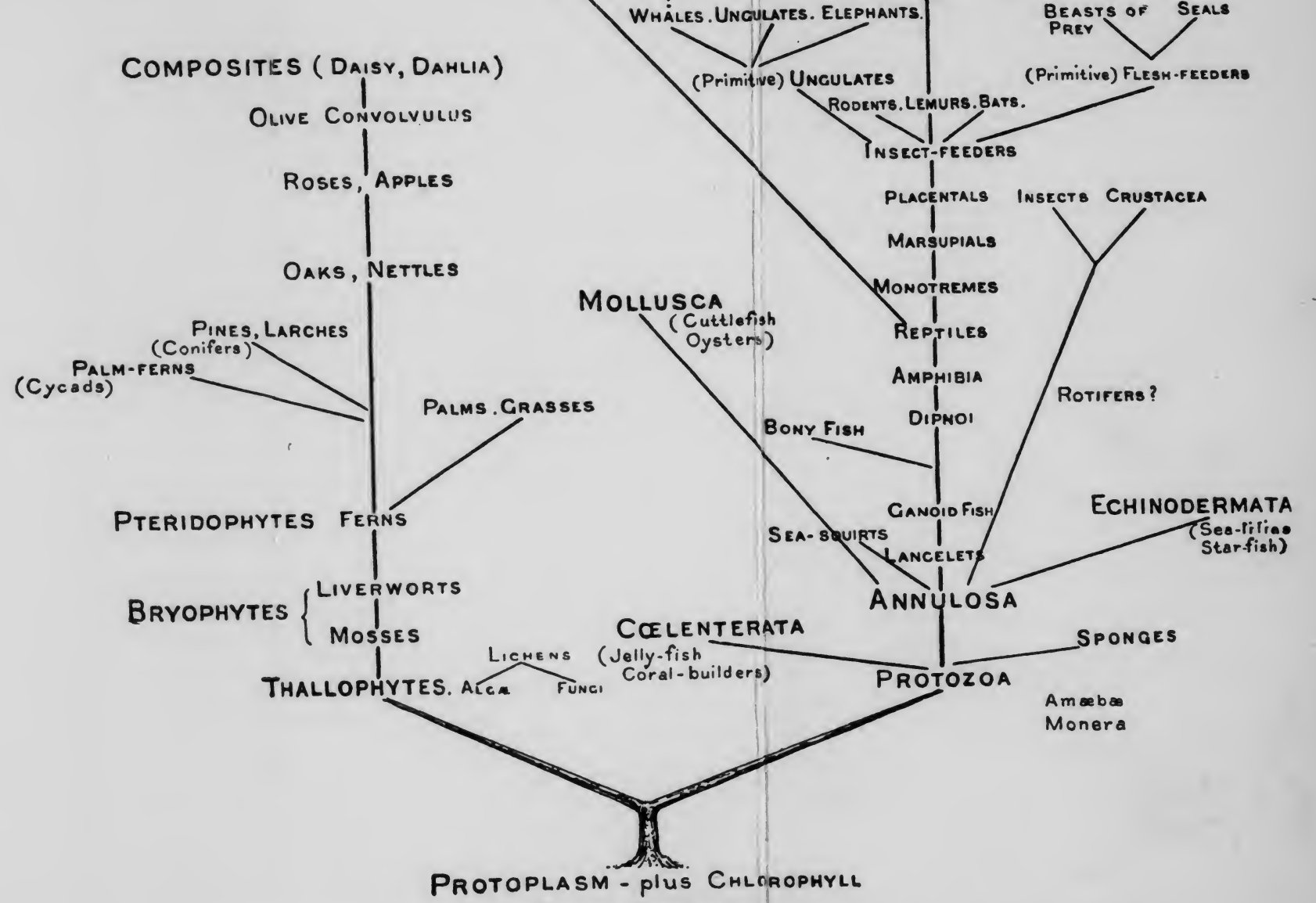

Protoplasm - plus ChLOROPHYLL

FIG. 38. - TREE OF LIFT, The relative position of each group indicates the evolutionary stage of that group; the ascent of the higher life forms
from the lower is more lateral than the lines indicate. 


\section{CLASSIFICATION}

organic evolution, the main object of which is to account for the origin of species.

This grouping of the whole organic world into large divisions related to each other, the splitting up of these large divisions into smaller allied groups-facts which w/ere established before the idea of evolution was consciously applied to taxonomy-can be accounted for only on the assumption of a real genetic affinity of the several related groups with each other. If, as we must assume on the hypothesis of descent with modifications, the new types branched off from the old ones in several directions, the graphic representation in Fig. 38 corresponds to a real genetic tree, giving the actual descent of the organisms indicated.* The complicated interrelation, then, between organic species is due to descent from common progenitors in radiating lines, each line forming new centres for further variations.

This conclusion is strengthened by several other considerations which flow as natural consequences from the fact that modern classification traces a real genetic relationship. As the new forms are each time produced by modification from one parent form, their relationship will best be recognized by comparison of the old inherited traits which are transmitted without alteration, and are therefore common to all younger branches. It follows, therefore, that the oldest forms of any given branch are the simplest in structure, and preserve most fully the features by which the organic relationship of the various groups of that branch can be recognized.

Furthermore, there is no correlation between the usefulness of an organ and its taxonomic value, as the earlier naturalists believed. On the contrary, as De Candolle found, the reverse generally holds good. This is easily understood when we remember that structures of no func-

* We must not forget, however, that such a tree of life is to a large extent hypothetical, being reconstructed according to the amount of knowledge available, and that it does not in all cases indicate what might have happened in reality. 


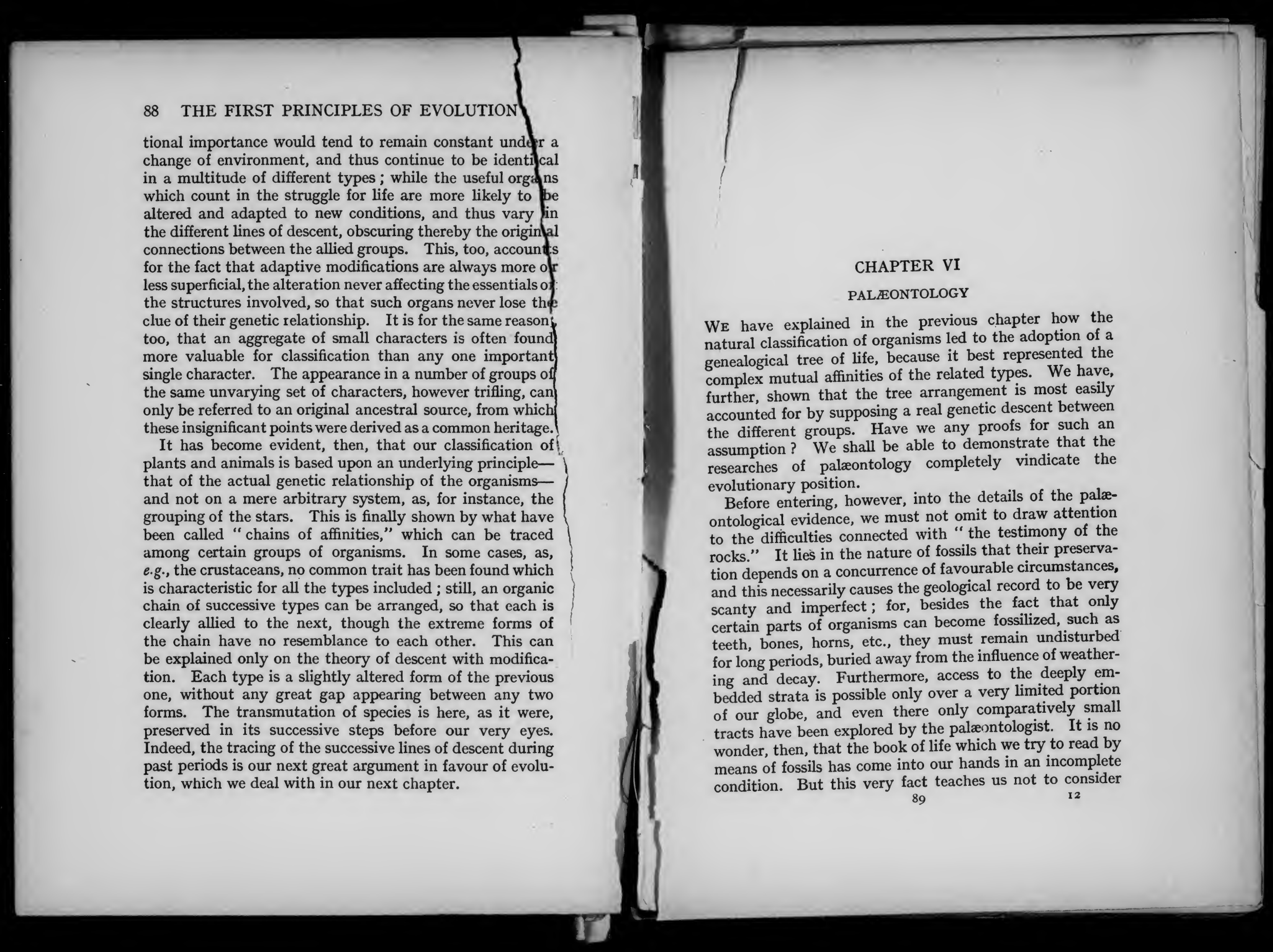




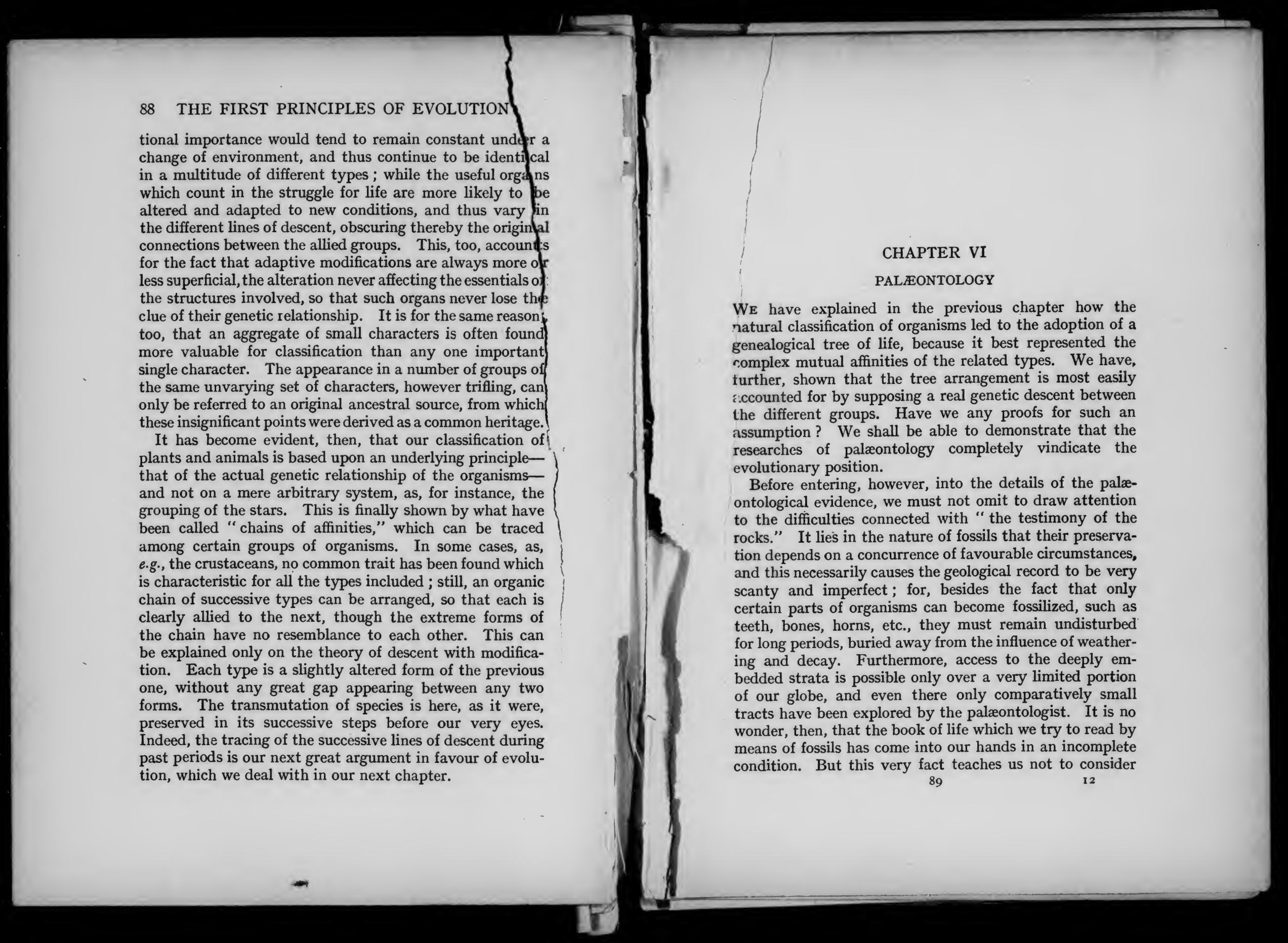




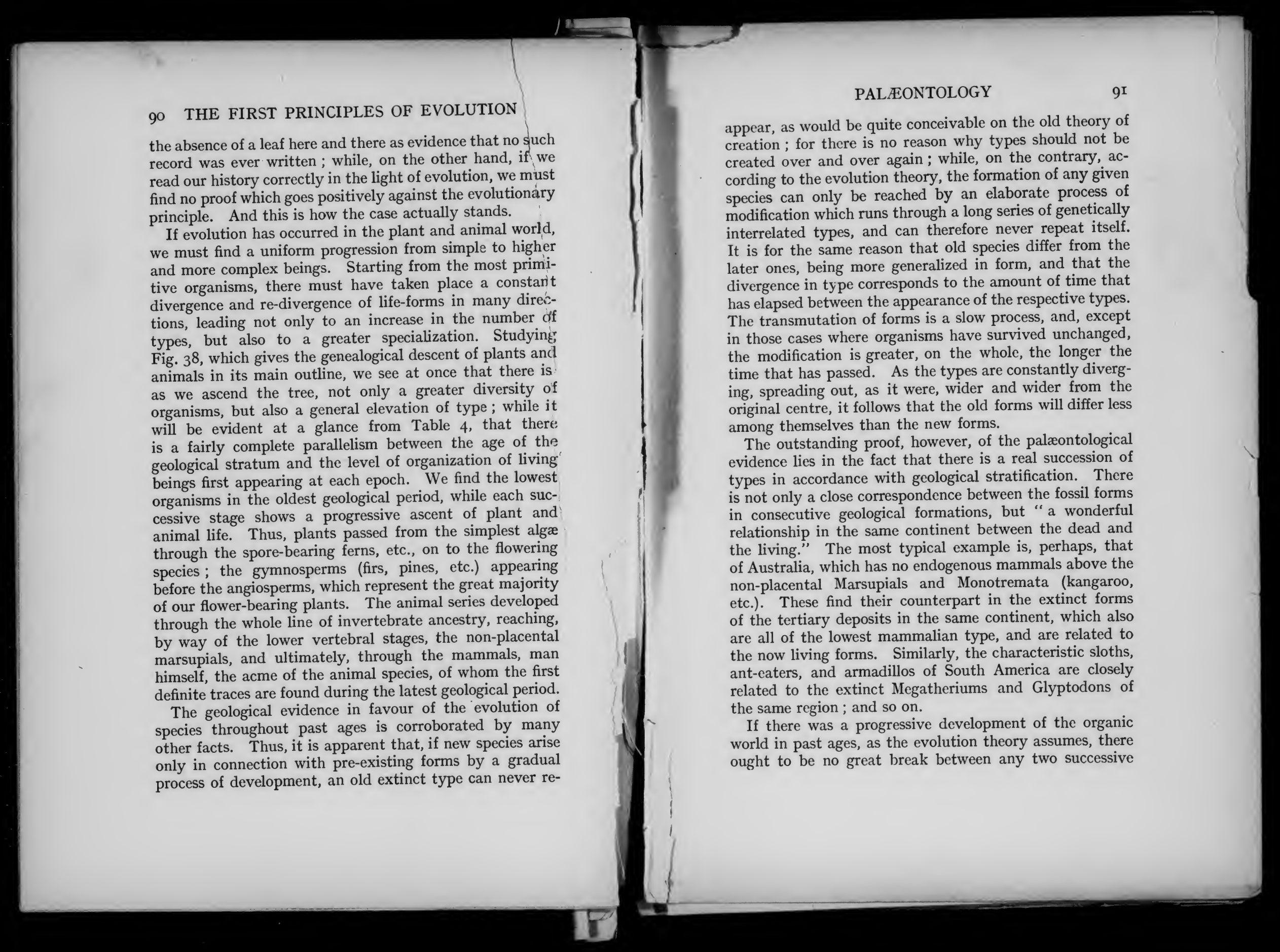


life-forms. Seeing that the gaps are still considerable in the far has palæontology been able to supply the "missing far has palæontology been able to supply the "missing

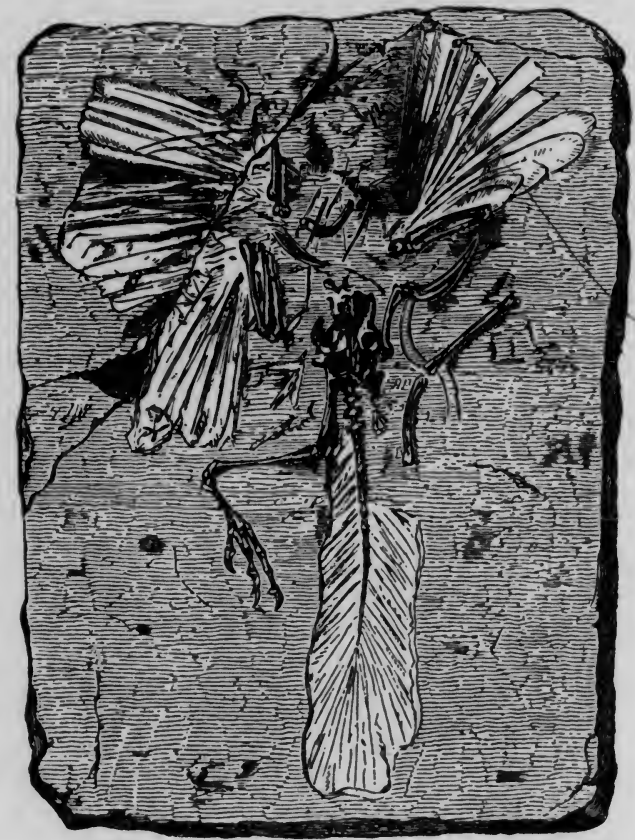

Fig. 39.-Slab containing Remains of Archeopteryx. From THE ORIGINAI IN THE BRITISH MUSEUM ; REDUCED, (From the article "Birds," in the Ninth Edition of "Encyclopadia Brilannica.")

forget the fact, previously mentioned, that the mere absence of positive evidence does not militate against the acceptance of the theory of descent with modification; while, on the other hand, favourable testimony, however scanty, is of the utmost value. Furthermore, it is erroneous to expect that any two divergent types can be directly connected by intermediate forms. This depends entirely on the actual line of descent, whether one type has originated directly from the other or not. Thus, e.g., it is popularly

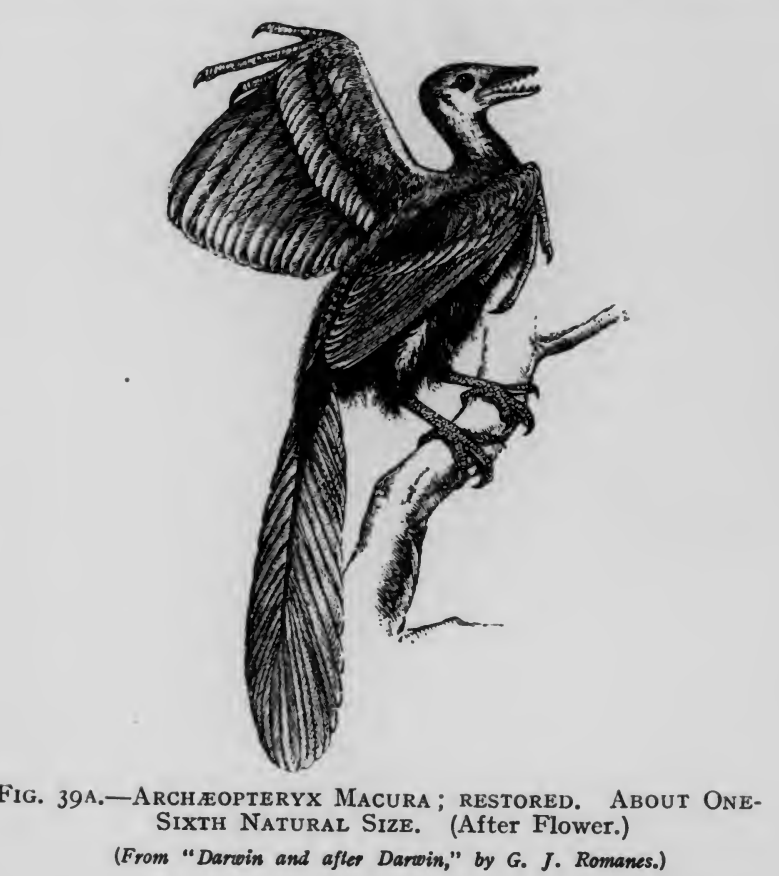

believed that man has sprung from the now-existing apes. This is not correct. We should express their relationship much better by calling them "cousins," both having descended from a common progenitor. It follows, therefore, that no direct link between man and present-day anthropoid 


\section{THE FIRST PRINCIPLES OF EVOLUTION}

apes can be found; we must rather look for a common unknown ancestral type combining the generalized features that old forms often connect younger, now widely separated groups.

In this sense a great many missing links have been unearthed with the progress of palæontological discoveries. The most striking example is, perhaps, that of the Archropteryx (Fig. 39A), which represents the transition stage between reptiles and birds, being in general appearance like a bird, with wings and feathers, etc., though it still has teeth in both jaws, a long vertebrated tail like a lizard, and three well-developed digits on the wings.

A beautiful series of intermediate forms has been made A beautiful series of intermediate forms has been made
out in the evolution of the horse. From a five-toed prototype it slowly changed through a number of stages, gradually losing most of its digits, remnants of which can still be traced in the splint-like bones at the side of the one remaining large digit, which now forms the hoof of the remaining large digit, which now forms the hoof of the taken place more or less in all hoofed animals. The earliest land animals, moving slowly over marshy tracts, had their full contingent of digits, which were used fully extended surfaces raised the foot from the ground and evolved the strong and swift type of hoofed animals, as the camel, deer, etc. Intermediate stages can be seen in the pachyderms, the three-toed rhinoceros, the four-toed hippopotamus, and the five-toed elephant.

A great many other such continuous series of fossils can be made out in similar ways, all witnessing to the truth of the evolutionary principle. We shall only mention the case of the Paludina shells of the tertiary beds of Slavonia which can be arranged into a nearly complete group of form, one beading by minute ster further, the development of the antlers in deer, which become more and more ramified as we ascend in the geo-

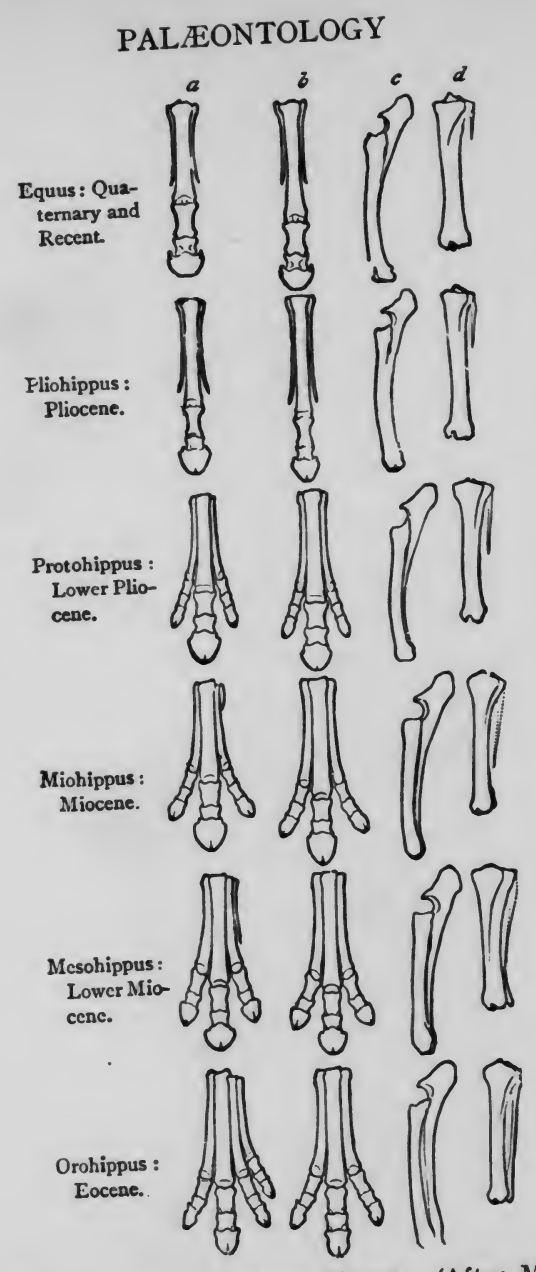

95

(After Marsh.)

G. 40.- Evolures of hind-foot; $c$, bones of fore-les $a$, Bones of fore-foot; $b$, bones of hind-foot (tibia and fibula).

( Daver 
96 THE FIRST PRINCIPLES OF EVOLUTION

logical formations from the Miocene to our own period. We finally give the extremely interesting case of the evolution of the tail in fishes and birds, both having progressed on similar lines. The oldest fishes had a long vertebrated, tapering, diphycercal tail, running right through the fin to

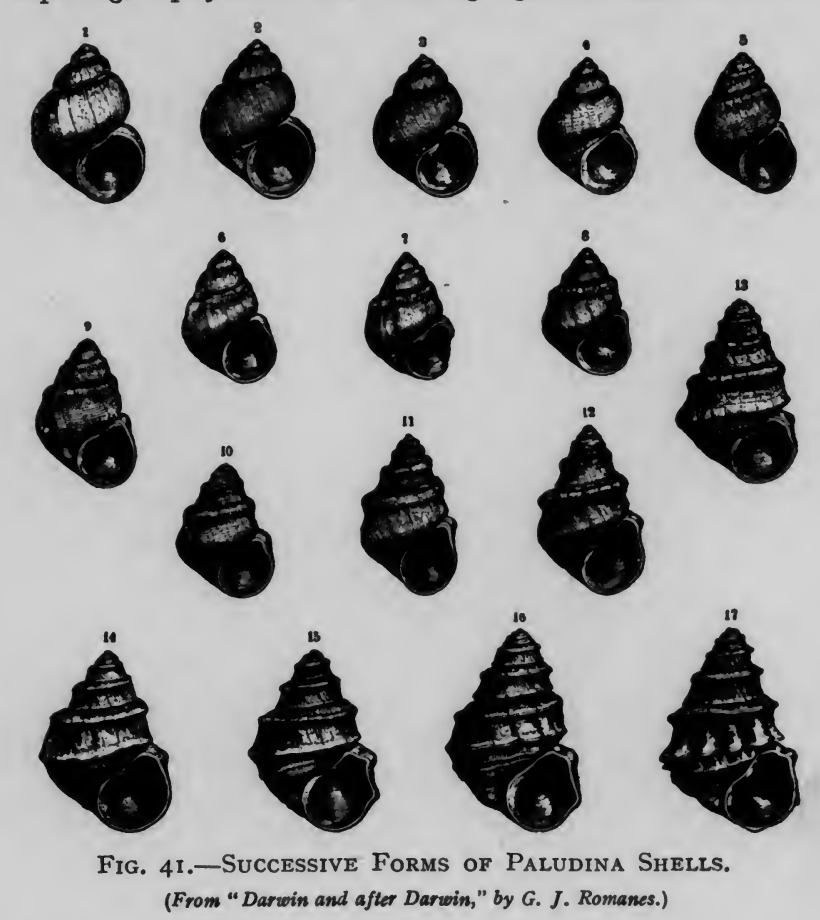

its very point, and giving off rays symmetrically on both sides. The next in development was the heterocercal fishtail, still long and jointed, but built asymmetrically, broader on one side than the other; while the latest fishes possess a homocercal tail which is not vertebrated, but
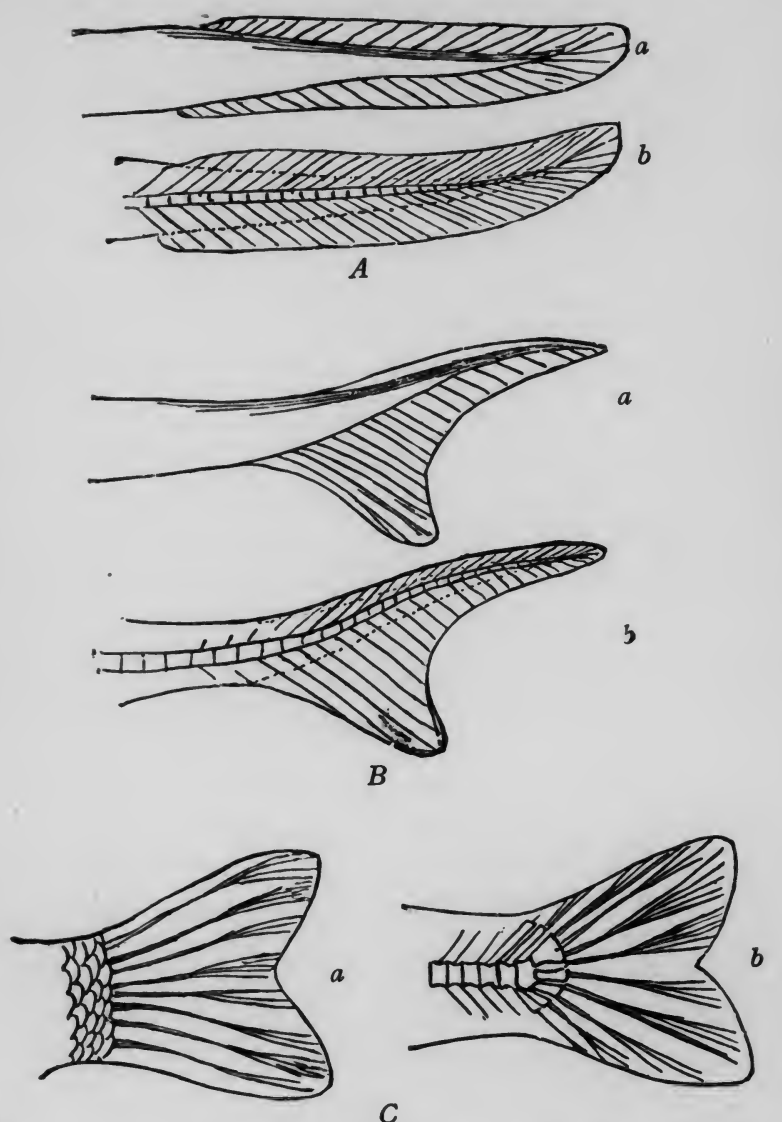
C

Fig. 42,-Development of the Fish-Tail.

$A$, Diphycercal tail; $B$, heterocercal tail; $C$, homocercal tail $a$, external form ; $b$, internal structure. (From "Danwin and after Darwin," by G. J. Romanes.) 
spreads out from the enlarged bony end in a symmetrical fin (Fig. 42). This order of stages is still repeated in the embryonic development of the most recent fishes, as would be expected according to the biogenetic law. The develop-

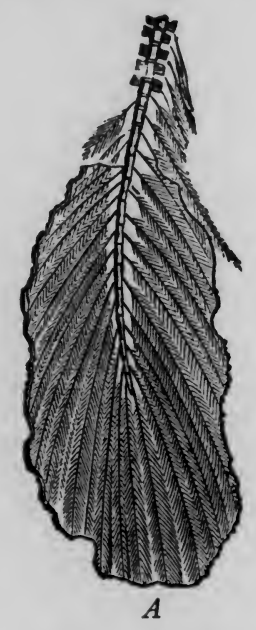

Fig. 43.-Development of the Bird's Tail.

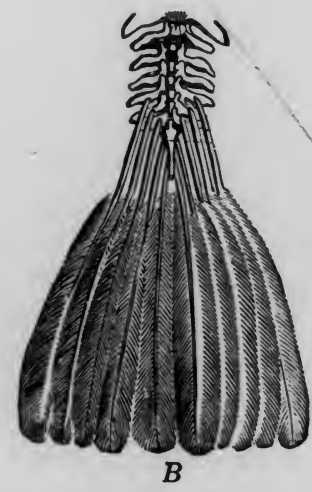

A Tail of Archaopteryx with simple joints ; $B$, tail of

ment of the bird's tail has passed through similar stages, the long vertebrated tail of the reptile-birds having changed into the consolidated typical tail of the modern bird (Fig. 43).

CHAPTER VII

GEOGRAPHICAL DISTRIBUTION

As palæontology deals with the distribution of organisms in time, so geographical distribution gives us the arrangein the for the present-day disposal of plants and animals over the world can only be accounted for on the supposition of an origina derivation of all related forms from common ancestors with their ultimate dispersal over the now inhabited areas. We shall see that the arguments from geographical disWe shall see that the ar hitherto adduced in favour of the theory of descent with hitherto adduction.

To begin with, we must point out that neither "predetermined adaptation" nor climatic conditions offer sufficient explanation of the geographical distribution of the ont the organic world. On the form the hat and the lind a complete con of organisms created for it. Now, though, of course, no species could survive, except in an environment favourable to its existence, we do not find the same organisms in all situations which could support them; as instance the rabit, which the rabbit, which, since its int heduction into Australia, thrives so well there that it has become a pest. On the other hand, if climatic conditions determine the distribution of organic forms, kindred organisms ought to inhabit similar regiors ; while diverse climates should have sharply contrasted floras and faunas. But this is by no means invariably the case. Thus, to give an example 


\section{IO0 THE FIRST PRINCIPLES OF EVOLUTION}

quoted by Darwin: "No two marine faunas are more distinct, with hardly a fish, shell, or crab in common, than those of the eastern and western shores of South and Central America; yet these great faunas are separated only by the narrow but impassable Isthmus of Panama." Contrariwise, according to the same authority, "we may trariwise, according to the same authority, "we may compare the productions of South America south o latitude $35^{\circ}$ with those of north $25^{\circ}$, which are exposed to considerably different conditions; yet they are incomparably more closely related to each other than they compara under nearly the are to the products of Australia or Africa under nearly the same climates." Seeing, then, that "like organisms ar not universally, or even generally, found in like habitats, nor very unlike organisms in very unlike habitats," we must reject both the above-mentioned hypotheses as inmust reject brinciple of geographical sufficient, and look for a further principle of geoge in the as already indicated, in the theory of descent with modifications. Assuming that each species is originally derived from a common centra each species is orist can be source, its grita by migration, the routes of migration being determined by natural barriers.

That such barriers play a decisive rôle in the mapping out of the following facts. We forrer is interposed facts. We find that, wherly a baing transmigration between two regions, effectively checking transmigration of the organic forms from either side, there is to be noted a difference between the life-forms thus separated, the extent of this demarcation corresponding on the whol to the degree of separation. It depends, of course, on the to the degreer of organism what kind of barrier will constitute a hindrance to its dispersal. Terrestrial animals will be effectively separated by great stretches of water, marine organisms by the interposition of land. High mountains, deserts, etc., f the organisms ; often act as a sufficis may

\section{GEOGRAPHICAL DISTRIBUTION}

IOI

serve the same purpose. It is thus, for instance, to be explained, according to Darwin, that the New and Old Worlds differ so greatly in their terrestrial products, except in the Northern parts, where free migration was possible along the land connection which exists between the two continents. Thus, also, is explained a similar circumstance, mentioned by Darwin, that three distinct marine faunas extend from north to south, occupying respectively the eastern islands of the Pacific; while westward from these islands, where there are no impassable barriers-islands and halting-places extending right to the shores of Africano such demarcations in the marine fauna are to be found. On the other hand as Darwin once more has so beautifully On the other hand, as Darwin once more hing insurmountshown by experiment, many such seemingly insurmountable barriers may be successfully overcome by organisms under appropriate conditions. Seeds may be transported by sea-currents for hundreds of miles without losing the power of germination; they may be carried still farther within the crops of birds, in the earth adhering to their claws, on floating timber, etc. Birds and insects may travel long distances over land and sea, or may be carried away in gales, etc. In this way, as we shall see later, many facts of island life which are otherwise unexplainable can be most readily accounted for.

We must refer, then, similarity of geographical groups to community of descent with dispersal by migration. This becomes apparent on a mere survey of the distribution of floras and faunas; for we find that allied organisms are celly kept together in well-defined areas, " biologica generally kept together in well-defined areas " biological regions" being occupied by species, less frequently by genera, which are related to each other. Thus, hummingbirds are confined to America, marsupials mainly to Australia; while of the rats and mice, the species restricted to the New World are distinct from those of the Old World. The arument from " special design of creation " which may be advanced here, comes at once to nought when 
IO2 THE FIRST PRINCIPLES OF EVOLUTION

higher taxonomic divisions are in question. For, while smaller groups may be restricted to certain areas, no such geographical limitation can be made out for the larger divisions of plants and animals. This becomes clear on our theory, when we consider that, as the number of organisms in any given class increases, the possibility of migration is accordingly multiplied. Thus, all the species of humming birds may be confined to America ; but it would have been a strange fact indeed if all the birds had thus been limited to one continent.

This correlation between " areas of distribution and affinities of classification" not only applies to living organisms, but also extends to the extinct species, thus greatly strengthening the proof that community of descent is the true factor involved. For, as we have seen in the previous chapter, existing species must be looked upon as the modified descendants of bygone organic forms. As A. R. Wallace has expressed it: "Every species has come into existence coincident both in space and time with a pre-existing and closely allied species."

The breaking up of biological regions into distinct, may come about in several ways. Thus, separate areas may come about in several ways. Thus,
we have an Arctic area round the North Pole, which has a we have an Arctic area round the North Pole, which has wards, scattered mountain regions are to be found, as the Alps and Pyıenees in Europe and the White Mountains in America, which in their snow-capped altitudes harbour plants and animal species of the characteristic Arctic type. period, continuous with the Arctic Circle, when the whole of the northern parts of Europe and America were covered with snow, and supported Arctic life-forms. As the ice with gradually receded towards the Pole, the arctic plants an animals withdrew on to the ice-bound higher mountainpeaks, thus becoming cut off from the main parent stock, and forming isolated patches of Arctic life in the midst of a now temperate biological region. Darwin accounts in
GEOGRAPHICAL DISTRIBUTION

I03

similar way for the now separated, though allied, proa similar warctic and temperate parts of the New ductions of the later and Old Worlds. According to now Pliocene period, when a mild climate the Arctic Circle was Arctic regions, the main population of the Arctic Circle similar in type to both continents. With the advent of similar in took place souththe Glacial period a wards, thus istinct biological divisions, which are organisms into two dimpassable now sharply separated from each oth origination of new geographical units is given in the change origination of nem the of sea-level, which mainland of which the part. Thus, the British Islively recent geological times, European continent in relatively recent geological times, and we can trace a comparative change in their fora and fauna, comprising a definite, though small, number of plant and animal species, which are peculiar to these islands. plant and animal species, whe link in the chain of our arguIn fact-and this is the last forms leads in time to proment-segregation of organic formisms involved. Though gressive modification of the organisms involv. as we have seen, the Alpine flora is Arctic in general char acter, it possesses some peculiar species of its own-the acter, it poscendants of the original Arctic stock. Similarly, modified descendants of Arctic Circle, as already mentioned the inhabitants of the Arctic Circle and segregation into two broke up with their dispersal and sorlds. There distinct types-those of the New and Old Worlds. There is, therefore, taking place a progressive modification in isolated groups ; and not only this, but there exists a complete correlation between the extent of the separation and plete correlation best exemplified in the the amount of cher offer a most phenomena of island life, which in the principles of geothorough-going substantiation of the principles

graphical distribution, as detailed at length above. We find, in the first instance, that there is no correlation
between the climate of a given oceanic island and its in- 
IO4 THE FIRST PRINCIPLES OF EVOLUTION

habitants. Thus, "there is," according to Darwin, " a considerable degree of resemblance in the volcanic nature of the soil, in the climate, height, and size of the islands, between the Galapagos and Cape Verde Archipelagos but what an entire and absolute difference in their inbut what an entire and absolt the Cape Verde Islands are related to those of Africa, like those of the Galapagos to America." Secondly, we notice a strict accordance to the rule above enunciated that effective geographical barriers lead to the evolution of endemic types in the isolated regions, and this in proportion to the extent of isolated regions, and this in proportion islands like the Sandwich and the Galapagos Islands, St. Helena, etc., that they have a profusion of peculiar types, though, compared with continental areas, they are, on the whole, poor in the total number of species. The amount of modification in any one island corresponds to the lapse of time and. We have seen that the British Isles, which formed part of the continent until relatively recent times, have comparatively few peculiar species ; while the most typical oceanic islands, divided from the adjoining mainland for long geologica periods, possess the greatest number of endemic forms. periods, possess the greatest number of endic forms. Thirdly, the stocking of the islands depends entirely on the possibilities of immigration, which in their turn are deter mined by the barriers which shut the islands off from the neighbouring regions. Thus there is an entire absence of batrachians (frogs, toads, etc.) on oceanic islands, while practically no terrestrial mammals are to be found on any one island situated more than 300 miles from a continen or great continental island. Bats, however, which can pass the water barrier by flight, are common in most islands. This principle applies even to details of geographical distribution. For instance, in the Galapagos Islands twenty-one land birds are peculiar out of a total of twenty-six; while of eleven marine birds only two are peculiar. Marine birds evidently find their way to the

island more easily than land birds. Madeira and Bermuda, n the other hand, which are constantly replenished with w sactically new stock from the adjoining mainland, have practically no pecrliar land birds. The same fact explains our fourth point-namely, that in every case the island forms are related to those of the nearest neighbouring continental region. From there the original stock has come, and from there is the supply kept up by occasional, more or less ther immigration frequent transport. Finally, this factor of immigration also explains the phenomenon of subsequent modification of species in isolated islands, as already mentioned above. An island, once having been stocked with its original set of life-forms, will have most of its inhabitants modified in course of time by progressive evolution. The more complete the isolation-i.e., the less chance of intermingling with fresh arrivals of the old type-the more complete will be the transmutation of species. Thus is explained will be the transmat oceanic islands show such a the above-mentioned fact thecies. Altogether, the evidence great number of peculiar specis

of geographical distribution is seent with modification. mony with the theory of descent with modification. 
PART 1I.-THE THEORIES OF EVOLUTION

THE last five chapters, dealing with the various " facts of evolution," have brought before us a multitude of phenomena, of which each series proved itself so much independent evidence in favour of the theory of progressive development in nature. We pointed out at the beginning of this section that the proofs which establish the general truth of the process of org anic evolution do not in any way affect our decision as to what may prove to constitute the particular underlying cause or causes of this process. The fact of evolution is to be kept quite distinct from the method of evolution. method of evolution. As to the latter, we must remark that, if all things evolve, it is only natural to expect that there exists an evolve, it is only natural to expect that "Deory propounded by Charles Darwin, and known as "Darwinism," was by no means the first proposed-though it was the first to gain general acceptance, thereby establishing the truth of evolution itself as an independent factnor can it in any sense be said to be the last word on evolution. Though we build on Darwinism, we have gone beyond Darwin. Evolution theories can be divided into four main kinds, according to their intrinsic principles:

I. Those which adopt the environmental conditions as the prime factor of evolution-as the theory advanced by Lamarck, known as " Lamarckism."

2. The theory of Natural Selection by Charles Darwin, supplemented by the theory of Sexual Selection. Both, representing Darwin's original contribution to the theory of evolution, we here call "Darwinism."

3. The theory of Mutation, or Heterogenesis, advocated by De Vries, which is a modification of the theory of natural selection.

4. The theories of Orthogenesis, which assume predetermined directive lines of evolution

But before entering into the detailed discussion of these various theories, we shall give a short account of the history of the idea of evolution, as it led up to the great epoch-making work of Charles Darwin, from which dates the whole new science of evolutional biology.

\section{CHAPTER VIII}

THE THEORIES OF EVOLUTION

\section{HISTORICAL}

THE first roots of the evolution idea can be traced back, as we have already said, to the Greeks, whose writings most modern views of contained many germs of readnature. Though we must guard against the error of reading too much into their theories, which were mostly philosophical speculations without scientific basis, it must be admitted that their conception of the universe was muct more in accordance with what has been found to be the mo in alical true interpretation of view which superseded it for centuries. motion motion. systems, whether the primary substance out of which the world constantly reconstituted itself was held to be water, air, fire, or any other single entity or combination of elementary entities (Thales, 600 B.c. ; Heraclitus, 500 B.C. and others). They anticipated not only the atomic theory af of matter (Dement, as was done modern theory of progressive developme firt as wer e.g., by Anaximander (570 B.C.), who first asserted the principle of the origin of the living from the non-living, adopted later by Aristotle ( 350 B.C.). Even the idea of the survival of the well-adapted forms was foreshadowed by Empedocles ( 450 B.C.) and accepted by Epicurus by Emped (300 B.C.). The Roman thinker and poet Lucretius (50 B.C.), who built his system of philosophy on Greek models, represents fairly well in his work all that was best 


\section{I08 THE FIRST PRINCIPLES OF EVOLUTION}

in Greek philosophy. He was an atomist, and declared survival of the fittest, and even argur survival of the fawn of his existence, having had a heroic golden age at the dassed through an initial according to ancient mythology, passed thed.

stage of savagery before becoming civilized.

The advent and ultimate victory of Christianity changed the whole aspect of human speculation. The authority of the whole aspect Genesis was held to be irrefutable-nay, the narrative of Gens breach to be made in the biblica inviolable. The first breach to be geogical remains. tradition was due to the study of gerstanding of the Fossils, which ar:cording to the understand of Nature," Middle Ages, were considered to be "sports of Nature," had been recognized by some advanced men of their time had been recentury, and Steno of (Leonardo da Vinci in the remains of once extan Padua in the seventeenth) as the re was too strong to allow organisms. But religious prejudice was too strong to allow such opinions to find their proper appreciation. Evist Hutton as the end of the eighteenth century the geologist Hutton was met with a storm of obloquy for presuming to propound was met with a storm contrary to biblical revelation. As to the a geological theory contrary to bigned supreme. The organic world, the creation story to be literally true tale of Noah's Ark was considered to be literally true. Even Linnæus, the famous systematizer of plants and animals, still declared in the eighteenth century: "There are as many different species as different

in the beginning by the Infinite Being."

As the first of the pioneers of the modern doctrine of As the first of the pioneers the French scientist Buffon evolution, we have to note his belief in the mutation of (1707-I788), who expressed his belief in "heresy." About species, though he later recanted such "here first decisive specine the bering of step towards the solution of the thenstaken by Lamarck, who published hilosophie Zoologique" formation of species in his classic "Philosophost important (r809), which must be looked upon as the most important contribution towards the science of evolution before

\section{HISTORICAL}

I09

Darwin But he was before his time. His work did not Din gain the attention of the scientists at the time in his purpose, that, when in 1830 a heated discussion took place in the French Academy between discuffor St. Hilaire the friend and colleague of Lamarck, Geoffroy St. Hilaire, the friend and colleague of Lamarck, and Cuvier, the latter, who upheld the unchangeableness of species, gained a decisive triumph for the catastrophic theory, thus postponing the ultimate victory of the evolutionary view by thirty years.

In Germany, the famous poet Goethe, who was at the same time a not unimportant scientist, foreshadowed in a remarkable degree the modern idea of progressive transformation. His views on the "Metamorphosis of Plants" (published I790), positing a primitive archetype (the leaf) of which the other parts of the plant are modifications and further, his vertebral theory of the skull, embody and, further, his vertebral thery of the skell embation. distinctly the principle of progesive transmution. Lorenz Oken (I776-I85I) and Treviranus (I776-I837), too, must be mentioned as forerunners of the developmental idea.

In England the foremost name in connection with the evolution theory in the eighteenth century was Darwin's evolution theory in the eighteenth cen tury was Darwin's (I794) anticipated to a large extent the views of Lamarck.

A great impetus was given once more to the evolutionary hypothesis by the progress of geology. For though Hutton had failed to overthrow the diluvian theory, which was the accepted creed of the time, Sir Charles Lyell, the foun the accepted creed of the time, Sir Charles Lyell, the founder of modern geology, " (fuced some decades later. His "Principles of Geology" (first edition I830), by substituting for the cataclysmic revolutions of the old schoo the explanation of a natural gradual transformation of the earth, not only paved the way for the acceptance of the evolution theory propounded by Charles Darwin, but the book itself of Species," according to his own testimony, and thus had 
a direct share in the formulation of the theory of natural selection. The idea of evolution was evidently in the air. section. The in Darwin himself mentions various writers who before him had expressed the belief in the gradual transformation of species. We have already mentioned in the introductory chapter what a large share in the origination and workingout of the developmental hypothesis was due to Herbert out of the development book, "Social Statics" (1850), Spencer. His earliest book, "Social Statics" (1850), several articles between the years 1852 and 1857 , but chief of all his "Principles of Psychology," published in 1855 , all present the evolutionary point of view. Of his great later works, comprising the "Synthetic Philosophy," which de with in a philosophical manner, extending its scope over the whole realm of natural phenomena, we have spoken previously.

But the outstanding figure in the history of evolution is Charles Darwin. While on his voyage as naturalist on the Beagle, he was drawn by his observations on the fauna the Beagle, he was drawn by hestion of of South America to the consideration of the question of the origin of species. As early as 1838, after reading of the strugete for existence and the selion ourable of the strugs an the cause of variations among plants and animals as the trusiduous their progressive development. But only after assiduous labour, extending over more than twenty years, did he publish his great work "The Origin of Species" (1859), which put evolution in the rank of a recognized branch of knowlede. Not only did he bring forward an overknowledge. Not only did he whelming mass of evidence in favour of evolution, but he also offered for the first time a satisfactory explanation thereof. Alfred Russell Wallace, who was exploring th Malay Archipelago about this time, had been led to adopt ind sarvival of the fittest. indepers In 1858 he sent a short paper on the subject to Darwin, to be read before the Linnæan Society. It is common knowledge how Darwin, on the advice of his friends, was induced to have a short abstract of his own theory read at the same time as Wallace's paper, and how both joint-authors same time anothe of the theory of natural selection vied in that epoch-making in appreciation of each other's share in that claim of Darwin idea. Wallace always admitted the prior claim of Dacidation who had spent years of untiring labour in the elucidation of the principle, while he himself had had but a flash of imagination. Religious prejudice once more tried to stifle the new science. But the championing of Huxley in the new science. But tond, and of Ernst Haeckel in Germany, together with the constant discovery of new important facts in favour of the evolution theory, which were now brought to light the evolution by ardent workers, ultimately achieved everywhere by ardent once complete victory for the new doctrised fact; ; it is merely before, evolution is now an established fact-, it is me the the method of evolution that is still debatable. consideration of this problem we now turn our attention.

\section{LAMARCKISM}

Lamarck was the first to elaborate a theory of organic Lalution which is still upheld. Though neglected at the the principles laid down by him the many modern scientists, have become an accepted creed with who look upon the Lamarck of organisms. Lamarck had all progressive develo a thorough grasp of the problem of organic evis question, is evidenced by his repeated publications on this question, is evecially in hi " "Phing from the years " and the preface to his "Système "Philosophie Zoologique, and the distinctly pointed out des Animaux sans Vertebres. "He distinctly pointed out that there are no divisions in the organic world correst. ing to the classes, orders, genera, etc., which we construct. To him even the species was, contrary to the then generTo him en mot a collecally held opich reprotion of individuals, bing as the duction perpetuates in the same condition as long as the 
their habits, their character, and their form vary." . . . "Species merge one into another; where we see isolated species, it is only because there are wanting other species which are more nearly related, and which have not yet been collected" According to him, nature has "produced the different living beings by proceeding from the most the different living beings by proceeding from the most simple to the most complex." - . " One is forced to constitutes a series of groups forming a true chain." This series, however, is not a single one, but is " branching and irregularly graduated."

How, then, have all these varying organic forms been produced from each other? "Time and favourable conditions are the two principal means which Nature has employed in giving existence to all her productions." A to time, he had very clear views on the succession of c tim " time has no limit" As geological periods. For him "time has no limit." As to the circumstances, "the principal ones arise from the influence of climate; from those of different temperatures of the atmosphere, and from all the environing media from that of the diversity of different localities and their ituation; from that of habit, the most frequent actions ; finally, from that of means of preservation, of mode of living, of defence, of reproduction etc. Moreover, owing to these diverse influences, the faculties increase and become stronger by use, becom differentiated by the new habits preserved for long ages, differentiated by the new habits prerved for long ages, and, insensibly, the organization, the consistence-in word, the nature and condition of parts, as also of the organs-participate in the results of all these influences, become preserved, and are propagated by generation (heredity). In other words, the change of organisms is (heredity). In other worck directly to the change of due, according to Lamarck, directly to the change
environmental conditions. As the latter are constantly altering with time, the organisms undergo continual

* All quotations of Lamarck's writings are from A. S. Packard's book on "Lamarck" 
II4 THE FIRST PRINCIPLES OF EVOLUTION

-that is to say, the nature and form of the parts of the body of an animal-which have given rise to its habits and its special faculties; but it is, on the contrary, its habits, its manner of life, which have, with time, brought about the form of its body, the number and condition of its organs ; finally, the faculties which it enjoys." And, concludes Lamarck, all such effects are transmitted to the succeeding generations by heredity. Lamarck himself gives many instances in illustration of this principle. He gives many instances in webbed feet aquatic birds. The thus accounts for the induced the birds to spread their toes effort to keep afloat induced the birds to spread their toes
asunder as much as possible. This led to a stretching of the membranes between the digits, which thus became gradually extended. In the same way the long legs of the gradully ext ched fet waders, the clawed feet of birds perching on tres, are accounted for. Want of use, on the other hand, brought about the disappearance of the limbs in snakes, the peculiar immobile fingers of the sloth, and so on.

In order to show how new organs could originate by the same process, Lamarck gives the example of a mollusc, same process, Lamarck gives the example of a mollusc, which we shall quote once more in his own words: "I conceive that a gasteropod mollusc, which, as it crawls along, finds the need of feeling the bodies in front of it, makes efforts to touch these bodies with some of the foremost parts of itself, and sends to these every time supplies most parts of itself, and as other fluids. I conceive, I say, that it must result from this reiterated afflux towards the points in question that the nerves which abut at these points will, by slow degree, be extended. Now, as in the same circumstances other fluids of the animal flow also to the same places, and especially nourishing fluids, it must follow that two or more tentacles will appear and develop insensibly under these circumstances on the points referred to." We see, then, that, according to Lamarckism, the evolution of species must be attributed to the influence of the environmental conditions on the organism. These nitiate new variations of the species, which are fixed in succeeding generations by heredity. A distinction is to be me direct action of the physical factors to be made bimals are modified, and by which plants and the low animals are mond the more indirect proce which brings about the progressive development of the higher animals, including man.

Lamarck tried to substantiate his theory by many illusLamarch already quoted. He trations, a few of wheans of the environmental factor, not only explained, by means of the environmental factor, not only the various kind of birds, but also the form of the flat fishes with their asymmetrical head and eyes, the long body of the serpents, the horns and hoofs of the quadrupeds, the wings of flying mammals, etc. But the main evidence the new school of Lamarckism, the Neo-Lamarckians of whom
we must mention Henslow, Hyatt, Packard, Osborn, Cope, and Herbert Spencer.

Professor Henslow has accumulated in his two books, “The Origin of Plant-Structures," and "The Origin of "Floral Structures," a vast mass of facts about plant life, Floral Structures," a vast mass of facts about plant life, all tending to show that the structures of plants are due to the influence of external agencies. Thus the structure of can according tendrils and pads of climbir to him, all be accounted for by the reaction of the growing plant-organism to the incidence of surrounding forces. It is a well-known fact that plants change their character with their environment, according as they are reared in dry or moist climates, in high or low altitudes, etc. Flowers dry or "self-adaptation to insectcan similarly be explained by " self-adar agency." The nectar-seeking insects alighting on the flower produce various stresses and strains in the floral parts, whence result not only the different irregularities in the shape of the floral organs, of petals, sepals, etc., but also the the secretive and hairy proce the nectaries themselves are, of certain flowers. Even the nectaries themselves are, according to this theory, to be ascribed to the nutritive 


\section{II6 THE FIRST PRINCIPLES OF EVOLUTION}

currents in the plant tissues, set up in direct response to the irritation of the feeding insects.

Coming from the realm of botany to that of zoology, we have the work of Professor Hyatt, who attributes the characteristics of molluscs and shells, as well as those of extant sponges, to the nature of the surrounding media. A. S. Packard upholds the Lamarckian factors as the A. S. Packerts, of the sufficient cause of the metamorphis of insects, of the peculiar pillars, of the climatic variations of butterflies, etc. With regard to the higher animals, we have the studies of H. F. Osborn, who explains the structures of mammalian feet and teth by the mechanical action of external agencies feet and teeth by the "friction, impaction and while Professor Cope sees in "friction, impaction about by use or motion," the originating strain, brought about by use or

It was Herbert Spencer in whom Lamarckism found its Itaunction to be an integral part of the theory of evolution, he held its application to be restricted to the lower, passive organisms. The development of the higher animals, including man, he considered to be due to the inherited effects of use and disuse. He made this principle of use-inheritance the central ide in his interpretation of the phases of organic evolution, basing upon it the gradual developof organic evolution, basing upon it the gradual developstructures, but also of their concomitant functions. Thus, e.g., the eye was originated, according to this view, by the persistent impact of light on a sensitive cell, which, being modified and developed with progress of time, attained its present perfection. The genesis of nerves is to be attributed to the repeated passage of molecular disturbances along the same paths within a specially unstable medium, etc Morality, too, Herbert Spencer treats from the same point of view. The amarckian factors of use and disuse resulting in in a cumulative heritage of acquired habits, are, according to him, the true cause of the evolution of all ethical feelings.

\section{DARWINISM}

We have seen in the historical part of this chapter that to to Charles Darwin belonce. But of while the theory of descent, i.e., of the origin of all species from earlier forms, is now an accepted commonplace, thanks to the labour of Darwin and his compeers, this is by no the special hypothesis advanced by no means the cases. This he did by Darwin to explain the origin of species. This hich by the well-known theory of natural selection, to which he later added the theory of sexual selection. These are the two ideas which entirely belong to Darwin, and may therefore be fitly combined under the term " Darwinism." therefore bynonymous with It is plain, then, that Darwinism is not syn is merely evolution, nor with organic evolution, of which it is merely one of many offered explanations.* In dealing with it we shall first discuss the theory of natural selection and then that of sexual selection.

\section{A. Natural Selection.}

The idea of natural selection was based by Darwin, as himself has recorded in his "Autobiography," on the he himser has reculturist analogy of the method of the breeder and horticulturist in the cultivation of domesticated varieties. For example, it is known that all the fancy breeds of pigeons, the carrier, pouter, fantail, etc., are derived in the last instance from from the fancier picks out those of his flock which exhibit the desired charac-

- Even learned writers have added to the confusion surrounding the " Darwinism" though he expounds therein views which differ in "Darwinism, he shall come to these later. 

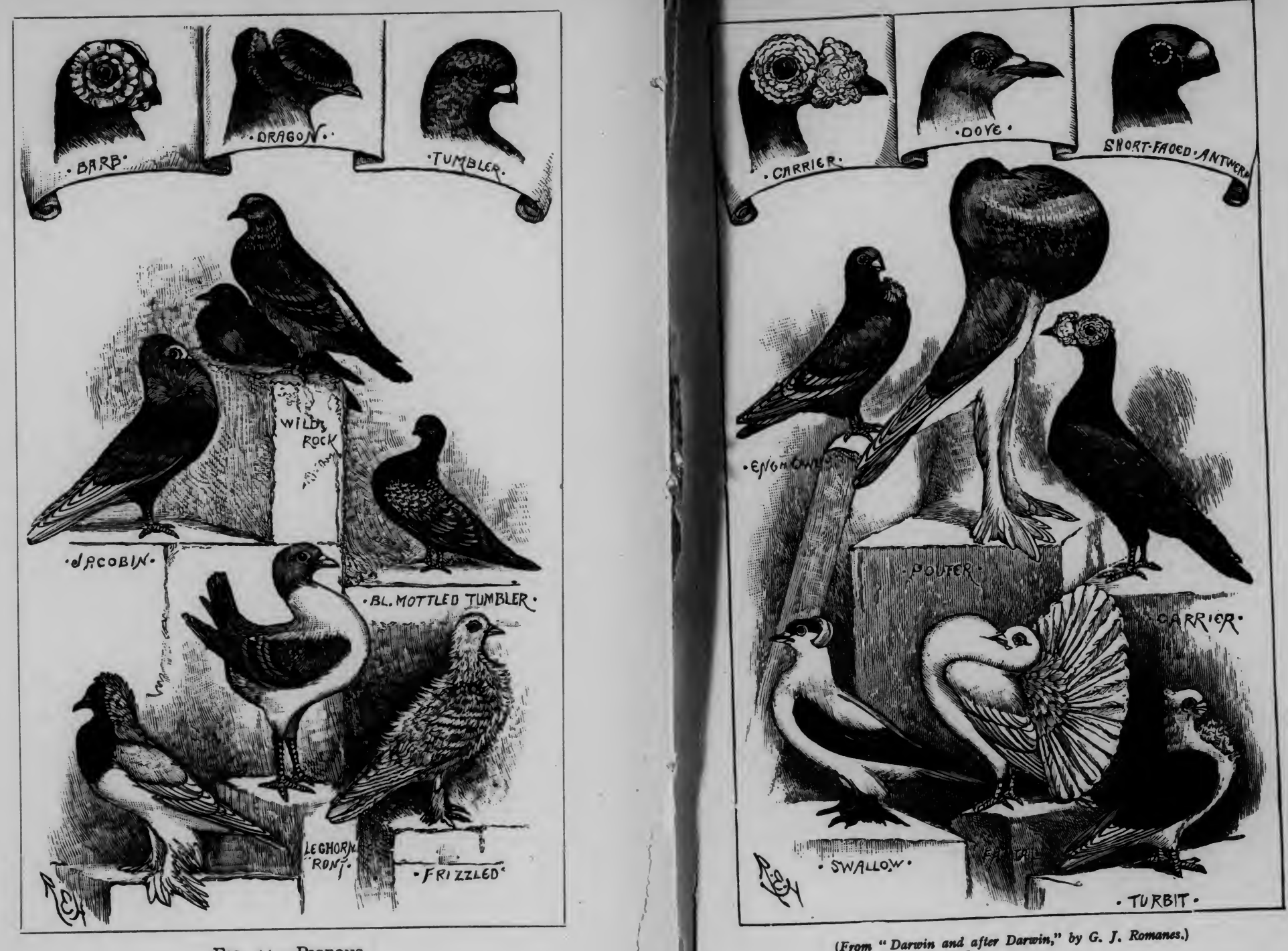

Fig. 44.-Pigeons

(From "Darvoin and affer Darrwin," by G. J. Romanes.) 
I20 THE FIRST PRINCIPLES OF EVOLUTION

teristics to the greatest degree, and breeds from them. By constantly weeding out those birds which are not up to the mark, and propagating from the remainder, generation after generation, types of pigeons have been evolved which differ from the original plain rock-pigeon in nearly which differ from the original plain the breeding of horses, dogs, cattle, etc., and to the cultivation of flowers, vegetable produce, and so on. In every instance improvement of the stock is obtained by "artificial selection" of the of the stock is obtain "s desired types and the rejection of the undesirable ones. Now, what is thus to a limited extent achieved by man's efforts for his own purposes nature effects on a grand scale throughout the whole range of creation.

But here the determining factor is the struggle for life, which is present everywhere in nature. Darwin was led to this fruitful conception by reading Malthus's book "On Population." Malthus tried to show that the population, which increases in geometrical ratio, is always tending to outstrip the natural increase of the food-supply. This applies, so Darwin reasoned, in equal measure to organisms in a condition of nature. Thus the elephant is con is considered to be the slowest-breeding animal ; yet the progeny of a single pair would multiply within 740 to 750 years to nearly I9 million individuals, if each elephant survived for propagation. A single annual plant, according to for prillion in twenty years Linnæus, would increase to a million in twenty years if each seedling produced only two seeds yearly. But the fertility of plants and animals is in most cases very muc g eater. A single herring is estimated to produce 40,000 eggs yearly, the carp 200,000, and the sturgeon as many as 2000,000 . The fertility of the lower organisms is as appalling. The output of a single tapeworm is most probably not less than 100 million eggs, while the prodigality of plants is notorious. The world would soon be overrun by any one species were there not a check to its unlimited propagation. This check is furnished in nature

\section{DARWINISN}

I2I by the struggle for existence. We know that, genstant speaking, the balance of specions-that is, the number apart from periodical fluctuations normal range, except in of individuals is kept within the normal range, except in those cases where a species is dying out or increasing rapidly at the cost of another. This implies that out of rapidly at the cost of descendants the greater part must perish.

perish. Now, this destruction of the existence, which is brought about by the struggle for existence, which is threefold : First of all, there is the struggle against adve natural conditions, the inclemency of the climate, the unnatural conditions, the soil, the advent of catastrophes, productiveness of the soll, ; secondly, there is the battle such as floods, storms, etc. , secondlitat, either the direct with other species in the same habitat, competition for fight with enemies or the still severimilar in habits, food with allied species, which, being similar in habits, frequent the same ground. These two factors lead necesfrequly to the decimation of the species as it is, but cannot sy the the done by by themselves alte batle for life. We have found that third element in the battle for individuals, only out of the total progeny of a given set of indive difficulties a certain number can survive. In meeting the dich of the of their existence, the question now arises: Which of the individuals of a given species shall succeed, which succumb? individuals oxistence where goes on, in the species itself.

within the species itself.

For though the offspring are on the whole in the likeness of their parents, it is common knowledge that this identity is not complete. There exist what have been called variations among any given set of individuals descended from the breeder, for example, could not the same first instance select unless there win different qualities in his material to sely fre out for cannot create new characters, but can only pick out for further improvement those provided by nature. That this variability exists also in the natural state has now 


\section{THE FIRST PRINCIPLES OF EVOLUTION}

been amply proved by exact measurements of organisms." In fact, there are no two individuals which could not be found to vary in some one feature.

Now, the struggle for existence has a different effect on each of the individual members of a species, according to its natural endowments. It is evident that those individuals that are well adapted to their surroundings, having some advantage or other over their fellow-creatures, will succeed in the struggle of life and leave progeny; while those less fitted to their environment are weeded out entirely. In other words, a natural selection takes place from among them, leading, as Herbert Spencer has expressed it, to the "survival of the fittest." Just as in artificial selection the breeder selects the desirable types for propagation, rejecting the undesirable ones, so nature is conceived as doing the work of natural selection. We must, however, beware of seeing in this phrase more than a metaphor. Nature does not select consciously, nor with a set purpose-that is, teleologically. All we can say is, that a given set of external conditions acts as the selective agent, determining which of a given number of individuals is going to survive. It is the better adapted types which oust those less adapted. The offspring of the selected surviving members of a species inherit, on the average, the advantageous parental qualities, and vary now round the higher level of their parents. As the new generation is once more subjected to the same selective process, advancing a further step, a gradual and progressive modification of the species takes place, generation after generation, leading to a wonderful adaptation of animals and plants in all their parts and functions to their surrounding conditions. But now, not only do the environmental factors vary constantly, but the very modification of a species introduces a new element of change in the economy of the competing organisms, altering the equilibrium of all

"See A. R. Wallace's "Darwinism," and especially Bateson's "Material for the Study of Variation."

\section{DARWINISM}

123 the other species in relation to their ex wanic world is Thus a continuous transformation of the organic wo going on, producing an infinite variety of the various orclose the inter-relation can be between the vample: The ganisms, Darwin has shown in a beautiful example. The ganisms, Darwin hiola tricolor) and the red clover (Trifolium wild heartsease ( pratense) are fertilized almost excluble that, if the whole "Hence we may infer as highly probable that, if the whe, in genus of humble-bees became extinct, or very rare, England, the heartsease and red clover would become very England the number of humble-bees rare, or wholly disape in any district depends in a great meir combs and nests and of field-mice, which destroy their combs and he habits of Colonel Newman, who has long attended to the habits c' rumble-bees, belied over are thus destroyed all overyone on the of mice is largely dependent, every says: 'Near villages number of cats; and Colonel Newman sas : "Near ville-bees and small towns I have found the nests of hiumber and small tow more numerous than elstroy the mice.' Hence it is quite number of cats that destro animal in large numbers credible that the presence of a feline animalion in a district might determine, through the inter of certain first, of mice, and tistrict!"

lowers in that district! To give an illustration of the wall take the same cases principle of natural selection, we shall take explained the as quoted under Lamarckism. Lamarck explained the development of the we efforts of the individuals who, inherited effect of the effor memstriving to keep afloat on the water, streing their gradual branes to the uttermost, thus producing thir gradual branes to the Darwinian principle, we must expansion. According to the assume that, as the occasion arose for birds between the digit water, there were some with the we being best fitted better developed than others. Now, these being best fing 
I24 THE FIRST PRINCIPLES OF EVOLUTION

from whom once more those with the largest webs would be selected, and so on generation after generation, until a fully-developed web would ultimately be evolved by natural selection. Similarly in the case of the snail : it was not, according to Darwinism, the effort of the snail which caused the horns to grow, but snails with slight in dications of horns had the advantage over those without such rudimentary organs; each time the snails with the best-developed horns would be selected for propagation, until the final length of the snails' horns was attained.

until the final length of the snails' horns was attained.
It must be clearly understood that natural selection works primarily for the interest of the species; it is not at all concerned with the life of the individual. For it is the cecies which is preserved by the selection of the fittest members, the unfit individuals being rigorously weed-d out for the benefit of the race.

Further, it will have become clear that natural selection works only on useful variations. It can have no effect on indifferent qualities, while harmful characteristics come under its control only in a negative way, being eliminated by the selective process. Natural selection is therefore first and foremost a theory of adaptations, explaining how these have come about, and are being constantly improved upon. The origin of species is, as a matter of fact, nothing but a particular case of adaptation, as applied to the formation of species. But the process holds good for all adaptive modifications, whether they concern the morphological distinctions between varieties, species, genera, or any higher taxonomic order of our classificatory system. Adaptataxonomic order of our clas the evide tions, then, in general, furnish the evidence in favour
natural selection. To these we now turn our attention.

\section{ADAPTATIONS.}

There are hosts of facts which were seen for the first time in their true significance by the light of Darwin's theory of natural selection. Others there are which were

\section{DARWINISM}

only discovered after a principle was found whereby to correlate the various phenomena of plant and animal life Throughout the whole organic world more and more evidences have been accumulating in favour of the new theory, so that we have now material at our disposal which is truly overwhelming, not only in the extent of its range, but also as regards the details in every branch of study. We can here give only a small selection from each group of facts.

\section{(a) Plant Structures.}

In plants we find a great number of adaptive modifications which, being of special service to the species possessing them, can easily be explained by the theory of natura selection. To these belong, for instance, all the protective structures which ward off the attacks of herbivorous animals. There are, first of all, the thorns and spines of many plants, developed in the most diverse ways, either growing out directly from the branches or being modifications of leaves, etc. They are usually so arranged as to protect the exposed parts of the plant, covering in tall species only the lower portions. We need only remind the reader of the wild rose, the holly, thistle, etc. Other plants, as the stinging nettle, are furnished with irritating, stinging hairs. Herbs like the deadly nightshade, henbane, etc., contain strong poisons; they are thus made unpalatable, and are therefore avoided by animals. Clover has a small amount of tannic acid in its leaves, which acts as an effective check against the attacks of snails; while in other species, as the sorrels, oxalic acid serves the same purpose. All such contrivances, leading directly to the preservation of the species, must be looked upon as having been evolved by the process of natural selection.

But Darwin has shown that a great many other phenomena of plant life-in most cases newly discovered by himself-can be accounted for on the same theory. Thus in climbing plants their various organs, as tendrils, pads, etc., are due to an inherent organic quality, being developed 
I26 THE FIRST PRINCIPLES OF EVOLUTION

by natural selection and not by the direct action of external agencies. Similarly, the beautiful arrangements of in-

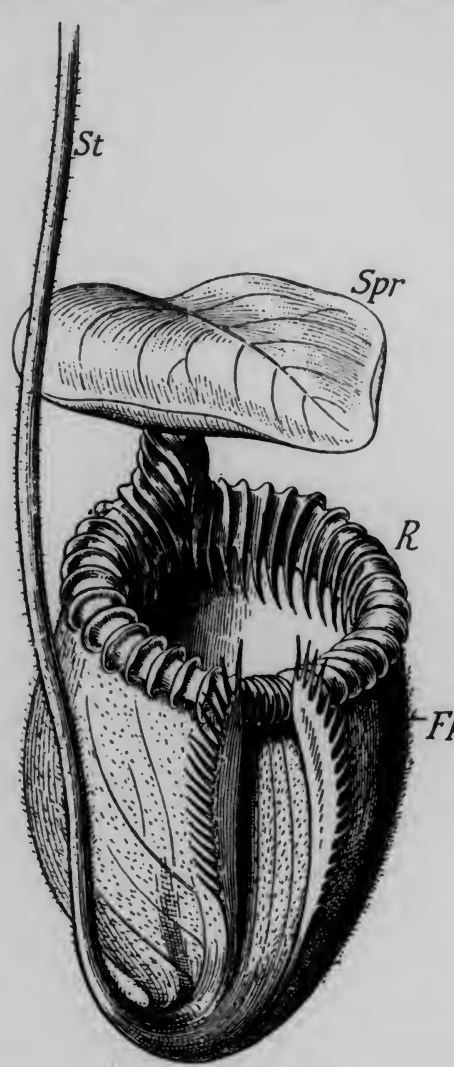

Fig. 45.-Pitcher OF NePenth
Villosa. (After Kerner.) sectivorous plants, often most complicated in structure and perfectly fitted for the capture of insects, can, according to Darwin who, for the first time, whor the first time ted their mode of action, only have gradually arisen by a slow process of selection. The pitcher plant of Borneo-e.g. Nepenthes villosa (Fig. 45), has its leaves modified into a complete pitcher-like structure, which contains a digestive fluid capable of dissolving nitrogenous substances. Insects falling into this pitcher are caught as in a trap for the rim is equipped with downward-pointing teeth, effectively preventing their exit. The leaf of our sundew, Drosera rotundifolia tundifolia (Fig. 46), has the same power of digesting animal food. Small insects alighting on the $S t$, Stalk of leaf; $S p r$, its apex; $F k$, pit- slimy surface of its (From "The Evolution Theory," by A. Weismann.) leaves are captured by

\section{DARWINISM}

127

the "tentacles," which, curving in upon them, help to digest them.

wonderful cases of adaptation Perhaps one of the mers and insects. As early as I793 a German naturalist alist, Christian Konrad Sprengel, discovered what he quaintly called "the secret of fact that flowers are specially constructed to attract the visits of insects, so as to be fertilized by them. It was not until It was investigated Darwin investigated the light of natural selection that this subject found its ful recognition. recognition. Indeed, the fertilization of flowers by insect agency now forms a f vourite illustration fi fivourite illustration of the popular writer on natural selection. The first fact to be higher plants which

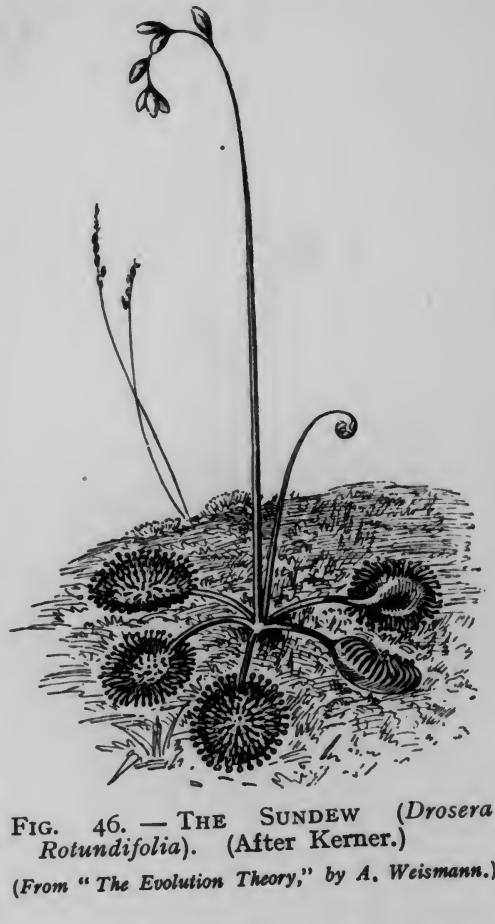
are fertilized by the wind, the pollen being wafted about brasses, etc. The conspicuous flowers, as the hans plants, on the other hand, which are Whilst the plants of insects, have conspicuous flowers. Whilst the plants. are robbed of their honey, they are in turn benefited by 
their "unbidden guests" through the cross-fertilization which the latter effect during their visits. For without them this would be impossible. As Darwin has shown, cross-fertilization is one of the essentials for a strong and vigorous stock.

We have not only the general well-known features in flowers to attract insects, as bright colouring, particular markings, etc., serving as guides to the nectaries, but in a great many cases there exist very special adaptations, its insect visitors. The insect, while seeking for honey, must collect pollen from the stamens of one flower, and convey it to the pistil of the next it may frequent. Now convey it to the pistil of the nes cross-fertilization. Thus the meadow sage (Salvia pratensis) is fertilized by the bee, which, entering the corolla, presses upon a short, handle-like process of the stamens. In consequence the pollen-bearing anthers, previously hidden within the helmer wards upon the intruding insect, dusting its back with pollen. Now, when the bee visits another more matur flower, the pollen is rubbed off on to the stigma of the pistil, as the latter in the mature stage is bent downwards, just in position to meet the back of the bee (Fig. 47). just in position the most marvellous adaptations for cross-fertilization in orchids. Very often the circle of visitors of a given kind of flower is limited, sometimes to only one kind of insect. In such cases the inter-relation between flower and insect is carried out minutely in every detail of structure. Thus some flowers with long coroll tubes can only be fertilized by butterflies which have a long proboscis. We have mentioned previously that the mouthorgans of bees and butterflies have developed from the ordinary biting organs of primitive insects, and we must assume that their evolution has taken place pari passu with that of the flowers they frequent. This close interrelation could have been attained only by a selective process, bringing about at each successive step a mutual process, bringing about at insect. On the Lamarckian adjustment between flower andinsect. minutely specialized view it is hard to see how such a minutel adaptation between plant and animal organisms could have arisen by mere "strains and stresses." How, in the first instance, did a regular flower become an irregular first instance, did a regularly applied to one and the same petal of the flower? Furthermore, how can the same stimulus be same stimulus be supposed to have had such varied effects in different flowers? And further still, how can the elongation of a corolla tube be corolla tube be explained on Lamarck-
ian principles so as to lead to an exact agreement with the length of a butterfly's proboscis? On fy's proboscis? O the theory of natura selection this mutua adaptation is easily

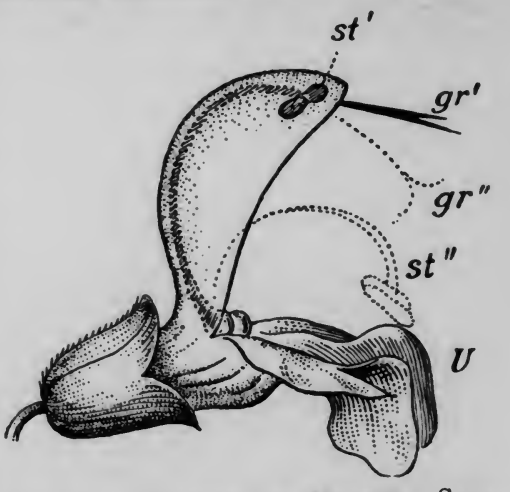

Fig. 47. Flower of MEadow SAGe (After H. Múller.) $t^{\prime}$, Immature anthers concealed in the "helmet "of the flower; sh, mature anther lowered; $g r^{\prime}$, immature stigma corolla, landing-stage for the bee.

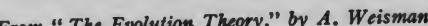

accounted for. Flowers vary, and so do insects being mutually useful to each of structures, chance of surviving, and so hand which, by continual selection, were more and more improved.

Another contrivance evolved by natural selection for Ane plants is the the achievem also was first disphenomenon of heterostylism, which also was first 


\section{I30 THE FIRST PRINCIPLES OF EVOLUTION}

covered and explained by Darwin. There are some flowers, as the primrose and the cowslip, which possess two forms, one having a long style and short stamens, the other a short style and long stamens. Now, it was found by Darwin that such dimorphic flowers yield the most and best progeny when the two different forms are crossed with each other, while each form is almost barren if fertilized by its own pollen. Looking at Fig. 48 , we see that if a short-styled

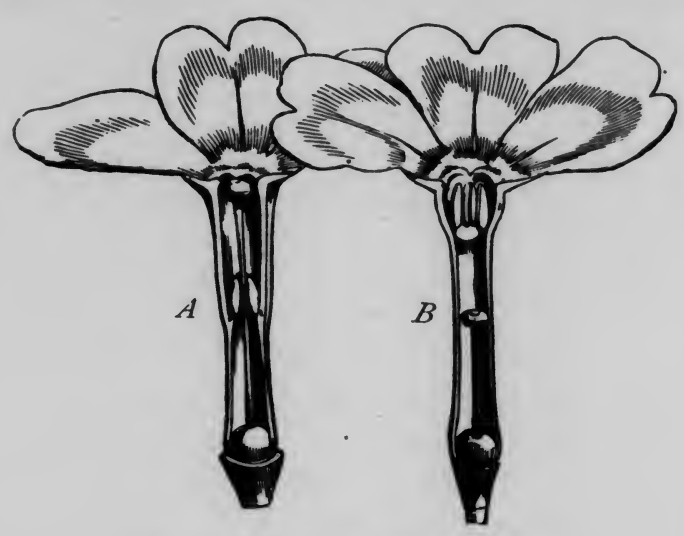

FIG. 48.-CowsLIP (Primula Veris).

$A$, Long-styled form ; $B$, short-styled form.

(From "Darwinism," by A. R. Wallace.)

flower is visited first by an insect, the pollen from the long anthers will readily be deposited on a long-styled flower, the short style of the other form being out of reach. On the short style of the other form being out of reach. will often happen that its pollen is carried on to a long style, thus producing self-fertilization. This explains the fact that the wild short-styled plants are always more productive in seeds, seeing that they can only be fertilized by the other form, while the long-styled plants often remain

\section{DARWINISM}

barren, though fertilized with the pollen of their own kind. These phenomena become more complicated in trimorphous flowers, in which styles and stamens have each three forms. Here Darwin distinguishes between legitimate unions, those which are effected by the pollen of a stamen equal in length to the styles of the fertilized flowers, and illegitimate unions, where the lengths of stamens and fertilized styles are unequal. The latter are comparatively or wholly sterile.

Finally, we must point out some beautiful adaptations in plants for the purpose of dispersing their seed. Many in plants for the seeds, being small, have various contrivances, such as wings, plumes, etc., in order to be wafted about by the wind. Others have hooks by which they attach themselves to the fur of grazing animals; while others, again, being bulky and hard, are enveloped in an edible pulp, which is often attractively coloured, in order to be eaten by animals. These, passing the seeds out, well manured, give the plant a chance of taking root, often far away from its original position.

\section{(b). Animal Colouration.}

The problem of colouration in the organic world has become, like so many other biological questions, a special subject for scientific study ever since Darwin showed that the evolutionary principle can successfully be applied to its elucidation. We have seen how the bright colours of flowers can be accounted for by progressive adaptations. We shall find that most of the phenomena of colouration in animals can be explained by means of natural selection ; though, be it said here, we must guard against pushing this explanation too far, as has been done by some Darwinists.

Before Darwin's time no special meaning was attributed to the colour of animals, the general opinion being that it was due to the action of light and heat. But though it is true that the particular colours of an organism must be referred to certain intrinsic physical and physiological 
132 THE FIRST PRINCIPLES OF EVOLUTION

causes, it is otherwise with the arrangement of the tints, which, as F. E. Beddard has pointed out, must be distinguished as colouration from the mere colours. The patterns to be seen in various animals can be attributed to a large extent to the action of natural selection, for they can often be shown to be a survival factor in the struggle for life.

Thus many animals are protectively coloured by resembling more or less the general colouring of their natural surroundings, which enables them to conceal themselves surroundings, which enables them to conceal themselves
for defensive or aggressive purposes. A good example is the common hare, which, when squatting down on the ground, is hardly distinguishable from a lump of brown earth Arctic animals are generally white either permanently throughout the year, as year, as the polar bear, the snowy owl, etc ; or only during the winter season, as the Arctic fox, the ermine, the ptarmigan, and so on. This accords with the needs of the respective animals ; for those which have a dark summer coat live in regions free from snow in summer. That adaptation is the cause of the white fur is evidenced by those cases which, on first appearance, seem to be exceptions to the rule. The sable and the musk-sheep are brown, while the Arctic raven is black all the year round. But in these cases there is no need for special colour protection; for the sable frequents trees, and is easily concealed among the dark branches; the musk-sheep, being gregarious, gains more by its dark colour than if it were white, as stragglers can thus easily find their flock; while the raven is a carrion feeder, and therefore needs no concealment. The sandy, tawny colour of the animals of the desert is well-known, as instance the lion, the camel, and many others. It would seem as though animals like the tiger, the jaguar, etc., with their dark stripes and spots, would be very conspicuous ; but they are well concealed in their natural haunts among the dappled shadows cast by jungle grass and tree branches. Nocturnal feeders are mostly of a dusky colour, witness the rat, mouse,

\section{DARWINISM}

bat, and owl. There are hosts of animals frequenting trees and shrubs which are protectively coloured. We need only mention the green frog, the green snake, lizards, beetles, grasshoppers, butterflies, moths, etc., and, chiefly, caterpillars. It is a significant fact that, while the green butterfly, which rests with upturned wings, has its green colou developed on the underside of the wings, in the green moths the visible upper side of the wings is of that colour. That there are so few green birds in temperate regions is explained by the fact that birds have a better chance of survival in winter among the bare branches of trees by being in general a dull, rusty brown. Whether the white underside of birds, whales, dolphins, etc., and of the flatfish is due to natural selection, is very doubtful. A to the birds, the idea that the white surface harmonizes with the bright sky is certainly erroneous, for it would show dark from below; while the experiments by Professor Cunningham seem to indicate that some environmenta factor-probably light-is the real cause of the differentiation in colour between upper and lower sides of the flat-fish.

Protective colouration extends even to the eggs of animals, for natural selection commences its action at the very beginuing of an animal's existence. The eggs of insects are often sympathetically coloured in agreement with the object upon which they are laid-green on leaves, and brown on the bark of trees. Originally the eggs of birds were most probably white, and they remain so whenever they are hidden in covered nests or otherwise between earth and stones. Tinted and richly spotted eggs, on the whole, agree in their colouring with their surroundings, as, e.g., in the case of the plover, which lays sand-coloured eggs on the beach.

The phenomena of colour in caterpillars have been most attentively studied by Weismann, Poulton, and others. We have already mentioned that a great many caterpillars feeding on leaves and grasses are green, and have thus a 
134 THE FIRST PRINCIPLES OF EVOLUTION

protective resemblance to their environment. But whether this is brought about in all cases by natural selection is doubtful, for Poulton has shown that the green colour is due in many instances to physiological causes: to the food contained in the alimentary canal, or to the green colour

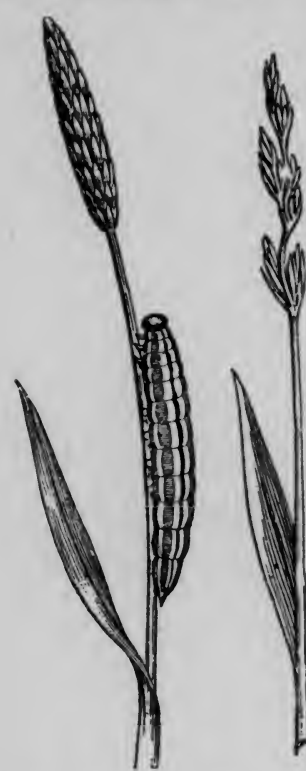

Fig. 49.- Caterpilla OF A SATYRID, STR. (From "The Evolution Theor
by A. Weismann.) of the blood or of the skin. Weismann explains the longitriping found in certain caterpillars (Satyrida) frequenting grasses as a special adaptation, since the stripes add to their concealment among the grasses (Fig. 49). In a similar manner (Fig. 49). In a similar manner other caterpillars of the same family living on bushes and trees have diagonal stripes, which, breaking up the surface of the large green body, increase its resemblance to a ribbed leaf resemplance to a ribbed leaf Beddard, the longitudinal stripes of the Satyrids are not only characteristic of the grass-feeding caterpillars, where they have adaptive value, but they appear active value, but they appear also in larve feeding in the interior of reeds or upon the leaves of trees, in which cases they are certainly useless. It would seem, then, that the longitudina striping of the Satyridm is rather a race characteristic, common to a whole group of caterpillars, and is not due to natural selection in special, the more so as such stripes are no infrequent features among other classes of animals. Once existing, they may, of course, serve the function of protective colouration. Indeed, according to the theory of Professor Eimer, there occurs, independently of natural selection, a regular succession of markings in animals Longitudinal stripes are succeeded by spots, which, by coalescing later form cross-bars; the uniform colouration being the last term in the series.

The the last term in the colour adaptation, being either green or brown. In the large Emerald moth (Geomelra papilionaria) this dimorphism offers a distinct advantage to the larvæ, fo their resemblance to the green or brown catkins of the birch, which they frequent, is thereby greatly enhanced. The do is explained by Weismann as a new adaptation in progress of transformation; for not only is the green variety rarer, on the whole, as in the Convolvulus Hawk-moth (Sphinx

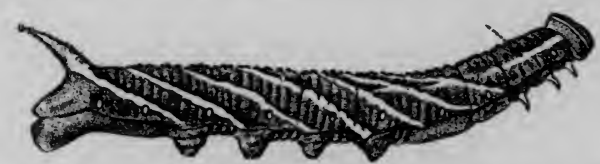

Fig. 50.-Caterpillar of the Eyed Hawk-Moth (Smerinthus

Ocellatus), STRIPED DIAGONALLY.
(From "The Evolution Theory," by A. Wiesmann.)

convolvuli), but in other cases-as, e.g., in the Privet Hawkmoth (S. ligustri) - the same larva changes during its later stages from green into brown; while in others, again, all the larvæ are brown. The brown colour is evidently more protective than the green, and is in process of superseding it.

The latter instance leads us to the group of cases with variable colour-resemblance- that is, the animals in question have the power of changing their colour in accordance with their surroundings. We have first of all the seasona change, of which we have already given examples when speaking of Arctic animals. A change of dress also takes place in temperate regions in a number of birds and deer, though, be it said such change cannot always be considered the 
kind of alteration of colour is characteristic of many animals, from fish downward to cuttle-fish, which are able rapidly to adjust their general colouring in harmony with the changing tints of their surroundings. Thus, trout and sole are dark in muddy water and light on clear ground; the common frog adapts its colour from green to a dark brown, according as it rests among leaves or on the ground: while among reptiles the chameleon is proverbial for its changing colours. We may reckon all these phenomena to be due to natural selec-
tion. Poulton has shown in a remarkable series of experiments that the chrysalid of certain butterflies change their colour according to the prevailing tint of the

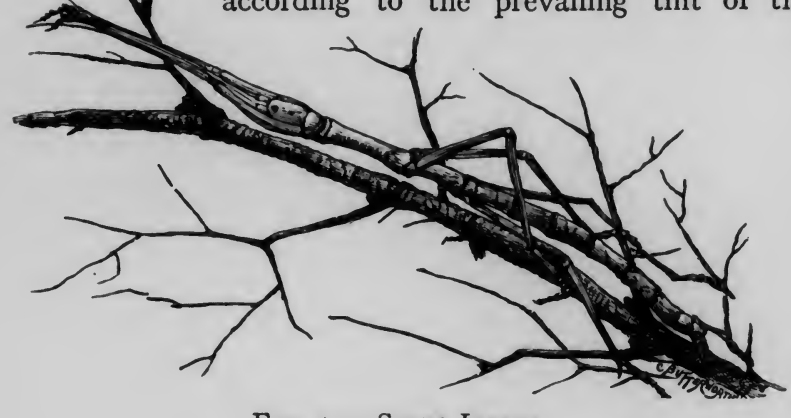

Fig. 51.-STICK INSECT.

(From "Darwin and after Darwin," by G. J. Romanes.)

surroundings they are reared in. But as in some cases colours were produced which are very rarely seen in nature, in others, again, colours which are never to be found in the natural state, it is at least doubtful how far this colour change may be attributed to the action of natural selection.

We have so far considered colour resemblances where the individuals concerned harmonize in a general way with the prevailing tints of the environment. But colour aptation in animals may go much further. There is a adaptation in anism imitates a whole series of castonishing fidelity, so that particular object, often with astonishing fidelity, so that concealment is most effectively attained. Such cases are most prevalent among insects, though they are not ex-

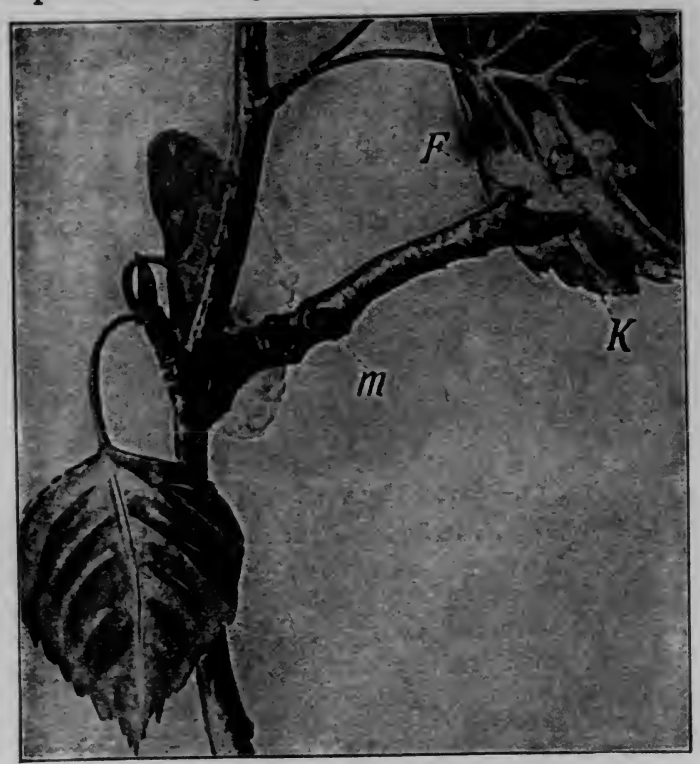

Fig. 52.-Stick Caterpillar (Selenia Tetralunavia), seated on BIRCH Twig. (Natural size.)

$K$, Head ; $F$, feet ; $m$, tubercle, resembling a "sleeping bud." (From "The Evolution Theory," by A. Weismann.)

clusively confined to them. We have first of all a number of locusts of the tropics, the so-called stick-insects (Phasmida), which, with their long bodies and irregular outstretched limbs, resemble a dead branch with lateral twigs (Fig. 5I). The geometer larvæ have, as a general 
I38 THE FIRST_PRINCIPLES OF EVOLUTION

rule, twiglike shapes. In some of them this characteristic is further enhanced by a close likeness in colour and general appearance of the body. A caterpillar like that of Selenia tetralunaria (Fig. 52), resting perfectly motionless at an angle from the stem, has a most deceptive resemblance to a branchlet, which is still more increased by little protuberances of the body, imitating buds or irregularities of the stem. It would seem here that, while the original configuration of the geometers is given initially in thir constitution, this special feature was improved upon by the action of natural selection. There are some moths, too, which when resting with the wings close upon the

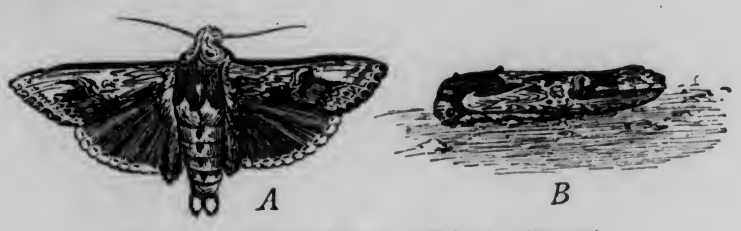

Fig. 53.-Stick Muth (Xylina Vetusta).

$A$, In flight ; $B$, at rest.

(From "The Evolution Theory." by $A$, Weismann)

body look like bits of decayed, lichen-covered wood, as e.g., the Buff-tip moth (Pygara lucephala) and the Xylina (Fig. 53).

Resemblance to leaves is not an uncommon occurrence Resinsects. The winged species of the Phasmidx (already mentioned), with their veined wings, their leafy expansions on legs and thorax, furnish a very good example (Fig. 54). Closer still is the approach to a leaf-like structure in various species of butterflies. The most famous of these is the Kallima butterfly of India. Its wings, when upturned, represent on their underside a perfect copy of a leaf with a midrib and a regular succession of side veinings. Differently coloured spots on the wing imitate patches of decay and mildew, while the prolonged tail of the hind-
DARWINISM

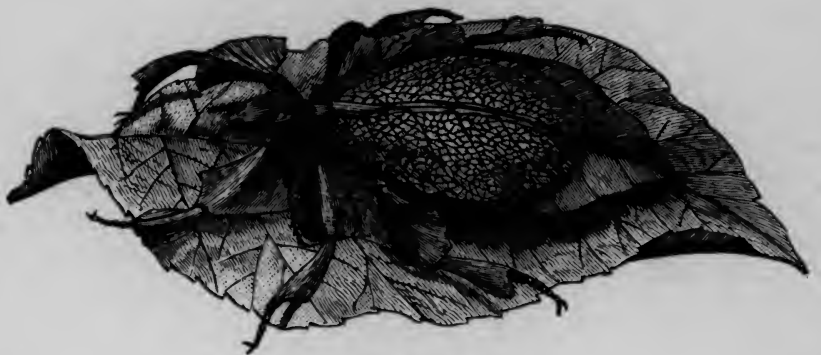

Fig. 54.-LEAF INSECT.

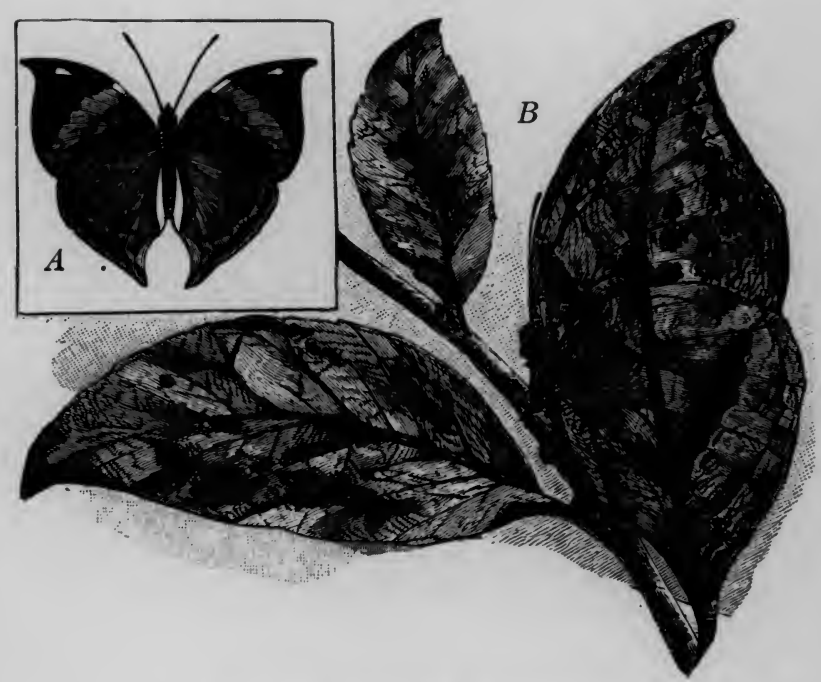

Fig. 55.-Kallima Butterfly.

$A$, Upper surface; $B$, under surface. (Both from "Darwin and after Darwin," by G. J. Romanes.) 
I4O THE FIRST PRINCIPLES OF EVOLUTION

wing, which touches the stem in the sitting posture of the butterfly, makes it appear as though the leaf was directly growing out of the stem (Fig. 55). One cannot but explain all these instances as adaptive modifications, brought about step by step through natural selection; for it is obvious that the closer the resemblance of a given individual to a leaf the greater would be its chance of

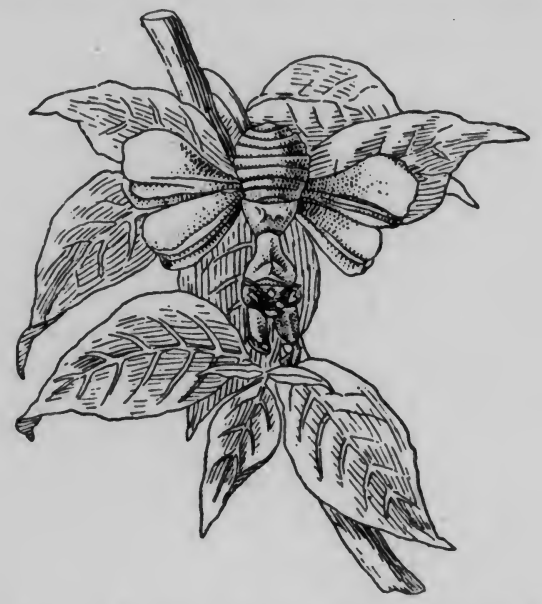

Fig. 56.-Indian Mantis (Hymenopus Bicornis) in Active Pupa
Stage. (From "Colours of Animals," by E. B. Poulton.)

survival. A most extraordinary instance of special protective resemblance is that of certain moths and spiders, which by their general form and colour produce the impression of patches of bird's excreta. The little Chinese Character, Cilix spinula, and many grey and white geometers, when resting on a leaf with outstretched wings present this appearance. The same disguise is used by certain spiders to attract prey within their reach. Alluring devices occur also in other animals. For instance, the Indian Mantis (Hymenopus bicornis) imitates with its flattened legs the petals of a flower, and thus captures other insects (Fig. 56). As an instance of special resemblance among higher animals we may mention that a certain species of fish has frond like appendages, which make it nearly indistinguishable from bunches of seaweed; while an Australian lizard (Moloch horridus) is covered with spiny excrescences in imitation of the thorny bushes among which it lives.

Here we may also reckon those cases where harmless and relatively defenceless animals, when in danger, take on an attitude of defiance, presenting a terrifying appearance, in order to frighten peff thir enemies. A typical off their enemies. A ty example is the larva of the

Puss moth (Cerura vinula).
When disturbed, it with-

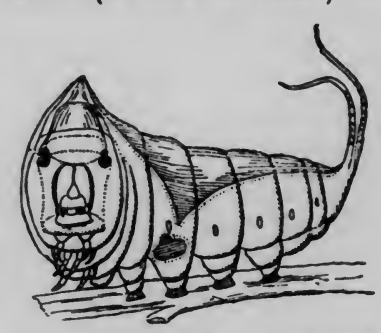
Fig. 57.-The LaRva of the ING" ATTITUDE, (Natural Size.) From "Colours of Animals," by E. B. draws its head into the first body-ring, which, with its inflated bright red margin and two intensely black eyelike spots, produces the impression of a large, flat face (Fig. 57). Perhaps the eyelike spots of the Eyed Hawk moth, giving in the defiant attitude the appearance of a head with staring eyes, belong to the same category (Fig. $5^{8}$ ).

This leads us on to another series of colour phenomena in animals, where the colouration, far from adding to the concealment of the individual, has been developed for the contrary purpose-namely, to render its possessor more conspicuous. A. R. Wallace would explain in this manner certain regular markings in gregarious mammals, birds, etc., which, being prominent and easily seen from a dis- 
142 THE FIRST PRINCIPLES OF EVOLUTION

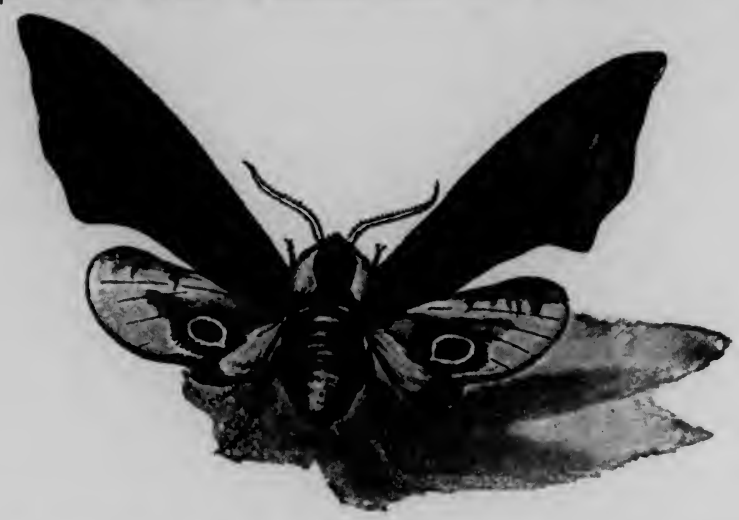

Fig. 58.-The Eyed Hawk Moth in its "Terrifying " Attitude. (From "The Evolution Theory," by A. Weism inn.)

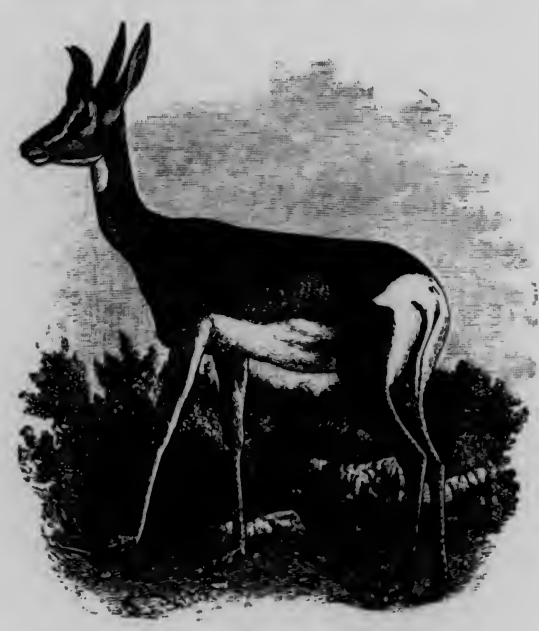

Fig. 59.-Gazella Sgrmmeringi (From "Darwinism," by A. R. Wallace.)

\section{DARWINISM}

I43

tance, serve as a common means of recognition to the members of the flock. They would also, in his view, aid the two sexes to distinguish between members of their own and of closely resembling species, and thus prevent the evil of intercrossing. We figure here a gazelle (Gazella the evil of intercrossing. We figure here a gazelle (Gazella scemmeringi), with its white patches on face and hind-
quarters (Fig. 59), and the banded recognition marks of three African plovers (Fig. 60). It must be pointed out, however, that G. J. Romanes and Professor Lloyd Morgan have a d w wallace's contention that these marks have been developed by natural solection for the specific purpose of preventing intercrossing of allied forms. Recognition marks must already be in existence in order to allow of the differentiation between the species, and cannot therefore have been tion between the species, and $c$ evolved by that process of differentiation. Or, as Professor
Lloyd Morgan has put it : "The recognition marks were not produced to prevent intercrossing, but intercrossing has been prevented because of preferential mating between individuals possessing special recognition marks." A somewhat different interpretation has been given to what has rabbit, for instance, though protectively coloured, shows when running to its burrow a white upturned tail, which renders it very conspicuous. Here the recognition mark serves to indicate approaching danger to other rabbits which may be near. It thus acts as an important means of mutual protection.

True warning colours, however, have the purpose of rendering their possessor conspicuous to its enemies, so that it may remain free and unmolested from their attacks. It was Wallace who first suggested this explanation, in order to account for the brilliant colouring of certain caterpillars; and the principle has been found to apply not only to a large number of insects, but also to higher classes of animal life. Warning colours are, as Wallace rightly conjectured, accompanied by strongly distastefu 
144 THE FIRST PRINCIPLES OF EVOLUTION

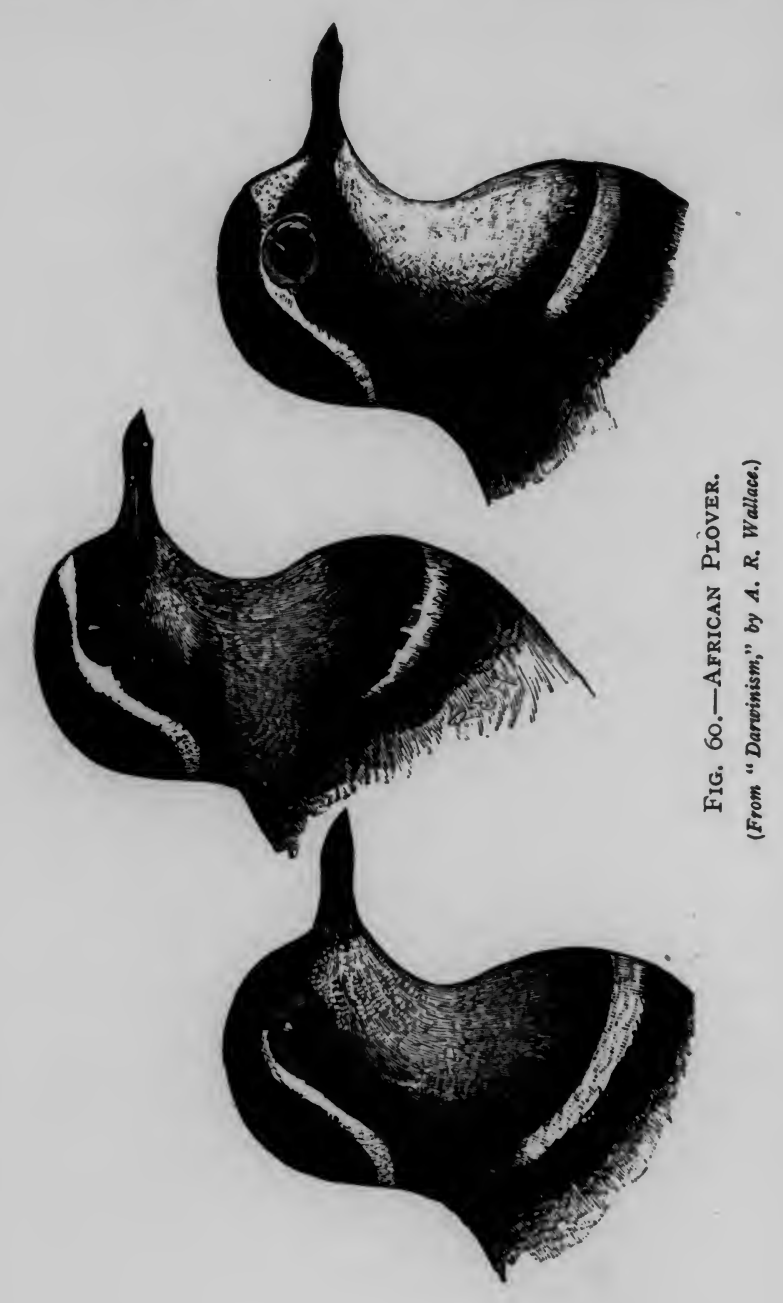
qualities, which render the prominent dress being an effective skunk offers a typical offensiveness. Among mammals the example (Fig. 6I). It is very conspies and white body and its large bushy tail, whe its leisurely walks at dusk.

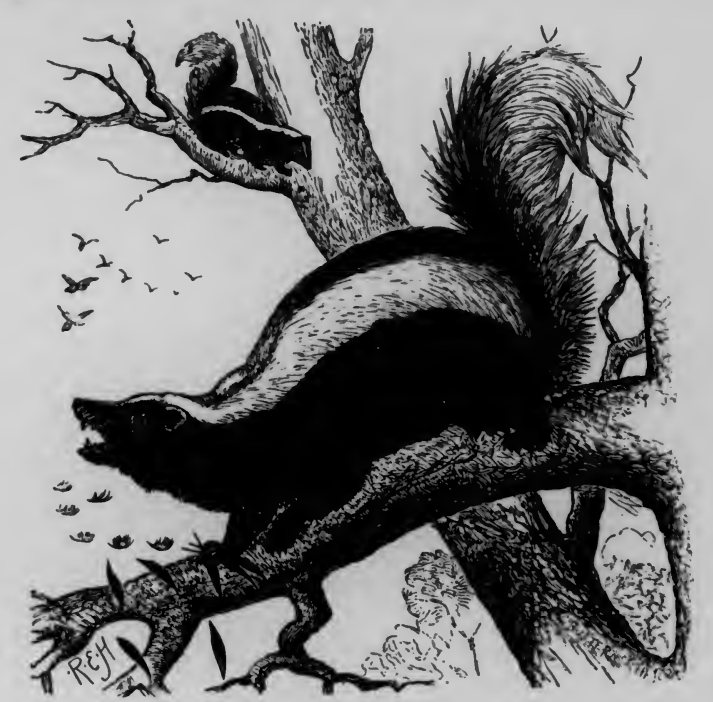

Fig. 61.-Brazilian Skunk.

(From "Mammats, Living and Extinct," by W. H. Flower.)

persistent smell, and using as a weapon of smell, and using is is safe from the defence a very dangerous foetid fluid, it is safe from tharious defence a very animals. Among reptiles we have various attacks of other animasonous snakes-as, e.g., the Coral snake (Elaps) in tropical America, which is banded and yellow red, and the Hydrophis, similarly ringed black coloured prothough poisonous snakes are more generally colour 19 


\section{I46 THE FIRST PRINCIPLES OF EVOLUTION}

tectively. The only known poisonous lizard is the Heloderma of North America, which is prominently blotched with black and pinkish-yellow. Of amphibians Mr. Bell describes a frog of Santo Domingo which "hops about in the daytime, dressed in a bright livery of red and blue," the daytiche dre and which was found on experiment to be unpalatable. Other frogs of the same district are soberly coloured, hide during the day, and only come out at night to feed. The common European salamander (Salamander maculosa), too, with its yellow blotches on a black background, is most probably poisonous.

The most numerous instances of warning colouration are found among butterflies, in all stages of their existence. We have first of all brightly coloured caterpillars-as, e.g. those of the Magpie moth (Abraxas grossulariata), the Buff-tip moth (Pygara bucephala), and the Cinnabar moth (Euchelia jacobea). They have black and yellow or orange markings or rings. The latter two moths are rendered markings or rings. The latter two moths are rendered still more conspicuous by being gregarious. These larvæ
have been observed to be generally nauseous and distasteful to their would-be devourers. Other caterpillars possess irritant hairs, sometimes, as in the Tussock moth, possess iritant hairs, " "tums," The Tussock moth, " The are conspicuously coloured, and offer a first point of attack to the enemy, which, of course, withdraws quickly, with no greater loss to the caterpillar than that of a bunch of hairs. Poulton found that the chrysalis of the Magpie moth, being conspicuously coloured black with yellow bands, is obnoxious like the larva and the moth itself. The latter is very like the larva and the moth itself. The latter is very ground. Other moths are similarly gaudily coloured, as also a host of butterflies, all being inedible. Such butterflies often possess very conspicuously marked hind-wings, hich frequently end in spurs and elongations, thereby which frequently end in spurs and elongations, thereby directing the enemy's attack to the most obtrusive, but least vital part. Lastly, we must mention gaily coloured nauseous beetles, as the Ladybird, and wasps, hornets,

\section{DARWINISM}

etc., which advertise their dangerous stings by their conspicuous stripes of contrasted black and yellow.

The theory of warning colouration presupposes that the enemy recognizes the highly coloured species before the attack has led to the destruction of the victim. It would be of great advantage, therefore, that the enemy should learn to discriminate quickly the palatable from the unpalatable species. Now, this object is furthered by the general scheme of warning colouration, which is on the whole very simple and uniform. It consists mainly of black (or other very dark colour), which is contrasted either with white or with yellow, orange, or red. The pattern consists of stripes, rings, or spots. Therefore, there needs to exist only a simple association between this colour arrangement and unpalatability. Among inedible butterflies the colouration agrees to a remarkable degree in an immense number of species. This, according to Fritz Miller, offers the great advantage that the numbers of victims which succumb to the attacks of inexperienced victims which succumb to the attacks of inexperience
enemies is proportionately diminished in each species.

We cannot leave this subject without drawing attention to a serious objection which has been made against the theory of warning colouration. This theory presupposes, as was stated before that the protected species possesses some offensive quality, be it of taste, smell, etc., sesses some offensive quality, be it of taste, smell, etc.,
of which it gives its enemy timely notice by its conspicuousness. But now Beddard has shown that in a number of instances such bright-coloured species are not rejected as food, as they ought to be according to the rejected as food, as they ought to be according to the theory; while, on the other hand, some distasteful species are soberly coloured. Dr. Eisig would explain brilliant colours in general as the incidental result of pigmentation, which in itself causes the distasteful character, so tilat, contrary to the accepted opinion, bright colouring would be the cause of the inedibility of the species, and not vice versa.

We have just mentioned the fact that among inedible 


\section{I48 THE FIRST PRINCIPLES OF EVOLUTION}

butterflies there is often in allied groups one prevalent type of marking and colouring. We must add that sometimes an unpalatable species is mimicked by another which is not related to it. Thus the Danaids, inhabiting the same regions of tropical America as the Heliconias, show the same peculiar arrangement of colour and wings as the latter. This case leads us on to the phenomena of true mimicry, where the mimicking species itself is harmless, but imitates another inedible species in its outward appearance, and thus gains the advantage of being mistaken for the mimicked immune form. This is the explanation which was first advanced by Bates in I862, and it has since been found applicable to a great number of cases, not only in the order of Lepidoptera, but also of other insects, and even among higher animals. The imitating forms occupy the same regions as their immune prototypes, and are generally much less numerous. The classical example of mimicry is that discovered by Bates among the butterflies on the Amazon, in South America. He found that among the abundant Heliconidæ of that region, which belong to the offensive, brightly coloured and slow-flying species, was mixed a small number of Pieridæ, or " whites," which, though themselves harmless, resemble the Heliconidæ very closely (Fig. 62). Not only this, but different species of the mimicking family imitate particular species of the Heliconias inhabiting the same localities. Similarly we find in Africa two other types of inedible butterflies, the Danaidæ and Acraidæ, both being mimicked by a number of edible butterflies.

There are some interesting details connected with the phenomena of mimicry. First of all, we find that it is often the females only which deviate from their type and imitate another immune form. It is apparent that the egg-laying female is in greatest need of protection. In other cases the males show more or less indication of a protective change, which is evidently in process of development. Other instances there are again where the males follow

\section{DARWINISM}

I 49

one pattern and the females another. It is not at all rare to have a group of butterflies mimicking at the same time a number of immune prototypes, according to their opportunities and the districts they inhabit. Thus the male

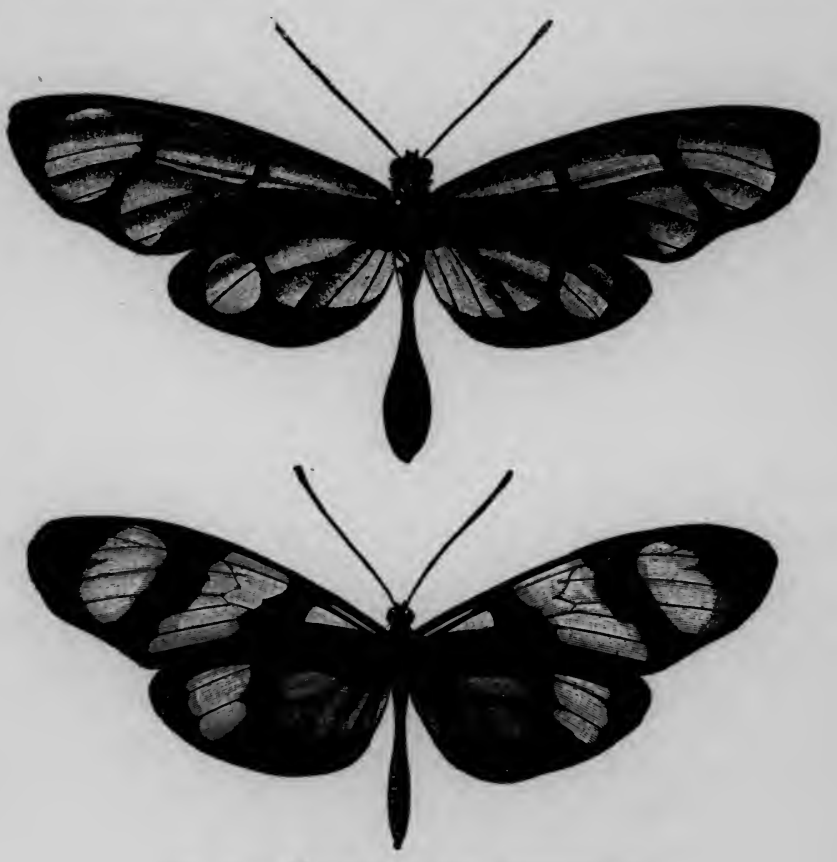

Fig. 62.-Mimicry Among Butterflies. Methona psidii (Heliconidæ) and Leptalis orise (Pieridæ)

(From "Darwinism," by A. R. Wallace.)

Swallowtail (Papilio) of Africa shows the typical pattern, while the female deviates largely from it, being without the characteristic "tails." But there are no less than three or four different kinds of females, each imitating a 


\section{I50 THE FIRST PRINCIPLES OF EVOLUTION}

specific Danais, according to the region they frequent. Contrariwise, an immune species may be copied by a host of other butterflies.

Coming to moths, we find an extension of mimicry to prototypes not belonging to the same order as the mimicking form. The Hornet Clearwing imitates a hornet (Fig. 63) while two of the Hawk moths, called Bee-hawks, (Sesiida) resemble humble-bees. In fact, hornets, wasps, and bees re frequently mimicked by other harmless insects, the most common example being that of certain flies which on a superficial glance look like bees or wasps, though they have only two wings, instead of four, like the latter

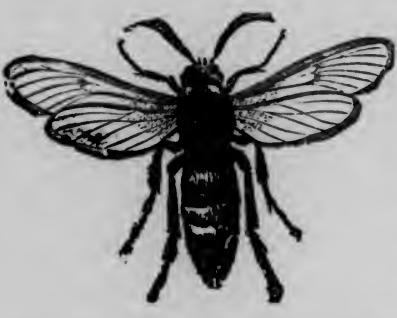

Fig. 63-Hornet Clearwing. (From "Animal Colouration," by $F . E$. Fig. 64). Spiders have been found which have the appearance of ants, but it is doubtful whether this disguise enables them to attack the ants or to avoid destruction by birds. A most wonderful example of mimicry is that between the leaf-cutting ants and certain insects in tropical America. The ants carry bits of leaf on their backs, and the insects completely imitate ant plus leaf by having their bodies expanded into a thin, flat, leaf-like appendage. Of mimicry among the higher animals there is little to say. Some innocuous snakes don the attire of others that are venomous. Dr. Seitz described a Humming-bird Hawk moth which imitates a humming-bird ; but whether this constitutes a case of true mimicry is, to say the least, doubtful. The instance of the caterpillar which, on being disturbed, assumes the appearance of a vertebrate face has already been mentioned, and may be reckoned under the head of mimicry, as also a number of similar cases described by Poulton.

\section{DARWINISM}

I5I

One of the conditions of mimicry, according to Wallace, is that the mimicking species should be less numerous than the mimicked model, but this condition is not always fulfilled. Another essential feature is that both forms should inhabit the same district. How otherwise could there be given the opportunity for developing the protective device? Now, there are instances-and they are
-DIPTERA

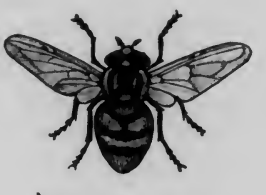

Volucella inans.

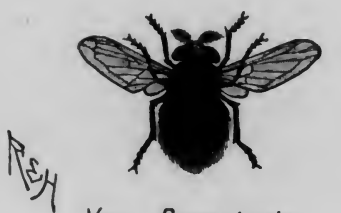

VOL. BOMBYLANS.
HYMENOPTERA
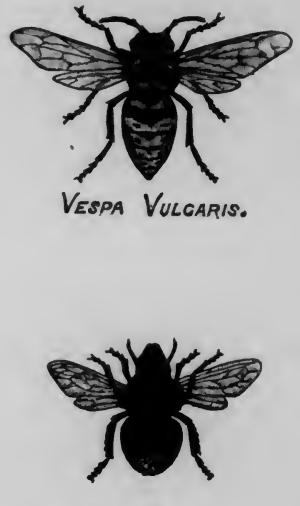

BOMBUS LAPIDARIUS.
Fig. 64.-Mimicking Flies.

Volucella, fly; Vespa, wasp; Bombus, bee.

(From "Darwin and after Darwin," by G. J. Romanes.)

not infrequent-where the two identical-looking forms do not inhabit the same country. For instance there is Sesiid moth which resembles a humble-bee, but no humblebee exists where the moth lives. This would seem to be a serious argument against mimicry, to which must be added another fact-namely, that mimicry has been found between certain organisms where it cannot possibly have any useful purpose, and therefore cannot be attributed 


\section{I52 THE FIRST PRINCIPLES OF EVOLUTION}

to the action of natural selection. Indeed, resemblances may be due to other factors-to affinity of descent, to the action of similar environment, etc. Thus it becomes evident that not all cases of resemblance between forms frequenting the same district are to be put down a instances of mimicry. For those cases where the two mimetic forms do not commingle, as that of the moth and the humble-bee just quoted, Mr. Scudder has advanced two possible explanations. It may be that the bee which served as a prototype has died out in the district, or the moth may have migrated from its original habitat.

There are still left cases of animal colouration which do not find their explanation on any of the above-named principles, but are attributed by some authors to the action of sexual selection. With that subject we shall deal later on.

(c) Instincts.

So far we have dealt with adaptations due to natural selection which concerned mainly morphological traits But in order that such structures may prove useful to their possessors, they must be associated with proper functions. And, indeed, we find that instinctive behaviour prompts the protected animal to adopt the appropriate attitude which serves as a means of its survival. Of what use, for instance, would protective colouration be to an organism that would not lie motionless, so as to be mistaken for a part of its natural surroundings? On the other would not gain anything by its peculiar colouration did it not in time of danger execute the necessary movement in order to produce the aggressive resemblance to a vertebrate face. The mimicking species of butterflies, too, as we have seen, have the slow, deliberate mode of flight of their immune prototypes, which helps them to be easily identifed by their enpers as a species to be avoided. In fact, physiological functions not less than morphological

\section{DARWINISM}

I53

its sway of organic evolution, and have, as Darwin pointed out for the first time, been developed exclusively for the benefit of the species possessing them. They, too, are important factors in the survival of the fittest and have to be explained on the same principle.

In the firs ins instincts vary just like anatomical In the firt instance, instincts vary just like anatomical features. Everybody knows that the faculties of the various pups in a litter of dogs differ considerably from the outset; in fact, the breeder chooses accordingly for his special purpose. And there is sufficient evidence to show that purpose. And the instance, Prof Loyd Morgan quotes Mr. Blackwell as stating that "birds of the same species possess the constructive powers of nest-building in very different degrees of perfection." If, then, certain variations of such given faculties should prove more useful than others in the struggle of life, they would me presed by natural selection and gradually perfected. be preserve by natur the must account for the highly It is in this manner that we must account for the highly developed instincts of certain insects, however complicated. The evidence here, as in other cases of evolution, cannot be obtained directly by observation, but the gradual steps in the formation of a given instinct can only be followed in various collateral lines of the related species. Darwin has various collateral ling of the rell-making instincts given a most beautiful example in the cell-making instincts of the hive-bee. It is well known that the hive-bee builds a most regular comb of hexagonal cells which intersect at their bases; while the humble-bee, at the other end of the scale, fills the old cocoons with honey, "sometimes ading to it short tubes of wax, and likewise making adding to it short tuber of wax cells of wax." Beseparate and very irregular round tween these two extremes we find the Mexican Melipona domestica. The cells of the latter "are nearly spherical and of nearly equal sizes, and are aggregated into an irregular mass. They are always made at that degree of nearness to each other that they would have intersected nearness to into each other if the spheres had been comor broken into bees building 
I54 THE FIRST PRINCIPLES OF EVOLUTION

perfectly flat walls of wax between the spheres, which thus tend to intersect. Hence, each cell consists of an outer spherical portion, and of two, three, or more flat surfaces, according as the cell adjoins two, three, or more other cells. When one cell rests on three other cells-which, from the spheres being nearly of the same size, is very frequently and necessarily the case-the three flat surfaces are united into a pyramid ; and this pyramid, as Huber has remarked, is manifestly a gross imitation of the three-sided pyramidal base of the cell of the hive-bee." The close arrangement of the intersected hexagonal cells is evidently for the bee a great saving of wax and labour, and must have been attained gradually by a process of natural selection. Darwin would explain in a similar manner the curious instinct of the cuckoo, which lays its eggs in the nest of other birds; as also the slave-making instinct of certain ants. We cannot possibly enumerate here the endless functional adaptations in animal and plant life due to natural selection, be they for the purpose of self-preservation or of sexual propagation. We must not omit, however, to make mention of those wonderful cases where two organisms of entirely different classes have become mutually adapted to each other, so that they always live together, each one deriving thereby benefit from the other. Such instances of "symbiosis" occur either between two animal or two plant organisms, or between animal and plant. Thus there are hermit crabs living in shells covered with a colony of polypes. The latter have in certain cases become modified, and excrete a stinging fluid by which they ward off attacks against their host (Fig. 65) at the points where the protective threadlike individuals of the polype are arranged along the margin of the shell. The crab repays this service by bringing food within the reach of his protectors. The roots of many of our trees are covered with a network of fungi, which, whilst supplying the tree with salts and water, receive in their turn nourishment from the roots. Finally, there are the cases of symbiosis between

\section{DARWINISM}

I55

animal and plant organisms, of which we only mention that of the fresh-water polypus (Hydra viridis) with an alga. The green alga furnishes ready oxygen to the polypus, which in its turn offers within its interior a quiet habitat to its guest.

It is largely in reference to instincts that the question arises how far the Lamarckian factor of use-inheritance

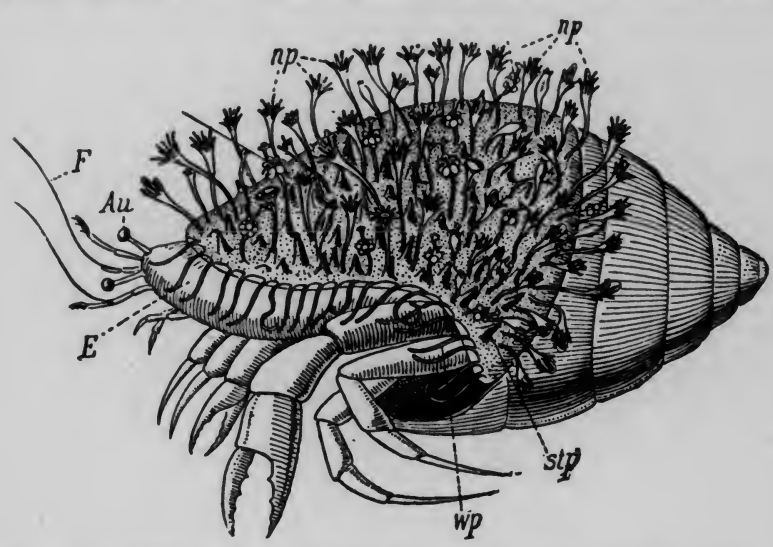

Fig. 65.-Hermit CRAB (E) within a Gasteropod Shell, on which (Slightly enlarged.) me common root-worm (which is not clearly shown) there arise numerous nutritive polyps with tentacles $(n p)$, among which are spine-like personx $($ stp), ; and on the margin of the mollusc shell a row of defensive individuals (WP). F, Antennæ; (From "The Evolution Theory," by A. Weismann.)

is a potent means of evolution. Though we cannot enter here into the details of this problem, which will be discussed in full later on, we must just refer to a few points which have been raised with regard to instincts. Observation would seem to tend towards the conclusion that instincts have originated by the accumulation of the in- 


\section{I56 THE FIRST PRINCIPLES OF EVOLUTION}

herited effects of acquired habits. It is a well-known fact that actions at first produced consciously become after constant repetition stereotyped into habits, and are performed automatically. This is the way in which the Lamarckist would explain the origin of all instincts. They are, according to Professor Wundt and G. H. Lewes, hereditary habits. In proof of their contention they would submit, firstly, that habits are formed in every individual, and, secondly, that there are a great number of instincts which, not having any survival value, cannot possibly have which, not having any survival value, cannot possibly have selectionists point out: (I) It has to be proven in every single instance whether a certain action is truly instinctive. Often all that is instinctive is, as Professor Lloyd Morgan often all that is inting acquire the habit in question, while each individual in its turn has to learn it anew-as, e.g., the knowledge which young birds acquire of avoiding unpalatable food, of drinking water, etc. (2) There are cases where the instinctive action is only performed once in the lifetime of the in dividual, the formation of a habit thereby being excluded. Yet the instinct shows itself perfect in each successive generation-as, for instance, in the spinning of the cocoon by caterpillars, etc. The neuter ants and bees are sterile; therefore their instinctive social behaviour cannot possibly be hand handed down by them to the next generation. Mr. Perrier habit of the neuter insects were developed and fixed by heredity before they became sterile. But in this case, Lloyd Morgan argued, the effects of disuse of these special instincts in the individuals, while fertile, should have led, accordin prip to the shoule to the same principle, to their gradual degeneration and disappearance.

The final decision in the matter of instinct, as in the whole problem of use-inheritance, depends on the answe which is given to the question: Are acquired characters inherited? This point we shall discuss later. (d) Human Faculty.

How far has man to be included in the general scheme of organic evolution? We have seen in the chapter on morphology that there exist many vestigial structures in the human body linking man unmistakably with his animal ancestry. Darwin himself was fully aware of the consequences of his theory of evolution, and indicated quency in the first edition of his "Origin of Species " that already in the "light would be thrown on the origin of man by this work " light would be thrown on the origin of man in the "Descent of Man," where he showed that not only the physical features, but also the mental and moral characteristics of man must be regarded as the product of characteristics of man, must be regard from lower animals. a continuous progressive development from lower animals. The precise method of the evolutionary process of man's intellectual and moral attainments is still a matter of controversy. We shall discuss these problems later, when we deal with super-organic evolution. " Here we would only insist upon the continuity of the natural process of evoluinsist upon the continuity of the natural process of evolution, which is now accepted by nearly all leading scientists. The only notable exception is A. R. Wallace, the codiscoverer of the theory of natural selection. Whilst attributing the perfection of the bodily structures to the action of natural selection, he ascribes to the agency of a faculties which distinguish man from his lower progenitors. "A superior intelligence has guided the development of man in a definite direction, and for a special purpose, just as man guides the developments of many animal and vegetable forms."

The argument on which Wallace bases his case is, firstly, that natural selection is unable to account for a certain

- To understand Wallace's position correctly, we must remember that he is a spiritist believing in a hierarchy of spirits. The guiding intelligence is, as he would have it, not necessarily a "supreme intelligence" but may be any of the higher intelligent beings that "people all space." 
number of distinctly human bodily features ; and, secondly, that there are certain higher mental endowments of civilized man which, as they cannot possibly be due to this cause, must have been superadded to his animal nature at an early stage in anticipation of his future needs. The bodily peculiarities are the feet and hands, the naked skin, the voice and brain of man. The mental faculties alluded to are the mathematical and metaphysical faculties, the æsthetic, and the moral sense.

To begin with, we must point out that the inadequacy of natural selection to account for all or any of the aforesaid features-and this may be left as a moot point-does not establish a case for Wallace's "spiritual influx." As to the differentiation of foot and hand, it can be explained as the outcome of the erect attitude of man, which latter in its turn may well have arisen as a useful variation through natural selection, seeing that man's next-of-kin, the anthropoid apes, occasionally assume the semi-erect position. The naked skin Darwin would explain as due to sexual selection. Whether the voice of man is so much superior to that of singing birds may be doubted. As to the brain capacity of the savage, which is, according to Wallace, far beyond his actual requirements, here, too, it may be asked whether the life of the savage is really so simple as Wallace would make out. In the use of articulate language, of abstract ideas, etc., it decidedly goes far beyond what any of the highest animal organisms can attain, and the difference in brain organization may be thus accounted for. The higher mental faculties of man, though developed to a great degree of perfection through the practice of thousands of years of civilization, are by no means absent in the savage. In the first instance, they may well have been developed, as we shall see later, through the agency of natural selection. As to the specific endowments, such as abstract conception, music, etc., it is true they cannot be due to natural selection ; for we can hardly assume that they had at any stage of their development sufficient survival value. Herbert Spencer would account for their origin on the Lamarckian principle by the transmission of the accumulated effects of inherited mental acquirements. But even for those who, like Wallace, do not accept the inheritance of acquired characters, there is still another mode of explanation at hand. There is what has been called a "social inheritance," through which the acquisition of one generation is handed down to the next, be it by oral tradition or by the help of printed literature. Thus is attained in time an ever-progressing culture without the necessity of an actual advancement of the mental and moral nature of civilized man. Weismann has shown in his "Essay on Music" that the musical faculty is latent in primitive tribes, and only needs developing by an appropriate social environment. The same may be said of the mathematical faculty and the artistic and moral feelings of man. As F. C. Constable has put it: " At no time are the possibilities of man's brain exhausted in achievement. Under evolution the brain capacity of the average ment. Under evolution the brain capacity of the average
individual is always in advance of the practical demands made on it."* This must be considered a natural law of growth and development, and does not require the prophetic prevision of a teleological cause.

\section{(e) Degeneration.}

It has become apparent from the foregoing account of natural selection that its principles are applicable as much to the highest as to the lowest phenomena of life. There has been a gradual progressive development of the higher types of organisms from the simpler ones ; from the primitive beginnings of the amœba there has evolved the species "man." But while there can be no doubt as to the correct interpretation of this law of evolution in general, we must guard against an error which is often made through a mis-

* F. C. Constable, "Poverty and Hereditary Genius," London, 912. 
I60 THE FIRST PRINCIPLES OF EVOLUTION

understanding of the phrase "survival of the fittest," which is synonymous with " natural selection."

It is clear that a continuous change of environment leads to a constant readjustment of the organisms affected. Those best adapted to their surroundings survive, while those unfit to meet the new contingencies are eliminated. But it may be asked : If the survival of the fittest has led to the transformation of the lower, more primitive forms into the higher, more complex species, how is it that any simple forms have survived at all? Why did not all species evolve? The answer to this question is twofold: In the first place, the terms "high" and "low" with reference to the scale of organic beings are merely relative. The amœba is by no means so simple as would appear; it is a very complicated, highly organized piece of living mechanism. We arrange the successive branches of the tree of life according as we imagine them to have evolved in the course of time, and look upon man as the highest offshoot of this tree. But, after all, this is a sort of anthropomorphism-viewing the evolution process from a human standpoint. Secondly, it must be well understood that the survival of the fittest only insures that those best the survival of the fittest only insures that those best
adapted to a given environment propagate and leave offspring, while those ill-adapted succumb in the struggle for existence. On the whole, the continuous change and increasing complexity of the environmental conditions made for progress - the advent of a new species formed each time in itself an additional complicating factorbut wherever conditions remained stationary there arose no need for new adaptations, and the old forms continued their existence unchanged. The fittest, then, to survive are by no means always the highest-the best in our sense approaching nearest to the top of the tree of life-but are those best adapted to their conditions of existence. So long as the conditions become more complex and varied, there results progressive organic evolution; if they remain stationary, the organisms, too, being well fitted to their

\section{DARWINISM}

I6r

surroundings, do not alter; while if the conditions of life become less complex, those organisms will have the best environment by becoming themselves less com the latter case we have the phenomenon of degeneration. Retrogression, therefore, is under certain conditions as much a phase of evolution as progress. The term " evolution" must not be taken to cover progressive evolution only.

We have already noted in a previous chapter that there are organs which have become rudimentary through loss of use and function. Now, while there may be retrogression in one part of the body, other parts may be progressing at the same time, or ma pre at a standstill. It is may be at a standstill. It is the balance of all these opposing processes which determines whether an organism is to be looked upon as degenerate or not. In order to establish a true case of degeneracy. the retrogresi must involve a majority of important organs. Such retrograde processes occur in cases of parasitism, when an animal previously leading an active

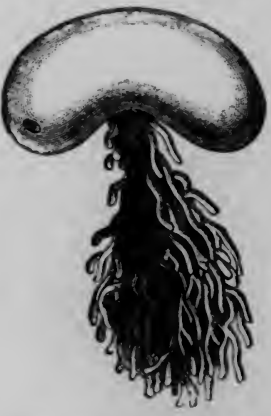

Fig, 66-SAcculiva. (From " Degeneration," by Sir
E. Ray Lankester.) life becomes a parasite, feeding

passively on a host which supplies the sustenance readymade. Thus there are parasitic crustacea which, but for their life-histories, would be unrecognizable as belonging to the family of crabs. The adult Sacculina is a mere sac without legs, mouth, or intestine, absorbing nutriment by root-like processes (Fig. 66). Often the degeneration only extends to one of the sexes, be it male or female. In the parasitic crustacean Chondracanthus (Fig. 67), the male is parasitic crustacean Chondracanthus (Fig. 67 ), the male is
very much smaller than the female, and lives attached to it. very much smaller than the female, and lives attached to it. 


\section{I62 THE FIRST PRINCIPLES OF EVOLUTION}

the skin of animals (Fig. 68). Sometimes immobility leads to retrogressive changes, as in the Ascidians, which, according to Professor Ray Lankester, must be looked upon as ing to Profsor sessile.

Degenerate processes are not confined to morphological structures, but may affect also intellectual and moral traits. It is in the domain of man's mental progress that

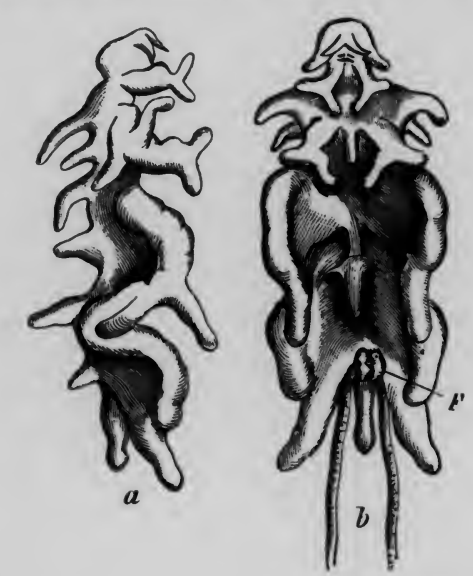

Fig. 67.-Chondracanthus Gibbosus. (Magnified about 6 times.) $a$, Female from the side; $b$, female from ventral surface, with male
$(F)$ attached.

(From "Textbook of Zoology," by C. Claus.)

we must specially guard against confusing the " fittest" with the "best." The fittest to survive may be the best, if the environing conditions are such as to favour the most highly developed individuals, physically, mentally, and morally. On the other hand, even the worst may prove to be the fittest if adaptation to environment. To the full consideration of this subject of social progress we shall return later.

\section{B. Sexual Selection.}

While natural selection is able to account for the useful traits to be met with in the organic world, from the lowest beings to the highest, including man, there is left a whole group of characters which cannot be explained in this manner. These are the secondary sexual characteristics of the animal world.

In addition to their distinctive sex - glands, differentiating the male from the female, most animals possess further sex distinctions characterizing the two sexes, as size, colour, or various structural appendages. Horns, spurs, grasping organs, etc., are to be found in the male, while the special organs of the consist of pouches, mam-

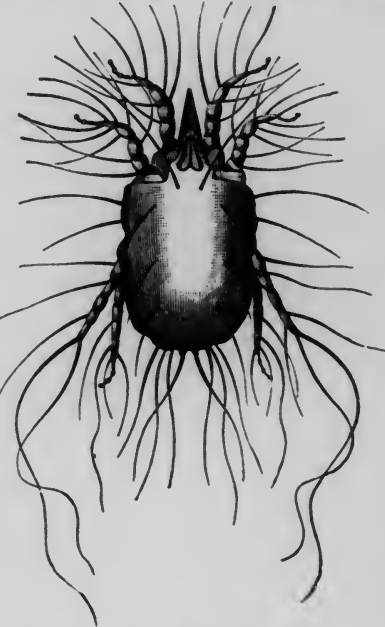

Fig. 68.-Acarus EQUi. Larom "Degeneration," by Sir E. Ray
Lanker.) $\mathrm{mæ}$, etc. Some of these special organs, as the copulation apparatus of the sexes and the mammæ of the female, have direct connection with the act of pairing, or of rearing the young, and can be explained as the result of natural selection, since it is clear that they are essential for the survival of the race. Selection does not imply only sursurvival of the race. Selection does not imply only sur-
vival of the fittest, but also their reproduction. It is otherwise with such features as ornamentation, the powe 
I64 THE FIRST PRINCIPLES OF EVOLUTION

of song, etc., which are sex characteristics of many male animals; and, further, with certain distinguishing traits af the colour of the skin, hairiness, the form of the face, and so on. These cannot possibly the form of the face, and so in the struggle for life, and have had any survival value in the struggle for life, an therefore cannot have been developed by natural selection. It is for these cases that Darwin propounded his theory of sexual selection.

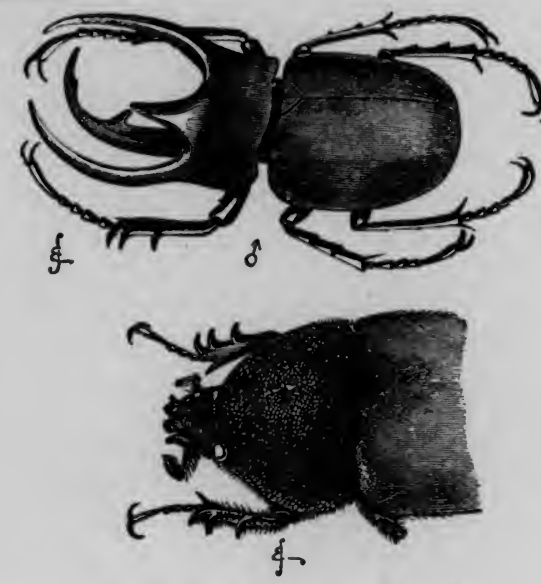

Fig. 69.-Chalcosoma Atras.

Upper figure, male (reduced); lower figure, female (natural size). (From "The Descent of Man," by C. Darwin.)

While in the lower animals the two sexes are, on the While in the low whole most ase ascend the organic lacher, the most pronounced differences between male and female in coloration and general appearance. We have already noted that tion and mich other species could not possibly have been recognized as belonging to the same species as the males had not breeding experiments

\section{DARWINISM}

I65

verified their common origin. Among insects a number of beetles can be mentioned, whose males are marked by various horny appendages, etc. (Fig. 69). The stridulating organs of the cricket and related species, which produce the characteristic rasping noise, are also which produce the characteristic rasping noise, are also
confined to the male individuals only. In fishes there
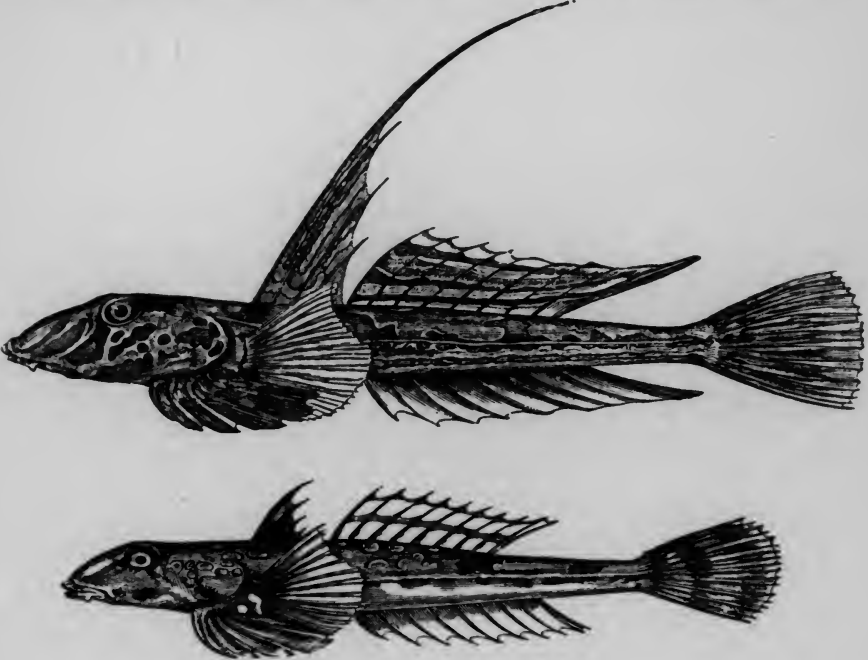

Fig. 70-Callionymus LyRa.

ig figure is more reduced than the upper.

(From "The Descent of Man," by C. Darwin.)

is, on the whole, very little external sex differentiation, though a few prominent examples were given by Darwin (Fig 70) (Fig. 70). Among ampibians and sexes are generally alike; some male reptiles, however, show various appendages, as horns, wattles, etc. (Fig. 7I). It is among birds that we find the greatest abundance of sex differentiation, running from identical coloration in 


\section{I66 THE FIRST PRINCIPLES OF EVOLUTION}

the two sexes of some species through all gradations towards the most extreme differences, as in the case of the pheasant, or the bird of paradise. In other species we find fleshy or feathery appendages or inflating tubes, etc., find fleshy or feathery af the male (see Fig. 72 ); while the as distinctive fongsters exquisite and elaborate vocal music of many songsters is exclusively confined to the same sex. Among mammals we generally find the males equipped with weapons, as horns and spurs, or with manes, crests, etc.

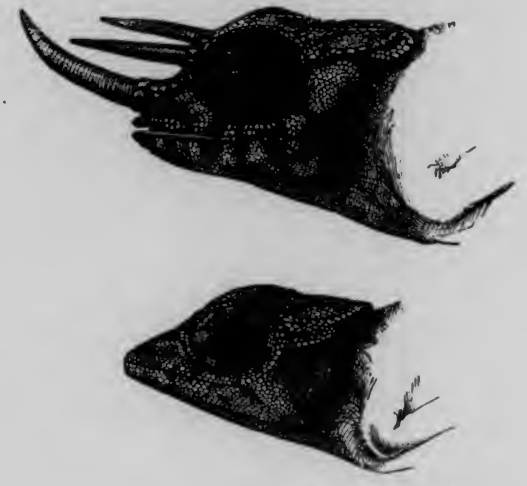

Fig. 7I.-Chameleon OWenil

Upper figure, male; lower figure, female.

(From "The Descent of Man," by C. Darwin.)

It is for all these secondary sex characteristics that It is for sexual selection. While natural selection accounts for the useful in organic nature, sexual selection is intended to explain the beautiful. As netural selection picks out the fittest to survive in the battle of life so sexual selection seizes upon the most battle of tife, so sexual solection seizen upon the in progapation But while natural selection the celective conditions of life leading to a struggle for existence, in

\section{DARWINISM}

167

sexual selection the choice is made by the females. It is they who, attracted by the strongest, most prepossessing or ornate males, mate with them, and thereby lead by a continuous repetition of this selective process to a pro gressive enhancement of the selected types. That in many

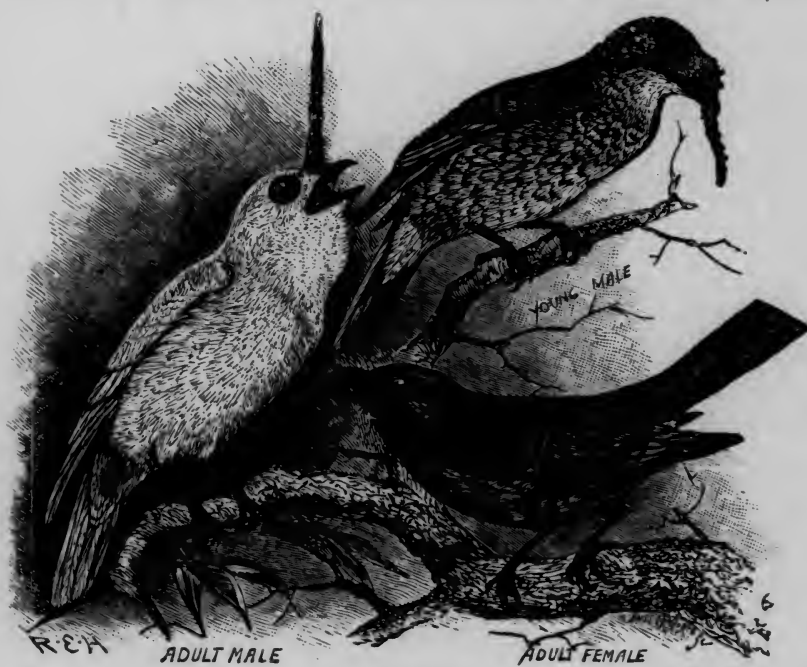

FIG. 72.-BELL-BIRD (Chasmorhynchus Nivens) (1 natural size.) The adult male shows the ornamental appendage in inflated con(From "Darwin and after Darwin," by G. J. Romanes.)

for the possession of the females is beyond doubt. The battles of pugnacious birds and mammals, or even lower down in the scale among spiders, during the love season, are too well known to need description here. The more peaceful combats, too, of male birds in displaying either their highly ornamental dress or their musical powers during the breeding season have often been described. The case 
68 THE FIRST PRINCIPLES OF EVOLUTION

of the elaborate love antics of the bower-bird, which builds bower and special arena covered with coloured litter, has become classic. Now, Darwin contended that the females exhibit an æsthetic preference for the most alluring malesi.e. i.e., those that are in singing or fighting. He adduced various instances, showing that the females do not mate at random, but often exert a deliberate choice in the selection of thei partners. Such "preferential mating" is bound to lead to a constant improvement of the selected quality if the to a constant improver generation. $O$ selection is continu gertunate rejected course, this presupposes that the less fortunate rejected males are unable to find a mate, and are thus altogethe excluded from propagation. For if the unsuccessful male were not thus prevented from leaving offspring, the next generation could not exhibit, on the average, any improvegeneration could not exhin Darwin was at pains to show that there is in the animal world either a preponderance of males, or what amounts to the same thing, polygamy, which limit the number of females available for breeding with the males In those cases where both sexes are highly ornamented, In those casin, first evolved in the male by sexual selection, and then transmitted in the male by sexual selection,

through inheritance to both sexes. To come to the criticism of the theory of sexual selection, we may forestall our conclusion by saying at once that, on the whole, sexual selection as proposed by Darwi has not withstood the test of time, and stands condemned in the opinion of most authoritative writers on evolution As far as the origin of the fighting apparatus of males is concerned, the horns, spurs, etc., seeing that the law of battle corcte of for the possession of the females often a specific case of the vanquished, we have in the natural selection. For, as we have said, the fttest to survive in the evolutionary sense are not those who merely just manage to keep themselves alive, but those who succeed in propagating their kind. Natural selection exists for the race, and not for the individual
As regards the ornamental sexual characteristics, it must be pointed out, to begin with, that they are by no means always confined to the male sex. Darwin would account for those cases where both sexes are highly decorated by the transmission of sexual characteristics from the male to the female descendants by inheritance. But what about to the female descendants by inheritance. But what about those instances where, contrary to the rule, the female is
the more brilliant individual ? It is not proved that in the more brilliant individual ? It is not proved that

Furthermore the hypothesis of sexual selection preFurthes, as we have said, firstly, that there are a greater supposes, as we have said, firstly, that there are a greater number of males than females; and, secondly, that the
rejected males should not find any mates at all. Now, neither arguments can be fully substantiated by facts. The next point is: Do the females select their mates, and do they do so according to an rethetic standard ? As to conced that in some instances the the first, it may be conceded that in some instances the females show decided preference for certain males, but in the majority of cases no such choice is apparent, the female accepting the first mate that offers. But the further point is: Are organisms so low down in the scale as butterflies of choosing according to an tandard at ? We can hardly believe that butterflies or birds would be influenced in their choice of a mate by a little more or a little less colour. Lloyd Morgan, in order to save the theory, argues that the female does not exert a conscious choice, but is incited to pair with the male who, by his disp sexual emotion in her. But if this is so, would a slight variation in brightness or colour make all the difference whether a male were accepted or not, as we must believe according to Darwin's theory? Finally, it has been shown defite definitely by experiments on certain butteflies that the females mate indiscriminately with all males, whether they have their own brilliant wings, false coloured wings, or no wings at all. The mating most probably takes place by chemotaxis-i.e., by the attraction due to substances 


\section{I7O THE FIRST PRINCIPLES OF EVOLUTION}

exhaled by the body. In the case of birds it has been he different from ours, their metic standard, if and we cannot it exists, by our own. Lastly, if the females did effect a deliberate or unconscious choice according to an æsthetic standard, we should have to posit a different taste in the the an immense degree-more than can conveniently be brought under the degree-more than

What purpose, then, have the display and the love antics of the males during the mating season, if they are not intend for the answer to not intended for sexing of brilliancy and excitement durin A general heightening of brilliancy and excitement during the breeding season occurs among male animals, as low in the scale as fish, or even worms. As no pairing take place among these creatures, the change cannot be explace am referred to sexual selection.

What, then is the alternative explanation of the What, then, is the alternative explanation is act,
secondary sex characteristics? Sex colouration is a fact and has to be accounted for. A. R. Wallace, who pin his faith to natural selection, attributes the diversity of colour in allied species to the need of recognition among the song of birds, too, the members the same specition must, according to him, be looked upon as a recognition call between the two sexes. As for the differentiation of colour between the male and female, the dull tints of th female are the result of protective colouration, produced fy natural selection on account of the female's greater need by natural selection on account of the task of breeding and of protection, since upon her the task of brecting and rearing the young generally devolves. The brilliancy of the males is due to their greater vigour, the surplus of vital energy manifesting itself not only in more pronounced and vivid pigmentation, but also in the growth of tufts, accesvivid pigmentation, These are apt to appear, as A. Taylor . has shown, at certain definite lines of the body, just like the primitive ornamental spots in animals, which later
flow together into bands and blotches.

\section{DARWINISM}

I7I

The argument against Wallace's theory is short. First of all, the fact that the females remain protectively coloured through the action of natural selection does not go against the contention that the brilliancy of the males is attained by sexual selection, where no such reason mitigates against it. Secondly, even granted that the more intense colour of the male in general may be explained by excess of vigour this would not account for the origin of the gorgeous and elaborate patterns of the males, nor for the development of the excessive ornamental appendages of some birds, which would seem a positive hindrance to them.

As a final argument against sexual selection, Wallace advances the following: Seeing that natural selection is constantly weeding out harmful traits, it is not conceivable that the elaboration of mere beautiful characteristics by means of sexual selection should not have been checked by it. "The extremely rigid action of natural selection must render any attempt to select mere ornament utterly nugatory, unless the most ornamental always coincide with the fittest in every other respect; while if they do so coincide, then any selection of ornament is altogether superfluous." But Lloyd Morgan points out, as already indicated above, that preferential mating and natural selection are by no means incompatible with each other "The two processes begin at different ends of the scale of efficiency. Natural selection begins by eliminating the weakest, and so works up the scale from its lower end until none but the fittest survive; sexual selection, by preferential mating, begins by selecting the most successful in stimulating the pairing instinct, and so works down the scale until none but the hopelessly unattractive remain unmated."

Other theories of secondary sex characters have been proposed, but do not cover a wide enough range of phenonomena to have met with general acceptance. None has been able to take the place of sexual selection propounded by Darwin. As Professor L. Plate sums up his defence of the 


\section{I72 THE FIRST PRINCIPLES OF EVOLUTION}

theory of sexual selection: "It is better than any other hypothesis advanced so far, and has to serve us until a more adequate one is found."

\section{DIFFICULTIES OF THE THEORIES}

We have so far examined the theories of Lamarckism and Darwinism separately in their historical sequence. But in order fully to understand their import, we must consider them in their mutual relationship. Not only do these two theories form the main armoury of the present-day evolutionists, but the question of the origin of species has of late largely resolved itself into a discussion of the respective merits of the two rival systems. For though Darwin devised his theory of natural selection mainly to replace that of Lamarckism, he by no means disdained to avail himself of Lamarckian principles. He fully acknowledged the effects of the environmental factors, and relied upon them in many cases where they appeared to afford a better solution of the problem under consideration. It is otherwise with Wallace, the co-discoverer of the theory of natural selection. He would reject not only the Lamarckian principle, but also sexual selection, or any other accessory theory of evolution. For him natural selection is the only true, the only possible factor in the progressive development of species.* This ultra-Darwinian standpoint has of late come very much to the front through the labours of Professor A. Weismann, a German scientist. He, with many adherents, forming the Neo-Darwinian school, maintains the " all-sufficiency" of natural selection, and is in entire opposition to the modern upholders of the Lamarckian theory, the Neo-Lamarckians, who, on the other side,

* But he rejects natural selection as an effective factor in the evolution of the higher faculties of man, which he attributes to is in the title of bis book on evolution,

\section{DARWINISM}

discard natural selection altogether, or allow it at best merely a secondary rôle in the scheme of evolution.

The difficulties of either of these extreme schools are very great indeed when taken singly, each side being able to make out an apparently strong case against the other. Before entering, however, into a detailed discussion of the arguments for or against either school, we must for clearness' sake once more emphasize the main difference between the two contending theories. In both theories, Lamarck's as well as Darwin's, the environment plays an important rôle. But we must note a fundamental distinction in the way the surroundings act in each case. According to the Lamarckian theory, the environmental factors have a direct effect on the individuals subject to their influence. The individual adapts itself to the new conditions, and becomes modified accordingly. It is the environment wi. handing down in succession the newly acquired characters to their offspring. Thus a gradual transformation of the whole species takes place in agreement with the environment. It is otherwise with natural selection. Here, too, change of organisms takes place, when new environm too, conditions arise. But in this cas not mould the individual directly into fitness with new conditions of life, but acts, as it were, like a sieve, allowing those only to survive who are from the beginning adaptable to the new circumstances, while those not adaptable die out. Thus the standard of the surviving individuals is constantly raised by the progressive selective action of the environment. Fig. 73 represents the difference very neatly in a graphical manner. In $A$ the Lamarckian effect of the environment transforms all (or nearly all) individuals in accordance with the new conditions (which are supposed to lead to an elongation of form). In $B$, where the action of natural selection is illustrated, the environment will only let pass through the more or less elongated forms, of which, in accordance with 
I72 THE FIRST PRINCIPLES OF EVOLUTION

theory of sexual selection: "It is better than any other hypothesis advanced so far, and has to serve us until a more adequate one is found."

4. DIFFICULTIES OF THE THEORIES

We have so far examined the theories of Lamarckism and Darwinism separately in their historical sequence. But in order fully to understand their import, we must consider them in their mutual relationship. Not only do these two theories form the main armoury of the present-day evolutionists, but the question of the origin of species has of late largely resolved itself into a discussion of the respective merits of the two rival systems. For though Darwin devised his theory of natural selection mainly to replace that of Lamarckism, he by no means disdained to avai himself of Lamarckian principles. He fully acknowledged the effects of the environmental factors, and relied upon them in many cases where they appeared to afford a better solution of the problem under consideration. It is otherwise with Wallace, the co-discoverer of the theory of natural selection. He would reject not only the Lamarckian principle, but also sexual selection, or any other accessory theory of evolution. For him natural selection is the only true, the only possible factor in the progressive development of species.* This ultra-Darwinian standpoint has of late come very much to the front through the labour of Professor A. Weismann, a German scientist. He, with many adherents, forming the Neo-Darwinian school, maintains the "all-sufficiency" of natural selection, and is in entire opposition to the modern upholders of the Lamarckian theory, the Neo-Lamarckians, who, on the other side,

* But he rejects natural selection as an effective factor in the evolution of the higher faculties of man, which he attributes to spiritual agencies. We see from this how little justification there

\section{DARWINISM}

I73

discard natural selection altogether, or allow it at best merely a secondary rôle in the scheme of evolution.

The difficulties of either of these extreme schools are very great indeed when taken singly, each side being able to make out an apparently strong case against the other. Before entering, however, into a detailed discussion of the arguments for or against either school, we must for clearness' sake once more emphasize the main difference between the two contending theories. In both theories, Lamarck's as well as Darwin's, the environment plays an important rôle. But we must note a fundamental distinction in the way the surroundings act in each case. According to the Lamarckian theory, the environmental factors have a direct effect on the individuals subject to their influence. The individual adapts itself to the new conditions, and becomes modified accordingly. It is the environment becomes modified accordingly. It is the environment
which directly transforms the individual, each generation handing down in succession the newly acquired characters to their offspring. Thus a gradual transformation of the whole species takes place in agreement with the environment. It is otherwise with natural selection. Here, too a change of organisms takes place, when new environmental conditions arise. But in this case the environment does not mould the individual directly into fitness with new conditions of life, but acts, as it were, like a sieve, allowing those only to survive who are from the beginning adaptable to the new circumstances, while those not adaptable die out. Thus the standard of the surviving individuals is constantly raised by the progressive selective action of the environment. Fig. 73 represents the difference ian effect of the environment transforms all (or nearly all) individuals in accordance with the new conditions (which are supposed to lead to an elongation of form). In $B$, where the action of natural selection is illustrated, the environment will only let pass through the more or less elongated forms, of which, in accordance with 
the law of variation, there will always be a certain number among the mass of individuals. According to Lamarckian interpretation, the change affecting the individuals is directly induced by the environment, and is transmitted to the next generation. According to the Darwinian theory, the variations are given primarily; natural selection

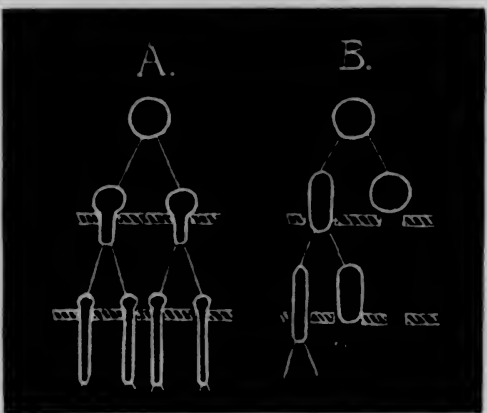

Fig. 73.-Diagram to illustrate- $A$, The Transmission of AcQUired Characters ; $B$, Modification of Type by Natura

In $A$ an organism, represented by the circle, has offspring. The environment is represented by a board with holes through which they must pass. In so doing they become elongated, $B$ a rounded organism has progeny which vary. One cannot pass through the board and is eliminated; the other, bein somewhat elongated, can pass and has progeny, which agai vary in a similar manner, the more elongated type being

(From "Darwinism and Race Progress," by J. B. Haycraft.)

merely ensures the survival of the types best fitted to the environment, while the unfit are weeded out and disappear.

How far can either theory be upheld as an independent system-i.e., as a principle sufficient in itself to bring about the progressive evolution of species?

We shall first discuss the difficulties of Neo-Lamarckism, and then those of Neo-Darwinism.

\section{A. Neo-LAMARCKISM.}

We have seen that, according to Lamarck, two modes of action of the environment can be distinguished. The one consists in the direct influence of external conditions, climate, food, etc. ; in the other the effect is more mediate through the functional use or disuse of active organs. In both instances the effects wrought on the individual are supposed to be inherited by successive generations. NeoLamarckians may accordingly be divided into two campsthe botanists, who mainly insist on the first factor of Lamarckism, and the palæontologists, chiefly of America, who, led by their studies of extinct types of animals, look upon the inherited effect of use and disuse (use-inheritance) as the important element in the progressive development of species.

We have, then, to decide the following double question Can Lamarckism in either form, whether singly or combined, account for the evolution of species? Is the inheritance of acquired characters an accepted fact of science ? In order to develop the argument more clearly, we shall posit -what has still to be proved-that the latter question has been answered in the affirmative. For without it Lamarckism would be deprived of its basal assumption.

Now, as to the first case, that of passive acquirements, the difficulty arises: How is it that the organism reacts in a definite manner to a constantly varying change of conditions, so that useful improvements of organs arise and accumulate in certain given lines? How can we imagine, for instance, that the complicated modifications of the limbs of certain articulata, the stridulating organs of the limbs of certain articulata, the stridulating organs
of the locusts, or the " brush and comb " apparatus of the bee (Fig. 74), have been developed in this manner, seeing that they are made of unyielding chitin? The mutual adaptation of the different parts is too complex to have been brought about by the environmental stimulus; while the principle of use-inheritance is excluded in the case of 


\section{I76 THE FIRST PRINCIPLES OF EVOLUTION}

such passive structures. Or, to take another example: How can passive adaptation explain the change of an edible butterfly so that it mimics an inedible species? At best it may, perhaps, be admitted with Plate that indifferent

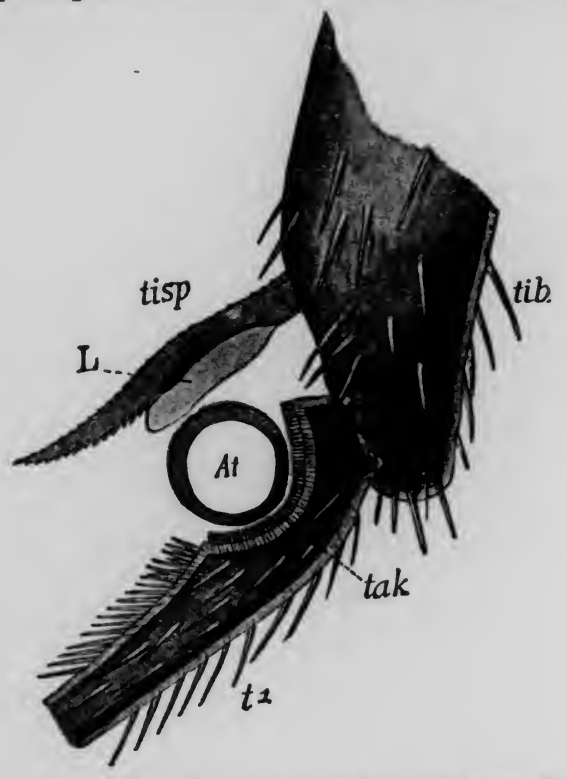

Fig. 74. - Brush and Comb on the Leg of a Bee (Nomada). $t i b$. End of tibia; $t^{1}$, first tarsal joint with the brush and its comb with its lappet $(L)$ the cross-section of an antenna $(A t)$ is indicated.

(From "The Evolution Theory," by A. Weismann.)

qualities may thus be imposed upon the organism from without, or very occasionally simple useful characteristics, if the environmental conditions affect a mass of individuals persistently for a long time. But here the question at once arises: Are such changes inherited ?
To many biologists Lamarckism is mainly represented y the principles of functional adaptation. Their arguby the prismann-are mainly directed ments-as, e.g., those of Weismann-are mainly distem. It is clear, of course, that passive adaptations cannot at all be accounted for in this way. But even active adaptations can by no means allays be explained by the inherited effects of use means always be explained by the inherited effects of use the harmless gland of a snake into a poisonous weapon ? How could the effect of use alone elongate the fangs of the Babirussa, seeing that they first have to pierce the skin, when they would be completely useless? Furtherskin, when they would be completely us this school as in more, herited habits - that is, as due to the constant repetition of acts which are transmitted to the offspring - what have we to say about those instincts which are performed only once in the lifetime of the individual ? Here there can be once in the lifter. Or, to take the case of the neuter bees, they cannot possibly transmit their functions to the next generation, for they are sterile.

But the chief point still remains: What proof have we But the chife parents that characters acquired during the and thereby accumuare transmitted to their progeny, and thereby accumulated? It is quite true that the muscles of the blacksmith become strengthened by constant use ; but what evidence have we that this improvement is eo ipso inherited by his children? Lamarck himself simply took the inheritance of acquired characters for granted, and so did most of his followers, until Weismann showed that there was by no means so favourable a case for it as has generally been assumed. It would be far too lengthy a task to enter here assume of acquired characters. This is a question of heredity, and is dealt with in the appropriate textbooks.* We would

" See the author's "The First Principles of Heredity" (A. and c. Black). 
I78 THE FIRST PRINCIPLES OF EVOLUTION

merely point out that Weismann distinguishes sharply merely point body of the individual and the germ-cells between the body of the next generation. His view, which form the stock of the next generation. His view, upo body of the individual by external conditions do game time do not generally affect the newly acquired qualities and in the same manner. The newly acquired qualities cannot therefore be transmitted to the next generation. All arguments in favour of such occurrence can be shown to be either fallacious or not unequivocal. In any case, to be if admitted as possible, it must be considered too rare even if admitted as possiblen with as a constant factor a contingency to be reckoned with as a constant factor in the elaboration of new characters. It follows from this that any theory of evolution based upon this factor, such as is the theory of Lamarckism, must be discounted so long as it fails to establish its first premise-the inheritance of acquired characters.

\section{B. NEO-DARWINISM.}

We have already noticed that there are two schools of Darwinists. The first is represented by Charles Darwin himself and his defenders, Romanes, Plate, etc., who, whilst looking upon natural selection as the main factor of evolution, still do not believe it to be the only factor. To them the environmental effects of external conditions, including the environmental effects of external conditions, including use-inheritance, are accessory means of species formation. The other school, starting with Wallace and headed now by Weismann, maintains the "all-sufficiency" of natura selection, believing it to be the only true cause of the origin of species* The criticism against Darwinism divides itself into two parts, according as we have to argue against into two parts, according as we have to argue agains natural selection in general, or whether we have to deal with the extreme selectionists, who do not admit any other

* Weismann himself admits, however, the validity of sexual selection? species-forming principle. Among the critics of natural selection we find some authors who go so far as to refuse to accord it any value whatsoever in the scheme of evolution; others have advanced grave difficulties, which apply specially to the narrower principle of Neo-Darwinism. We can here only give a very brief summary of some of the more important objections.

As to the general arguments against natural selection, the first in order is perhaps the contention made by some that natural selection does not, as a matter of fact, exist in nature. There is, in any case, so it has been said, no positive evidence for it. Now, it must be admitted that it is practically impossible to trace by direct observation any special case of selection in nature, as the conditions are generally too complex to be sifted with scientific correctness. Still, some experimental observations have been made which go far to show that adaptations, as interpreted by the selectionists, have a life-serving value. Thus Cesnola fixed specimens of the brown and green varieties of Mantis religiosa on plants, and found that the individuals tied to plants of a harmonious colour escaped death; while the others, being conspicuous through their colour contrast with the plant, were mostly devoured. Poulton and Sanders made similar experiments with the pupæ of a butterfly (Vanessa urtica) and had similar results. This tends to show that protective colouration is a real survival factor, giving a decided advantage to its possessors in the struggle for existence. But, on the whole, the principle of natural selection is, as Professor Lloyd Morgan has insisted, "more a logical conclusion than a matter of direct observation." We know that there is an overproduction of organisms; we know that only a certain number of them can and, as a matter of fact, do survive it follows, therefore, that selection must take place according to some underlying law. According to the theory of Darwin, this determining principle lies in the adaptation of the individual to the environment, which leads, as 
I80 THE FIRST PRINCIPLES OF EVOLUTION

Herbert Spencer has expressed it, to " the survival of the fittest."

Taken for granted that natural selection acts in the manner indicated, it still does not explain-so runs the next argument against Darwinism - the origin of species. Starting with the given qualities of the individual, and Starting with the given quarions, it simply rears accepting the pre-existence of variations, it simply rears upon these as a basis the superstructure of organic evolution. All that natural selection does is to determine by a process of elimination which are to survive to form the next generation. "It may," as it has been tersely put, " "explain the survival of the fittest, but cannot explain the arrival of the fittest." Whence the variations ? I is clear that Lamarckism accounts for new characteristics in its own manner, explaining them as the direct resul of the action of the environment upon the individual. Darwin himself fully recognized this dependence of natura selection on "what we in our ignorance call spontaneous or accidental variability." Since his pioneer work on the subject of variation, a great deal of research has been done in this branch of inquiry, to which we shall return later. But while thus variability forms the starting-point of the process, it does not follow, as some antagonists would have process, " selection acts only negatively." It is true it it, that "selection acts only negatively." It is true it certain lines, accumulates them in successive generations, and thereby originates new biological characters out of indefinite beginnings. It certainly creates species from out a mass of fluctuating varieties.

We now come to the other series of criticisms, which, as we shall find, possess a good deal of validity when directed against the extreme standpoint of Weismann's school Darwin and his strict followers do not hesitate to make use of other factors of species formation, whenever the principle of natural selection seems insufficient for a solu-
tion. It is otherwise with the school of Neo-Darwinists. They try to explain all organic evolution by natural selec-

\section{NEO-DARWINISM}

I 8

tion, and natural selection only; and, as we shall see presently, they have therefore been put to considerable straits in order to uphold their position against the vehement attacks of friend and foe alike.

It follows from the extreme view taken up by the NeoDarwinians with regard to the exclusiveness of natura selection as a means of species formation, that all specific characters-i.e., those by which we distinguish one specie chor natural selection only fosters useful characteristics, and all species which have survived by virtue of their adaptations must be distinguishable by these very adaptive traits. As the case has been put by Wallace in an extreme way: "It is a necessary deduction from the theory of natural selection, that none of the definite facts of organic nature-no special organ, of the definite facts of organic nature-no special organ, no characteristic form or marking, no peculiarities of instinct or of habit, no relations between species or between groups of species-can exist, but which must now be, once have been, useful to the individuals or the races whic possess them." Now, first of all, does the theory of natura selection imply of necessity any such logical deduction ? Secondly, is it a fact that all specific characters owe thei origin exclusively to their usefulness? As to the first contention, Romanes has shown to the full that the conclusion drawn by Wallace is only valid if we do not admit clusion drawn by. Wallace is only valides natural selection. any other evolutionary principle besides natural selection. As to the second point, there are innumerable specific characteristics to which no possible use can be assigned, either in the present or past condition of their existence. It is true many traits have been explained on utilitarian principles which previously appeared quite valueless. Still, there are a great many others for which the plea of ignorance cannot be raised. The trivial colour distinctions to be found between many different species of birds, mammals, etc., can certainly not be reckoned of any selective value whatever.

Of course, the strict followers of Darwin are not logically 


\section{I8 THE FIRST PRINCIPLES OF EVOLUTION}

forced to deny the existence of unadaptive specific charform to any cause acting uniformly during a long series of generations on many individuals would probably produce a constant modification. The ultra-Darwinists, on the other hand, who are ready to go so far as to admit the occurrence of such useless indifferent fo far all features, can only fall back on the asth such characters came into existence
dependent upon other useful traits.

A similar, but much more relevant, objection advanced against Darwinism concerns the first beginnings of adaptations. "Natural selection," according to this view, "is incompetent to account for the incipient stages of useful According to the Darwinian theory, the Accoraing to the Darwinian theory, the progressive elaboration of organs takes place by the accumulation of slight variations through small successive steps. These variations have been called "fluctuating," "continuous," or " individual " variations ; for they fluctuate tinuous," or "inge or mean and can around an average or mean, tinuous series. Now, the principle of natura selection implies that any such variations can only be preservec and seized upon for further development if they have survival value - that is, if they are of sufficient value to be a determining factor in the struggle for life-otherwise a deter in question now natural selection has no hold on then. The to survival? ches is suficient to lead to survival ? Can the small differences which constitute, according to Darwin, the material of organic evolution, be of sufficien value to decide in a given case between the life and death of an individual ?

Now, there cannot be any doubt that we have here a weighty objection-one that cuts at the very root of the theory of natural selection. Darwin was fully aware of its seriousness, and he and his followers have tried to overcome this obstacle by various accessory explanations.

In the first instance, as Plate pointed out, there are a number of contingencies where even slight differences may

\section{NEO-DARWINISM}

183

be vital importance in times of stress and danger; for be of vital is selection it is evident the and does it most stringently. Secondly, we does its work, and doest, emphasized by J. L. must keep clearly in mind the fact, emph Taylor, that " the whole and not merely a part of the organism is selected, and therefore each variation does not organis velue, as if selection depended on require to be of the auxiliary factors it alone." In addis problem. have been adduced towark For those, like Darwin himself, who admit Lant means principles, the external conditions furnish a potent means for initiating new variations, which are handed down by inheritance, until they can be taken advantage of by inheritan on the other hand, the anti-Lamnatural selection. arckians, who do not admits characters, have availed themselves of a similar argan in a thery England, have propounded a theory which has variously Eeen called " organic selection," "orthoplasy," ontobeen called "organic selection." On this theory, the genetic," or "coincis characters, though not transmitted individually acquired to tide the successive generations to the offspring, serve to tide the successive genation over the critical period until germinal (inborn) variations of the same kind appear which are inheritable. Ontogenetic (individually acquired) adaptations and natural selectio work together towards the same end.

Of

Of other factors involved in the making we mention the laws of growth, correlation, change of environment and of function. Darwin has given a beautiful example of the first. The sutures in the skulls of young mammals, which would seem to be an adaptation of young mobably arisen in the for aiding parturition, has of growth for they occur in first instance by inherent laws of giles, which only have to the skulls of young birds and reptiles, which only have to break through an eggshell at birth. Or adaptations may originate in the first instance as useless characters in correlation with other useful traits. It is well known that 
I84 THE FIRST PRINCIPLES OF EVOLUTION

there exists a certain relationship between the different parts of an organism, so that a change in one part goes together with change in the other. All such indifferen traits may suddenly acquire survival value when new contingen arise. There may occur either a change of environment which brings into prominence a feature up to then of no special importance, or an alteration of function may take place in the organ due to changed conditions of life. The organ developed by natural selection for one purpose assumes a new function, thus starting at an initial stage of usefulness which it could not have an initial stage of usef function alone. Thus it is hard acquired through its new function alone. Thus it is hard to understand how the primitive stages of lungs could have been of any value-least of all of vital the lungs first air-breathing ani are nothing but the swimming bladder
verted into a breathing apparatus (Fig. 75 ).

Though all three explanations together would account for a great number of cases, it is evident that they are hardly able to cover the whole ground of possible adaptations Seeing that, according to natural selection, all the tions. Seeing that, according to natural selection, all the cters must have survival value, this problem presents one of the greatest difficulties of Darwinism, especially for the extreme Neo-Darwinists who cannot fall back on Lamarckian principles. In fact, Weismann, in order to free the theory principles. devised a subsidiary hypothesis - that of germinal selection-which is intended to explain not only the beginnings of adaptations, but also their disappearance, the possibility of correlation, etc., from the exclusive standpoint of . This theory we shall discuss later in detail.

Finally, we must mention the opinion of De Vries and Finally, we must mention the opinion of De Vries and
his school, who deny altogether the efficacy of the small Darwinian variations as an effective means of evolution. Organic evolution, on this view, does not take place by means of small continuous steps, but rather in a saltatory

\section{NEO-DARWINISM}

ay way, each successive stage from the previous one. These discontinuous variations, or, as they have been called by De Vries, "mutations," furnish the sole material for the action of natura

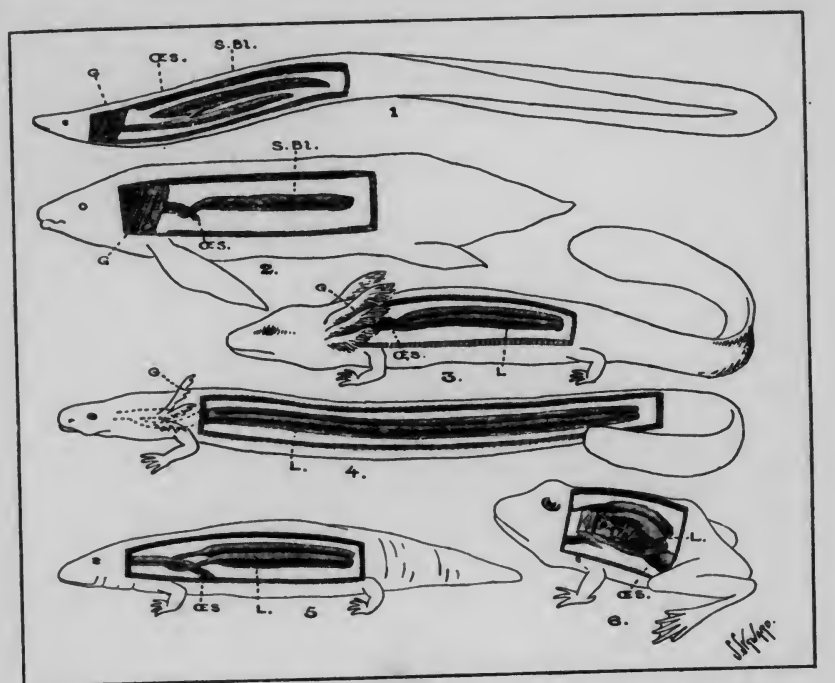

Fig. 75.-Evolution of LungS From Swim-Bladder of Fish x. Kel. 2. Mud.fish (Ceratodus); swim-bladder used during the dry season as a and on land. 4. Siren, the same as previous stage, but lungs more developed. 5. and 6. Newt and Frog, both possessing gills only in the tadposephagus or gullet $S . B l$, swim-bladder ; $L$, lung.

In each illustration the integument is showe to be partly removed in order to exhibit the

selection. As each step involves a sudden advance, this theory is freed to a considerable extent from the difficulty besetting the original theory of Darwin.

Similar considerations, as just discussed with regard to the beginnings of adaptations, apply with equal force to the problem of their degeneration and disappearance. We 


\section{I86 THE FIRST PRINCIPLES OF EVOLUTION}

have seen that organs which cease to be useful become atrophied. How can this process be accounted for? The old Darwinists relied mainly on Lamarckian factors as an explanation. The disuse of an organ leads to its diminution, which, if inherited in successive generations, must effect its gradual reduction and final disappearance. Adverse environmental conditions, too, may similarly bring about retrogression. Much weight was formerly laid on a saving of nourishment which would be beneficial to those individuals least encumbered with useless organs. But it is hardly conceivable how an ounce of substance more or less could mean anything, say, to a whale, whose hindlegs have been dwindling for ages. There remained only one strictly Darwinian interpretation of rudimentary organs-namely, reversed selection. If an organ becomes positively harmful through its size, natural selection wil weed out those individuals which possess the disadvantageous structure in the greatest degree, and will thus lead to its gradual reduction and elimination. The wingless beetles on wind-swept islands are a case in point. It must, however, be admitted that instances of reversed selection are rare on the whole, and cannot therefore solve the problem. Romanes first tried to devise a satisfactory answer on strict Darwinian lines. If natural selection is necessary in order to evolve an organ, it follows, so he reasoned, that the organ can only be sustained on its attained level by the same force. As soon as natural selection ceases to act-and this must happen whenever an organ become useless-retrogression must set in. This theory of the " cessation of natural selection" was later on more elabor"ated by Weismann, who gave it the name of "panmixia" -i.e. an indiscriminate mating of all without regard to the quality of their traits. This would lead to a general levelling down of the whole stock. We shall discuss the value of this theory later, but must remark here that Weismann himself found reason later on to supplement this theory by that of germinal selection. Just as ger-

\section{NEO-DARWINISM}

187

me one hand, the tendency of minal section of usefulness, so characters on decline sets in, germina in the same manner, as soon as decline sets in, gertimately lead selection will accelerate this process, and ultimater. We to a complete elimination of the useless character.

shall deal later on with germinal selection as a whole. A further important argument against natural selection is the following: How is it that the required variations always appear at the right time for natural selection to act always appear at thecially can we reckon upon a coincidence upon, and how especially can we reckon interdependent characters, which go to make up complex organs or parts? The selection of the fittest, it has been said, is too much a matter of chance.

Tow, as to the first question, there is no doubt that the Now, as to the first question useful variations often do not occur, in which case the organic forms, not being adaptable to the new cirion, stances, simply die out. "Selection follows variation, not variation selection." It is therefore a misstatement of the problem to ask why the necessary variations are of the problection; often they are not, but always at hand for sel upon when they are present, natural selection can act upon them. That the right variations do occur so frequently is due to the fact, which Plate has demonstrated, that, with a given change of conditions, more than cne prossive pross being swifter, of danger may one of being more wary, or more ferocious, the characteristics these traits may lead to its survival, the characteristics of the different individuals being combined later through intercrossing into a mixed type. The resemblance of the intercrossing into a mix have been brought about in leaf-butterfly to leaves mustual accumulation of different this manner by

structural points.

As to the second question-that of co-adaptations-it has been the battle-ground between Neo-Lamarckians and Neo-Darwinians for a long time, without either party 
I88 THE FIRST PRINCIPLES OF EVOLUTION

gaining a decisive victory (see especially the controversy between Spencer and Weismann). It is evident that if, under the influence of new conditions, one part of an organ or organism is changed, the whole vital economy of the individual would be disturbed, unless the other parts, closely connected with the varying part, also changed concurrently and in harmony with it. Thus, to take Herbert Spencer's illustration: As the antlers of the giant stag gradually increased in size, it was absolutely essential that the skull should become proportionately thicker, and the neck and forelegs stronger, in order to support the increased weight. To Spencer and the Lamarckian school this question seemed to afford sufficient evidence in favour of the Lamarckian principle of use-inheritance. For it is clear that on this hypothesis co-adaptive changes find an easy explanation. The correlated parts change together simply because they are subject to the same influence of the inherited effects of use Passive adaptations, however, caninherited effects of use Pasive ad not thus be accounted for, and, further, in any case, use-inheritance is still unproven. Other explanatory factors, then, from the selectionist point of view have to be considered.

There is, first of all, the principle of simultaneous correlative variability, according to which organs functioning together have the tendency to vary in the same general direction. The elongation of the bone of an arm or leg is accompanied by a lengthening of the attached muscles, as also of the supplying bloodvessels and nerves. Secondly, the fact must not be overlooked that in many instances harmonious changes of complex adaptations do not need to occur simultaneously, but may follow each other, as, for intance, in the case of mimicry. Thirdly (n) principle of coincident selection already mentioned, individually acquired modifications would be able to take the place of the appropriate necessary adaptations until these arose by germinal variation. Thus, while the antlers of the elk increased by spontaneous variation, the support necessary for the additional weight could be supplied temporarily by the increased strength of each given individual. Finally, Weismann has used his theory of germinal selection as a possible explanation of co-adaptive structures.

We come now to our last argument against Darwinism which amounts to this: Natural selection can only effect progressive change of any given species, but is unable to break up the species into several distinct types. Or, to words of Romanes: Natural selection produces monotypic, but not polytypic-i.e., divergen evolution. Swamping by intercrossing is the great obstacle to the effective action of natural selection. For it is clear that, unless the new-arising varieties are kept separate from the old stock and from each other by some means, intercrossing will sooner or later lead to a levelling down of the whole stock, and make nugatory every attempt at creating new and distinct types. Furthermore, it is difficult to see how, without isolation, a minority of a new adaptive type can be turned into a majority.

As regards the latter point, Delboeuf has calculated mathematically that the number of a given new variety is bound to increase up to and above the number of the non-varying type, thus replacing it gradually. But Plate, thoroughgoing Darwinist though he is, does not see his way to accept this law. He admits, however, the accumulating effects of Mendelian inheritance, and has tried to show that a new type must gradually become preeminent, if it happens to be distinguished from the old one by a positive character, which generally is dominant in the Mendelian sense.*

* In Mendelian inheritance the cross between two parents shows the characteristics of the "dominant " parent, the traits of the other parent bing "recessive "-i.e., extefally not visible. The hybrids mating among themselves give offspring, of whom 75 per cent. dominants, 25 er cent on further inbreeding are found 75 per cent. dominants, 25 per cente 25 per cent. recessives all breed true. It is clear, therefore, that on 
I90 THE FIRST PRINCIPLES OF EVOLUTION

For the Mutationists the question of intercrossing is much less urgent; for mutations are new varieties fully formed, capable of holding their own from the very beginning, and therefore less liable to be swamped. To the Darwinist, however, the difficulty of intercrossing is very real indeed. Darwin himself hardly realized to the full the seriousness of this objection, and his defence of natural
selection on this point is certainly not effective. His followers-Romanes, Plate, and others-have fully admitted the inadequacy of natural selection to account for evolution in divergant lines. Some form of isolation is now generally assumed as a necessary adjunct to the Darwinian theory. To this subject we shall address ourselves at the end of this chapter.

Auxiliary Theories of Natural Selection.

It has become clear, from the foregoing survey of the respective merits of Lamarckism and Darwinism, that neither theory is by itself capable of giving a satisfactory explanation of the process of organic evolution. Lamarckism suffers from a fundamental weakness, in that its very basis-the inheritance of acquired characters-has
so far not been substantiated by scientific facts. On the other hand Darwinism, especially as expounded by the Teomportance. It is for this very reason that a number of auxiliary hypotheses have been devised in aid of natural selection; while Weismann, by his special theories of panmixia and germinal selection, endeavoured so to

mating two separate Mendelian strains, though the hybrid combines both parental characters (one visible, the other hidden), in the succeeding generation both strains breed out separately. As there are always more dominant offspring than recessive, it will be seen that a newly appearing dominant character must gradually outnumber any given recessive character For further details see the textbooks on heredity.

\section{NEO-DARWINISM}

I9I

strengthen the Neo-Darwinian position as effectively to dispense with any Lamarckian taint of it. We shall discuss the latter two theories, in addition to those of intra-selection, coincident selection, and isolation.

(a) Panmixia.

Cessation of selection as a cause of atrophy was first copos by Romes. Later on, Weismann, whilst exprining the validity of the principle of use-inheritance, adopted the same idea, called by him " panmixia," in order adopted the same idea, called by him "panmixia," in order to account for the dwindling and disappearance of useless factors. If natural selection leads to the mating of select types, so that those below a certain standard are prevented tyes, so that the cessation of ypes, including the in ferior ones, must take place, and thus lower the averag quality of the whole stock. Weismann explained in this manner, for instance, the prevalence of short-sightedness among civilized people. The individuals with defective . eyesight not sharpness of the eyesight of the population sinks gradually. The same would apply to the deterioration of the teeth of man, of the breast-gland of modern women, etc. The fact that degeneration generally progresses so slowly, often taking thousands and thousands of years, seemed to him a sufficient proof of the inadequacy of the Lamarckian explanation. For if the effect of disuse were transmitted in accumulating ratio in the successive generations, a useless organ ought to disappear much more quickly.

Weismann originally attributed a great effect to panmixis and considered that nearly 90 per cent. of the reducmixia, and consider that nearly 90 per it ; the remainder, tion of rudimentary organs was due to it; the remainder, up to the complete loss of the organs, being accounted for by reversed selection. Romanes was much more modes in his estimate, and only allowed about to to 20 per cent. 
192 THE FIRST PRINCIPLES OF EVOLUTION

to this cause; while Lloyd Morgan gave only 5 per cent. reduction of the original size. The final reduction of the organ to zero is still not accounted for by any of these theories. Calling to aid a failure of the force of heredity, as Romanes did, can hardly be considered a solution of the problem. First of all, the force of heredity does not explain anything in this case. It only restates the problem. We want to know what the force of heredity is. Secondly, if the force of heredity does fail, we should have to explain why it wanes in some cases and not in others. For the reduction and elimination of rudimentary organs occurs apparently in the most irregular, haphazard manner.

But can panmixia really reduce an organ? Plate, in agreement with Spencer, Eimer, and others, denies any such possibility. An organ in a given condition of its existence varies around a mean or average, the plus and minus variations generally being equally frequent. It follows, therefore, that if all the existing variations are crossed in propagation, the organ remains stationary. Selection only improves the organ by cutting off the minus variations; the absence of selection would simply leave the organ where it was before the selection. At most it could only sink a very little below the average. That this is so is seen in organs which are not under the sway of selection at all. There are numberless such indifferent species characters, which ought gradually to dwindle and disappear, yet they remain fairly constant, though continually exposed to the swamping effect of panmixia. Panmixia may explain the functional degeneration of an organ, but cannot explain its actual rudimentation.

Weismann himself in later times abandoned panmixia as a sufficient means of explanation, and resorted to a new theory-that of germinal selection-which we shall discuss presently in detail. But first we shall deal with the theory of intra-selection. (b) Intra-Selection.

Roux in his notable work on " The Struggle for Existence Rarts of an Organism" (I88I) advanced a new " theory, by which he thought to explain the adaptations of inner structures in contradistinction to external adaptations which are due to natural selection. Basing his principle on the established fact that the very activity of an organ tends to strengthen it, he showed that parts most exped to stimulation will increase at the cost of those exposit to stimulion between the various cells and parts of an organ, leading to direct functional adaptation. Thus, e.g., the spongy tissue of the bones is arranged in a regular manner, showing a surprising fitness in its microscopical structure. Now, the direction of the tiny bone-plates is due, according to inger to the pressure exerted on the bone; where it is greatest, there bone-tissue is formed, while at the points of least pressure bone-tissue is absorbed. In this way is brought about the minute self-adaptation of inner parts, which could hardly be explained on the principle of natural selection. For it is inconceivable that principle of natural selection such minute differences in structure could value for selection to act upon

survival value for selection to act upon.
The theory of intra-selection, or, as Weismann has The theory of intra-selection, or, as Weismann has
called it, "histonal selection" (selection of tissues), has been variously estimated. It is true that Roux for the first time elucidated clearly the principles of functional stime the lo increase and disuse to decrease of the functioning part; but doubt has been thrown on his further corollary that such physiological adaptation leads to internal structural selection. Plate adduces many reasons against such conclusion. First of all, it is impossible to distinguish clearly between inor all, it is imposible to distinguish clearly betwe be in ternal and external adaptations. If the latter can be due to natural selection, there is no inherent impossibility that the former might be due to it also. Secondly, the 25 


\section{I94 THE FIRST PRINCIPLES OF EVOLUTION}

embryonic development, which is essentially nothing else than a multiplication and laying out of cell complexes, theems to show that each cell complex develops according to a definite, predeterined order, to a definite, predetermined order, depending on the hereditary qualities of the germ. Thirdly, there are many structures which do not obey the law of functional adaptation-that is, they do not improve by use, as, e.g., the teeth, the perceptive parts of the sense-organs, etc. Finally, not the best-fitted parts are selected by intra-selection, but those best situated, which situation is originally accidental, and not due to the intrinsic value of the part. Thus bone-plates are developed where the stress is greatest, irrespective of any other quality they may possess.

Kellogg is not quite so sweeping in his condemnation of Kellogg is not quite so sweeping in his condemnation of
Roux's theory. He is glad to find in it the possibility of explaining mechanically "the initiation of certain fine and delicate inner adaptations," which natural selection is certainly not able to do.

\section{(c) Germinal Selection.}

The theory of germinal selection was propounded by Weismann in 1895-96. By it he thought to overcome the many difficulties in the way of a full acceptance of a the many diffcultion in thoroughgoing selectionist hypothesis of organic evolution, without having recourse to Lamarckian factors. It was intended not only to supply an answer to the question of the degeneration of useless or gans, but also to offer an explanation for various other problems, hitherto conexplanation sidered insoluble on strict Neo-Darwinian lines. In sh.

We have seen that Roux assumed a struggle for existence between the different parts of the organism. Weismann, in his theory of germinal selection, transferred this selective in his theory of germinal selection, transelved this competition theories of heredity assume the germ cells to be constituted of minute physiological units, which in their totality give origin to the new individual. Weismann called these

\section{NEO-DARWINISM}

I95

hereditary units " determinants," because each such unit determines the quality of the cell or cell complex of the body arising from it. There is a different kind of determinant for each independently variable cell or cell complex - e.g., all the red blood-corpuscles are represented in the germ by one determinant, etc. These determinants have the faculty of growing and multiplying, just like the ordinary organic cells.* Now, seeing that only a small amount of germ substance is originally given with each individual, the determinants have to grow intensively in order to supply material for the countless young germ-cells of the adult organism. We cannot assume an absolutely even stream of food-supply among the determinants. There will be slight fluctuations, so that some will get less,
some more, nourishment. This, in its turn, will lead to a some more, nourishment. This, in its turn, will lead to a
lesser development of the former determinants, while the latter will become stronger and more powerful wit this very effect, brought about in the first instance by accidental variations of the blood-supply, will tend to prolong itself in the same direction; for the strong determinant, having greater assimilative power, will thereby draw still more nourishment towards itself; while the weak determinant, varying in the minus direction, being, as it were on an inclined plane, will tend to dwindle more and more. The latter process will continue till the final disappearance of the determinant. As each determinant is represented in the grown-up organism by its corresponding part, the latter will vary in accordance with its determinant, and be developed in a lesser degree, if its determinant is weaker, and vice versa.

In this manner Weismann explained the gradual dwindling and elimination of useless organs. It is true, admitted, that panmixia alone does not lead to an accumulation of minus variations, but in time, he argues, minus variations of the corresponding determinants will be slowly * See on this subject the textbooks on heredity, especially A. 


\section{Ig6 THE FIRST PRINCIPLES OF EVOLUTION}

accumulating within the species; for the individuals with the the smallest museful determinants, advantage in the struggle for life, their useful determinants, which represent valuable final structures, not being hampered in their food-supply by useless determinants. The initiation and slow accumulation of minute variations in a useful direction is furthered by germinal selection unti a useful direction is furthe value. Germina they are large enough to attain selective value. Germina selection, once started within the germ in a certain direction, continues automatically, and becomes thus " source of definite variations," until the latter, if harmful, are weeded out, or, if useful, are fostered and still further are weeded out, or selection. Many other phenomena improved by natural section. Many of progressive evolution, hitherto ascribed to use-inheritance, can be accounted for by this theory. Thus the degeneration of the teeth, of the little toe, the increase of shortsightedness in civilized man, may be explained by the shorline of the corresponding germinal units, while the origin decline of the corros of the specific higher human faculties, as music, etc., not immediately useful in the struggle for life, can be attributed to the same process in a positive direction. Finally, Weismann would account for accumulation of determinants. It is all due to the "invisible prelude" within the germ.

is all due to the "then would Excellent as the theory of germinal selection would appear to be in the wide application of its principle, it must be admitted that it rests on a very slender basis indeed. For it must be understood that the determinants indeed. are so far ideal, un, But even admittin fessor Weismann's imagination. But even admitting their reality, there are various considerations which tel seriously against the hypothesis. It is unlikely that any thing more takes place than an oscillation of the deterthing mean, just as in the case of bodily minants arouriour of this. Firstly, it is known that most variations fluctuate evenly around a norm. Secondly, a great number of

\section{NEO-DARWINISM}

specific characters are fairly constant, thereby showing that their determinants vary but little. Thirdly, if the struggle of the determinants lead to a persistent increase of some and decrease of others, we should see an overdevelopment of some organs and under-development of others : in other words, the embryonic development of the germ would result in monsters. This is certainly not the case. Weismann himself recognized the force of this conclusion, and assumed a sort of "self-correction" within the germ-cell which guards against the excessive development of the determinants in the positive direction, while no with regard to variations in the negative direction. But, then, the question arises: Why do not all useless organs disappear completely? Finally, experiments on the influence of food-supply on development, such as those by Weismann himself on the larvæ of flies, and by others, by Weismann himself on the larva of flis, and by others, have shown that lack of food does not lead to the loss of structures, but only to a generally dwarfed condition of the mature individuals.

(d) Coincident Selection.

We have already mentioned the theory of coincident selection as an auxiliary non-Lamarckian explanation for the survival of small fluctuating variations. Weismann had already referred to the fact that, while the initial stages of germinal variations may not always be effective in the struggle for life the innate plasticity of the organism is struggle for life, the innate plasticity of the organism is often great enough to induce individual modification which, though not inheritable, enable the individual to escape extinction. The individuals with the greatest amount of organismal adaptability will be most successful and hand down this innate tendency to their successors, and hand down this in congen in that direction. But congenital germinal variations, having the same tendency as the individually acquired modifications, will also appear and have time, under the 


\section{I98 THE FIRST PRINCIPLES OF EVOLUTION}

shelter of the individual modifications, to be accumulated in successive generations. As Lloyd Morgan puts the matter: "Where adaptive variation, $v$, is similar in direction to individual modification, $m$, the organism has an added chance of survival from the coincidence $m+v$; where the variation is antagonistic in direction to the modification, there is a diminished chance of survival from the opposition $m-v$; hence coincident variation will be fostered, while opposing variations will be eliminated."

This hypothesis would help to account for two related difficult points in the theory of natural selection. Firstly, it would explain the possibility of the slow accumulation of germinal variations in their first stages before they attain selective value ; secondly, it would make correlated adaptations feasible by supplying ontogenetic (individually acquired) modifications, until the material for the appropriate germinal adaptations arose.

It has been objected to this theory that, since the individually acquired modifications possess the main selective value in these instances, there is no reason why the corresponding germinal variations should be fostered at all. The individuals with the right, but slight, congenital variations would have no special advantage over their fellows who show no such coincident variations. Nor is there any ground to assume that the individuals with the greatest amount of plastic modification in a given direction will tend to exhibit similar innate variations to a greate degree than those individuals not possessing this plasticity.

\section{(e) Isolation.}

There are left for our consideration in connection with the theory of evolution two great problems which require solution-namely, the question of intercrossing and that preves arise, how can they prevail against the old-established forms, seeing that these, being in the majority, would tend to swamp them by mere numbers? Unless intercrossing is

\section{NEO-DARWINISM}

prevented somehow, the new form would be submerged at the very commencement of its career. On the other hand, infertility or absence of intercrossing is a prominent feature among related species. How can its genesis be accounted for, as incipient varieties are generally not infertile among themselves?

If natural selection led in all instances to the extinction of the worsted race, the problem of intercrossing would not arise at all. But in this case evolution would take place in a ladder-like manner; there would only be continuous advance in a single direction, as the progressive types succeeded each other. This, however, is not what we actually find in nature. The organic world forms a branching tree of life ; evolution is progressing in ever-diverging and rediverging lines. The battle is not only to the strong, but the race also to the swift. Many different adaptations may arise under newly imposed conditions, which, in the absence of an effective check against interbreeding of the selected types, would eventually become blended in their common offspring. In short, isolation is an essential factor in the process of organic evolution. Its importance has been variously estimated. Romanes, looking at the problem from a comprehensive point of view, recognized in isolation, together with heredity and variation, the three basal principles " on which is reared the whole superstructure of organic evolution." From this standpoint, natural selection would simply be a special case of isolation, differentiating the fit from the unfit. Of the other forms of isolation we can distinguish, with Plate, geographical, biological, and sexual isolation (or segregation), the whole of them being comprised by Weismann under the term of "amixia," or " cross-sterility." We shall discuss their merits seriatim.

Geographical isolation as a means of organic evolution was first advocated by Moritz Wagner, who in I868 propounded a "law of migration" which was intended to replace that of natural selection. He held that migration, 
200 THE FIRST PRINCIPLES OF EVOLUTION

and consequently geographical isolation, was the real factor in the formation of species. His theory failed in so far as it claimed to supersede natural selection, and to form the sole explanation of organic evolution. But the principle of geographical or topographical isolation as an prescory factor in species formation found most forcible advocacy with later evolutionists, such as Romanes, J. T. Gulick, and D. S. Jordan. Gulick, and with him Romanes, distinguishes indiscriminate isolation (separate breeding or apogamy) from discriminate isolation (segregate breeding or homogamy). In the former case isolation takes place in hiscring without any indiscriminately from among a given stock, without any reference to the qualities of the separated sections; whil in discriminate isolation the different portions of the stock are selected according to a given principle, as, for instance, when the stock is divided according to colour, and so on Now Gulick showed that, starting with indiscriminat isolation, the members thus separated by local barriers tend to vary in a given direction from the parent stock, and thus gradually verge towards homogamy. To this conclusion Gulick was drawn by his researches on the Hawaian land-snails. These exhibit a divergence in character, which varies from valley to valley, and can, according to his view, only be attributed to the effect of isolation. For there is no great variation in the climatic conditions of the whole district; while, on the other hand, the difference between any two forms can roughly be estimated by the actual distance in mileage between their habitats. It would follow, then, that mere indiscriminate isolation, which leads to local segregation of a given stock, is apt to produce increasing differentiation of the separated sections. For, as Gulick says: "No two portions of a species posses exactly the same average character, and therefore the initia differences are for ever reacting on the environment and on each other in such a way as to ensure increasing divergence as long as the individuals of the two groups are kept from intergenerating." Plate, however, would attribute their divergence rather to the combination of geographical isolation with new biological conditions, which would lead to changed habits and modes of life.

Isolation is possible between various organisms within the same habitat. If on account of pressure of circumstances a group of individuals is forced to seek new conditions of existence, it will, though living in the same district, gradually become ser and, by the assumption of new habits and features, slowly diverge from it. This is quite a common consequence of the struggle for life, and has led to the multiple varieties of specific forms we see in nature. There are numerous forms of very near related species, differing only slightly in their mor in their morphological structure and physiological habits. Any change in the breeding-time, a variation in sexual maturity, the adoption of different foods, etc., may all lead to biological isolation.

Morphological divergence brought about by isolation is often associated with cross-sterility of the modified forms. In fact, while infertility between two related species seems to be the rule, varieties of the same species are generally more or less fertile with each other. We should, then, have to explain how this sexual isolation comes about with the gradual development of varieties into species. There are two opposing theories. According to the one, sterility is the primary factor, while the morphological differentiation follows. This is the theory of logical differentiation follows. This is the theory of
physiological selection, first enunciated by Catchpool (I884), and chiefly defended by Romanes. The other theory puts the morphological divergence first, which, influencing the sexual function of the organism, leads to sexual isolation of the respective forms.

Romanes distinctly pointed out that cross-sterility is not necessarily always the initial or only form of isolation, causing differentiation of species; but he held that any other kind of isolation would prove in the long run ineffective to attain specific divergence, unless some amount of 
202 THE FIRST PRINCIPLES OF EVOLUTION

cross-infertility ultimately supervened. As a matter of fact, such infertility is a common feature between species. It has been argued, however, with good reason against this theory that physiological isolation by itself is incapable of producing any specific divergence. It presupposes that a given group of individuals, while perfectly fertile among themselves, develop a certain amount of sterility with the remainder of the stock, without showing any other morphological distinction. Now, unless this group is capable of keeping within its own circle during mating - which is impossible, as they are assumed to be distinguished by no other morphological or physiological feature-they will interbreed with the remainder, and thus be swamped. But even if they were to breed among themselves, they would still not develop in a divergent direction, for they do not differ from the main stock, according to the theory itself, in any one trait, except that of sterility.

Inter-racial infertility, then, cannot be the cause of morphological differentiation, and we must fall back on the second theory, in order to explain the relation between specific divergence and cross-sterility. In favour of this latter view we can adduce, first of all, two general biological facts. It is now established that even among well-defined species crosses are by no means impossible. For instance, hybrids of lion and tiger, or of wolf and dog, have been reared, which shows that sterility does not form a primary condition. Further, it is well known that slight changes in the mode of life of an organism will often have a profound influence on the sex system, and lead to infertility. According to Plate, sexual isolation may ensue upon morphological differentiation in various ways. There may be no direct infertility between two forms, yet, the hybrids being either constitutionally weak or-sterile, the result is the same as if the original forms were sterile with each other; or a mutual aversion to intercrossing may arise between the two forms in question, and thus lead to "preferential mating." That such " race-feeling " often exists is a well-

\section{NEO-DARWINISM}

203

known fact. Darwin mentions several such instances from among higher vertebrates, and it has even been observed in lower animals. Recognition marks often aid in keeping the different breeds apart.

How this racial aversion arises is difficult to tell. In many cases it may be handed down as a habit from generation to generation. Where no direct tradition is established-as when the young never see their parents-it must be assumed to arise as a germinal variation, together with the morphological traits. Whenever such race aversion arises, specific divergence takes place; while no polytypic evolution is possible unless this or some other form of isolation is present.

Crossing may be made impossible by direct changes in the sexual organs. These changes may affect either the external copulating apparatus or the more subtle "sexual affinity" which exists between the male and female germcell.

Finally, according to Wallace and Weismann, incipient infertility between varieties may be gradually increased by the action of natural selection. Wallace's argument is as follows: If in a given region two related forms are adapted to slightly different conditions, the hybrids between these varieties will on the whole be less adapted. They will, therefore, be weeded out by natural selection if they are less fertile than the pure breeds. If, however, they are just as fertile as the parent types, the whole population will form a mixed race, which will, on the whole, be less well adapted to the environment. It would follow that in the struggle for existence between two such regions the species with the mutually infertile varieties would be favoured by natural selection. Species with varieties which are infertile inter se would tend to displace species with mutually fertile varieties.

There are several arguments to be adduced against Wallace's conclusion. Darwin himself did not see his way to accept this theory. The facts that sterility fre- 


\section{THE FIRST PRINCIPLES OF EVOLUTION}

quently exists between species not inhabiting the same region, and that there are cases of reciprocal crosses, where one form can be fertilized by the other, but not vice versa show that sterility does occur without the help of natural selection. Furthermore, Plate reasoned that all that would happen in the cases adduced by Wallace would be an elimination of the hybrids in both instances, only it would be somewhat slower with the mutually fertile varieties. If the infertility were correlated with an indifferent character, natural selection would not be able to influence it at all. On the other hand, if there existed correlation with a useful trait, the combination of such traits in the hybrid should act rather favourably than otherwise, seeing that, according to Wallace himself, " the offspring of crossed unions will be more vigorous on account of the cross."

We have already mentioned that there are two additional factors which effectively dispose of the difficulty of intercrossing. In Mendelian inheritance the hybrids of the original strains breed out pure in the next generations in spite of the initial blend, so that, whenever a new character follows the Mendelian law, there is no fear of its being swamped even without isolation. The other factor-that of mutation-we shall discuss fully in the next chapter.

\section{CHAPTER IX}

THEORIES OF EVOLUTION-Continued

WE have so far dealt with the two most prominent theories of organic evolution, and have seen that neither of them offers a complete solution of all the problems involved. Darwin's theory of natural selection, after its first triumph, has in later days been discovered to be weak at many points, and has had to be propped up with various auxiliary hypotheses. Some people in whom, it would seem, the wish was father to the thought, saw herein the complete breakdown of the modern theory of organic evolution. It will have become evident from the foregoing, however, that the principle of evolution does not stand or fall with Darwin's explanation of it. Side by side with the criticism of Darwin's theory a good deal of constructive work has been going on, and as the outcome we have several new theories which are competing with the old ones in their aim of supplying the key to the problem of organic evolution. Some of these theories are wholly antagonistic to natural selection; others, again, whilst trying to replace it would allot to it a not unimportant secondary position.

We can distinguish two main modern schools-the mutationists, who look upon discontinuous variations (mutations) as the material of organic evolution (heterogenesis), and those scientists who assume a determinate progressive movement in the organic world as an intrinsic part of its organization (orthogenesis). 


\section{Heterogenesis.}

Darwin distinguished two kinds of variability in organisms. First there is definite variability, "when all, or nearly all, the offspring of individuals exposed to certain conditions during several generations are modified in the same manner." These are now called " modifications" or " som mow "somatic (bodily) variations"; for according to the parental body generally accepted belief, they affect the parental body only, and are not transmissible to the offspring. Darwin himself, as we have seen, held them to be inheritable to a certain extent, and saw in them an accessory means of ceranic evolution. The second kind of vability is the ind fite of shows no indefnite or spontancous; " the endless slight peculiarities definite direction, leading to " the endless slight peculiarities which distinguish the individuals of the same species" spontaneous, because no known cause could be assigned to it by Darwin. "Occasionally even strongly marked differit by Darwin." " "ccasionions of structure so strongly proences appear "' deviations of structe "monstrosities.". nounced as to deserve to be "called "monstrosities." These are the " single variations" or "sports" of Darwin Since Darwin's time a good deal of light has been thrown on the problem of variation. We now call Darwin's indefinite variations "germinal variations"; for they have ben found to be due to the intrinsic structure of the been found to be due to the intrinsells themselves. Of hereditary substance of the germ-cells themselves. O germinal variations there are two kinds-the Darwinian individual variations, now termed " fluctuating" or "continuous variations," and the discontinuous variations, to which belong Darwin's single variations or sports. As to which belong Darting " because they the former, they are called "fluctuating because they fluctuate around an average or mean. They can be arranged in a continuous graduated series, which can be represented by frequency-curves. In Fig. 76 the statur of men in inches is plotted along the horizontal line, while the distance of the curve from that line indicates the number of men of each given height. We see that, as the men approach the average or mean stature, their number gradually increases, only to decrease again pronurtion portionately, shew Darwin based the process of organic eving varions, which, accumulation of the small fluctuating variations, which, taken up by natural selection and directed into definite lines; lead gradually to the origination of new species. Extreme variations or sports do occur at times, but though they may give rise occasionally to new breeds-instance

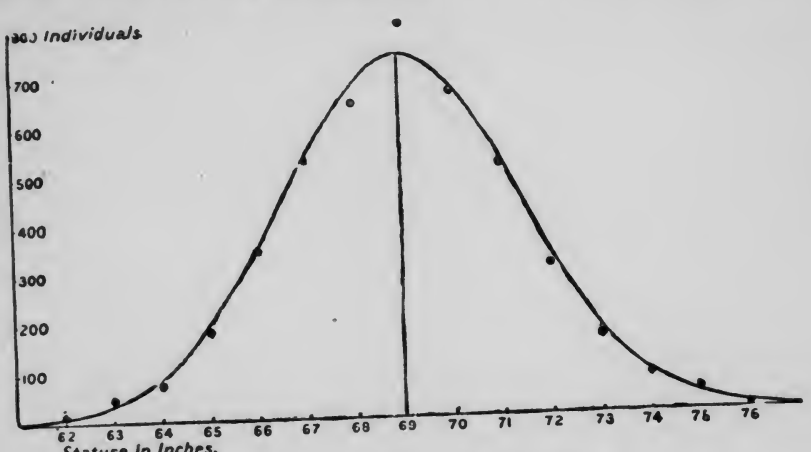

Fig, 76-Curve of Stature.

From "Recent Progress in the Study of Variation," by R. H. Lock.)

the Ancon sheep, the Niata cattle, etc.-they are too rare the Ancon are therefore unable to form the main material for new species.

to form the main material for new species.

Now the mutation theory (or heterogenesis) lays stress precisely on these discontinuous variations as a means of organic evolution. The idea of progressive development of species by steps or jumps has been advocated from time to speris to time. Von Kollick propliscories (in I900) of the as early as 1864. The rediscoveries (in rich inheritance Mendelian laws of heredity, according to which inheritance takes place by definite unit-characters not merging int 
each other ; further, the studies of Bateson and others on the discontinuity of variations, gradually led scientists to a new view of the process of organic evolution. Korschinsky new view or the process formulated a theory of heterogenesis in a the new school is (1899-1901). But the main exponent of the new school is the Dutch botanist Hugo de Vries, who embodied his labours in his work on "The Mutation Theory" (I900), which has become a classic on the subject, and later in a more condensed form in his book " Species and Varieties, their Origin by Mutation" (I906).

To somewhat into To understand his position, we must go somewhat into his account of biological species. It is well known that Linnæus was the first to establish the species as a unit of classification, believing them to be the permanent entities originally created. Before his time the genera held this rank and the species and subspecies were supposed to be rank, an the st it is a commonplace now how Darwin derived from them. It is a comution of all organic beings, demonstrated the gradual evolution of all organic beings, showing that species originated from varieties, the latter being but " beginning species." It is clear from this that species, as originally conceived by Linnæus, are merely comprise a greater or conver number of subspecies or varieties. On closer smaller number of suspecies or varies's investigation examination, now, it is found, as De Vries's investigation show, that these smaller units are by no means all equivalent to each other. In some cases all the subdivisions are of equal rank; they seem to have no central important form from which they can be derived. They are distinguished from wherences in nearly al from each other by a number their organs and qualities, which differences are due to newly arising germinal units. Such forms De Vries desig nated as " elementary species." Thus the ordinary systematic species of the whitlow-grass (Draba verna) and of the violet (Viola tricolor) consist of numerous well-defined subviolet (Viola tricolor) conmerising over 200 such constan species, the forme con a parent-species, by varieties are clearly derivative from a parent-species, by the addition (of a previously lost) or the loss of a single marked characteristic. These are the varieties in $\mathrm{D}$ Vries's sense. It must be pointed out at once that elemeries as De Vries's varieties, originate mentary specinge sudden change of by mutationthe germinal substance. New forms are establshed by mutation in one step; they are from the very beginning fully developed in all their characteristics, as the extensive researches of De Vries on the evening primrose (Enother researchia) have shown, and they breed true. The mutalamarckiana) harent organism ; but tion, then, does not alter the origin the main line forming new branches, as it were, arise from the main line, forming independent constant species at the side of the parentspecies. Draba verna, according to this interpretation, would have to be looked upon as a conglomerate of elementary species, all having originated by mutation. The new mution species in mutations mey be the battle of life, they may be indifferent, or the mas harmful. In the last case natural selection steps in and removes them, just as in Darwin's theory. It is through the weeding out of a number of arising mutations that gaps the evolution, allowing us to make are pror taxicens in the organic world. The larger taxonomic division mutation theory, then, as is apparent, is in direct opposition to Darwin's view of the slow persistent change of species through the gradual accumulation of small individual variations. On the other hand, De Vries's hypothesis variation the agrees with De must understand that ultimate deciding factor, survival of the fittest implies here, as Th. H. Morgan has * Korschinsky denies that adaptation, which comes Natural through the struggle for erganic

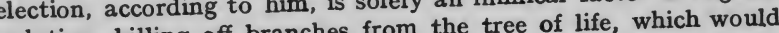
" organic world (see the section on Orthogenesis). 
2I0 THE FIRST PRINCIPLES OF EVOLUTION

put it, the survival of the fittest species (in the De Vriesian sense).

The continuous variations which Darwin relied upon as the material of organic evolution,* De Vries regards as bodily mortifications. He sees in them the mere effect of the conditions of nutrition in the largest sense-light space, temperature, etc. Such "fluctuations" are, according to De Vries, who is an anti-Lamarkian, not inheritable, and cannot, therefore, have anything to do with the development of specific forms. Selection may take place from among these, fluctuations, but such intra-specific selection, as De Vries calls it, must soon find its limit after a few generations. Moreover, according to Galton's law of regression. it is liable to revert towards the old level, unless selection is kept up to revert towards the old level, unless selection is kept unsting. $\dagger$ Mutations, on the contrary, are constant from the beginning, and remain so in successive generations. They are therefore able to hold their own without further selection, except in so far as mutations not adapted to their surroundings succumb in the struggle for existence. The mutants themselves show fluctuating variability of their own, which, however, does not affect their intrinsic qualities. The same mutations arise in a number of individuals of the same species over and over again. De Vries assumed that there exist active periods of mutation for each species, occurring from time to time and alternating with periods of quiescence, which may last hundreds or thousands of years.

It must be distinctly understood that mutations are not necessarily large. The steps may be slight, though each step means a definite constant departure from the parent type. The fundamental point of De Vries's conception

* Darwin originally laid the chief stress on single variationsi.e., the mutations of De Vries-but, owing to the criticism of Fleeming Jenkin on the effect of swamping, he changed his views, and adopted the individual variations as the main material of organic evolution.

$\dagger$ See on this point the textbooks on heredity (Biometrics).
HETEROGENESIS

2II

of mutations is that they are due to germinal unit characters. Each germinal change involves a distinct step there being no gradations between the different units. This view accords well with the Mendelian theory of heredity, according to which individual parental traits are heredity, according to which individual parental traits are represented in the germ by distinct units, which may crosses between varieties (De Vriesian mutant-varieties) Mendelize, that is, follow on breeding the Mendelian law of inheritance.

law of inheritance.
Now, what is the evidence De Vries has to offer for his theory of mutation? Apart from general theoretical considerations and an analysis of an abundant mass of botanical facts, his main work consists in researches on the mutations of the now famous evening primrose of the mutations of the now famous evening primrose of at home in America and is generally cultivated in gardens, De Vries found growing wild in a potato-field near Hilversum Amserdam he considered to be two new related elementary speciesviz., Enothera brevistylis and $\mathscr{E}$. lavifolia; the former, as the name indicates, with short style, the other smoothleaved. $\mathrm{He}$ transferred the plants for experimental observation. The self-fertilized parent-form of the observation. The self-ertilized parent-form of forms, which proved to be constant. Fig. 77 shows the various mutations which appeared in the successive generations, the horizontal lines giving all the descendants from the lamarchiana parents for each year. Cultures from other CEnothera forms produced similar results.

It must be admitted that, apart from the botanical evidence, the zoological side of the question is represented only by a few observed cases of mutations. Still, the exprime acumen in marshalling his facts have convinced a good many evolutionists of the value of his theory, the more so as Darwinism of the old type has been rather oppressed of late with objections, 
2 I2 THE FIRST PRINCIPLES OF EVOLUTION

which the mutation theory seems in a much better position to to overcor as against Darwinism. It advantages of this theory as against Darwinism. accounts without difficulty for the incipient stages in the development of organs; for organs, arising by mutation, may persist, even though they possess no value for th me danger of swamping is lessened, as mutations race. The danger on arise repeatedly over and over again, and are constant from the beginning, etc. In spite of all this, it would be wron to substitute the mutation theory for Darwinism in toto and to imagine that it is able to solve all the difficulties o organic evolution, as Th. H. Morgan seems to indicate.

\begin{tabular}{|c|c|c|c|c|c|c|c|c|}
\hline $\begin{array}{c}\text { Genera- } \\
\text { tion. }\end{array}$ & gigas. & $\begin{array}{l}\text { O. } \\
\text { albida. }\end{array}$ & $\begin{array}{l}\text { O ob- } \\
\text { longa. }\end{array}$ & $\mid \begin{array}{c}0 . \\
\text { rubri- } \\
\text { nervis. }\end{array}$ & $\begin{array}{l}\text { Onothera } \\
\text { lamarckiana: }\end{array}$ & $\begin{array}{l}\text { O. na. } \\
\text { nella. }\end{array}$ & $\begin{array}{l}\text { O. } \\
\text { lata. }\end{array}$ & $\begin{array}{l}\text { O. scin- } \\
\text { tillans. }\end{array}$ \\
\hline I. & - & - & - & - & 9 & - & - & - \\
\hline II. & - & - & - & - & I 5,000 & 5 & 5 & - \\
\hline III. & - & - & $\overline{76}$ & -8 & Io,000 & $60^{3}$ & $\begin{array}{r}3 \\
73\end{array}$ & \\
\hline IV. & I & 15 & 176 & 8 & $\begin{array}{r}14,000 \\
8,000\end{array}$ & 49 & $\begin{array}{r}73 \\
142\end{array}$ & $\begin{array}{l}1 \\
6\end{array}$ \\
\hline VI. & - & $\begin{array}{l}25 \\
11\end{array}$ & $\begin{array}{r}135 \\
29\end{array}$ & $\begin{array}{r}20 \\
3\end{array}$ & $\begin{array}{l}\text { I } \\
18,00\end{array}$ & 9 & 5 & I \\
\hline VII. & - & - & 9 & o & 3,000 & II & - & 二 \\
\hline VIII. & - & 5 & I & o & 1,700 & $2 I$ & I & \\
\hline
\end{tabular}

Fig. 77.-Mutations of Enothera
De Vries.)

He himself has pointed out that there is so far no evidence to show that successive mutations "heap up " new charto show that succindaacters in defite value of mental problem of organic evolution. As to the value of the mutation theory in itself, there seems to be no doubt
that it stands on firm ground as regards the experimental the question is whether mutations are a common eno organic world to serve as the enoughelf, though of mutations as being frequent, estimates he often speaks of mutations as being frequent, estimates their average appearance as from I to 2 per cent. only of the parent-stock. Seeing that the majority are
HETEROGENESIS

weeded out again in the struggle for existence, there seems to be little chance for them to yield enough material for progressive evolution.

The further question arises, whether the individual variations of Darwin can be brushed aside in such a wholesale manner as De Vries has adopted. Plate sees in De Vries's mans nothing but a complete misunderaccount of Daries mistook Darwin's individual variations, and classed them as non-inheritable Lamarckian modifications, while Darwin himself speaks of non-transmissible and transmissible characters, and took only the latter as the material of organic evolution. The truth is that Darwin did not clearly distinguish between the two kinds of variations, nor was there made at his time the two kinds of variations, nor was there made at his time a clear difference between continuous and discontinuous variations, except in so far as sports were known, which as the name implies, were looke un studied more minutely, and we have now two campsstudied more minutely, and we have now two campstinuous and discontinuous variations, and the biometricians, who do not acknowledge any such dividingline. At present it is difficult to decide between line. At present it is diffcult to dohannsen's these schools. It would appear from Johannsen's experiments "On the Inheritance in Populations and Pure Lines" that selection in populations (i.e., mixed strains or lines) leads to a change of type by sifting out successively the intercrossed deviating lines. There takes place sively the "purification" of the strains, until at the end a gradual "purification" of the strains, until at the end practically one pure line is left, which cannot further be a single ancestor) would thus correspond to an elementary specie of De Vries. On the other hand, the same author species of De the variations of mixed populations, proving thereby that they are not a differentiating mark between modification and variations, as De Vries thinks. Besides that, as 
212 THE FIRST PRINCIPLES OF EVOLUTION

which the mutation theory seems in a much better position which the many to overcome. this theory as against Darwinism. It advantages of this the incipient stages in the accounts without difficulty for the incipient stages in the development of organs; for organs, arising by mutation, may persist, even though they possess no value for the race. The danger of swamping is lessened, as mutation race. The dang over and over again, and are constant from arise recald be wron the beginning, etc. In to substitute the mutation theory for Darwinism in tolo, and to imagine that organic evolution, as Th. H. Morgan seems to indicate.

\begin{tabular}{|c|c|c|c|c|c|c|c|c|}
\hline $\begin{array}{c}\text { Genera- } \\
\text { tion. }\end{array}$ & gigas. & $\begin{array}{l}\text { O. } \\
\text { albida. }\end{array}$ & $\begin{array}{l}\text { O ob- } \\
\text { longa. }\end{array}$ & $\begin{array}{c}\text { o. } \\
\text { rubri. } \\
\text { nervis. }\end{array}$ & $\begin{array}{l}\text { Enothera } \\
\text { lamarckiana: }\end{array}$ & $\begin{array}{l}\text { O. na. } \\
\text { nella. }\end{array}$ & lata. & $\begin{array}{l}\text { O. scin. } \\
\text { tillans. }\end{array}$ \\
\hline I. & - & - & - & - & 9 & - & - & - \\
\hline II. & - & - & - & 二 & $\begin{array}{l}15,000 \\
\end{array}$ & $\begin{array}{l}5 \\
3\end{array}$ & $\begin{array}{l}5 \\
3\end{array}$ & 二 \\
\hline $\begin{array}{l}\text { III. } \\
\text { IV. }\end{array}$ & $\bar{I}$ & $\overline{15}$ & 176 & $\overline{8}$ & $\begin{array}{l}10,000 \\
14,000\end{array}$ & 60 & 73 & I \\
\hline v. & 1 & 25 & 135 & 20 & 8,000 & 49 & 142 & 6 \\
\hline VI. & - & II & 29 & 3 & 18,00 & 9 & 5 & I \\
\hline VII. & - & - & 9 & o & $\begin{array}{l}3,000 \\
700\end{array}$ & $\begin{array}{l}111 \\
21\end{array}$ & I & 二 \\
\hline
\end{tabular}

De Vries.)

He himself has pointed out that there is so far no evidence He himsef has poin " heap up " new charto show that succling acters in definite lines, which, after all, remains the fundamental problem of organic evolution. As to the value of the mutation theory in itself, there seems to be no doubt that it stands on firm ground as regards the experimental ther mutations are a common facts. The quastion in the organic world to serve as the enough occurrence in the organic wries himself, though in the organic world to serve as the he often speaks of mutations as being frequent, estimates their average appearance as from I to 2 per cent. only of the parent-stock. Seeing that the majority are

\section{HETEROGENESIS}

weeded out again in the struggle for existence, there seem to be little chance for them to yield enough material for progressive evolution.

progressive evolution. The further question arises, whether the individual valations of Darwin can be brushed aside in such a wholesale manner as De Vries has adopted. Plate sees in De Vries's account of Darwin's views nothing but a complete misunderstanding. He tries to show that De Vries mistook Darwin's individem as non-inheritable individual variations, and cla wile Lamarckian modifications, while Darwin himelf speaks of non-transmissible and transmissible characters, and took only the latter as the material of organic evolution. The truth is that Darwin did not clearly distinguish between the two kinds of variations, nor was there made at his time then and discontinuous a clear differen betw variations, except in so far as sports were known, which, as the name implies Since his time, however, the laws of variation have been studied more minutely, and we have now two campsthe mutationists, who differentiate sharply between conthe biometinuous and discontinuous variations, and the biomedo not acknowledge any such dividingline. At present it is difficult to decide between these schools. It would appear from Johannsen's experiments "On the Inheritance in Populations and Pure Lines" that selection in populations (i.e., mixed strains or line) leads to a change of type by sifting out succesor lines) leads to a change. type by sieting out successively the intercrossed deviating lines. There takes place a gradual "purification" of the strains, until at the end practically one pure line is left, which cannot further be improved upon. Such a pure line (i.e., a line derived from a single ancestor) would thus correspond to an elementary a single a species of De Vris. has shown th variations of mixed populations, proving thereby that they are not a differentiating mark between modification and variations, as De Vries thinks. Besides that, as 


\section{I4 THE FIRST PRINCIPLES OF EVOLUTION}

W. R. F. Weldon commented in his review of De Vries's "Mutation Theory," we are at the present stage of our knowledge unable to say how much of an organism is due to environmental factors, how much to the inborn germinal factor.

\section{ORTHOGENESIS.}

The outstanding problem of organic evolution still reThe outstanding pronce the variations which form the mains uns of necies? The Darmaterial for the origination winian theory of natural selection gives no answer to this question. It only deals with the selection of specific traits which from a "wholly fortuitous, miscellaneous, indewhich from a "wholly terminate "mass of variations lines of development. This process, which may be called " orthoselection," must be distinguished from orthogenesis, which implies that the original lines of variation are from the very beginning limited to a few well-marked directions ; that, in fact, the evolution of the organic world is due to an inherent growth of the organism. This organic due to an intalism maintain, a congrowth is, as the upholderion dition sui generis of the living substance, independent of the influence of external physical conditions ; while others, like Eimer, Cope, etc., more in accordance with the mechanistic interpretation of life, would rather attribute organic istic intereen the living organism evolution to the interict deal first with

the mechanistic theories, then with those of the vitalists.

\section{(a) Mechanistic Theories.}

Whilst discussing the difficulties of the Darwinian theory, we mentioned two auxiliary hypotheses of natural theory we mow definitely selection, both devised in order to shout, at least in directed adaptations may be brought about, at least in their beginnings. by mechanical principles. Roux's intraselection and Weismann's germinal selection may both be looked upon as selectionist attempts at an orthogenetic

\section{ORTHOGENESIS}

explanation of variations, though both theories soon hand over their further elaboration to the exclusive control of natural selection. Lamarckism, too, by its insistence on the accumulating effect of use and disuse and the direct result of persistent functional stimuli, is in a sense a theory of definitely directed lines of development. As a matter of fact, the two most prominent mechanistic theories of fact, the two are orthogenesis, those of Professors though Eimer himself, based on Lamarckian principles; though Eimer himself, who first propounded a definite theory of orthogenesis is not identical with Iamarckism.

Professor Eimer was led to the discovery of the principle Professor Eimer as a means of organic evolution by his intimate studies on the dark blue wall lizard (Lacerta muralis cerulea) of Capri. He showed that the markings of the lizard followed definite rules. Similar principles were found to apply to other classes of animals-beetles, Several laws of orthogenesis have thus been enunciated by him: (I) The markings of animals in general do not occur haphazard, but are determined by the laws of growth. The primitive longitudinal striping is transmuted into spots; these by confluence striping is tranc; while the last of a regular series of successive markings (Fig. 78) (2) "The new markings (or other morphological characters of the body covering) appear on the body of the animal from behind forward and from above downward, or conversely, whilst the old ones disappear in the same direction "The male is ordinarily a step or so "(3) "The male is ordinarily a step or so in advance of the female in expressing the direction of development, though there may exceptionally occur female preponderance." (4) “A succession of transformations, each following the other, runs along over the body of the animal" in a wave-like fashion. (5) "The same directions of evolution a may be operative (5) "The same direction mediately related forms, and may lead to quite similar 


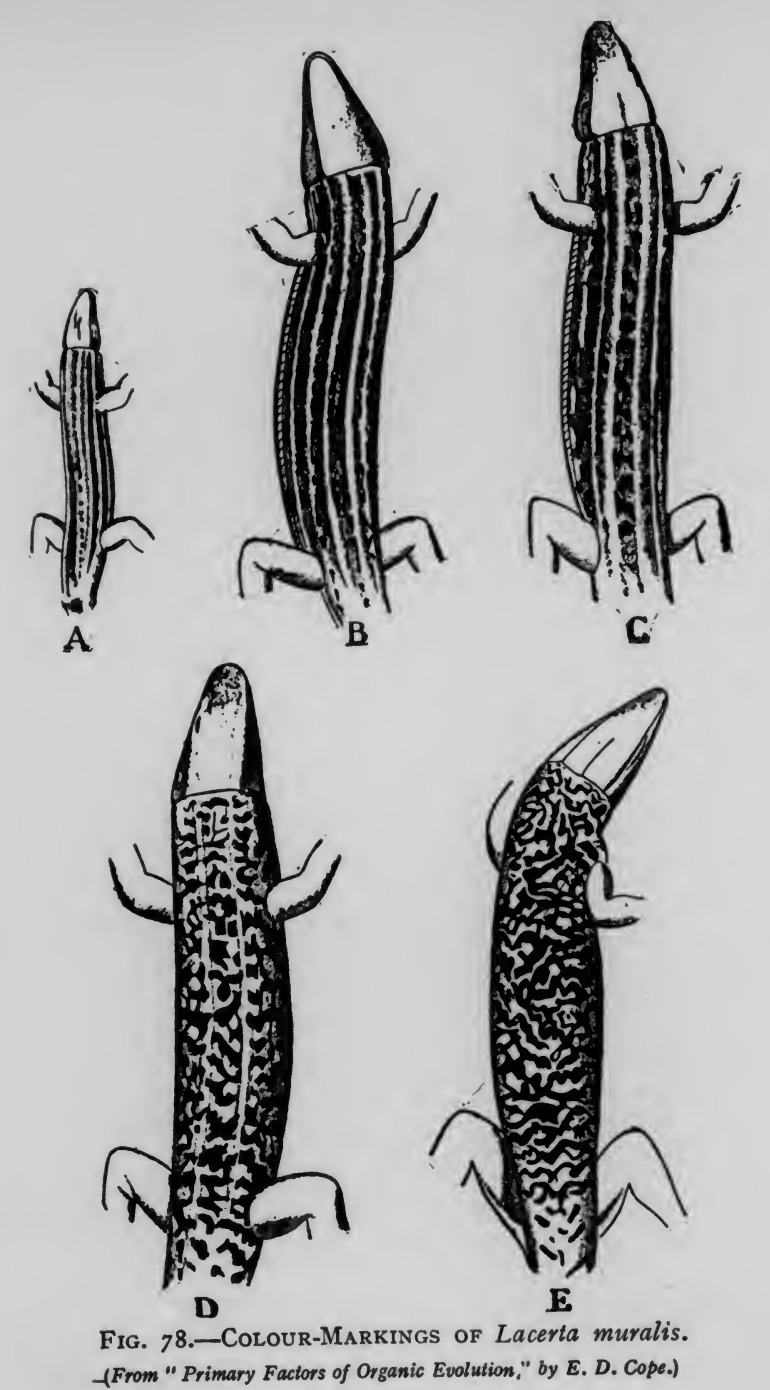

morphological results." (6) “Different characters may mevelop in the same organism in different degrees and in develop in the directions of evolution different directions." may get reversed and long remain at a standstill at (8) "Evolution may often long remain at

a definite stage" (genepistasis) ; etc., etc.

In order to fully understand Eimer's views, we must point out that, according to him, the whole organic world forms a continuous growth (phyletic growth), which is merely the sum of modifications due to the grow the outseparate individuals. Such individual seprer in come of the interaction of inner constittion warm external environmental conditions (lood, warmily leads to It is the variety of external factors which necessarily leads to variety of growth, so that his theory thus takes for granters. with Lamarck, the inheritance of acquired characters. Organic evolution is thus nothing but phyletic growth, broken up into separate units (species, etc.). Such diferentiation of distinct species takes place by genepistasisthat is, some organic forms become arrested in their that is, sole cessation of developgrowt , whe organism, ment may affect some of the fhar process of isolation while others progress. No further proces the various is necessarily called to aid in order to keep the various species distinct. Natural selection only acts subordinately as an eliminating factor of unfit species.

Professor Cope's theory is similar in its principles. He Profesor Cothmism). "It is the too, assumes a growth modifications of this energy which contitute The interaction of this growth-force with external stimuli results in physiogenesis and kinetogenesis, according as the influence is physico-chemical, affecting the organism directly, or mechanical, affecting the organism indirectly directlyse. He also posits a through the effects of (archesthetism), " preceding in primitive consciousness part of time and in history the evolution of the greater part of plants and animals." "Life is," according to this theor 


\section{I8 THE FIRST PRINCIPLES OF EVOLUTION}

" energy directed by sensibility." Cope produces a vast mass of palæontological facts showing definitely directed mass of palaontolo regard to osseous struclines of evolution, estc.), of vertebrate animals.

the (bones, the whole, the It must be admitted that, on the whonesis is great in favour of determinate variation by orthogenesis is great in amount, though it remains a moot point whether all in amount, tho in a few well-marked grooves. Orthogenesis variations run in an explanation to some of the vexed certainly supplies an explanation to some the first beginnings of problems of evolution. It explains the first beginnings of variations; it accounts for the excessive formation of certain features in animals which so often lead to the extinction featuresessors. It also affords the key to the paralle of their possessors. It also afferent lines of evolution and lead development seen in differes in different classes of organisms ing to analogous structures in differe pigment spots of -as when a lens, e.g., is added to the pigm

many lower otherwise unrelated animals, etc.

The one drawback of the orthogenetic theories lies in the fact that they are based on the inheritance of acquired characters, which so far is not a substantiated fact of science. But, as Plate says, it is well conceivable that orthogenesis may hold good without the necessity of this ortherion variaassumption, as long as in the germ-cells directly through tions may be induced in the gernal

(b) Vitalistic Theories.

All the based All the theories that we for on a mechanistic interpren of life exhibited by the granted that the phenoll as by the race, are explainable individual organism, as well as by the race, are explainable -or will be explainable-by the interaction of physicochemical forces. This mechanistic school, though succhemical formly establishing once for all the theory of cessful in firs of the gradual transformation of species against lost prestige - belief of special creation, has of late largely lost prestige

\section{ORTHOGENESIS}

219

satisfactory theory of the mode of evolution. We have seen that there exists a superabundance of theories and auxiliary hypotheses, without there being any single one which is able to solve the problem in its entirety. Partly on the strength of this negative criticism, partly from a positive basis of its own, the newly arising school of NeoVitalism rejects in toto the Darwinian or any other mechanistic explanation of evolution, and substitutes for it a teleological interpretation. They maintain that life is in its ultimate essence more than a mere conjunction of physico-chemical forces, that the actions of organized beings proceed teleologically-i.e., purposefully-and that therefore a special vital principle must be assumed, which, whilst controlling the energetic forces of the organism, is itself not subject to the laws of matter and force. Seeing that all life is dominated by a teleological factor, evolution, too, can find an explanation only on the assumption of inherent final causes.

Such an internal "automatic perfecting principle" as a means of the progressive development of the organic world was first proposed by Carl von Naegeli in his "Mechanico-Physiological Theory of Evolution" (I884), without, however, finding any wide acceptance.* It is only of late that the vitalistic school, mainly represented by German biologists, has brought the " autonomic factor " once more into prominence.

We cannot here enter into a detailed discussion of the various theories of neo-vitalism, but shall review shortly the three main trends of thought, as distinguished by Plate-viz., the agnostic, the psychical, and the metaphysical.

Agnostic vitalism, as defended by G. Wolff, denies the possibility of a mechanistic explanation of biological problems, but refrains from advancing a vitalistic solution of its own as still being beyond our understanding. In

- Naegeli himself looked upon such a principle as by no means indicative of vitalism. 


\section{THE FIRST PRINCIPLES OF EVOLUTION}

other words, it gives up the problem for the time being.

The psychical vitalism of Pauly, Francé, and others, goes back in its principles to Lamarckism, which includes in its teachings a psychological element as a formative factor of organic progress. Lamarck's theorem that " inner feelings " create desires in the organisms, and thereby lead to the fulfilment of such desires by the development of existing or the creation of new organs, is considered by many authors as a vitalistic principle, and is certainly claimed as such by modern psycho-vitalists. They have, however, extended this principle, and maintain that all organic happenings - those of the most primitive organisms as much as those of the highest rational beings - are in the last instance dependent on a psychic element. According to this theory of voluntarism, as it is also called, we should have to assume that every cell has an understanding, a soul, which enables it to act purposefully for the fulfilment of its own ends. The only and final objection against such an assumption is that it gives an unwarranted extension to the meaning of the terms consciousness and thought, which are generally reserved for organisms with a developed nervous system.*

Coming now to metaphysical vitalism, which represents the most prominent school of this mode of thought, it assumes as the basis of all vital phenomena a non-energetic, immaterial force, which directs and transforms the energies of the living organism in a teleological sense. H. Driesch calls this immanent, autonomous principle the " entelechy," borrowing the term from the Aristotelian "entelecheia "i.e. "that which has the end in itself." Reinke speaks in a similar sense of "dominants." The same force as determines the development and form of the organism is also responsible for the development of the race, which thus

* It must be remarked that a psychical factor does not necessarily imply a vitalistic interpretation, unless we assume that psychic phenemena are eo ipso of the vitalistic order. roceeds according to an immanent teleological final cause.

Finally, we must mention in this connection the "Creaive Evolution" of the eminent French philosopher Henri tive Evolution most Bergson, who in his book has work in the field of evolution profound and since the days of Darwin. viously mentioned, a vitalist, believing in a "vital impetus "; but he differs from them in this respect, that he does not attribute to life a teleological tendency. "Hardoes not ather behind us than before. It is due to an mony is rather as common aspiration, identity of impulsion, and is the fundal cause of It is the vital impetus which is the fundamies of unforevariations. Life creates a continuous series of unfor seeable forms during the evolutionary process, which "splays out like a sheaf," the different divergent lines being " splays out like a sheaf," "The evolution of life is somemutually complementary thing other than a series of adaptations of a plan. cumstances, also it is not the realization of a plan. . . Evolution is a creation unceasingly renewed; it creates Es it goes on, not only the forms of life, but the idea that as it goes on, not only the understand it." Adaptation to will enable the intellect to uns only "the sinuosities of the external conditions explains only " the movement itself, movement of evolution." Evolution, the movement itself, is due to the original " internal push, that has carried life, by more and more complex forms, to higher and higher destinies."

The main "tendencies" of the evolutionary lines into The mided itself, are followed by which the current of life has divided itself, are followe Bergson in a most ingenious and original manner. He sees in the identity of the original vital impetus the explanation in the identity of thelopment in different classes of organisms of the parallel development in similar structure of the as, for instance, the origin of the simsiar structure ortebrata.

eye in such different classes as molluscs and vertebrata. As to the metapho details of his masterly exposimust reluctantly forgo the details of hife and matter. We must 
222 THE FIRST PRINCIPLES OF EVOLUTION

(he usual understand, howe order of events. According to her, cutting it out of "the duce life, but life creates matter,

continuity of becoming " according to individual needs.

How far does metaphysical vitalism succeed in solving

the prot it

the problem ofigin of variations that the in the explanation of the origin is mechanistic theories fail. This is the mow, do the levelled against the Darwinian school. Now, do vitalists show a better result here ? Do they account for vitals setaphysical principles ? the happenings of lif In the first instance, is end ? Many phenomena of tended towards a harm to life certainly occur which point to such a died out through mere fact that so many organic forms have died out thro lack of adaptation; further, that misformed organisms lack vital factor often fails in sometimes arise, show adherents of this this supposed the dilemma by assuming that doctrine have tried to escape the dilo but "aimfulness" not purposefulness (Zweckmassigheid), but " (Zielstrebigkeit) alone is sufficient to characterize the oranism, the end not necessarily being attainable. But organism, the end no teleological principle of life is with this admission

practically given up.*
Do such explanations as entelechy, dominants, vital impetus, etc., really carry us any further in our underimpetus, etc., really carry us any further in our units that standing of organic processes ? Reinke himseived by our the action of his dominants cannot be conceived by oume intellect. They certainly cannot be verifed, and Howeve applies to all the other metaphysical categor of the evoluvivid and impressive Bergson's illumination of the evolutionary process may be, examined carefully it turns out to be no more than a description of the different lines of to be original vital evolution so far as not tell us why it was constrained to movement, but does not tell us whe condemns radical finalism as much as radical mechanism.

\section{ORTHOGENESIS}

223

break up into different tendencies, and that of a particular kind and in a particular order ; and this is, after all, what we are seeking for.

\section{Conclusion.}

Having traced our course through the intricacies of modern evolutionary theory, what do we find as the result of our rather prolonged inquiry? It has become evident that the problem is by no means so simple as the pioneers f evolution thought. And, we must add, the difficulties heve overcome by their successors. he the transOne thing is sure, however : organic evolution or the transformation of living beings has been established as a scientific fact on a sufficient and independent basis, and is now the accepted creed of the age. The only question is: How has this progressive differentiation of the organic world come about? Here it must be said that, while there are now a good many scientists who would discard natural selection as a satisfactory mode of explanation of the origin of species, there are very few indeed who would not allot to it at least a secondary influence. If it is not "guiding the ramifications of the tree of life" in any case "it applies the ramifications of the tree of life," in any case "it applis the pruning-knife to them," lopping off useless branches, and thus making room for the development of the fittest. Natural selection is at present, so far as it goes, the only acceptable theory of adaptation ; for Lamarckism canno be considered as proven, so long as its basis. the inheritance be consiced as provedished and of acquired characters, has not been established, and teleological vitalism, whilst assuming

But-and here it is that the deficiency of natura selection makes itself apparent-while natural selection explains the further development of adaptive variations, explains the further dervival-value, it certainly cannot ance they have attained survival-value, it certaint for the "origin of the fit." This is the central account for the "origin of the fit." This is the central mutation theory, by assuming large mutations instead of 
small variations, overcomes one weak point of Darwinism, that of the progressive accumulation of small initial steps ; but, still, it simply posits the mutations : it does not account for their accumulation in definite directions (save by relying on natural selection). Orthogenesis seeks to overcome both these difficulties by crediting the organism with an innate tendency towards directive lines of variation. It thus solves the problem of the beginning of variations, before natural selection is able to take hold of them. But it is still left an open question why the organism varies in definite directions. Eimer and his adherents would attribute the directive influence to the effects of the environment upon the organism-a theory which assumes ment upon the organism-a theory which assumes metaphysical principle, which, as we have seen, is not amenable to scientific inquiry.

In short, while natural selection can be looked upon as the efficient cause of the progress of evolutionary lines, their first beginnings must be attributed to a still "unknown factor in evolution."

\section{SECTION III}

\section{SUPERORGANIC EVOLUTION}

IT is customary to make a broad distinction between the inorganic and organic, the former embracing the physical world of lifeless matter, the latter including the living organisms and their phenomena. To these two divisions organisms and has added a third-namely, the superHerbert Spencer has added a third-namely, the super-
organic, which deals with " facts, not presented by any organic body singly, but which result from the actions of aggregated organic bodies." These phenomena, though " The phenomals, are already apparent to a cer chiefly characteristic of "mankind as socially united"; so that superorganic evolution is concerned mainly with the progressive development of human society. On the prinprof of the could naturally ciple of the continuity of evolution, we should naturally expect no definite break between organic and superorganic phenomena. The links between them are formed by those facts which are classed as mental and moral. We have already had occasion to point out that the mind must be held to be under the sway of natural selection, just like held to be under the sway of natural selection, just like the other phenomena of the living organism. We must now deal . fully with these "higher" faculties, which lead ultimately to the whole imposing superstructure of civilized society. We shall accordingly discuss, under the head of social evolution, first mental and moral evolution, then the general progress of human society, and lastly the special development of the various social institutions. 
if we may so call them, associated with the latter. Even such a stout defender of the soul (in the metaphysical sense) as Professor McDougall holds it " not improbable that the experience of each generation modifies in some that the experience of each gen of its successors," thereby degree the psychic constitution of its successors, "thereby assuming an evolution of the hypothetical soul, though on
Lamarckian lines.

CHAPTER $\mathrm{X}$

SOCIAL EVOLUTION

I. Mental Evolution.

BEFORE entering on our subject proper, we must deal with certain preliminary questions in order to clear the issue before us. We have indicated above that mental phenobefore us. We have in a preneral scheme of evolution. It has been shown in a previous chapter that there is no ground for treating the higher faculties of man as belonging to a distinct category of their own. Here we must add that consciousness in general cannot be held to be that concious

For, at whatever stage consciousness may be considered to have had its beginnings, comparative psychology has made it clear that the phenomena of the mind evidence themselves in close parallelism with the development of the sensory and nervous structures of the organism " All the sensory and nervous structures of the organism. "All mental process is accompanied by neural process in the correlate, or, in the language of Huxley, every psychosis is definitely correlated with a neurosis" (Professor William McDougall. Now, whatever view may be taken of the relation between body and mind, it is clear, as Professo Lloyd Morgan has put the argument, that if the complex molecular vibrations of the brain have developed from the simpler molecular vibrations of the ovum, the complex states of consciousness associated with the former must have evolved from the simpler states of infra-consciousness,
We shall find in the following that we can trace a continuous line of mental development as we gradually ascend the tree of animal life.

(a) Behaviour of Lower Organisms.

t is only in the last two decades that the psychology of lower organisms has been the subject of systematic study. With the belief in an evoluWith the advent of Darwing tionary explanation of all problems of life, the pendulum had swung rather to the other extreme. There was a tendency, in order to bridge over the gap between the brute creation and man, to interpret animal behaviou brute cre from the attributoo much from the anthr. J. Romanes did in his works, to ting, as, for instance, G. J. Romanes did in his works, to lower organisms psychic faculties which later researche have proved to be beyond their natural capacity.

It was Professor J. Loeb who, in his work on "The Hel moveHeliotropism of ments of lower animals can be accounted for in the same manner as the movements of plants; and that therefore no special psychological factor is needed for the interpretation of their behaviour. What we have to assume as the fundamental quality of the living organism is the the fundame living organism reacts to excitability of protoplasm. The living organ the stimuli, which may either come from within (the general instability of living matter due to metabolic changes) or may arise from outside influences (mechanical, chemical mave stimuli, etc.). In thive for e.g. the intra-uterine movements of the embryo) or rhythmical 


\section{THE FIRST PRINCIPLES OF EVOLUTION}

movements (as those of the heart, etc.). In the latter instance, when an external stimulus strikes the organism, it responds by a change in its behaviour through a reflex action-i.e., the sense-impression produced by the stimulus action-i.e., the sense-impression produced by the stimulus when in a higher animal a limb is irritated, the impulse, travelling up along the sensory nerve of the limb to the spinal cord, is there, as it were, reflected to the motor nerves of the same limb, which set the appropriate muscles in motion, withdrawing the limb from the source of irritation. But the term "reflex" is often employed also for those immediate simple reactions in lower animals where there is no special nerve tissue for conducting the stimulus, the undifferentiated protoplasm acting in its stead. Thus, as we shall see, one-celled organisms react promptly to all sorts of external stimuli. There is in principle no difference between these reactions and the reflex reactions of higher multicellular animals. On the other hand, Loeb has shown that such simple reactions, though apparently purposeful, can be explained by the same mechanical laws as the movements of plants, which are generally accounted for by the changes in tension of the different parts, due to the incidence of the impinging physical forces. This theory of tropism has been elaborated by Loeb to a considerable degree, and it forms the most thoroughgoing mechanistic interpretation of the psychical phenomena of animal life.

It is well known that plants are subject to the influence of light, that they have the tendency to grow towards the light, which reaction of the plant protoplasm is ascribed to heliotropism. Likewise it has been found that the roots to heliotropism. Iikewise it has been found that the roots dip straight into the ground through the influence of gravity; geotropism is said to be the cause of the growing downwards of the roots. Similarly, chemotropism is the reaction towards chemical stimuli, etc. Now, Loeb was able to show that the movements of a great many of the lower animals are mechanically determined, in precisely the same manner as those of plants, by the direct action of light, gravity, etc., on the organism. Winged aphides, when exposed to light, regularly orient their bodies into whe directon to light, regularly orient their bodies into the direction of the light rays and move towards the source of light. The same can be shown of the caterpillars of Porthesia chrysorrhcea, the imagos of flies, and other animals Porthesi a chrysorrhxea, the imagos of flic. The larvæ of flies, of They are all positively hem certain beetles, etc., on the other hand the heliotropism the light ; they are negatively heliotropic. The heliotropism varies not only according to the condition of the animals, but also during different periods of their lives. Thus the but also during caterpillars of Porthesia are positively above-mentioned cater their emergence and before their heliotropic only after thing their nuptial flight, etc. Acfirst feed ; bees only during their nuption the rection is the cording to Loeb, the precise method of this reaction is the following: He assumes a specific sensibility of the bodytissue to the chemical action of light. This chemical sensitissue to the chedy. Now, bility is ident striking a symmetrically built, positively if the light, striking a symmetron one side, the photoheliotropic organism, is stronger on one side, the photo chemical reaction on that side is greater, an increase in the tension of the muscles of that side takes place, and the the tension the light. As soon as its organism the direction of the median plane comes to coincide light once more becomes light rays, the incidence of the light once more becomes equal on both sides of the animal, and movement takes place in a straight line. With negatively heliotropic place in a straign is the reverse, the animal turning from the light.

In light. In this way Loeb would explan frogs animals, even as high up in the organic scale as crabs, frogs, and mice. These, though often described as purposeful, are, according to this theory, merely the result of a mechanica according to this organism and environment. That, fo reaction between organis hide themselves in crannies and instance, so many anir desire holes, is, as Loeb has demonstrated, not due to their desirm for concealment, but is simply a phenomena of stereotropism, which induces these organisms to seek close contact with 
230 THE FIRST PRINCIPLES OF EVOLUTION

solid bodies. It is chemotropism which attracts the fly to lay its eggs on decaying meat; while geotropism forces the butterfly to place itself vertically for taking wing as

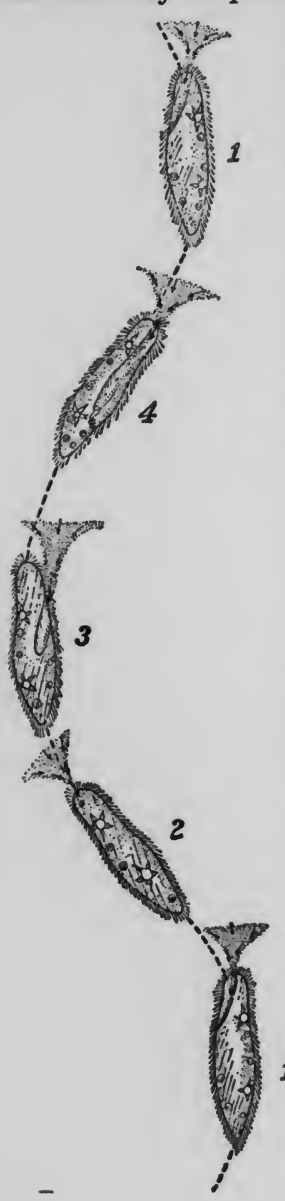

soon as it emerges from its cocoon. The moth, too, is drawn to the ight, not by curiosity, as Romanes still had it, but by positive heliotropism. Tropisms, though often useful for the animal, do not always work out to its benefit (instance the moth). There is no original purposive aim in animal actions, though it is clear that those reactions that proved to be harmful were gradually weeded out by natural selection.

Lately these mechanistic theories have received a decided check by the investigations of Prof. H. S. Jennings on "The Behavior of Lowner Organisms" (Ig06). By his beautiful, painstaking researches on the actions of unicellular organisms (bacteria, amœbæ, infusorians, etc.) (becteria, amcebe infusorians, etc that even the lowest living beings show a behaviour which he has characterized as that of "trial and error." He demonstrates that every organism has its specific

Fig. 79.-Spiral Path of Paramecium. The figures $\mathrm{I}, 2,3,4$, etc., show the successive positions occupied. currents of water drawn from in front. (From "Behavior of Lower Organisms" by H. S.
Jennings. By permission of the Columbia University
Press.) "action system"-i.e., it performs a certain definite " Thus, for instance, Paramecium, a minute infusorian, performs by means of its cilia a forward (or backward) movement, a rotation around its long axis and a swinging of its its oral en it responds negatively by an course (see Fig. 79). Now it responds negativis " avoiding reaction," whenever it gets into conditions away from the optimum of its existence. It reacts by moving backwards and swerving its oral end in a circle, whereupon it resumes its normal spiral forward movement, which thus it resumes its now direction (see Fig. 80). The more leads it into a new direction (see pronounced the avoiding reaction, the larger the circle described and the greater the deviation from the original path. Thus, by successively trying various directions, the pan manes to escape the injurious agent. Jennings holds that this is the type of behaviour of all Jennings holds that this is the type of bit (by changing lower animals. Various positions are tried (by changing the extent of the avoiding reaction), and the one is ultimately " selected" which brings the organism out of reach of the stimulation. Fig. 8I shows the movements of Euglena viridis, a unicellular flagellate, when orientating of Euglena viridis, a unicellular " towards a source of light.

itself by a "positive reaction" towards a source of light.

Whether these reactions can really be put on a par with the the is a variation of selection, i.e., a choice in the real movements, but is it a selection, ieng un Loeb's theory, meaning of the word ? G. Bohn, taking up Loeb's theory has tried to show that these phenomena may well be explained on a mechanistic principle by attributing to lower organisms " differential sensibility" towards the various organism is not only able to orient itself stimuli. The organing is the direction of the source of by tropism according to the direction of the source of stimulation, but can respond to a change in the intensity of stimulation by an alteration of its course. Tropism plus differential sensibility is all that is required in order to determine these movements, without calling to aid any 

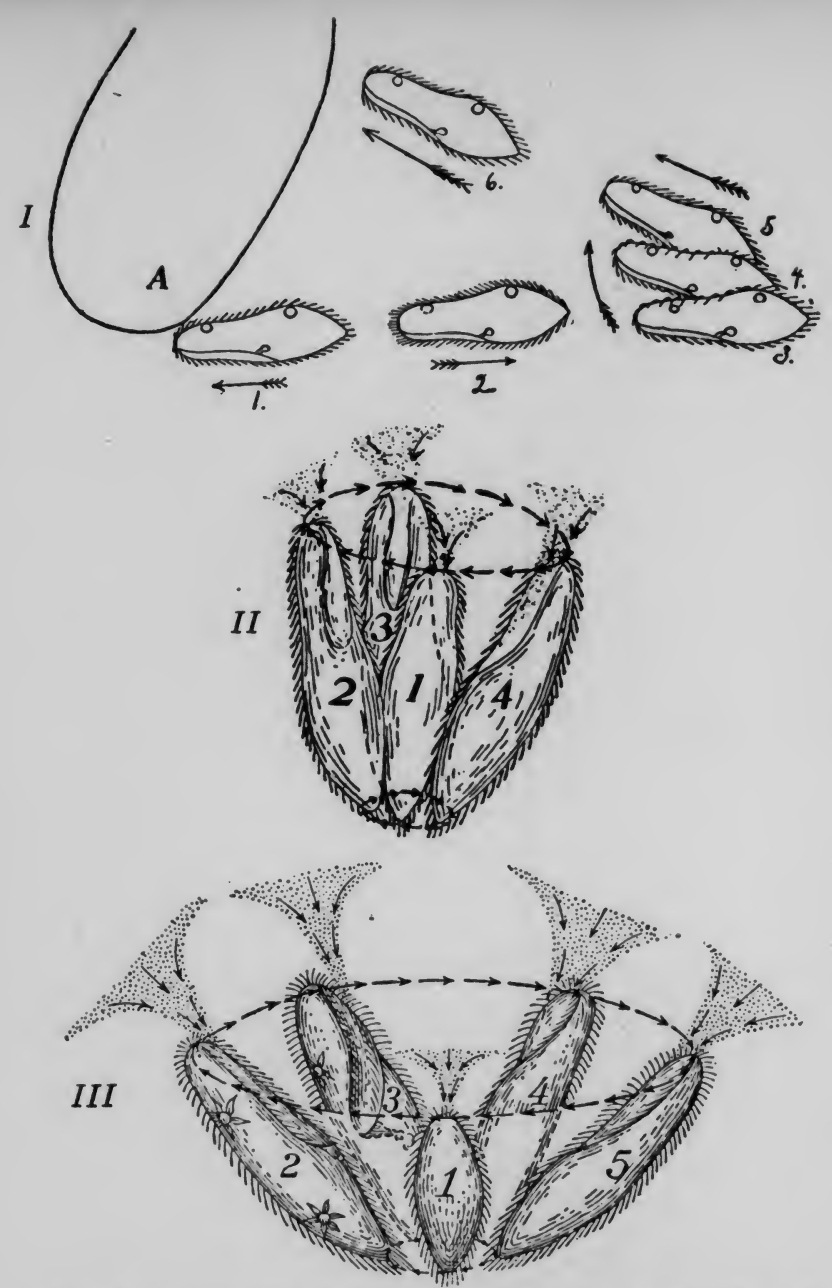

Fig. 80.-Diagrams of Avoiding Reactions of Paramecium. $A$ is a solid body or other source of stimulation; I shows the backward movement, swerving of the oral end in a circle, which is larger in 111 , representing a more
pronounced avoiding reaction ; $x, 2,3,4$, etco, successive positions occupied. (From "Behavior of Lower Organisms," by H. S. Jennings. By permission of the Colwmb

\section{MENTAL EVOLUTION}

233

psychical factor whatsoever. Jennings himself has demontrated that with Paramecium, for instance, the swerving the decided the stro It would seem, then, that the reaction of these tiny animalcules is dependent on the strength of the stimulus, and is not so much a matter of choice. More to the point would

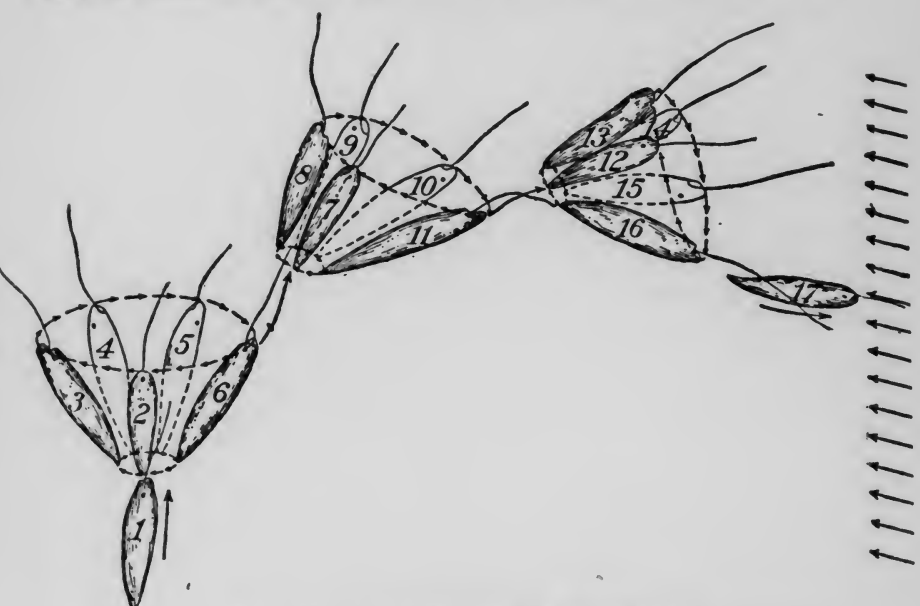

Fig. 81.-Orientation of Euglena.

The organism, originally swimming in the direction of $I$, is suddenly illuminated by a light indicated by the arrows on the right. It swerves and changes into a succession of dition in directly by 2 to 16$)$ cuntil it fina

(From "Behavior of Lower Organisms," by $H$.S. Jennings. By permission of the Columbia
University Press.)

seem his observations on the behaviour of another uniseem stentor (see Fig. 82). He cellular organism, the ses. found that, when the same irritant stimulus is applied over and over again, the animal does not continue in its mode of reaction, but modifies it in various ways in order to rid itself of the undesirable stimulus. Ultimately, if no other 
234 THE FIRST PRINCIPLES OF EVOLUTION

procedure succeeds, it breaks away its connection and seeks a new abode. This seems very much like a conscious means to ends, and Jennings does not adaptation of means to ends, Looking at the behaviour hesitate to draw this conclusion. of lower organisms from the psychic point of view. he sees no fundamental difference of kind between difference of kind betwen the psychic life of unicellular organisms and that of the higher
animals, including man.

To this we must answer that in this case we should have cording consciousness where, according to the general consensus of opinion, it is held to be absent. A frog deprived of its brain, so that only the spinal cord is left, executes appropriate reflex actions, wiping away with its actions, miping away with its leg acid dropped on its side.
IG. 82.-Stentor Roeselin. It is even able to do this with Bending over to remain in the other leg if the first leg is contact with a shred of prevented from moving, though the experimenter to the with seemingly greater diffiright.
rity. Further we should have (From "Behavior of Lower Organ- to attribute psychic qualities
isms." By H. S. Jennings, by per.
mission of the Columbia University to plants also, for insectivPress.)
orous plants are able to "discriminate" nicely between various stimuli, reacting "discriminate the that indicate in the appropratestances $*$ We enter here upon the digestible food-substances. ${ }^{*}$ We enter has actually been

- It must be remarked that this logical step has actually been taken by some. Pfluger, for instance, attributed consciousness to the decapitated Among botanists we have a similar tendency. Prospinal cord). Among credits plants with tactile perceptions; Francé even with a " soul and intelligence" discussion of the problem of consciousness. Where does it begin? Unless we would adopt the belief that all it begin? Unless we would adopt the belief that all matter is endowed with consciousness - $a$ thesis held by many, and by no means indefensible - consciousness must have originated at some stage of organic development. hut even on the first supposition it is clear, as Lloyd But even on the must make a distinction Morgan has pointed out, that we must make a dentience between consciousness as accompanying min sentorand consciousness as a guiding and directing factor"effective consciousness," as he calls it. The first may be assumed as present in all sentient beings. With the latter we generally credit only such organisms as are able to " " grofit by experience" which presupposes at least a dim profit by expecience remembrance of the resully held not to occur until a higher

we shall see, is generally held not to occur
stage of mental evolution has been reached.

\section{(b) Instinct.}

What is instinct? The conception of instinct depends

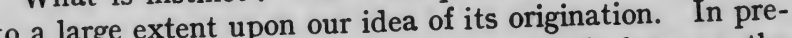
to a large extisis was made between the Darwinian times a sharp to be endowed with instinct brute creation, supposed to be endowed with instict only, and man, who was guided by reason. This facile interpretation, which saw life from the static point of vieweverything being determined by a final decree of Providence everything being deter the - has had to give wa mental phenomen. is tionary point of view, is not a special faculty of mination merely the psychic expression of the structural ong the which, like the anatomical traits, tends towards the wellbeing of the individual and the preservation of the species. Indeed, in one sense it may be looked upon, in Bergson's Indeed, in one "a prolongation of the expression, as noth it acts mechanically, work of organization." In so fart in being dependent on the inherited structure of the organism, and having no conscious knowledge of its own purpose. In fact, this type of instinctive behaviour can well be 
236 THE FIRST PRINCIPLES OF EVOLUTION

described in Spencer's phrase as " compound reflex action." Just as in the simple reflex a given stimulus produces a definite reaction, so here a mechanical sequence of movements is set in train with predetermined uniformity, so that the individual is unable to deviate from it. Thus, to quote from Romanes: " $\mathrm{P}$. Huber has described a caterpillar which makes by a succession of processes a very pillar which makes by a suctam pr... If such a caterpillar was put into a hammock partially finished, far from feeling the benefit of this, it was much embarrassed and even forced to go over the already finished work, starting from that stage which it had left off before it could complete its own hammock. So, again, the hive-bee, in the constrection of its comb, seemscompelled to follow in the construction of its comb,

an invariable order of work." But such " chain-reflexes," where one step determines the mechanical kind of instinct is unalterably fixed by external conditions, a more adaptable type of action arises when the inner a manic factors - namely the internal physiological state of the organism as a whole-take a part in determining the effect of a given stimulus. It is a commonplace observation that a hungry animal reacts towards food differently from a sated one. In other words, the "setting" of the organism, as Professor L. T. Hobhouse has called it has a decided influence on the ultimate has called it, has a decided influt It implies a certain plasticity of instinct, giving the first step in the adaptability of instinctive behaviour in animals.

Thus we pass insensibly from a rigid reflex response to an adjustable type of instinctive action. How far this adaptability extends is a matter of degree. While in "pure" instinct the series of actions is prescribed within the limits of hereditary organization, each stage determining the we find in other cases that the response to specific stimuli may_be less rigidly circumscribed. Though the general

\section{MENTAL EVOLUTION}

237

plan of the whole instinctive action is fixed by the interna impulse, the steps towards carrying it out are left, to a certain extent, to individual adaptation according to circumstances. It is here that the first dawn of intelligent cumstances. It is here that the first dawn of intelle in instinct is prior to all individual experience, working blindly towards an end, intelligence takes note of the means towards achieving that end. That instinctive behaviou may be subject to individual intelligent modification within fairly wide limits has been proved for many animals low in the scale as insects. The old-fashioned sharp as low in the scale as insects. The ol division between instinctive action (of which the insect used to be taken as a type) and rational behaviour has become untenable.

Another feature of a similar nature must be noted here. Just as the response to specific stimulation gradually loses its igidity with regard to the action of the adult loses its rigidity with regard to the action of the adult ning of the basis of behaviour in the young. In lower organisms-in wasps, for instance-the whole train of biological action is predetermined within narrow lines from the very beginning of existence. In higher animals, such as the chick, and much more in the human infant, we find no such definiteness What is inherited in these cases is a general instinctive impulse, not instinctive knowledge. The chick pecks instinctively at small, especially at moving, objects ; but it pecks at first as readily at a stone as at a morsel of food. It is only individual experience that teaches it to discriminate between them. This circunstance would seem to tell rather against the chick But, as Lloyd Morgan has pointed out, in higher animals parenta guidance is able to take the place of much of the instinctive regulation among lower creatures.

Coming now to the question of the origin of instinct, we have already seen that Herbert Spencer explained it as a combintion of reflexes, knit together into one complex action through the accumulated experience of successive 
238 THE FIRST PRINCIPLES OF EVOLUTION

generations. This implies that the effects of individual experience are wrought into the biological inheritance of the race. Indeed, there exist, as has been expounded in a previous chapter, two rival camps among evolutionists The Lamarckists, believing in the inheritance of acquired characters, look upon instincts as inherited habits, which were originally acquired by the individual and handed down to the offspring. This would justify G. H. Lewes's contention that instinct is "lapsed intelligence." Professor Wundt has distinguished two classes of instinctive acts those which are acquired by the individual during his lifetime, and those which are connate-i.e., inborn in the individual. The latter he assumed to be due to the transmission of individually acquired habits.* Romanes, following Darwin, admitted a twofold genesis of instincts, by use-inheritance and by natural selection, leading to primary instincts in the latter more important case and to secondary instincts in the former. while a combination of both factors produced blended instincts. The main argument against the Lamarckian origin of instinct lies in the fact so often noticed, that the inheritance of acquired characters is so far non-proven. If all instinct were lapsed intelligence, we should find the more intelligence the lower we go in the animal scale, which is certainly not borne out by facts.

The most generally accepted theory of the evolution of instincts is based on natural selection, as originally propounded by Charles Darwin. Instincts vary in the different members of the same species in like manner as bodily structures. It is by the constant selection of the most adaptive variations - those that serve the biological end of the race in the greatest degree-that instincts were gradually perfected and evolved into a more and more complex type.

Before leaving this subject we must not omit to mention

* In order to avoid confusion, it would be better, as Lloyd Morgan points out, to denote the former (i.e.,the so-called acquired instincts) as habits, and not as instincts.
MENTAL EVOLUTION

the latest hypothesis of instinct, enunciated by Professo the late cardinal error is Henri Bergson. According to hat to see in vegetative, instinctive, and rational life three successive degrees of the development of one and the same tendency, whereas they are three divergent directions of an activity that has split up as it grew." The different tendencies separate out, as it were, though incompletely, tendencies separate or af ife, from the common mo intellieach pursuing its own course. Though there is "no intelligence in which some traces of instinct are not to be discovered, more especially no instinct that is not surrounded with a fringe of intelligence," these are in reality "two with a finge of ine and the same principle," being " two developments of of and the "Instinct itself Bergson divergent modes of know defines as "sympathy (in the etymological sense of the word)." He assumes that one species possesses an instinctive knowledge of another on a particular point, simply because both species must be considered as " two activities" having their common root in the fundamental unity ties "having thir common of life. He quotes as an instance the marvellous exactithe with which certain wasps paralyze their prey, without killing it, by stinging it just at the nerve-centres, however many there be. This procedure keeps the victims, which have to serve as food for the next generation, motionless, wet free from putrefaction. It has, however, recently been yet.free from putrefactionstions of Dr. and Mrs. Peckham shown, by the classic investigations of Dr. and Mrs. Peckham on wasps, that the stinging instinct is by no means so unerring as was supposed. The victim is often killed, while the larvæ do not seem to suffer by partaking of decaying food. Bergson tries to make light of this objection. He food. Berg how could points out how inconceivale it is that the waspl knowhave tentatively acquired the necessary anatomical knowledge, and have gradually perfected it by hereditary transmission. On the other hand, he rejects Neo-Darwinism as being too much a theory of chance.

Bergson's own explanation, however, breaks down, on Professor Poulton's showing, as soon as we take a large 
240 THE FIRST PRINCIPLES OF EVOLUTION

enough survey of the working of animal instincts as a whole. The supposed sympathy is non-apparent where we should most expect it. That the maternal instinct of a bird should fail, as has been observed, to lead it to recognize its own young as soon as this is placed a little distance from the nest, is certainly a proof that no mysterious sympathy is at work between parent and offspring. The made for the laying of eggs, the weaving of cocoons, etc., in order to achieve the proper hatching of the young, can also not be based on sympathy, for here the parents never see their young. Nor can the phenomena of mimicry be due to this cause; while the supposition of a continuous selection of the most adaptive types still remains the best solution of the problem.

As regards Bergson's view that there are two divergen lines of mental evolution-that of instinct, represented mainly by the insects, and that of intelligence, leading through the vertebrata to its culminating-point in manwe must point out that Professor McDougall has shown in his " Social Psychology," that the main social character istics of man are based on instincts which have been inherited from his animal ancestry. Indeed, according to this view, "the instincts are the prime movers of all human activity," "and all the complex intellectual apparatus of the most highly developed mind is but the instrument by which these [instinctive] impulses seek their satisfactions." And this opinion stands by no means alone.

(c) Intelligence.

We have seen that intelligence arises gradually in the domain of instinct. While all instinctive behaviour is "prior to experience," being the automatic expression of the inherited organization, intelligence consists in the ability of the individual to "perform acts in special adaptation to new circumstances" "It thus involves an element of choice, which is based on the method of "trial and error," whereby the organism is enabled to profit by its own experience.

The first step in the elaboration of intelligence is reached when, as already adverted to, the instinctive behaviour of the organism, instead of being rigidly determined in all its the organism, instead of it were, only in general outline. It particulars, is fixed, as it were, only in general outline. It
becomes gradually defined by individual adjustments of the organism, which shape its action in accordance with the requirements of the surroundings. We have already quoted the case of the pecking instinct of the chick. The newly hatched bird does not, in the first instance, discriminate between eatable and uneatable objects. But having pecked at a nauseous Cinnabar larva, let us say, it learns to avoid it in the future. What exactly is the process of rejection? The actual mode of learning is, according to Professor Hobhouse, the following: At the first trial there occurs in the chick a succession of reactions, which can be written down chick a succession of reactions, which can be written down
as : stimulus-pecking-unpleasant taste-rejection. After the first experience the same stimulus comes to elicit the movement of rejection without the intermediate stages. The chick may be seen to run on the first impulse towards the distasteful morsel, but soon checks itself, wiping its bill as though it had tasted it. The excitement aroused by the stimulus becomes coupled with the character of another excitement, which it has previously brought about (here the rejection movement), so that the second now follows the first automatically. This process is called follows the first autom "assimilation." In this way instinctive tendencies are
either inhibited or reinforced by acquired habits.

We can now go a step further. Not only may instinctive reactions be modified by the effect of experience, but new reactions, towards which there was no original tendency, may be taught to come to be fed by their keeper. According to recent ideas of comparative psychology, we cannot attribute to the fish any distinct appreciation of the relationship between food and keeper. There is rather formed 
242 THE FIRST PRINCIPLES OF EVOLUTION

a regular association between two excitations, the going forward for the food and the sight of the keeper, so that the latter is absorbed into the character of the former. There is no conscious knowledge ; but food and keeper become is no in two abstract ideas, associated in the animal's mind, not as but as two perceptions namely, the going after the food and the seeing of the keeper. Intellectual behaviour at this stage, then, is due to "impulse," as Dr. Thorndike has termed it-i.e., to the direct feeling of doing as distinguished from the idea of the act done.

In this manner must be explained intelligent action in In this masses of lower organisms. How far down such intelligence reaches it is difficult to tell. There is a good inteal of difference, not only between species of the same class, but even among individuals of the same species. One can only indicate approximately the average level of One can only in any one class. intelligence attain to this standard, the lowest (and the low intelligence can be attributed are the worms (earthworms) though it has been doubted even here. Limpets and snails are said to be able to return to their home; in this case they must becredited with some perception of their locality the find ample evidence of intelligent Higher up in the scour among insects, especially bees, wasps, ants, etc. We shall only mention what may be considered the most far-reaching extensio of the use of tools. Dr. Peckham pictures a solitary wasp using a stone to beat down the earth over its nest (see Fig. 83). The same mode of mental procedure is stil predoninant as high as the fishes.

Ascending somewhat higher in the scale of mental evolution, we find no essential change in the process of intelligent adjustment, but rather an extension thereof. The method is still one of direct correlation between senseThe method in motation, instead impression and motor reaction, but this relation, instead of holding good only for one particular sequence, can now be varied within certain limits, thereby enlarging the scope

\section{MENTAL EVOLUTION}

of intellectual adaptation. The second term of the relation may be represented by any object of perception, instead of by a particular one. Thus a dog which accommodates itself always to one particular place, may do so by habituation -i.e. by the process of assimilation previously described But if the dog is able to find its way about in some other But if the dog is ablo to substitute one perception for home, it must be able to substitute another, and must therefore be credited with memory and the idea of the object. In other words, it will be able to form generic instead of particular images. It has an

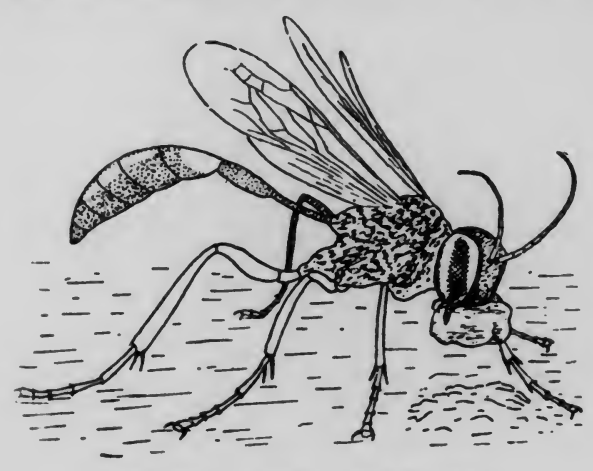

Fig. 83.-WASP USING Stone.

(From "Animal Behaviour," by C. Loyd Morgan.)

idea of locality in general, and not of one particular place only. But, it must be understood, such ideas are only practical ideas. The inference drawn remains still within practical in of (1) in the manner of an abstract thought, but is rather implied in the action of the animal. Professor Hobhouse has called this stage of mental development practical or perceptual judgment. It enables animals of the type of dog, cat etc to form practical ideas of objects in general, of locality, persons, etc. They are capable of apprehending 


\section{THE FIRST PRINCIPLES OF EVOLUTION}

the relations of different parts in their surroundings, and can learn by perception of the results obtained, though they cannot tell the why or wherefore of their action.

We must note however, that this view, which can claim experimental evidence in its favour, is not completely shared by other psychologists. Thus, Dr. Thorndike, who made a series of observations on cats and other animals, came to the conclusion that what is involved in the process of learning is merely a direct linking together of sensory images by the process of assimilation. Out of a succession images by the process of ascimilation. Out of a succession action. By the method of trial and error " gradually all the other non-successful impulses will be stamped out, and the particular impulse leading to the successful act will be stamped in by the resulting pleasure." Thus a cat enabled to escape from a specially prepared box by pulling a cord, for instance, first hits upon the appropriate movement by for insta chance. The with the pulling of the string, both acts become finally worked into an habitual sequence. Both explanations given above agree in principle : behaviour at this stage of mental evolution is not based on rational thought, but on perceptual association.

Higher up in the scale of the animal series there takes place, as Professor Hobhouse has put it, "an increase in the elaboration and articulation of "practical ideas" " witnessed at the lower stage. Monkeys manage to manipulate sticks and other tools with precision, and are able to learn by " reflective imitation," in which the act of another, which produced no direct result to the observing animal, is by it copied and applied to its own ends."

(d) Reason.

The vast interval which separates human achievements, so far as they depend on human intelligence, from animal achievements; so far as they depend on animal intelligence, is connected with the distinction between

\section{MENTAL EVOLUTION} perceptual and ideational process. Animal activities areas either purely perceptual, or, these ideas serve only to prompt and man conducts ' in actual execution. On the other hand, man con action his head,' by means of trains of ideas, schems of action before he begins to carry them out. He is thus capable of before he begiffulties in advance. He can cross a bridge overconing from Dr. Stout before he cooveriour of animals and puts the difference betwe clearest possible light. While the that of man in the clearst poss for practical purposes, animal makes use of generic images for pr f his experience man is capable of analyzing the content of his expertual apart from the perception of the "moment. Conceptul apart implies no new faculty. "It merely brings into thought imp common element in diverse exclear conscious was already at work in guiding practica periences ", Pristinguishes one object inference." Practical judgm separating it into or one series of events from oth. smaller but still concrete percepts; conceptch jum still breaks up the percept into componts present mere attributes of the perceived, rese qualities, being equally applicable to colour, etc. The come to stand for definite ideas, other concrete objects, com the "world of ideas" capable of recombination. It is the "wom mind. This which is the distinctive property of the simultaneous depends, however, for its realization on the it is the naming development of the use of language; for it is the naming dev a cons which allows it to be fixed, and therefore to of a concen from its object, so that it may serve as be detached symbol.

abstract symbol. How far do animals possess a language dinctive cries, known that quadrupeds, birds, etc., utter these vocal signs expressive of their emotions, and that the are understood by their fellows. But such utterances are anly concerned with immediate feelings, the response being a sensori-motor reaction on the intellectual plane being a senorimals are able to com- 
municate complex facts to each other, since they have no power of description. All accounts of such feats resolve powe of din aprote movements, " on the principle of "follow-my-leader. "Even where words are understood by lower animals, their sounds simply serve as signs, carrying no more content than perhaps the implication of a whip.

Language in the proper sense of the term-human lanLencer from its immediate complex was called by a distinctive name. It is impossible at present to say when and how this decisive occurrence took place, ${ }^{*}$ though it may be taken for granted with Lloyd Morgan that the lower modes of intercommunication among animals, based on instinct and intelligence, furnished the necessary steps. Infant psychology, interpreted on the evolutionary principle, is in total agreement with such an assumption. The human infant, at first only uttering emotional cries, gradually attains the stage of the word-reflex, when a word is used as a mere exclamathe from whence it passes to the word-sentence, using the tion, from whence it passes to the word-scntence, using the single word as a description of fact (e.g., " hot" for " milk is hot "). The formation of proper articulate sentences follows apace.

It is the combination of reflective thought with descriptive language which raises humanity so high above scriptive langage which raises hum its nearest congeners. We need hardly dwell on the further elaboration of the ideational process, its systematization into science, its flight into the fields of imagination and philosophy. By making possible for the first time the development of a self-conscious ego, capable not only of cellow reflecting on its own self, but also on that of its neighbour,
it paves the way for all the higher attainments of ethics it paves the way * Mr. S. S. Buckman suggests that the emotional sound (e.g.,
"ma"), being coupled in association with a particular object of "ma"), being coupled in association with a particular object o sense-experionce (here the motect

\section{Moral Evolution.}

How far does the developmental hypothesis apply to ethics?

Here, too, as in so many fields, the theory of evolution has produced a profound change, replacing the old static morality, decreed unto all men for all time, by the more morality, decreal ideals rational idea of a cont a progressive and social customs. But though the vien morality has been generally accepted, there is still, as in pre-evolutionary times, on the fundamental question of morals an irreconcilable opposition between the two modern schools of ethical thought. Professor Sorley has moder sche careful to distinguish the pointed out that we " ethics of evolution." " evolution of ethics" from the "ethics of evolution." While the former traces the gradual change of the mora sentiments throughout the ages, the latter involves moral valuation of human action, and endeavours to fin mo sto may be admitted that the stane question the evolutionary schor with that of moral worth, has so of moral progress than with that of moractory far not been able to give an entirely satisfactory answer to the latter problem. But the two sides of ethical theory are by no means irrelevant to each other. The criterion are by ne evolutionists, is or the ethical siew of its genesis : to a great extent depende school is while it would seem that the modern intuitive school is led to assume a supernatural origin of the moral sense in man, largely through its belief in an immaterial spiritual world.*

Our main question to decide is : Can the moral instinct

Our of man be traced back to hor them a intuitionists stoutly deny this. For them conscience is a

- The chief representatives of the modern metaphysical (Idealist) school in England are Martineau ("Types of Ethical Theory "). 


\section{THE FIRST PRINCIPLES OF EVOLUTION}

special faculty of man, speaking with an unerring voice, which can only be understood as an integral part of man's divine heritage. According to this view, there lies a whole world of difference between the moral feelings a whole werestures. It is of man and the criticize this theory in detail. not here our business to criticize this the It must suffice, in order to clear the ground for the evolutionary view of ethics, to adduce the main arguments against it.

In the first instance, it must be pointed out that there is the ethical judgments of is no reason for separating the and ascribing them to rional judgments, and ascribing them to special moral sense, revealing intuitively what is right and what is wrong. We shall find that the progress of morality in man is bound up to a large degree with his mental and social development, and can only be intermental an this a metaphysical theory preted on this basis. Berly of ethics, as Professor Sorley has pointed out, "simply brings forward a new difficulty - that of understanding how the temporal process in which human morality is developed can be related to a reality which is defined as out of time or eternal." Furthermore, a review of the customs and beliefs of different ages and countries shows customs and beries that it would be so many inconsistencies and vagaries that it would be futile trying to find an absolute guide for right conduct. Professor Sorley, himself a not unsympathetic critic of the idealist school, has shown that the attempt to call in a metaphysical principle to account for the moral ideal in man has failed no less than that of the evolutionists. man is no further reason to There is, therefore, on this groun the moral sentiments hold to a supernatural origin of the moral sentiments and we must try, in accordance with the general trend of evolutionary ideas, to trace the conduct of man to it primitive animal source. That this may be possible is not denied even by those who look upon this task as . Tays Mr. A. E. Taylor, in his " Problem of Conduct": "That animal behaviour, if closely studied

\section{MORAL EVOLUTION}

249

y competent psychologists, would present us with the analoga of morality, it is only reasonable to believe." Finally, we see every time in the moral growth of any child that ethical notions arise only slowly by a gradual proces of mental elaboration.

We shall give in the following, first an account of the We shall give in the following, frst an out, and then the later human developments.

(a) Animal Origins.

Exiclusively with Ethical conduct can some have tried to show, but altruistic behious adjustment between consists rather in action. Still, for the puspose of selfish and unselfsh action. Sack to their primitive subtracing the moral sentiments back to their primitive subhuman beginnings, we have mainly to consider the development of the sympathetic emotions. It is these which ment of the symere of emerge with evolution, gradually subordinating the selfish immoral evolution, grater of fact, pulses and desires to a hiscious attitude of sympathy is what later becomes the conscious attitude performed in the originally nothing but an instinctive action, performed in the exercise of animal function. Just as self-preservation bids the organism to use all its powers towards complete indithe organism to so it is part of this satisfaction to vidual satisfaction, so it instinct, which tends to further indulge in the procreative instinct, whe quite impossible the life of the species. It is at this stage quither-regarding to discriminate between self-regarding and other-regarding actions, such difference arising only slowly with the simulactions, such diffe in the depth and extent of sympathetic emotions.

It was "Descent of Man," insisted It was Darwin who, in the "Descent ond psychical sides upon the continuity of the physical ane tried to reduce of human nature, and for the furs timitive biological the moral feelings of man to their primitive biological elements. As such must be considered the parental and elements. As such the social instinct, as witnessed in $3^{2}$ 


\section{THE FIRST PRINCIPLES OF EVOLUTION}

animals. Mr. A. Sutherland has elaborated this thesis at great length, showing how the act of bearing and rearing the young becomes at once more prolonged and complicated as we ascend the animal scale. With the lowest cated a merely a physical process, the organisms propagation in mody. Their fertiligerm-cells being voided outside the body. Their fertilislowly are means evolved by which a more direct contact between ovum and spermatozoon is secured for the the male semen is purpose of fertilization, were the process of fertilideposited within zation takes place with a minimum of waste. But the fertilized product, the egg, which now receives a shell, is still hatched outside the maternal body, being greatly exposed to the dangers of destruction. At this stage, exposed to the darest development among birds, the which reach young already receive a great deal of attention from the parent. We need only mention the familiar spectacle of the hen and her little brood. Further progress takes place by lengthening the time of embryonic development, which by lengthening the tim the birth now goes on within the moung, as in the mammals, though early examples occur in some viviparous fish and reptiles.

Meanwhile, there has appeared in birds-apart from faint traces in a few fish-the first definite instance of faint traces in a family life, where the male parent is drawn into the widening circle of sympathetic relationship. The highe we ascend, the more prolonged becomes the period of gestation, and the greater is the relative immaturity and helplessness of the newly born offspring. The assiduous co both parents is now needed in order to prepare the young for their future task; and thus is laid the first animal foundation of later marital life. For with the con tinuous increase of the period during which the members of the family are held together, more and more scope is iver the rise of conjugal affection, which ultimately, with the establishment of the permanent family group, becomes one of the most important factors of moral

progress.
All the steps so far sketched in the gradual building-up of the sympathetic emotions have most probably been attained by means of natural selection. We must remember that in the lower organisms the waste of germs that never come to maturity is appalling. Gradually a great saving of energy is effected for the individual by its producing less offspring, though the needs of the species its producing less offspring, though the needs of the species lower animals the greater protection of the young among higher beings. The more advanced species would thus have an advantage and be fostered by natural selection.

So far, we have seen the sympathetic emotions limited So far, we have seen the sympathetic emotions limited
to the parental pair and their immediate offspring. But another factor appears by which the community of feelings is extended beyond these confines. Sociability is a distinctive feature of all gregarious animals. Many species tinctive feature observed that aggregate in large numbers, and it has been observed that the members of such herds are rendered most miserable when isolated from the main body. "The feeling of (the social instinct seems to be developed by the young remaining long with their parents; and this extension may be attributed in part to habit, but chiefly to natura selection." Co-operation and mutual aid are of common occurrence among animals. Apart from the merely instinctively automatic behaviour of insect communities, we stinctively automatic behaviour of insect communities, we
have many higher species showing considerable foresight in adopting means for mutual defence. Thus, the uttering of warning cries, posting of sentinels, submission to the leadership of the strongest male, etc., are mentioned by Darwin, as also the hunting in packs for the purpose of concerted attacks. Prince Kropotkin, in his "Mutual Aid," looks upon co-operation as the chief factor in the evolutionary process. But this can hardly be main- 


\section{THE FIRST PRINCIPLES OF EVOLUTION}

tained, seeing that unsociable species are holding their own not less successfully. It is among weak species that the social instinct has been evolved, by which they have been enabled to survive in the struggle for life.

If conduct be defined, with Herbert Spencer, as " the adjustment of acts to ends," it follows that the evolution of conduct will consist in a continuous improvement of such adjustment, leading to a prolongation and furtherance of life. But we have seen that, with the ascent in the animal scale, the field of emotions gradually widens, embracing first the progeny, then the mate and family, and finally, the fellow-members of the race. The consecutive stages in the development of conduct, then, imply a corresponding satisfaction of the various feelings connected with the procreative and social instincts, thwarting of these natural impulses these natural impulses lading to a feeling of pain and " moral " which involve a consideration of others as well as of oneself We see, therefore, that ethical conduct coincides with more highly evolved conduct in the Spencerian sense, the highes conduct being that which leads to a perfect life, not only in maintaining individual life and rearing new individuals, but also in aiding one's fellows in the attainment of this end.

According to this theory, it is the pleasurable emotions connected with certain actions which lead to the survival of the species possessing them; for the wider the sympathies of the individual, the greater, on the whole, the chances of success in the struggle for existence. It is evident that this must be so. For if pleasurable feelings were aroused by hurtful conditions, the animal reacting thus would soon be exterminated. A gregarious animal persistently straying widely from the main herd runs great risk of straying widely from the main herd runs great risk of
meeting premature death from its enemies. The pledsurable, then, becomes the useful to the species at large. A Lloyd Morgan puts it : "The two ends agree-the psychological end of the attainment of pleasure and the avoidance

\section{MORAL EVOLUTION}

pain and the biological end of race preservation." It has been objected to this theory that pleasure cannot It has real end of life. What the be, and, in fact, is notion in fulfilment organism aims at, is not pleasure, but action in fulfily of its organic requirements. Impulse is the primary motive. But since pleasurable actions coincide, on the whole, with useful actions, and painful with harmfu whole, with useful and pains, though not the ends of life, actions, pleasures immediate guides.

serve as its most immediate guides. Now, it cannot be said that animals are capable of ethical ideas in the real sense; for we have seen in the previous chapter that animals do not get beyond the perceptual stage of thought, while morality proper is only possible on the ideational plane reached by man. "But," possible on the ideation Lloyd Morgan, "pleasure and satisto use the language or Lloyd Morgan, " pleanin the perfaction attending particular situations contain the ceptual germs of what becomes, through reflection in man, ethical approbation.... The satisfaction or disman, ether arising from the performance or non-persatisfaction arising behaviour, evolved for the bioformance of instinctive behaviour, logical end of the preservation of the social come is deis the perceptual embryo from which conscience is developed."

The origination of conscience and the development of moral ideals is our next problem.

\section{(b) Human Developments}

The principal aim of all ethical inquiry is to find a The principal aim of does it come about that criterion of moral worth. How others bad-i.e., that he man calls certain approval forms moral judgmentirectly identified Feelings of pleasure and pain cannot be directly with ethical conceptions of right and wrong. We have to construct a bridge between the non-moral sensuous exconstruct a brigents and the moral sentiments of " periences of animas," as Professor Westermarck has pointed " 


\section{THE FIRST PRINCIPLES OF EVOLUTION}

had been moral emotions antecedent to them." Such moral emotions must, he says, be traced back to animal feelings of a non-moral character. He would relate mora disapproval or indignation to the impulse of anger and revenge in animals, while moral approval has its nonethical source in the "retributive kindly emotion," as evidenced in the sympathetic feelings of gregarious beings. These animal emotions have their distinctive biologica value, for resentment serves as a means of averting unpleasurable feelings, and therefore danger ; while sociability of course, secures positive benefits.

The question now is: How does the merely instinctive reaction of brutish behaviour evolve into the consciously moral attitude of man?

The change is made possible only by the attainment of man to the ideational level, where there exists conscious reflection, memory, and expectation, and therewith the possibility of contrasting experience as it is, with experience as it might be, or ought to be. It was, as Darwin already indicated, through comparison of one's own deeds with the knowledge of " what others consider as praiseworthy or blameable" that human conscience was developed. In other words, the sense of obligation becomes a fact only in conjunction with and through the rise of tribal feelings. Elation and dissatisfaction of a non-ethical kind may be observed in animals. Failure to catch its prey may lead an animal to "brood"; cats have been known to chastise their kittens for uncleanliness. The same pro-ethical sentiment may be found in the childlike savage who sulks over a disappointment. It is when tribal opinion makes itself felt upon, and is anticipated by, the individual, that nonmoral dissatisfaction turns into a sense of moral obligation. moral dissatisfaction turns into a sense of moral obligation. what might have been to the feeling of what is expected from us." Social custom, most rigid in the tribal stage of human society, imposes itself as an inviolable rule of conduct on all members of the community.

\section{MOREL EVOLUTION}

With this we have reached what may be considered the With the real ethical feeling in man. Actions are now perbasis of real ether inpulse, but in formed not only in response to an inner impulse, but in conformity to an external rule. But such moral sentiments, so far as they exist at right and wrong. For the savage, sound generalization of ris mental experience confined within the narrow and evil spirits very much akin to himself, moral obligation is confined to the relations within his own class. Such "group morality" is of a crude sort, being limited to an "group actua unreflective kind of exigencies sentiment proper has hardly yet arisen into full consciousness. Actions are not committed or omitted because they are deemed moral or immoral, but because they are supposed to lead to pleasant or unpleasant consequences to pose to Hobhouse: "Moral feeling oneself. To quote Professor Hobhouse: "Moral feeling is not at this stage disengaged from a prudential dread of human vengeance or of mysterious forces in which there is nothing peculiarly moral.'

Ethical progress does not consist so much in an actual imstinct as in a "rationalization improvement of the" It proceeds pari passu with the of the moral code." It proceeds pari passu with the development of human ideas. With the rise of a religious consciousness and the belief in a spiritual Deity, ethics, too, is transformed, being deepened in its content and extended in its scope. For as the conception of the Godheablime aspect head gradually attains a more leading finally to an immaterial universal Divine so conduct, viewed in the light of religious sanctions, becomes more and more ideal. The source of obligation is now derived from a spiritual authority, and thus becomes it the same time, the gospel of love, as super at the world, has preached by the "great ethical religions of the world, has helped to widen "the boundaries of the moralcommun," breaking down by degrees the walls of tribal and racia 
256 THE FIRST PRINCIPLES OF EVOLUTION

prejudice, and tending to weld together all human kind into one brotherhood; though, be it said, this process has by no means yet reached its final goal.

But the story of moral evolution does not end here. One further step has to be made for the complete rationalization of ethical conduct. Theological ethics still has a st, in so far as " the belief in personal tinge of self-interest, in so far as "the belief in rewards and punishments arbitrarily affixed by the choice of the Deity to particular forms of conduct "lays the stress on external sanction, often to the detriment of real morality. Ceremonial law tends to usurp the place of moral law, and there is no safeguard as to what religious fervour may not sanction. The grossest immorality has places and at various times been perpetrated in various places and at various times in the name of the gods.

It was the ancient Greek thinkers who for the first time sought to found a system of morality on a natural basis by trying to discover the real essence of human conduct.* To find an "objective" standard for man's action, derived solely from human experience, and serving as a rational guide in life, has been the aim of philosophical ethics ever since. We cannot here go into a discussion of the various theories worked out in successive ages. Suffice it to point out the consequences of this movement. Suffee it to point out the con entirely within the limits of man's social relationship. Right and wrong, instead of being derived from an external authority, are now made dependent on the good sense and feeling of the individual himself. "The sense of obligation has ceased to be a sense of what is expected of me, and has become a sense cen of me " (A. E. Taylor). In contrast of what I expect of myself (A. E. Taylor). In contrast with the tendency towards self-negation under a theological system, self-realization of the individuality is now insisted upon in fulfilment of the one great purpose of

* Ethical idealism, as conceived by the ancient Chinese thinkers, has had no direct bearing on Western civilization, and is, therefore here left out of account.
MORAL EVOLUTION

existence - the betterment of the human race. Thus ethics returns with a full consciousness of its own aim to its pristine beginnings - the life of the species.

The development of human morality consists, as already The development of humats of remarked, mainly in an elaboration of the concepts of ethics. But is there not at the same time an actua advance in conduct, due to an improved moral sense ? A. Sutherland would explain moral progress exclusively by natural selection, through the survival of the symby nature selfish types. To this pathetic and the wisitive factor may certainly be attributed the rise of primitive social sentiments. It used to be brought as an important argument against Darwin's theory that it made against ethical evolution. Huxley still held this view. "The practice of that which is ethically best-what we call practice of thrtu-involves," he says, " a course of congoodness or virtue duct which in all respects is opposed to that which leads to success in the cosmic struggle for existence." But Darwin himself has shown that the moral faculty might in the first instance well be due to the action of natura in the pointed out " Natural selection selection , for, as Rurvival of the fittest as regards individuals does not secure survival of the fittest as regards types. only, but also survival of the fittest as regards types. . Success in the civil war, where each is fighting against all, is determined by individual fitness and self-reliance. But success in the foreign war is determined by what may be termed tribal fitness and mutual dependence." It is the tribes with the greatest capacity for social coherence the tribes with the greatessful in the that have shown thense

But the rule of the survival of the fittest by the extermination of the unfit can hold only for primitive society As soon as more humane methods of warfare obtain, which As soon as me vanquished foe ; especido not aim at the anth the ally, however, with the spread of, hecomes subdued by nature, "red in tooth and claw," becomes subdued by man, her own product, who substitutes for the crude 
258 THE FIRST PRINCIPLES OF EVOLUTION

cruel way of natural selection that of rational choice and socian becomes master of his environmecis by his conscious purposive efforts . Not infrequently, ment by his conscious purposive efforts. Not infrequently, as D. G. Ritchie pointed out so well, the conquered peopl impresses its individuality upon the conquerors, and thu proves, after all, to be the fittest. It is more than doubtful whether any actual improvement of mankind has taken ple in man's place in moral capacity drols progress has been, on the whole, as we shall see presently, an improvement in the adaptation of mear better and more harmonious life.

\section{Evolution of MaN.}

We have already pointed out on various occasions that man must be looked upon as subject to the same laws of evolution as other animal species; indeed, he forms but the latest and highest offshoot of the tree of life. This conclusion, inevitable in the light of the Darwinian theory, soon found substantial verification. As early as 1863 soon found substantial verification. " Huxley showed in his essays on "Man's Place in Nature" that man is related to the higher apes, resembling them in all essential points ; in fact, " the structural differences which separate man from the gorilla and the chimpanzee are not so great as those which separate the gorilla from the lower apes." As regards his bodily structure and be classed together with the brain organization, he must be classed together with the anthropoid apes. We must, however, guard against the common fallacy according to which man is descended in the direct line from the now living man-like apes. Both to have originated from a common ancestor of a long extinct generalized form.

The fundamental cause of man's evolution is generally
Thestor of a long extinct generalized form. held to have been the assumption of the erect posture at some stage of his subhuman existence (see Fig. 84). The freeing of the upper limbs led, on the one hand, to the acquirement of skill in the use of tools, and, on the
EVOLUTION OF MAN

259

other hand, by this very extension of man's capabilities, to the intense development of the brain centres. It is

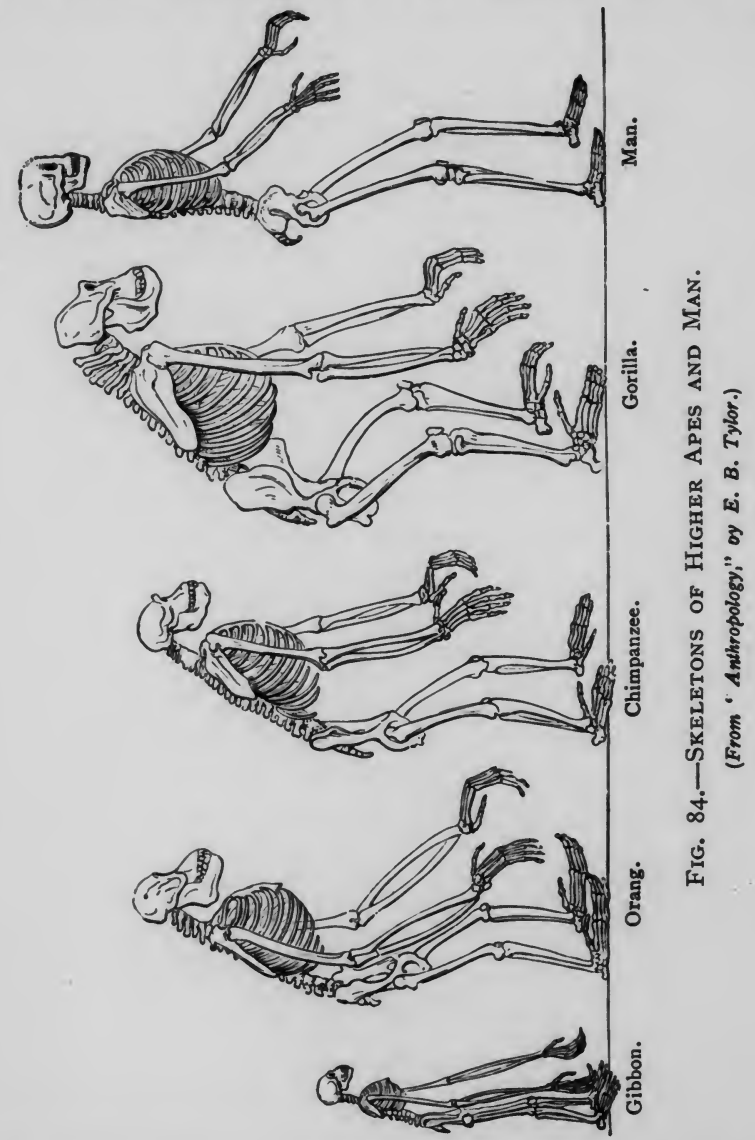

this which differentiates man from his nearest congeners. As A. R. Wallace pointed out, man has undergone little or 
no bodily change since he first entered upon his full human inheritance; he has been able to adapt himself to the changing conditions of his existence by an ever-progressing intellect. It is the advance in brain capacity that mark intellect. It is thelutionary stages. We therefore find, as his successive evolution we trace the gradual ascent of man tromis earlest precursors, a continuous increa (see Fig. 85). At the same time, the brutish features indicated by the prominent eye-ridges and heavy jaws

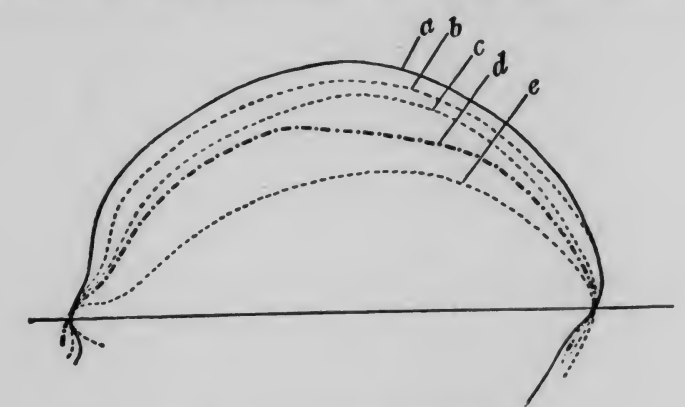

Fig. 85,-Outhine bF SkULLS.

$a$, Ordinary Irish skull $; b$, man of Spy ; $c$, Neanderthal man $d$, Pithecanthropus; $e$, gorilla.

(From a paper in "Nature," February 26, 1895 , by Dr. D. J. Cunningham. By per.

with receding chin, which serve the needs of powerful muscles, slowly disappear (compare the illustrations in Fig. 86).

The earliest evidence of prehistoric man found in the first half of the nineteenth century by Boucher de Perthes firs no credence, as was natural in view of the Slowly, the biblical pros shed however, as upon the origin of man by the evolution theory, the high antiquity of man became an established fact. His first

\section{EVOLUTION OF MAN}

$26 \mathrm{I}$

appearance can with certainty be traced so far back a the Pleistocene Age, and has by later authorities been refered back to the Pliocene and even Miocene period. The most The most primitive man-like remains yet found are those discovered in Java (I89I) by Dr. Eugène Dubois. They consist only of a skull-cap, a thigh-bone, and two teeth, and have become famous as affording at last the longsought " missing link" between ape and man. The ape(Pithecanthropus eroctus) of Java (see Fig. 86A) in any case stands midway between the two types, and has variously been assigned to the early Pleistocene or Pliocene strata.

It is usual to divide the prehistoric age of man into various periods according to the character of the tools Thus to the character of the tols employed by him ments of stone, and only very much later did he learn the art of using metals. We thus speak of the Ston Age and the Metal Age respectively, the latter extending right into historical times. The Stone Age itself, which - lasted throughout the greatest part of the Quaternary epoch, has been subdivided into Palæolithic (old stone) epoch, has been subdivided into Palæolithic (old stone) and Neolithic (new stone) Ages. The existence of a still earlier-Eolithic-Stone Age, maintained by some authors, has so far not been accepted on the evidence addunaThere is doubt whether the eoliths are of human manufacture.

Coming now to the description of palæolithic man, it must be pointed out that he is known by a number of fossil remains found in various localities, mainly in Europe, but lately also on other continents. The most typical example is, perhaps, the Neanderthal man, discovered in 856 at Neanderthal (near Düsseldorf, in Germany). The skull is, like all others of palæolithic man, of the longheaded type, with flat, retreating curve and beetling brow. It was declared by Huxley to be the most ape-like knowni.e., before the discovery of Pithecanthropus. We can reconstruct to a certain extent the life of these first men, as 
262 THE FIRST PRINCIPLES OF EVOLUTION

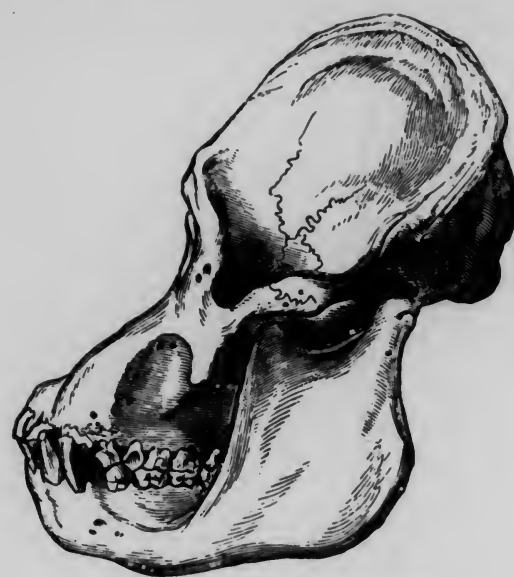

Fig. 86.-SkULL of AN ORANG.

(From "Mammals, Living and Extinct," by G. Flower.)

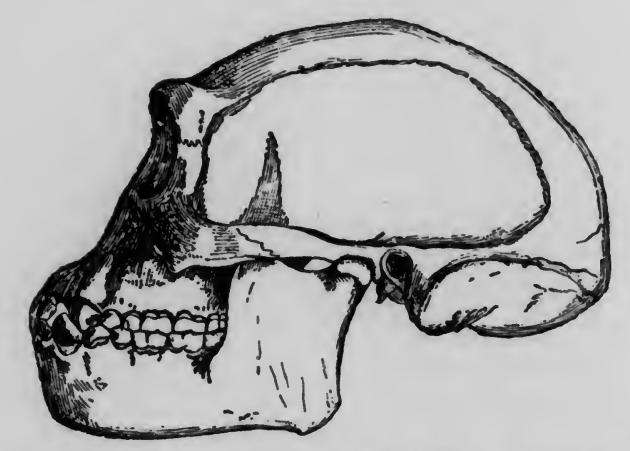

Fig. 86A.-Skull of the Fossil Ape-Man of Java (Pithecanthropus ereclus), RESTORED BY EUGENE DUBOIS.

(From Haeckel's "Evolution of Man.")

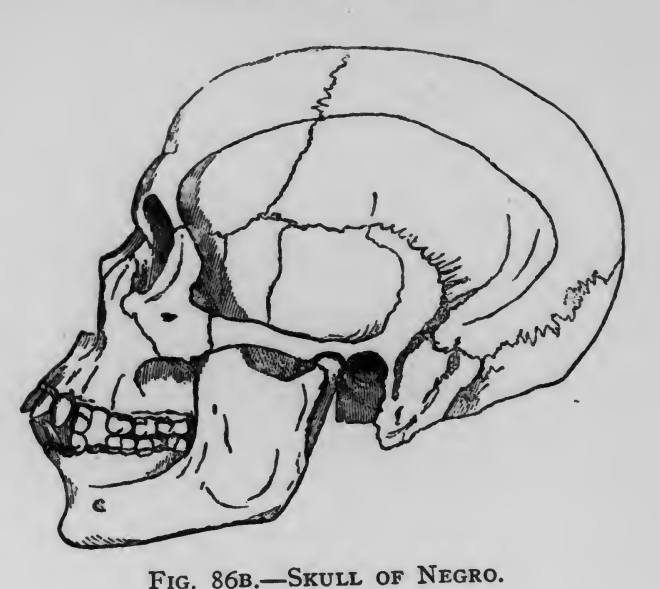

Fig. 86B.-SkULL of Negro.

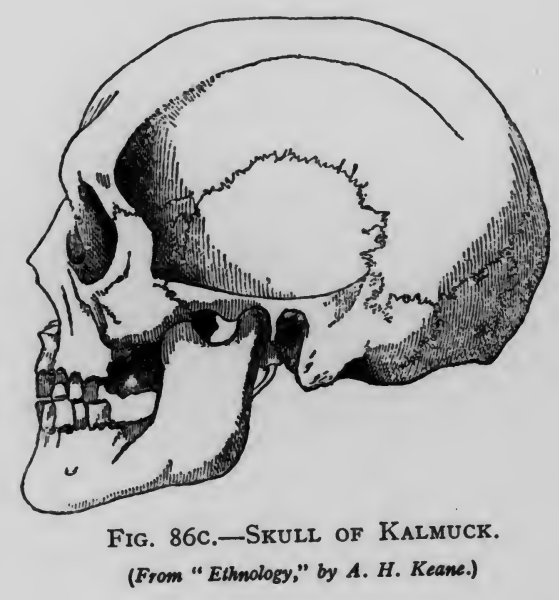



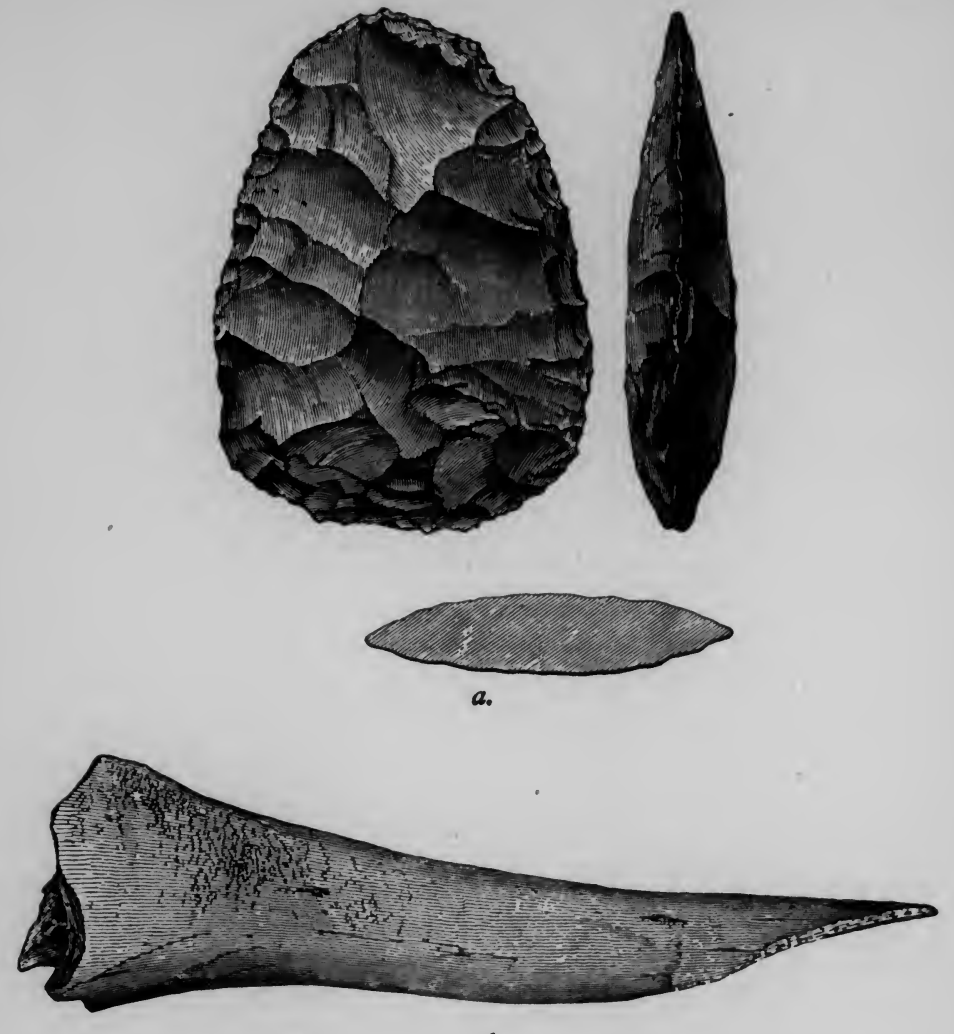

b.
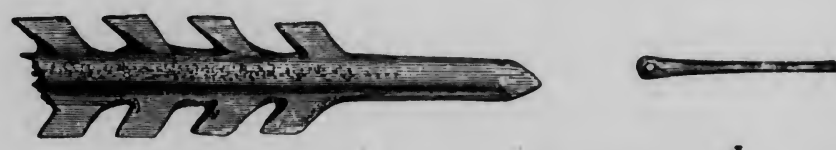

d.

Fig. 87.-Palezolithic Implements. (From Kent's Cavern.) Flint implement; $b$, bone awl; $c$, harpoon head; $d$, needle. (From "Elhnology," by A, H. Keane.) they roamed over Europe and Great Britain (then still com the ample specimens connected with the mainland, from of their work which have been collected in the numerous places of their habitation brought to light, especially in England and France. It is customary to speak of two periods of the Palæolithic Age, according as the relics are found in "river-drift" - -i.e., in the deposit of brick-earth found in "river-banksand gravel, forming the present terrak shelter. But this or in caves where primitive man took shelter. But this sequence cannot strictly be maintained. The most commonly accepted division is that proposed by M. de Mortillet, who distinguishes the Chellian, Mousterian, Mortution wadelenian epochs,* the latter corresponding roughly to the Cave Age.

corresponding roughly to the Caverful The earliest stone implements (excepting the doubtul
eoliths) were of the most primitive kind. They consisted mostly of chipped flints, oval or oblong, with a cutting edge, which was generally confined to the point, leaving the edge, wher for a grip. Scrapers, borers, knives, spearremas crudely fashioned. Among the heads, etc., were thus cro to be found awls, harpooncave remains there are also to be found aws, harponheads, needles, etc., made of bone or horn (see Fig. 87). Some of these products, especially of the Madelenian period, show remarkable artistic decorations, representing period, shetches of animals associated with roug know from fossil remains the cave man (see Fig. that the mammer tropical animals, existed together with palæolithic man in Great Britain, France, etc. ; and we must conclude that the climate at that time was much warmer in those regions the climate at that the hand, the Arctic reindeer is also than now. On the oth hrofessor Boyd Dawkins argues typical of this period. from this that, as the climate alternated between cold, there occurred seasonal migrations of the fauna from south to north, and from north to south. Professor Keane,

* The names refer to places in France, where the most typical implements have been found. 
266 THE FIRST PRINCIPLES OF EVOLUTION

however, does not think such periodical migrations probable and surmises rather that the reindeer lived at those tim, ine of palæolithic man was times in temperat extremely simple. He was a hunter and fisher; his clothing consisted of animal skins. No trace of pottery no kind of burial, is known of that period. It is even doubtful whether, in the earliest stages, he was able to kindle fire. The modern Australian aborigines were, when discovered the nearest representatives of this low type of culture.

The question here arises : Where did primitive man come from? Has all mankind descended from one original

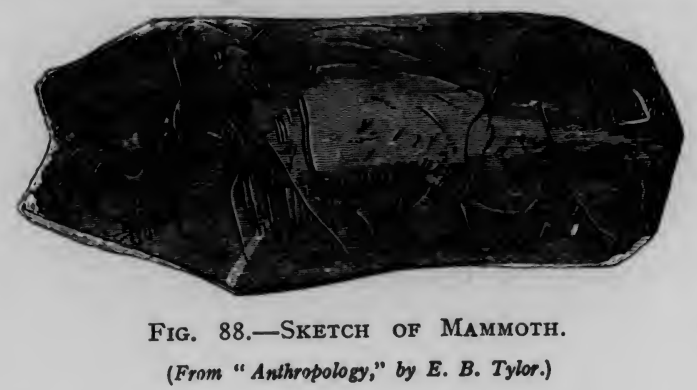

stock, as the monogenists assert; or have we to posit with the polygenists several primitive races of independent simian origin? We cannot here enter fully into this difficult subject. The main argument of the polygenists is based at present on the evidence of language; for it is been impossible to reduce the multiplicity of linguistic groups to one common type. The answer to this is that, generally speaking, language is no test of racial descent It could hardly be maintained that every stock language presupposes a separate original race. On the other hand, anthropological evidence points to the unity of the human race. There exists complete fertility between the various ethnical groups of man, thus showing that they have to be considered as varieties of the same stock rather than distinct specis. Further, tinct species. Further, as Darwin has alroably pointed out, the numerous, often unimportant, remalume the several races of organization point to a common origin. The objection that it is inconceivable that all the various coloured races could have sprung from one common progenitor is met by A. R Wallace with the argument that man in his subhuman stage was most probably more plastic.

When we try to discover the birthplace of man, we are largely led by conjecture. Seeing that man is related to the higher apes, America as an independent centre of evolution for man is clearly out of the question. The plateau of Central Asia used to be the favourite locality flateau 's crivation, from whence all civilization was for man's derivation, from whive waves of migration. supposed But later evidence points rather to a lost Indo-African continent as the cradle of mankind. This was situated until Tertiary times where now the Indian Ocean lies, covering also a great part of the scattered Australasian islands. It is in this region that the lemurs and anthroislands. It is in this rogich through their forepoid apes are found, both of which, through their forebears, lie in the line of human ancestry; and it is here, too, that, in accordance with the theory, the transitional ape-man of Java was discovered. It is generally conceded that the immediate precursor of man was an arboreal furry furry anis haired and yellow-skin.ed." Yellow-brown, th the to have been the primitive colour of man, all the other colours being derivative. Thus, e.g., is explained the fact that the children of the black Australians and of some negroes are of a pale brown colour when born, darkening negre assumption of an Indo-African only in later age continent also affords the complicated and still unsolved problem of migration of races. From this centre dispersion was possible in all 
268 THE FIRST PRINCIPLES OF EVOLUTION

directions by land routes, for the Mediterranean basin was then still dry land connecting Europe with Africa. while America could be reached from Europe by the now vanished North Atlantic continent. Ethnological evidence also tends to show, according to Professor Keane, that the first man to arrive in Europe came from North Africa, whith he whither he had wander

There appears to occur a complete break between the old and new Stone Ages, so far as Great Britain and Western Europe are concerned; though it is claimed by some authorities that-at least in some regions-a continuity of culture can be traced, to which the name of "nuity of culture can be traced, to which the name of "mesolithic" has been applied. Europe was, according to common opinion, repopulated by neolithic man, who arrived from the east or south. He must therefore have undergone a continuous evolution from palæolithic times in southern and south-eastern lands (the Mediterranean in south eaboard, Arabia, India, etc.), which weressor Keane holds Age. Professor Keane holds that the first settlers came most probably from Mauretania, across the Straits of Gibraltar--a tall, long-headed race (related to the ancient Iberians and Picts of Great Britain). It was only much later that barbaric invaders arrived by It was only me the way of the Danube, who have been Kelts.

with the small-statured, short-headed Kelts.
The Neolithic Age, the beginning of which may roughly be dated back to about a hundred thousand years ago, is distinguished by a great improvement in the working of the stone implements. Characteristic is the polishing of the sto which " celts" saws, knives, hammers, of tools, which const of "cels," saws, knive hafting had barbed arrow-heads, etc. (see Fig. 89). Hafting had been learnt, the stone being perforated and supplied with a handle. As typical remains of the earlier kind of culture must be mentioned the "kitchen middens," huge accumulations of the refuse left by the men of that age, especially in Denmark. They show that the dog had been tamed
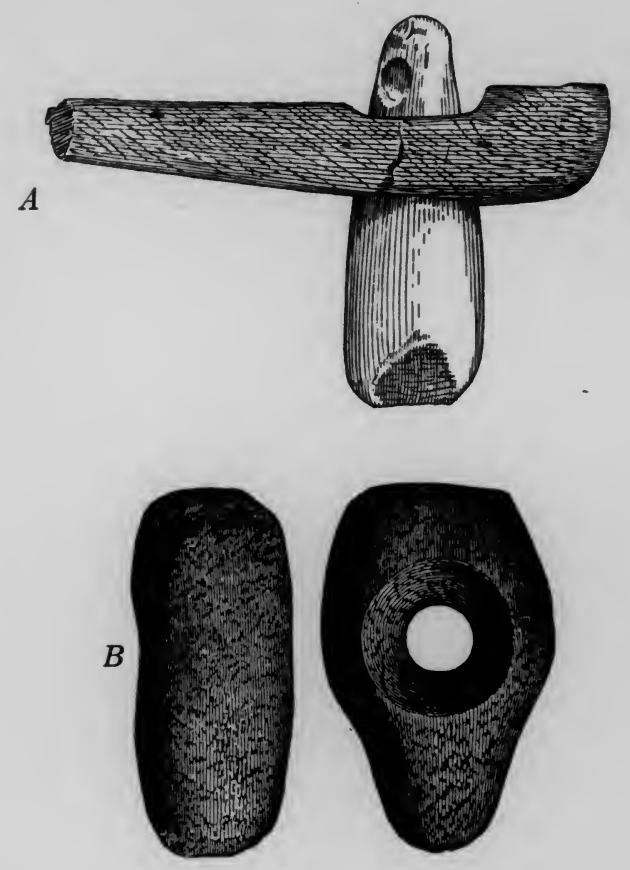

C

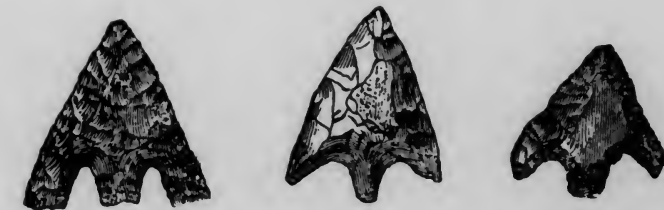

$A$, Polished celt and original handle (Cumberland); $B$, perforated (Scarborough); $C$, barbed arrow Wolds) 
270 THE FIRST PRINCIPLES OF EVOLUTION

and pottery had been invented, but the wonderful skill of Madelenian art was entirely lost. The lake-dwellings, found principally in Switzerland, are characteristic of the found principally in Syitzer later Neolithic period; they seem to have extended in some places right into the Metal Age. They were built on huge wooden piles sunk into the water. Exploration reveal fairly advanced conditions of life. Agriculture an cattle-rearing had already sprung up; spinning, weaving,

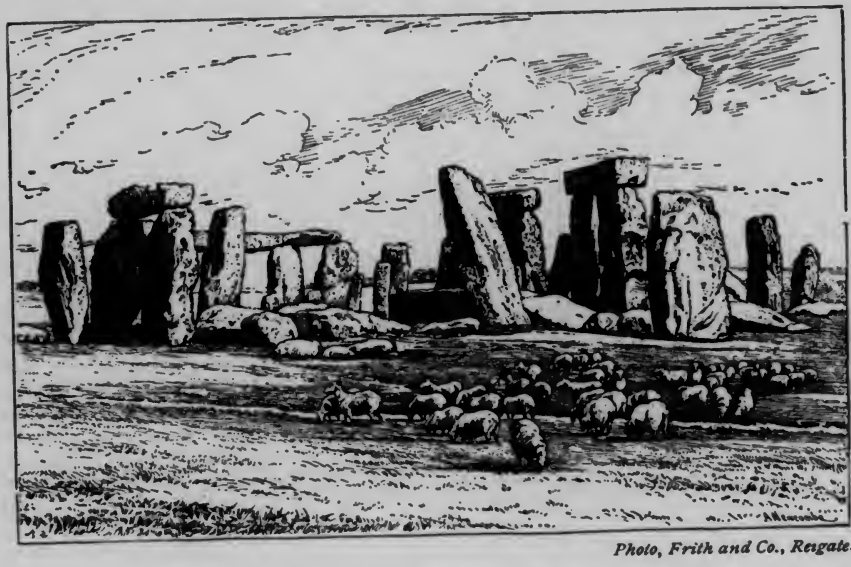

Fig. 90.-STONEHENGE FROM NORTH-WEST

and mining were known. Burial had become customary, as expread relics of barrows and as exemplal stone (Stonehenge, etc. ; Fig. 90).

monumental stone (Stonehenge, etc., Fig. 90). With the discovery of the metals we come nearer historic times. Progress is now made very much faster. The prehistoric Metal Age may be dated back about twenty thousand years. It started with the use of copper on which followed bronze, an alloy of copper with tin Iron was smelted only much later, and brings us right Iron was sich are now carried back by the latest authorities about ten thousand years, to the beginnings of Egyptian culture.

4. Evolution of Society.

Man is a social being and lives in groups. These are not mere agglomerations of individuals, as we find them among slowly evolving throughout the ages, has become more and more complex.* It is customary to distinguish three stages in the development of human society-namely, savagery, barbarism, and civilization. These ethnical periods must be conceived as having succeeded each other, but they can existing types of societies, which, having remained on a lower stage of culture, reveal a more primitive condition of mankind.

Without going into the smaller subdivisions of each period, we may describe the savage state as consisting in a life dependent on the wild products of Nature. Fruits, nuts, and fish form the staple food; natural shelters, later on primitive dwellings, serve as prot weather. Clothing and the use of fire become known only in the later stages of the period, while the materials used for weapons are flint, bone, and, during the higher stages, copper. The bow and arrow are, according to $\mathrm{L}$. $\mathrm{H}$. Morgan, the most advanced inventions of savage man.

The same authority would put the art of pottery as The same authority would put the art of pottery as
marking the next period-barbarism. With it we have the advent of husbandry and stock-breeding. The making of clothing, the building of canoes, the construction of permanent dwellings, first of wood, then of stone, gradually improve as we ascend towards civilization. The smelting in organization, which was very rudimentary in the savage

- The insect-communities of ants, bees, etc., are also organized ; but being based on a division of functional types, they are rigidly determined by instinct. 
272 THE FIRST PRINCIPLES OF EVOLUTION

period, grows apace. Tribal usages and customs are slowly codified into rudimentary laws, while political power becomes established in hereditary chieftainship, etc. The invention of writing and the formation of an alphabet invention of whiting and characterize the advent of
into the domain of history.

We are unable within the limits of this work to give an account of social evolution in all its aspects, but must content ourselves with a short survey of what may be considered the basic institutions of society. These are sidered the Bate; and C. Religion. We shall A. The Family, B. Thith a short résumé of the position conclude the chapter with a short resume of the position of science and its application to the problem of socia progress.

\section{A. The Family.}

Nothing would seem more trite than the observation that the family forms the basis of society. Yet this is by no means self-evident. It will become apparent in the followmeans self-evident. It will become apparent in the following pages that the origination of the State is closely bound up with the organization of the family. The study of

family, therefore, naturally precedes that of the State.

What constitutes a family? To the average layman father answer is obvious: it consists of the two parents, father and mother, and their children. Yet this modern family, as we know it, has a long history of development behind it, the initial stages of which are, as we shall see, not yet fully cleared up. In the exposition of the various theories we clear excellent résumé of the subject in his " History of Matrimonial Institutions."

\section{(a) The Patriarchal Theory.}

The earliest modern scientific investigation into the constitution of the primitive family is that by $\mathrm{Sir} \mathrm{H}$. Maine who in his " Ancient Law " (I86r) espoused the well-known who in has miliar with patriarchal theory. Scrin the main evi- dence for his views $\mathrm{Sir} \mathrm{H}$. Maine found in the Roman family before its transformation and decay during the historical period. The patriarchal family consisted of the eldest male and all descendants in the male line only. "None of the descendants of a female were included in the primitive the desce into the family by the legal fiction of adoption. All persons thus coming under the authority of the father of the family (paterfamilias) were said to be connected by agnation.*

The power of the house-father (patria potestas) was supreme, extending during his whole lifetime over all members of the household, even over married sons, their wives bers of life and children. He had over his children "the power of life ment"; he could "modify their personal condition at pleasure"; he could "give a wife to his son"; he could " give his daughter in marriage"; he could " divorce his "give his daughter in ma " could "transfer them to children of either " " could "transfer them to another family by adoption ", he could "sell them." The "Children under Power" could not " hold property apart from their parent. ... The father was entitled to take the whole of the son's acquisitions." But it should be observed that the paterfamilias was answerable for the delicts (or torts) of his "Sons under Power," as he was delicts (or "torts) of his "Sons under pis slaves" similarly " answerable for the torts of his slaves." The subjection of woman was complete. Legally she became the daughter of her husband, and therewith subordinate to his patria potestas.

We cannot here enter into a discussion of how such We cannot in the eldest male of the extreme pow "implicit obedience of rude men to their parent is a primary fact," while, " at the same time, if it is natural in the sons to obey the father, it is equally natural that they should look to him for superior strength or superior wisdom." The patriarchal system of

* Cognation, on the other hand, implied the kinship in the modern sense to a common pair of ancestors. 
274 THE FIRST PRINCIPLES OF EVOLUTION

the family can be traced among the Romans, Hindoos, Sclavonians, and the Indo-European stock in general, as also among Semitic people; and, remarks Sir H. Maine " the difficulty is rather to say what races were not "the differty is on the patriarchal model."

originally organized on the patriate generally admitted to have But though the patriarchate is gevelopment of the family formed an historical stage in the development of the family of certain peoples, it was by no means a universal stage passed through by all races ; least of all can it be looked upon as "the primeval condition of the human race," as Sir $H$. Maine would have it.

Of the Of the many objections brought formarck patriarchal theory by Spencer, McLennan, Westermarck and others, we shall only mention the most important. In the first instance, societies based on the patriarchal system are mainly pastoral or agricultural, which presupposes a conare maine of culture and social organization. Also, sider in involves is much too the idea of palria polest an ankind in its complex a legal notion to be attribut th Sir H. Maine, in primitive beginnings. It would seem that Sir H. Maine, in expounding his patriarchal theory, had too much in view expoun society, which implied already a very advanced type of civilization. Besides this, the fundamental assumptype of the patriarchal theory has been traversed by tion on thescent and inMcLennan and othive heritance in primitive races does not forlow the theory paternal side. In fact, the upholders of the theory of mother-right maintain that succession in the maternal line is the more archaic form of the family.

\section{(b) The Matriarchal Theory.}

The idea of mother-right originated with the Swiss cholar Johann Jacob Bachofen, and was later worked out independently by L. H. Morgan and J. F. McLennan Though the details of their schemes vary, all three assum promiscuous intercourse as the first stage of human sexual relationship; this was followed by mother-right, which in its turn was later replaced by father-right. Bachofen, whose "Mutterrecht" (mother-right) appeared in I86I - the same year as Maine's "Ancient Law "- -holds that, after the initial phase of unregulated hetairism, gynocracy arose through the revolt of the women against their degrading throus women's higher religious attitude which condition. It wim of his natural enabled her to infles physical superiority. Such gynocracy involved, not only recognition of kinship in the maternal line, but also the rule and leadership of woman-Amazonism. This, again, through a change in religious feelings, made room for the higher social relationship of fatherhood. As a relic of the high so rites. old state we interpreted according to Bachofen, as an These must be interpred, according to Bach the atura expiation to the goddess for the curtailment of the natura right through the exclusive appropriation of a woman by one man.

L. H. Morgan in his "Ancient Society" (1877) distinmishes, after a previous stage of promiscuity, five succesguive sive phases of marre (I) The Consanguine Family, founded merely indicate here: (I) The Consangune Fa in , upon intermarriage of brother and sister in a group (2) the Punaluan* Family, founded upon intermarriage of several sisters (or brothers) with each other's husbands (or wives) in a group ; the group of men being conjointly married to the group of women ; (3) the Syndasmian or Pairing ried to the place between single Family, where marriage taks paring the pleasure of the parties; (4) the Patriarchal Family being the marriage of one man with several wives; and (5) the Monogamian Family, based on marriage between single pairs, with exclusive cohabitation. The scientific single pair, which Morgan's conclusions rest-namely, the evidence on which the classificatory assumption that the nomelature of the ches system of relationship denotes actual kinship-has been severely assailed by later criticism. This, in conjunction

* Named after Punalŭa, the Hawaiian system of kinship. 


\section{THE FIRST PRINCIPLES OF EVOLUTION}

with various other arguments brought against the existence of communistic marriage, with which we shall deal presently, has practically disposed of Morgan's elaborate scheme.

Perhaps themost thoroughgoing attempt at an explanation of the matriarchal system has been made by J.F. McLennan in his "Primitive Marriage" (I865), republished in "Studies in Ancient History" (1876). He, too, starts with a state of promiscuity, when "groups would hold their a in children, while attached to the mother, would belong to the horde." He assumes that through the practice of infanticide of females, so common in primitive races, a dearth of women would ensue, which would lead to habitual wife-capture from other tribes, and therewith to the custom of exogamy-ies, the prohibition of marriage between persons of the same blood. This scarcity of women persons of the same blood. This scarcity of womed upon as the next stage in the evolution of marriage. As fatherhood was uncertain, kinship was reckoned through females only. The several husbands of the wife were at first not necessarily related to each other. In the higher form of polyandry, however, they are brothers-as, for instance, in Tibet. As meanwhile the woman has passed from her mother's house to that of her joint-husbands, taking up her abode with them, the transition was effected to the higher form of marriage, recognizing fatherhood. For in the last-mentioned case " the father's blood, though not the father," became certain ; while, with the recognition of the elder brother as the virtual father, marriage gradually approached the monogamous type. The obligation of the younger brothers among certain people to marry in turn the widow of their deceased elder brother, as also the levirat known among the Hebrews, which enjoins a man to marry the wis the widow of a childless brother, and other similar customs, are, according to this view, nothing but survivals of the once generally existing state of the higher form of polyandry. McLennan's theory has been vigorously attacked, espe- cially by Herbert Spencer, who showed that its fundamental cially by as we counterbalanced by the heavy death-rate of the male population through warfare; secondly, seeing that mutual wife-stealing among adjacent tribes could not possibly remedy the scarcity of women among all the tribes, exogamy could scarcely becmed form of marcould scarcely become a genel riage. Furthermo polyandry and wife-capture ; for, on the one hand, we find polyandry among peaceful tribes, and, on the other, wifestealing goes more often together with polygyny, the stealing wives to the conqueror.

The question arises: How far can original promiscuity (" communal marriage," as Lubbock called it) and the matriarchate be acknowledged to have been actual stages in the development of marital relationship ? The main prof of a primitive stage of sexual communism rests, proof of a primitive stage of sexual commes suppod to be firstly, on certain cases of group-marriage, supposed to be in existence among certain savage races, and, secondly, on the occurrence of some survival customs, as mentioned by Bachofen and McLennan. As to the former, their correct observation and interpretation has been seriously doubted while the latter have been explained in various other ways. while the latter have bect The religious orgies have been attributed to phallic worship the levirate may have resulted merely from the savage notion of the succession of property, the wife being included among the transferable chattels; and so on. As to the positive arguments against promiscuity, they will appear later during the discussion of the monogamous theory. The idea of the matriarchate as implying an actual rulership of womanhood is now generally abandoned, though the one-time existence of mother-right-i.e., the succession through the female line-is conceded by many authorities. For it has been found that mother-right is well compatible with the simultancous exhibition of male dominance, the 
278 THE FIRST PRINCIPLES OF EVOLUTION

mother's brother taking the place of the eldest male, where the father is not the head of the family.

\section{(c) The Monogamous Theory.}

It was Professor E. Westermarck who, in his " History of Human Marriage" (I89r), finally demolished the assumption of a primitive state of promiscuity, and raised, largely on biological grounds, the foundations for the belief in " original pairing" among the human species. Following the earlier conclusions of Darwin and Spencer, he looks upon marriage, not as a specifically human product, but as the latest efflorescence of sex-relationship in animal life. Marriage, according to his definition, is nothing else than " a more or less durable connection between male and gation till after the birth of the offspring." Marriage, seen from this point of view, is not merely a sexual act, but exists for the purpose of rearing the young. "It is for the benefit of the young that male and female continue to live together. Marriage is thefore rooted in family, rather than family in marriage." Now, promiscuity is by no means the rule among higher animals. Birds are notoriously monogamous in their unions, while animals of prey and the higher apes live generally in pairs. In tracing back, then, human marriage to its earliest stage, we must assume it to have started with a condition resembling that of man's ape-like ancestors. Furthermore, general promiscuous intercourse would be prevented by existing sex-jealousy of the combative males, which, as Darwin already pointed out, holds good also for primitive man. Finally, evidence tends to show that promiscuity as a rule leads to infertility ; it could, therefore not possibly form for any length of time a regular custom without leading to the extinction of the race. As Professor L. T. Hobhouse puts it: "Sheer promiscuity is probably to be regarded rather as the extreme of looseness in the sexual relations than a positive institution supported by social sanctions."
EVOLUTION OF SOCIETY

279

How have the other forms of marriage, polyandry and polygyny, arisen in the course of evolution? We have already seen that McLennan's explanation of polyandry, which ascribes its origin to the prevailing scarcity of women, cannot stand. Nor, in view of the foregoing arguwomen, can maintained that polyandry, ments, can Spencer's idea be maintain " successive limitaas well as polygyny, have originated by " successive limitations of promiscuity." Westermarck attributes polyandry to a surplus of men, "due, on the one hand, to poor conditions of life; on the other, to close intermarrying." At best, polyandry occurs only comparatively rarely; and is but a passing phase in the evolution of marriage.

but a passing phase in the evolution of marriage.

Polygyny, on the contrary, flourishes mostly under conditions of opulence, where men can appropriate more than one wife. It is generally only the most powerful or wealthiest who live in the state of polygyny. "It therefore presupposes," as L. H. Morgan already observed, " a fore presupposes," as L. H. Mrgan considerable advance of society, together with the development of superior and inferior classes." By degrees polygyny tends to give way to the monogamous union, which by its stronger emotional bond between husband and wife, acquires with it a great biological advantage for the acquires with it a ways. In the family. The transition is achieved in two wenty only the wemarked, it is generally only the nobility and the rich who can afford to have more than one wife, monogamy thus becoming compulsory through necessity among the bulk of the poorer classes; secondly, there sity among the bulk of the household to is the tendency chief wife, the remainder holding merely the place of concubines.

Starting then, with the family in the primitive state, consisting of a more or less temporary union of both parents with their offspring, we pass through the stages of polyandry with the whench and polygyny, which at berther-right in the development of human marriage. Mother-right may be considered to have preceded the patriarchate, in which the family becomes more firmly knitted together 


\section{THE FIRST PRINCIPLES OF EVOLUTION}

through the influence and rule of the paterfamilias. At the next higher stage we once more return in a circle, as it were to the original monomous union, this time of a highly-developed kind, with a strong permanent feeling of responsibility on the part of the parents towards each other, and to the children, though relics of the old subjection of woman still linger on. The highest mode of human marriage, which shows signs of becoming the prevalent type in the near future, is the one where " the closest moral bond " exists between husband and wife, while at the same bond " exists between husband and wife, while at the same
time the fullest "legal and moral personality" of the woman is vouchsafed, as well as that of the man.

\section{B. The State.}

It has been pointed out previously that, to use the words of Herbert Spencer, "the mere gathering of individuals into a group does not constitute them a society. A society, in the sociological sense, is formed only when, besides juxtaposition, there is co-operation." Now, it has already been position, there is co-operation." Now, " (argely dependent on the prevailing type of the family; while we may add here that the forms of family organization stand in close relationship to the economic modes of production. Co-operation in groups, be it for the purpose of industry or of warfare, has been the main lever in the attainment of ing the evolution of the State, we shall find that these groups were in the first instance based on community of kinship, and only very much later, in comparatively recent times, was this gradually replaced by community of local interest.

\section{(a) Primitive Communism}

Hunting and fishing are the most primitive modes of industry. Wandering from place to place in quest of game, savage man constantly shifts his hunting-ground, which for the time being is considered the prerogative of the tribe frequenting it. The chase being carried on jointly by the tribe, the spoils are divided in equal portions among the tribesmen, with the exception, perhaps, of the chief, who receives a preferential share. Social organization at this stage is low as yet, as seen, for instance, in the case of the Veddahs, who merely form a roving horde, and can hardly be said to have formed a society.

A marked step in advance is made by the domestication of animals. We find most pastoral people, though still nomadic, arranged on the patriarchal system, which becomes the upwards-tending type of society, as soon as the adoption of agriculture leads to a settled habitat. It is this stage of society which is generally described as primitive communism, and we shall now examine it more fully in its munism, and we shall now exam

economical and political aspects.
The land in primitive times is held in common by the tribe occupying it. This holds good, not only for the pastures of nomadic races, but also for the arable land of the more settled communities. The "village community" is the typical form of society in the early stages of agriculture, typical form of society in the early stages of agriculture,
through which all races are supposed to have passed in the course of their development. After G. L. von Maurer had first described (in 1854) the old Teutonic communal system of the Mark, traces of primitive communism were discovered in nearly all civilized countries (England, France, Switzerland, etc.); while in the more backward eastern countries (Russia, India, etc.) the same system was found to be still extant in a more or less modified form.

In the original village community the primitive tribal organization is still maintained to the full. The land around each settlement forming a village is divided into three kinds-arable land, pasture and meadows, and the still unreclaimed forest and waste lands. To the last all households of the community have an undisputed common right of use for wood, game, etc. ; while pasture-land also is generally held in an undivided state, being kept as a common grazing-ground for cattle, etc. In the most primi- 


\section{THE FIRST PRINCIPLES OF EVOLUTION}

tive village communities the arable land, too, is the property of the tribe, and is cultivated in common, the produce of the harvest bing distributed among the families of the more often the land is portioned out to village. But more often the land is portioned out to the separate family households, while the tillage and the harvesting are still done jointly. Each family has only the temporary usufruct of the allotted piece of land. This to important consequences. As each housecustd is deeme to community (excepting the chief of the village), the land, unequal in quality in the various parts, is redistributed from time to time by lot, the portions allotted to each family consisting of small strips which lie intermingled with those of other families. Custom holds primitive society in its grip as with families. Custom an iron hand. A rigid system of rules, defived from remote antiquity, binds down each member of the community, and determines when and how each operation in the field is to be performed. The very fact that the strips of land allotted to each family are not contiguous with each other. and re to small to be tilled separately, leads to a continuand are too small to be tilled separately, leas to ance of the unprogressive co-operative system of feld work long after the communistic spirit has died out in the medieval village. The redivision of land originally takes place yearly, but may be deferred for a number of years, until finally the redistribution is dropped altogether, and the individe possession of individual shares remain perlage communities can be found each respective family. Village communities can be found in all these stages of transition. It must be distinctly pointed out that the land does not become the property of any given individual, but belongs to the family as a whole. The patriarchal family is a unit, and has not yet broken up at the stage just mentioned, up, as happens in later tim a the the old communal rights are still traceable in the fact that the land is inalienable, and cannot be disposed of without the consent of the village council; while, as we have seen, the tillage is still managed jointly by the combined households.
Coming now to the political organization of the village community, we have already remarked that it is arranged on the patriarchal system. In fact, the village is nothing but the patriarchal family " swelled into the clan." Al members of the village community have, or at least claim in theory, descent froin a common ancestor. Strangers may be admitted into this self-contained society by adoption, which makes them legally kin to the tribesmen. All members of the archaic communistic State are essentially freemen with equal rights, all matters pertaining to the community being decided in council, which is presided over by the eldest headman, who but administers the affairs of the village accord to old-established usage. Law, too, in the primitive state is not a matter of equity between persons, but consists merely in the right of retaliation between families. A murder committed is not so much a crime against the life of an individual, but rather a loss to the family, which has to be avenged by taking the life of a member of the slayer's family, if the murderer himself cannot be killed in revenge. The earlier stages of human civilization are dominated by the blood-feud, which is somewhat mitigated in later times by substituting for it payment of compensation (wergild), graduated according to the computed value of the tribal member.

For we find that in time gradations of rank establish them selves among the originally free and equal tribesmen. The eldest of the clan at first only acts as headman of the council. He may, however, become elective and assume real rulership, be it through his valour in war, which secures him permanent military chieftainship over his followers, or through his greater amount of wealth, acquired partly from war booty, partly from his special share of land, which enables him to keep more cattle and sheep. The constant raids also lead to the subjection of tribes, and therewith to the institution of slavery, which is a conspicuous feature of civilization up to very tribal stage of society is exemplified as much in the City 


\section{THE FIRST PRINCIPLES OF EVOLUTION}

States of ancient Greece and Rome as in the agricultural village communities of the Teutons. Fustel de Coulanges has shown admirably how the religious family cult of the patriarchal system pervades the whole life of the Ancient patriar.

Before tracing the further development of the tribal state into the next stage-that of feudalism-we must not omit to point out that the existence of a primitive communistic society is by no means accepted by all authorities. One of the foremost critics is Fustel de Coulanges, who, after sifting all the given evidence in favour of primitive communism, holds it to be of insufficient proof. Without altogether denying the one-time existence of such a state of society, he maintains that the documents adduced have been misinterpreted that the land has always been held subject to overlordship. All that can be asserted is family ownership of land, which is not equivalent to communal ownership. On the other hand, his opponents believe that, apart from philological interpretation of documents, there are positive facts of a number of survivals which can only be explained on the assumption of a primitive tribal communism, which is nowadays the generally accepted theory.

\section{(b) Feudalism.}

The village community represents, as we have seen, the tribl stage of society. Agglomerations of such tribal comtribal stage of munities, with a powerful leader as king at their head have been formed over and over again in history, but proved mostly of temporary character only, and left no permanen effect on the general progress of society. It is by the gradual fusion of a number of tribes into one organic whole gradual fusion of a number of tribes into one organic w Feudalism proved to be the necessary transition stage from the patriarchal society, based upon kinship, to the moder society, based upon citizenship. The Roman Empire though master over nearly the whole of the then known world, failed to consolidate its vast possessions, because it
EVOLUTION OF SOCIETY

remained essentially a City State, centralized in its govern ment, which, incapable of expansion, remained foreign to the greater part of its subjects.

Feudalism arose as the result of the barbarian invasion of the Teutons into the Roman Empire, and can be said to have originated in the ninth century after Christ with the Franks. The ancient Teutonic communities were organized on the tribal system. But the constant warfaring expeditions and the occupation of newly conquered territory by the German tribes led to a series of consequences which ultimately changed a community, based on freedom and equality, into a society of vassalage and serfdom. The actual stages of transition are still subject to a great deal of surmise. But various points stand out sufficiently to indicate the process of feudalization. In the first instance, the chronic state of war gave the warrior chiefs greater and greater prominence, and made them ultimately powerful lords, with a strong following of devoted men who lived lords, with a strong following of devoted men who lived service in return for a share in the booty. On the other hand, we have already seen that the village chief often became the ruler of the community by acquiring great became the ruler of the commu wealth and influence. It is from these two sources that the feudal barons of the Middle Ages were derived. They land, which originally belonged to free communities. This happened in several ways. There is first of all the custom of " benefice," by which the king bestowed parts of newly conquered territory upon the chieftains in return for certain services and duties. The benefice was originally given merely for a number of years, but was gradually extended to last for the whole lifetime of the vassal, and finally became hereditary, just as the rulership of the villages, at first given to certain prominent families by mere custom, was ultimately claimed by them as an hereditary right.

But the "lord of the manor," as he was called, managed in time to appropriate to himself also a great deal of com- 


\section{THE FIRST PRINCIPLES OF EVOLUTION}

munal land of his own tribesmen. The free owner of the and often found it useful in those troublesome, lawless land often found it useful in those troublesome, lawless times to put himself under the protection of a superior lord able to defend him. In return for this protection, he voluntarily yielded his land to the lord, henceforth to hold it tarily yielded his lane many freemen from the lord as a benefice. Thus we lands and turned into dependent tenants. The waste lands and forests were frequently made over to the lord by roya grant, and their use by the villagers became subject to the lord's " right of approvement." Often, however, the tillage lord's "right of apple to the lord's " demesne," being either land itself was added to the lord "som the impoverished seized by sheer force or wrested from the impoverished freeman, who thus sank to the state of villeinage. The free inhabitants of the village were thus gradually reduced to serfdom or partial serfdom, being tied to the land which to serfdom or partial sere from some lord, and doing compulthey held in dop other hand, it must bery service for has bound to give them protection for their loyalty be said, was

and service. Indeed, the whole system of feudalism rested on a code of allegiance between classes of superior and inferior status, arranged in a minutely ad and tenure and service had ward to serf. Recognition of land tenure and sinship. The same taken the place of the mutual bond of kinship. The sam change is apparent in the advance of justice. We have seen that in the tribal stage the responsibility was collective, being shared by the whole of the clan. But blood-feuds being shared to become mitigated by the appeal to gradually tended to become clders. This method came mediation before a council of elder. thes, and led to the more and more in vogue during feudal times, and led to the custom of the " ordeal by judicial combat," which was only " a mode of reducing to orderly fashion the old right of " a morsonal redress." A further step was taken when the personal redress." A merely in order to make oath on behalf supporters appeared comof the party concerned-a method whe foudal power of the purgation." With the growth of the feudal power of the lords a new principle arose which slowly replaced the old system of family feud. The baron, the prince, the king,came to claim the right of preserving order within the borders of his territory. Wherever the king happened to be, the " hin territory. "Was declared a fine being inflicted for breach of it. As the power of the king extended more and more, the control of the king's peace spread, and finally became general. The king now delegated his power to certain functionaries, and this ultimately led to the establishment of judicial courts in the land for maintaining public order and justice.

The feudal system led to very important consequences. It carried within itself the germs of the future development of the modern democratic state. This, as is well known is based upon the principle of citizenship. Every adult member of society is recognized -at least, in theory-as a member of society is recognize free and responsible agent, who has aright to thefulldevelopment of his personality without let or hindrance, except that he must not encroach upon the right of his fellowcitizens to the same enjoyment. The bondage of the feuda system has been broken down, serfdom been abolished. The state is now no longer controlled by a despotic force from above, but by the people themselves, who claim a proper share in the government through chosen representatives.

In order to trace the change of the old hierarchical land system of feudalism to the modern industrial state, with its principle of free competition, we should have to follow the rise and deverout the rise and development of trade and industry through the last five centuries, especially in England. But this is mor a subject for the economist than for the evolutionist. Suffice it here to say that it was brought about, firstly, by the liberation of the agricultural labouring class from the soil, whereby they became free wage-earners; secondly, by the expanion of commerce and the establishment of by the expansion of commerce and the establishment industrial centres, which gradually supplanted the agricultural labourer by the industrial worker. The final step wa taken when, through the introduction of machinery and the steam-engine, the small home industry was converted 


\section{THE FIRST PRINCIPLES OF EVOLUTION}

into our huge factory system, with its international connections all over the world.

The result has been by no means unequivocally good especially for the wage-earning class; for an oppressive plutocracy has taken the place of an overbearing landed aristocracy. Indeed, the latest phase discernible is a aristocracy. Indeed, the latest phase discernible is a tendency towards a return of collective responsibility, this time undertaken by the state as a whole. The individual,
detached in complete freedom from his ancient trammels, is seen to be unable to withstand singly the intensity of the modern competitive system, which reduces the majority of the poople to the position of cogs in the wheel of our of the people to the position of cogs in the wheel of our gigantic capitalistic machine, thus rendering their liberty a mere sham. Signs are not wanting which indicate that the state is going to step in more and more to render impossible the exploitation of one individual by another, for it is becor society is a becoming recognized that each mat of society is a valuable asset to the community, and that only with mutua hearty co-operation can the best and highest development of each be realized by all.

\section{Religion.}

Society has, not unaptly, been likened to an organism. If we look upon the family and the state as forming the structural groundwork of the body politic, we may, whilst guarding against too close an application of the analogy, regard the ideological manifestations of society as the regard the idect ert then, to complete our survey of the evolution of society, we shall deal with the development of religion, appending a short résumé of the scientific tendencies of modern times.

That religion must be included under the all-embracing law of evolution is now generally admitted. Whatever definition may be given of religion, it is recognized that the religious consciousness, being of the psychological aven order, has developed from a lower to a highere among those who believe in a special and inspiration are many who affirm that "revelation and inspiration progressive," the Deity manifesting himself in the primitive savage in a crude and imperfect manner, and gradually rising to the spiritual conception in modern man.

It is customary since Professor E. B. Tylor's epochIt is customary since Prime Culture " (I87I) to distinguish making work on "Primitive Culture "(r8I) to distinguish two large periods in the evolution of religion. "The fist, which Tylor denoted as the stage of "Animism," implies the belief in spirits, which in the second stage gradually the belief in spirits, which in of one supreme Deity being change into deities, the idco of this evolutionary process. attained as the latest outcome of this en We shall first deal with the theory of Animism, and

(a) Animism.

Animism is the belief in spiritual beings, which are held Animism is the belief in spirid to control the material wo the idea of immaterial, superthe savage mind arrive at the idea of imat theory, natural agencies? There is, according to this theory, as the word " animism" implies, a natural tendency in the word "animil objects "a life and will primitive man to ascert kindred to his own." But this must, as savage man could pointed out, not be meant to imply that savage man objects not discriminate between animate and inanimate objects for this is a faculty present already in the higher animals. We must rather posit with Edward Clodd a pre-animistic We must rast, where any unusual stage, shared alike by man an phenomenon of nature exciter. It is only when man has emanation of a strange power. It is vague, of his own reached a "conception, more or less vague, of his own personality" that he comes to compare this power to that within his own body, and begins to people the world with within his own body, and cognceived as material duplicates of the living being. 


\section{THE FIRST PRINCIPLES OF EVOLUTION}

But how does primitive man arrive at this notion of a double or ghost of his own self? The daily experiences of death, dreams, and abnormal mental conditions, such as trance, ecstasy, etc., supply the necessary material. To the savage the distinction between death and life, dream and reality, is by no means easy. Sleep, which stretches the strong body motionless, is often accompanied by vivid dreams, during which the sleeper himself appears to play an active part. The explanation given by the savage is that a ghost of his own self exists which leaves the body during sleep to seek its own adventures, only to return on his awaking. Swooning is a more or less temporary departure of the ghost : while death ensues, if for some reason or other the ghost has left the body for ever. As the savage is by no means certain when this has occurred, he resorts to all sorts of strange ceremonies, which have the purpose of either delaying the departure of the ghost or of inducing its early return. Exorcism and sorcery are the savage's means of gaining power over the living person or over his ghost. At first this ghost is conceived as entirely material, separable from the body, yet dependent upon it. This fact, which seems so unthinkable and contradictory to modern minds, appears by no means so to primitive man. Indeed, it belongs to the essence of the origin of the belief in the supernatural that soul and body are in their beginnings not conceived as entirely separate and discrete entities. This happens later. The soul-image of the body becomes more and more dematerialized. Assuming gradually a position between substantiality and insubstantiality, held to be a sort of vaporous, ethereal materiality, it is finally likened to the shadow or breath, whence the etymology of the word " spirit," which in most languages denotes " breath."

The ghosts of the departed are, in the first instance, treated like living beings; food is deposited at the burialplace, arms are placed ready for them, even servants and wives are often despatched into the next world in order to attend upon their master in the new abode. It is from these food-offerings and rituals at the grave-side that Spencer derived all later religious observances. Religious , riginated with the propitiation ( from the food-offerings, while the grave formed the germ of the altar and sacred buildings, which were constructed at the original haunt of the ancestral spirit.* For as the ancestral spirit became a power far beyond the calculation powe its good-will " and " to mitigate its anger."

Once the idea of spiritual beings, modelled on the human prototype, was formed, the analogy was easily extended to other natural objects. Indeed, the division between man and the animal world, or even plants, is by no means distinct for the savage. If man has a double, why should not a beast or a tree? The idea that animals can take on human shape, or that human spirits assume animal guise, has nothing strange for primitive races. Even inorganic objects, as flowing water, the fleeting clouds, or the great clestial bodies, become the seat of indwelling spirits, which are their prime movers. In short, "savage theory of the universe refers its phenomena in general to the wilful action of pervading personal spirits."

There is a gradual transition from the conception of manlike spirits to that of the deities of the polytheistic religions. In the first place, to use the words of Professor L. T. HobIn the first place, to use the in an object, but which house: "The spirit which dwells in an object, but which can leave it and enter another, may clearly pass by easy in any object at all, but haunts it, or even, ceasing to haunt it, retains control over it." Furthermore, the spirit haunt it, retar con of a particular animal or a particular tree tends to become the representative of the whole species of that animal or of the whole forest. In other words, a step is made from individual ideas to general or specific ideas. Now, as

* Thus the altar in the Catholic churches still enshrines the relics of a saint. 


\section{THE FIRST PRINCIPLES OF EVOLUTION}

Tylor pointed out, such generalization, expressing what we "all "species" is accounted for by the save we call a "species," is accounted fork, or to an original referring it "to a common ancestral stock, or to an orion of archetype, or to a species-deity," or to a combination these conceptions. Thus the idea of the supernatural arose by separating as a divine entity what was originally merely the ghost or the soul-image of the body. To the Ancients the world was peopled with hosts of gods, the pantheons of Rome and Greece being the best-known historical examples.

Tracing finally, the latest step in the evolution of religious Tracing, finally, the latest step in the polytheism, the belie thought, we observe a progress frome in one-the onlyin many gods, to monotheism, the belief in one-the " God, "the creator and sustainer of all that is." This phase may be reached in various ways. There is, first of all, the tendency to picture the heavenly hierarchy on the all the the position model of thus becomes supreme, " overlord to one of the plane of the lesser deities being degraded to som is through the being." Another mode of development is through the exclusive worship of one national god, as that of Yahveh of early Judaism. The tribal god becomes recognized, no as the only god, but as the only god to be worshipped by as the only god, being despised as the tribe, the foreign gods of other by the term "Henoidols. This stage could be denoted by the term "Henotheism," coined by Professor Max Muller, and meaning the belief in a single god. There is, finally, a third way by which the idea of a Supreme Godhead may be reached, namely, by the identification of many gods, fusing the various qualities into one comprehensive whole as an undervarious qualities the universe. This philosophic tendency, ying principle of the univise. leading to a search for a First or Ultimate Cause, tion with the previously-mentioned fact of the exclusive worship of a national Godhead, finally brings about the highly abstract and sublime conception of an omniscient, omnipotent, and benevolent Being, which is now the generally accepted belief among all civilized races.

\section{(b) Other Theories.}

Herbert Spencer, starting from the hypothesis of a universal animistic conception of nature, held that " ancestor-worship is the root of every religion." But this conclusion, though of considerable vogue, has not found general acceptance. Animism in itself is simply the belief that " all things Animism in itself is simply " but in this statement there ment there is not necessarily included, as Professor F. B. Jevons has pointed out, a belief in the supernatural, though " the two beliefs seem to have been universally combined in varying derees." Animism is merely a natural explanation by the primitive mind of the everyday experiences of life, the primitive mind of the everyday experiences of life, while the idea of the supernatural suggests itself by an unexplainable breach in the uniform routine of nature. "It was," says Professor Jevons, "the violation of these" (natural) "sequences and the frustration of his" (the savage's) "expectations by which the belief in supernavas first called forth." natural pow we feeting for the supernatural-which thus Given, then, the feeling for the supernatural which thus it is seen, is not explained, but taken for granted-Jevons further traverses the ghost-theory by maintaining that not fear of the dead, but natural affection, is the basis of spiritual relationship; and he finds the source of this friendly bond between man and his god in the tribal custom friendly bond betwo of totemism. Following Profofessor Jevons would refer back all religious custom to a primitive stage of totemism. The totem, which represent

* Professor J. G. Frazer holds that magic, whereby savage man tries to work upon another person, implies a natural, though misundertries to work upon ance of events. It is merely primitive science, and, as such, antecedent to religion, which he defines as "propitiation of such, antecedent to religion, wh powers superior to man. The failure of magic, according to this view, leads to the appeal to supernatural forces iien to religion. Professor Jevons, however, sees in magic merely an aberration of the religious movement; for while magic art has only to do with malign influences, religion, according to a principle of love. See further. 


\section{THE FIRST PRINCIPLES OF EVOLUTION}

the tribal god in animal shape, is considered to be the super natural kinsman of the tribe, standing in the position of a friendly becrificial observances are nothin but the development of certain communion-rites with the totem-god, based on the blood-communion between members of the tribe. Ancestor-worship is, according to this theory, a private and not a public cult, running a cours of its own and becoming ultimately " assimilated in form and the gods." Polytheism and monotheism are two coeva offshoots of totemistic religion; the former resulting from an aggregation of different totem-gods through politica union of the tribes; the latter being in reality a higher form of the original inchate tribal monotheism* It follows from this theory that " the religious element is no part of animism pure and simple" ; there must be added "a specifically religious idea, one which is apprehended directly or intuitively by the religious consciousness."

A similar attitude with regard to the theory of ancestorworship has been taken up by Andrew Lang, though on other grounds. He held that there are two distinct strat of religious thought, a higher and a lower, which have no intrinsic connection with each other. The remarkable point is that he considered, upon the special anthropopoint is that he conid by (a) older one, which was only later pervaded and perverted by ghost-worship. While the latter is essentially a propitiatory cult, the original religion of primitive folk, according to this view, is a sort of monotheism, embodying cording to this view, is a sort of me view, is a sort of mondying, the creator of all things and the embodiment of "righteousness" (of course according to the standard of the savage). No worship or sacrifice is connected with his cult. Andrew Lang could not offer any explanation for the development among savages of such a highly abstract

* It would perhaps be clearer to denote this early stage of tribal
EVOLUTION OF SOCIETY

295

conception of an eternal creator ; but he repudiated strongly, the attempts. which have been made to account for the fact by assuming the influence of contact with higher religious creeds.

creeds. A more abstract origin of the reller. He defined religion suggested by Professor Max Müller. He defined religion shortly as " the perception of the infinite,"* and maintained that this feeling for the infinite furnishes in essence the that this feeling experience even in its lowest and element of religious expes with the simplest form. The primitive mind, impressed with the greatness and vastness of natural phenomena, elevates particular finite objects, as trees, rivers, clouds, the sky, sun, stars, etc., into deities, thereby expressing thei sun, stan " infinite complement." It is a sort of " natura underlying ", infinite complem took place a gradual developrevelation." Of course there took place a gradler, who was ment of the religious content. Professor Muller, who was first and foremost an etymologist, found the origin of the evolutionary process in language. It is language which first gave rise to the naming of the deity, the name being first gave rise to the nost directly sensegiven in the first instance frus the sky was called deva appealing characteristic. " Thus ") from its bright appear(Sanscrit for " shining," " bright ") from its bright appearance. Gradually, through mythological accretion, other characteristics were added as attributes of the god, sugcharacteristics name. He became a breathing and living gested by hew into a man-like agent (animistic stage) ; the hum and supernaturalbeing, finally to become superhuman and a deva or god. Indeed, deva Greek-is still the name for God. What we must clearly understand is that " the supernatural element was there understand is thing "though not yet disentangled from its from the beginning, thou

natural surroundings."

Two criticisms have been directed against this theory. Firstly, it assumes as the basis of primitive religion a metaphysical conception of the universe, which so far has been

* But he added later: "Under such manifestations as are able to influence the moral character of man." 
296 THE FIRST PRINCIPLES OF EVOLUTION

found only as the outcome of more advanced culture. Secondly, the evolutionary phases of Professor Müller's scheme depend too much upon etymological analogies, which to a large extent have been given up since his day as untenable.

There only remains to mention the rather original view of Mr. E. Crawley. With him " religion is not a distinct department of thought and action," but rather an "elemental part of life," a " tone or spirit," which pervades all menth marriage, death, the will to life, e the instinct to preserve it, is the source of, or rather is identical with, the religious impulse, and is the origin of religion." "Sacredness is the result of the religious religion. "The animistic view is that "it is the soul which gives life"; whereas view is that "it is the soul which give

Whilst we may not go quite so far as to identify with Mr. Crawley the religious impulse with the vital instinct as a whole it must be conceded that there is a good deal as a whole, it me religious consciousness int has generally been attributed to a special instinct. But as Professor W. McDougall has shown in his "Socia Psychology," it must not be supposed that " this assumed religious instinct of man is one that is his peculiar endowreligious instinct of manals." ment and has no relation to the instincts of the animals." For, "if we accept the doctrine of the evolution of man from animal forms, we are compelled to seek the origin of religious emotions and impulses in instincts that are not specifically religious." According to him, " religious not specific variety; it is rather a emotion is not a diversified product of the co-operation very complex and diversifed product of the co-operation of several instincts." We cannot here enter into a detailed account of his excellent analysis, but may point out that he looks upon awe (a compound of admiration and fear) as the principal element of the religious feelings, while as the principal elemotion. This
EVOLUTION OF SOCIETY

feeling of wonder and awe in conjunction with the natural tendency of primitive man to interpret the processes of nature on the analogy of his own volitional acts (animism) must be looked upon as the main source of all religious practice.

\section{APPENDIX}

A PrÉCIS OF SCIENCE

OuR account of social evolution would not be complete without at least touching upon the important subject of science. Mr. Crawley, identifying the religious impulse with life itself, naturally lays great stress upon the permanency of the religious element of life. In discussing the relation of religion to science, he is confident that science, whilst doing useful work by the side of religion, will never entirely supersede it. Now it goes without saying that the rise and development of the scientific spirit has been one of the greatest factors of human progress. Nor can there be any doubt that the method of scientific inquiry is invading one by one the fields of human experience formerly held to be the prerogative of religion. We may not agree with Herbert Spencer, who defined a religious creed as a "theory of original causation," but we must admit that all religious creeds contain a good deal of such theory. Savage man, unable to comprehend the elemental factors underlying natural phenomena, embodies his primitive ideas about the universe in the form of mythological stories, which have become part and parcel of the various religious systems. It is only with infinite pains and not without a prolonged struggle against authority, that science has succeeded in freeing humanity from the consequences of its own outgrown beliefs. In fact, the very subject of this book-the theory of evolution -has brought within the precincts of the "Knowable" many facts hitherto deemed beyond the ken of the human 


\section{THE FIRST PRINCIPLES OF EVOLUTION}

mind. It certainly has shown that man, in mind as well as in body, is as much subject to natural laws as the earth, the sun, and the stars, which were formerly held to be moved by " presiding spirits." Nay, even religion itself moved by "pres the influence of the evolutionary idea, and has not escaped the infuence of the scientific point of view.

is now generally treated from the scientific point of view.

There remains the final question: Is science likely in time to replace religion altogether? The answer depends, firstly, on what we understand by the term "religion," firtly, on we we the and secondly, As to the former reducible to an entirely rational system. As to the former point, taking religion to be a natural instinct of man, it may be taken for granted with Mr. Crawley that " neither the God-idea nor the belief in 'supernatural ' or 'spiritual ' the God-idea nolions sentiis essential to relithin the limits of ment may find complete satisfaction within the limits of naturalism. With regard to the rationalists attempts to explain the cosmos by mere reason without residue, there is nowadays a considerable tendency to admit failure in is nowadists of this respect. The exuber all, the last generation have not been fored that science is only it is being more and more recognized " explaining the "how" and not the "why" of natura sequences. There is a growing feeling that after the most sequences. " exhaustive ratiocination therfort Bax has called it, which Being, the alogical," as Belfort Bax hationality. Professor can never be completely reduced to rationality. Professor $H$. Bergson has advanced a most enticing thesis, trying to show that, while we are excluded by the very nature of our intellect from the elemental core of life, a sort of "supraintellectual intuition " may give us glimpses of it.

\section{Evolution and Progress}

We have traversed the whole field of super-organic evolution, and have followed the various convergent lines of social development which have led to the existing conditions

\section{EVOLUTION OF SOCIETY}

of modern civilized society. Can we draw any practical concluin conclus? The hypothesis of Natural Selection, has left a deep mark upon the social philosophy of our age. Biological ideas have become the common stock-in-trade of the social reformer, and are freely applied to the solution of sociological questions.

We have at the outset to guard against a frequent error, arising from too hasty a generalization with regard to the relationship between evolution and social progress. As has been pointed out once before, we must be careful to discriminate between evolution, which is a biological concept, and progress, to which we must attach a social value, implying "the realization of ethical ends." Progress is by no means identical with evolution, which, as we have seen, may be, and in fact often has been, retrogressive as well as progressive* As Professor L. T. Hobhouse puts it. " The fact that a thing is evolving is no proof that it is good ; the fact that society has evolved is no proof that it has progressed."

It is our first task to examine how far biological concepts have real validity for the affairs of human society. In the early triumphant days of the transmutation theory it was too easily assumed that it would give us the key to the too easily assumed that it would give us the key to the watchword of the writer on social questions. It was usedby Haeckel; for instance-to justify our present competitive industrialism as being a system allowing free play to the " school of laissez-faire, with Herbert Spencer as its greatest champion, saw in the biological law of the survival of the
fittest a verification of its own social theory that everything should be left to individual initiative and individual enter-

"It must be noted, however, that the word " progress" was used by Herbert Spencer in his early essays in the sense of "evolution," and was only later replaced by him by the latter term. 
300 THE FIRST PRINCIPLES OF EVOLUTION

prise, trusting that the best would ultimately come out at the top in this peacel warfare. It is only of late that the top in this peace facts have been discountenanced by more thoughtful facts have been discountenanced by more thou

Darwin already recognized the fact that " the moral qualities are advanced, either directly or indirectly, much more through the effects of habit, the reasoning powers, instructhrough the effects of habit, the rearal section; though to tion, religion, etc., than through natural selection, though to this latter agency may be safely attributed the socia instincts which afforded the basis for the development of the moral sense." In fact, as has been fully shown before, the social, essentially human features of life have bee the social, essentiall helues and forbearance rather the than by internecine warfare among the members of the tribe. Natural selection is to this extent mitigated in human society; or, rather, it is lifted upon a higher plane of action. Furthermore man, being endowed with reason and foresight, is largely able to adjust and modify his physical sight, is largely able to adjust and modify his physical surroundings to his own needs according to his own idealsthat is, he is able to create his own social environment. In other words, man, though subject as an animal to biological laws, "is not merely an animal. $\mathrm{He}$ is also a rational being, and accordingly he reacts to new circumstances in a way that can only be determined by taking the possibility of rational purpose into account.'

There is another fact to be considered. Natural selection, as applying to animal species, is a law of exter mination, the unfit being wiped out of existence. It is otherwise among human beings. Here, especially in the higher stages of civilization, selection takes place without higher stages of civilization, selection takes place without
elimination. To the physical struggle for existence there is superadded a "' natural selection' of ideas, customs, institutions, irrespectively of the natural selection of individuls and of races." This leads, as D. G. Ritchie pointed viduals and of races." This leads, a D. G. Ritchie poine inferior in warfare, yet may turn out to be superior by im pressing its own civilization upon the conquerors. Further, ideas and institutions may long persist, though the race among which they originated may bodily have disappeared. It is social inheritance which thus plays a predominant part in the progressive evolution of society, though actua part in the pritance of traits can, according to the latest views, by no means be neglected. While the racial type varies but slowly, "it is," as Professor Hobhouse remarks, "in the department of knowledge and industry that advance is most rapid and certain, and the reason is perfectly clear. It is on this side each generation can build on the clear. It is on this side each ge. work of its predecessors." Social tradition, which play but an insignificant rôle among lower animals, must thus be considered the most powerful factor in the progressive evolution of human society.

We are now in a position to consider shortly the practical bearings of the foregoing conclusions. Dr. Archdall Reid has shown that there exists a selective process in man which still takes place in reference to the action of certain microbes and bodily poisons. Thus it is well known that some races are more subject to certain infectious diseases than in a community exposed to the contagion of a given microbe, the least resistant members are persistently weeded out through succumbing to the disease; so that ultimately a race is evolved, practically immune agains the ravages of that disease. Similarly. in a race addicted to succumb quickest, bringing about generation by generation a natural " evolution against alcohol in the direction of an increased power of avoiding it." Now it has been maintained that in the same manner disease and intemperance act as a means of natural selection in our society, purging it from its weakest and worst members. As the progress it from its weakest and worst members. As the pugress of civilization tends more and more to check by its philanthropic and public efforts this elimination of the unfit, we are, it is said, interfering to that extent with the natura 
302 THE FIRST PRINCIPLES OF EVOLUTION

law of the survival of the fittest, with the result that the race is steadily deteriorating.

Now, though there is an element of truth in this contention, it is not quite so ominous in its significance as would appear on the surface. We may agree that in modern society, with its humanitarian tendencies and genera society, with its humare and more chance is given to the advance in hygiene, more and weak members of the commall survive and leave progeny is largely a matter of economic conditions. Those succumbing to disease are often merely " selected " by poverty cumbing to disease are from proved that these form the physlly and it is far from being proved that there exists a special unfit by inheritance.* Besides this there exists a special liability to certain microbic diseases, such as scarlet fever typhoid, tuberculosis (consumption), etc., which liability varies in different people and with regard to each given disease. A person may be perfectly fit in every othe disease. A pers ons. There is only respect, yet fall a victim to specific germ. Then ipon one conclusion we can arrive at : it is incumbent upon us rather to weed out the bacillus of tuberculosis (which is possible) than the tubercular patient (which, though possible, is cruel). $\dagger$

By many it has been argued that our modern competiBy many it has been as of natural tive system, exemplifying, as it does, the law of natural selection, is the best method of securing the survival of the fittest. This is true in the sense that, under any given conditions, those "best fitted to copent becomes a me stances " survive; but then this statement beco the fittest truism. The important question is. Who are the fittest ? They naturally vary according to the selective conditions, and may be either good, bad, or indifferent with regard to any quality selected. Now while under our present * * See the author's essay, "The

minster Review, January, I 11 I. $\dagger$ In present circumstances, the scourge of tuberculosis being still unabated, it is, to say subject in capitalistic system the successful may be the " self-reliant," the energetic and "cute" man of affairs, he is at the same time often the pushing, the unscrupulous, ready to oust and crush the pentle, the dreamy, the intensely moral man and crush the gentested be the truly select, the socially fit, we must devise a social system where these humaner traits may have full play without hindrance; where mutual co-operation becomes the rule instead of the exception; where, in fact, we all may live up to the great ethical standard of "each for all may live up to the

There remains the problem of the truly unfit-those who under no circumstances, however favourable, can adapt themselves to conditions of social life. So long as there the inheritance of acquired cxisted a genct no granted that all racial unfitness could be eliminated by a proper method of education and moral teaching. But this idea has now largely been abandoned as contrary to the keneral trend of biological science. Says Karl Pearson " "No degenerate and feeble stock will ever be converted into healthy and sound stock by the accumulated effects of education, good laws, and sanitary surroundings. Such means may render the individual members of the stock means if not strong members of society; but the same passable if not strong member through again and again with process will have to be gone through ar a their offspring and this in ever-widening circles, if the stock, owing to the conditions in which society has placed it, is able to increase in numbers." To this class of the socially unfit belong the imbecile, the mentally and morally insaneunfit belong the certain types of criminals, drunkards, among the latter comand vagrants, who are innately incapa. Now it goes withselves into any type of ordered society. Now it goes without saying that the advance of humanitarian sentiment has more and more restricted the law of natural selection from taking effect in these cases. We provide for the degenerate, while we may punish him, and take no heed that his offpeople not to propagate their own kind. More 
304 THE FIRST PRINCIPLES OF EVOLUTION

spring fill the world with an army of equally unsocial types. Whilst favourable environmental conditions, material and spiritual, are essential in order that growth may not be inhibited by inappropriate surroundings, they can only develop the individual within the limits of his heredity. Seeing that the individual no social ameloration can change the intrinitu "rational section what D. G. Ritchie so felicitously called "rational selection." By preventing the socially unfit from propagating their kind-whilst giving all due consideration to the unfit their kind - the new school of eugenics, insisting on the themsits hereditary factor, proposes to supplement social reform by race culture. Elimination of the worst social types, together with selective breeding of the socially best, would not only raise progressively the standard of the race, but would, by reaction and counter-reaction, improve the very would, by rectically no limit to the achievements of the world's progress.

\section{CONCLUSION}

CHAPTER XI

THE FORMULA OF EVOLUTION

IF we define philosophy with Herbert Spencer as "completely unified knowledge," then a philosophy of evolution should consist in a unification of all the special evolutionary processes under one comprehensive aspect. Having reviewed successively the rise of the stellar world, the growth of the earth with its elements, and the progressive evolution of plants and animal species; having traced the slow and animal species; having traced the slow ascent of man from lon moral, and social attainments, we now have to find the common principle binding together into one whole all these various phenomena of evolution. For, nature being one and indivisible it follows from the fact that evolution one and indivisible, it follows from the fact that be an allis going on in all its parts, that there must be an allpervading law of change, holding with equal truth for the material universe as for mankind and its social products. The credit of having conceived the idea of such an allThe crencer who first fully in his epoch-making " First fully in his epoch-making "First Principles " (I862), which forms the basis of his great work, the "Synthetic Philosophy." We shall follow his account, first giving a résumé of his formula of evolution, and then dealing with the subject of dissolution, the counterpart of evolution. 


\section{THE FIRST PRINCIPLES OF EVOLUTION}

\section{Evolution.}

We may, to begin with, give the definition of evolution, Whert as expressed integration of matter and concomiformula : Evolution is an integrion of matter passes tant dissipation of motion, during which the matter passos from a relatively indefinite, incoherent homogeneity to a relatively definite, coherent heterogeneity; and during which the retained motion undergoes a parallel transformation.

the retained motion undergoes a pate rest does not exist in Seeing that an absolute state of rest does not exist in nature, all matter must necossarily progress towards motion a greater concentration or greater diffusion, the motion involved being at the same time dissipated or absorbed respectively. While the different parts of a given system respectively. Whily the towards either the one process may predoming will or the other, the movement dissipation of the whole. result in either integration or dissipation fom its widest The progressive change, then, of a system from its widest dispersion to its greatest integration constitutes the main phase of its evolutionary process. This implies not only phase of its evolution i.e., " increased closeness of juxtaa greater aggregation, i.e., "incents of the whole, and among position among the components of the wreater coherence the components of each part, leading to a greater cohere is of the previously relatively incoherent mass; but there also an increase of combination, producing mutual dealso an increase of coment parts." The first law of evolupendence of the comified in the history of our solar system. tion is well exem according to modern theories, the We have seen that, according to minated from a vast sun and the attendant planets originated from a vast nebular fire-mist, which, gradually cooling down and connebular fremets and their sate densing, gave of bodies, in the course of development, lites. Each of thestion through the same process of progresgoes after its separation throug semi-fluid ball, which sive consolidation, starting as a fiery gradually crusts over with a hard shell, extending with time deeper and deeper into the interior. The geological
THE FORMULA OF EVOLUTION

than this formation of an outer solid layer and its further the organic world, the law of integration manifests itself in many ways during its evolugration manifest not only in the development of the individual, but also in the progressive transmutation of species. vidual, but also in the progressive trachine for integrating The living organism is essentially a machine for integrating foodstuffs and building up organs, i.e., mutually interdependent parts, out of originally dispersed matter, the process of integration being predominant over that of disprocess of integration being predive period of life; while integration during declinbalance on the side of disintegration during the declining years of the organism leads to its ultimate dissolution. Embryonic development, too, passes through a series of stages, which, on the whole, are a folding-in and gatheringtogether of various cell-masses into specific organs. The together of variec is characterized, generally speaking, evolution of species in by a double integration. Ther " especially among worms called " longitudinal integration," especially among worms and arthropoda. The lower members possess a great many successive segments, all being identical ; while in the higher forms, as in insects, crabs, spiders, etc., these are greatly forms, as in insects, being modified in structure, and thus reduced in number, bele body. leading to a shortening and integration in the which are "Transverse integration" takes place in organs which are originally double. Thus the nervous system, arranged in the lower organisms, on both sides of the body, becomes the low scale of united into one cent in part) occurs in animal beings. A similar unisation of comthe case of the generative organs. The of ingle individuals pound animals out of an agglomeration of single individuals furnishes a further example of organic integration. Coming to superorganic evolution, we find social integration, which, to superorganic evolution, we findency among animals, leads starting with the gregarions tribes and their gradual consoliin man to the formation of tribs. The organization of dation into large states and nations. The organization of society itself, be it political or industrial, becomes more and more consolidated with the progress of civilization; while 


\section{THE FIRST PRINCIPLES OF EVOLUTION}

social development, again, implies an " ever-increasing coordination " of the members of society, all "living for and by one another." The intellectual and æsthetic achievements of mankind, such as language, science, art, etc. ments of mankind, such but to dilate here upon this subject follow the same law

would lead us too far. The integration of matter-which always implies a cone
comitant dissipation of motion-is the main phase of the evolutionary process, and, $\mathrm{f}$ unaccompanied by any other evolutionary process, according to Herbert Spencer, effects, it constitutes, according certain conditions-when "simple evolution." But under certain quantity, or when the retained internal motion is large in quantity, or when its dispersion is retarded-secondary changes take "place which, superadded to simple evolution, render it "comwhich, "superaded secondary redistribution of matter (and of pound." This secondary in a change from a homogeneous motion) consists, firstly, ${ }^{*}$ and, secondly, in a transition to a heterogeneous state, and, from the indefinite to the defnite. The tendency to hetergeneity naturally leads to a multiplication of parts, simplicity being changed to complexity. It goes without pling that the diffused nebular state, from which the saying that the originated, is very much more cosmos is held to have originated is vifarious groups of simple in its constitution than the multifarious groups of stars, planets, etc., which make up the fully evolved siderea system. The various celestial bodies, being in all stages of development, present among themselves great differof deveristent. Similarly, the ences which were orignally comparatively molten mass of the earth assumes after its first consolidation a more and more complex and multiform aspect, as one geological epoch follows the other. It is, however, in organic beings, which contain in their highly compounds a great quantity of lockedcomplex ch the condition for compound evolution are exceptionally favourable. It is here, in the plant and

* More correctly, from a less heterogeneous to a more hetero4 to us. animal world, that we find the process of progressive differantian individual, starting as and composition, a single cell of relatively simple structure and chly becomes elaborated during growth into a highly complex cell-mass with separate organs of the most varied kind. Parts, uniform in their primordial condition, assume during Parts, uniors the most diverse forms and structures. We embre leaf, sepal, petal, stamen, only need to remember that the from identical shoots; or and carpel of a plant, all originate from identical shoots; that the limbs of higher animals sprout out as little knobs at the side of the body, being at first indistinguishabl from each other (see Fig. 36). In the evolution of society, from each other (sentipin of the law of differentiation is well ke most characteristic division of features of the progress of civilization. Primitive society is relatively homogeneous, not only in the composition of its mers, but also in its political and industrial organizaits meril sides of government are still tion. The religious and consciousness as intimately intertwined, there being no consciousness as yet of a possible differentiation between religious and social observance. There is no sharp division between what are now the various departments of industrial life, " what are now the warrior, hunter, toolmaker, builder," "every man it is only in fairly advanced etc., at the same time. It is ony in societies that separate trades and occupations arise; while under modern industrialism the process of this subdivision of labour has reached its climax by breaking up single trades into so many separate actions. On a more abstract trades into so madual differentiation in plane we see the same process of the higher arts of man. Written language, painting, sculpture, and architecture, so different in their modern aspect, can be traced back to a common origin, the crude asect, designs of primitive man, painted or incised on decoratils or articles of use. Likewise poetry, music, and cave become so only after a dancing, separate arts now,

long process of differentiation. 


\section{IO THE FIRST PRINCIPLES OF EVOLUTION}

involves, as aforesaid, a change from the indefinite to the definite. "Development, no matter of what kind, exhibits not only a multiplication of unlike parts, but an increase in the clearness with which these parts are marked off from one another." It is hardly necessary to go in detail from one another." It is hardly necessary to go in detail through the whole series of natural phenomena in order to illustrate this law. The evolution of a mist-like nebula into distinct celestial bodies, or the further development of a rather undefined fiery globe into a solidly limited planet is clearly a progression from the indefinite to the definite. is clearly a progression from the indefin Living organisms yield ample evidence of the same law in their embryonic development, which consists in a gradual marking-off of distinct organs from an undefined cellular magma; while the outstanding trait of the evolution of species may be summed up as the disappearance of interspecies may be summed up as the disappear the of intermediate forms, bringing into sharper contrast the surviving groups. From "indistinct varieties" there are produced "distinct species." Of the applications in the higher fields of human achievements, we shall only mention that the progress of progress of science is essentilly an advance from ins sciences have only gradually been delimited from the common store of knowledge by a more and more precise definition of their scope and method.

In order to complete this short survey of the formula of evolution, we have only to add that the various changes assumed by matter during its ascending phase also hold good for the accompanying motion. This, too, undergoes during the evolutionary process a parallel redistribution, becoming more integrated, heterogeneous, and more definite.

Herbert Spencer has gone a step further, and tried to deduce the foregoing laws of evolution from one underlying principle-the cause of all evolutionary processes. This principle is Force, which he looks upon as the ultimate This principle "To this an ultimate analysis brings us down, and on this a rational synthesis must build up."
It is to the law of the "Persistence of Force"* that the change from the uniform to the multiform, and from the indefinite to the definite, must be traced. We cannot here enter into a detailed account of this extremely technical subject, but may just say that the transformation of the homogeneous into the heterogeneous is attributed by Spencer to two results flowing from the primary law of the persistence of force. In the first instance, the different the persistence of force. In the first instance, the different
parts of a homogeneous whole being exposed to different incidences of force, each part will be modified in its own way, thus leading naturally to "the instability of the homogeneous." Secondly, the incident force itself, originally falling uniformly on the aggregate and " differentiating the parts on which it falls in unlike ways," is through " the multiplication of effects" correspondingly differentiated. Furthermore, " the permanently effective incident force, when wholly or partially transformed into mechanical motion of the units, will produce like motion in units that are alike, and unlike motion in units that are unlike." The result is that a "segregation" takes place whereby the various kinds of units composing the whole are separated from each other, the whole mass, previously indefinite in character, thus being divided into definite, well-defined parts. The formation of species by natural selection is a good case in point. Organisms originally comingled are segregated by the force of environmental conditions into separate and distinct types.

Is there any limit to the evolutionary process just described? "Can things increase in heterogeneity through all future time? or must there be a degree which the differentiation and integration of Matter and Motion cannot pass ?" Seeing that during the ascending phase of evolution all motion is gradually dissipated, there must ultimately result a state in which there is complete cessation of motion. But this final stage of "complete equilibration" is preceded by a " moving equilibrium," which is,

* Better known as the law of the Conservation of Energy. 


\section{THE FIRST PRINCIPLES OF EVOLUTION}

according to Spencer, a transitional condition, through which every evolving aggregate passes. This is best illutrated by a spinning-top which is kept upright by its rapid trated by a spinning-top which is kept upright by its rapid rotation round its axis. It is in a state of moving equilitop, after some "wabbling," comes to rest motionless on the ground, it is said to be in complete equilibrium. There may arise in a system during the course of evolutionary changes manysuch transitional kinds of moving equilibrium each giving place to the next, until at last final equilibrium is reached. That the solar system, since its nebular origin, has experienced a series of mechanical readjustments, due to the radiation of the originally contained heat, is now to the radiation of the originally contained heat, is now well-accepted fact of science. Furthermore, it is also generally assumed that there must come a time-however. far distant-when the sun's energy will be exhausted, so that the whole solar system must inevitably tend towards a state of complete integration and complete equilibration. The existence of a great number of dark extinct stars points to this conclusion. The mechanism of the moving equilibrium is exemplified in living organisms in manifold ways. Not only are their functions balanced from hour to hour, from year to year, with the change of seasons, but to hour, from year to year, with the change of seasons, but
also by a process of slow adaptation to entirely new environmental conditions. Death in this sense must be looked upon as the final stage of complete equilibrium. As an example of equilibrium in the super-organic, we shall As an example of equilibrium in the super-ortinic, adjustment between a given population and its means of subsistence. As the food-supply increases, the population is able to grow, until through its excess of numbers there is a dearth of food, which in its turn depresses the birth-rate, and so on alternately. The balance which in a similar way is perpetually going on between the various animal species living in the same neighbourhood has already been adverted to in a previous chapter.

\section{Dissolution.}

We have mentioned incidentally that there may go on in different parts of an aggregate opposite movements either towards greater integration or towards greater dispersion of the whole. It must now be pointed out that, while the ascending evolutionary phase of the process implies a concentration of matter and dissipation of motion, the descending phase, accompanied by an absorption of motion, leads to a diffusion of matter, and finally to its " dissolution." "When evolution has run its coursewhen an aggregate has reached that equilibrium in which its changes end, it thereafter remains subject to all actions in its environment which may increase the quantity of motion it contains, and which in course of time are sure, either slowly or suddenly, to give its parts such excess of motion as will cause disintegration. According as its s ze, its nature and its conditions determine, its dissolution billions of years." In tracing out the process of dissolution, we may follow Herbert Spencer by starting with the most complex phenomena, those of the social system, and ending with the most simple those of the physical order. While the evolution of society consists essentially in an integration and mutual co-operation of all its constituent parts, the reverse process of national and racial decay is characterized by disorder, disintegration, and by the final disappearance of the component members of society. The life of the individual, leading from infancy to senility through a series of moving equilibria, ends with the state of complete equilibrium which we call " death" upon which ensues the final disintegration of the decaying body, due to chemical decomposition. It is a so genera ly assumed that the earth, through a retardation of its motion, will slowly be drawn into the sun, and thus be reduced to a gaseous state-a fate which must happen to all the other component bodies of our solar system. As regards the chemical 
3 I4 THE FIRST PRINCIPLES OF EVOLUTION

constituents of the universe, we have seen in a previous chapter that, while there takes place during the evolution of the stars a gradual condensation of matter, leading to the appearance of the various chemical elements, radioactivity shows us their dissolution, each atom being disintegrated into its component corpuscles.

integrated into its component corpuscles.
The fina question arises: If the evolutional process described ends everywhere in complete quiescence, what can we say of the cosmos as a whole, holding as it does a multitude of sidereal systems? We have already menmult finally lose its heat and become extinct, forming a dark star. On the other hand, celestial extinct, forming a dark star. On the other hand, celestial each other-an occurrence which must happen not rarely - will inevitably be vapourized into a gaseous mass, con- ituling whe stituting what we conceive to be a nebula. As these nebulæ form once more the starting-points for new worlds, we now see that, while there is go ng on in the universe a process of dissolution in one place, " a renewal of activity and life" occurs in another. Evolution and dissolution must thus be looked upon as alternate states embracing all forms of existence.

Herbert Spencer's formula of evolution is so far the only one that has been suggested to account for the totality of natural phenomena, and we have found that within its limits it covers a variety of facts in a truly astounding limits it covers a variety of facts in a truly astounding manner. its general validity, the main argument being that it is based on too mechanistic an interpretation of nature. Spencer tried to reduce all phenomena, those of the physica world as much as those of life and society, to one underlying principle - that of "the persistence of force." But lying principle- that of " the persinted out, he has by no as Professor William James has pointed out, he has by no means worked out his fundamental assumption with consistency or clearness. By persistence of force he " sometime means the phenomenal law of the Conservation of Energy, sometimes the metaphysical principle that the quantity of
THE FORMULA OF EVOLUTION

315

existence is unalterable, sometimes the logical principle that xisthing nothing can happen without a reas an assignable differtical postulate that in the absence of any assignable difference you must call a thing the same." A similar objection has to be brought against his use of the word "force " in the realms of the organic and superorganic. "Vital force," "mental force" and "social force" were to Spencer mani"mental force" and "social force" all being in their last " and be proportionate to source due to physical force, and " being proportionate to the amount of physical force that is 'transformed' int them." "What on earth is 'social force' ?" exclaim Professor James. "Sometimes Spencer identifies it with Professor James. "Somional to social activities '(showing the latter to be proporth the work the amount of food eaten), sometimes with the work don by human beings and their steam engines, and shows it to be due ultimately to the sun's heat. It would never occur to a reader of his pages that a social force proper occur to a reach stimulus of social change might be anything that acted as a stimulus of social change - a leader, for example, a discovery, a book, a new idea, or a national insult ; and that the greatest of 'forces' of this kind need embody no more 'physical force' than the smallest. The measure of greatness here is the effect prosmalles. The mot a quantity antecedently absorbed from physical nature."

The most thorough-going criticism, however, of the Spencerian view of evolution has lately been made by Professor Henri Bergson, who not only attacked Spencer's " false evolutionism," but elaborated at length in his "Creative evolution", Evolution "(1907, English tran which certainly has opened of change " of high originality, which certainly has opened an entirely fresh outlook upon the problem of life and the universe. 
evolves. It is not by recomposing the evolved with itself that we shall reproduce the evolution of which it is the term." We may divide up in this way the whole movement as often as we like ; we shall never by this means lay hold of the actual interval of duration-change itself Bergson goes on to elucidate most beautifully how the whole natural bent of man's intellect has been moulded into the direction of this mechanistic interpretation of nature. "Intellect is never quite at home, except when it is working upon inert matter. . . . Of the discontinuous it is working upon inert matter. . . - Of the discontinuous without reversing its natural direction and twisting about on itself, think true continuity, real mobility, reciprocal penetration-in a word, that creative evolution which is life."

And the reason for this is that human intellect was not made intrinsically for speculative philosophy, for the understanding of the universe, but was evolved for the practical purposes of life-to orient our existence in the material world. In fact, in Bergson's view our intellect cuts out of the flux of existence, according to our needs of action, the very forms we call material objects. Being made for the inorganized, it is " characterized by a natura inability to comprehend life." It therefore deals-as all science must do-with life in a mechanical way, and represents becoming by a series of states, the result being that, " though we may do our best to imitate the mobility of becoming by an addition that is ever going on, becoming itself slips through our fingers just when we think we are holding it tight."

This mechanistic illusion of change Bergson has most happily illustrated by likening our method of thought to the cinematographical reproduction of life. Just as the cinematograph film only represents a series of snapshots, each giving an immobile picture, so our intellect merely each giving an immobile picture, so our intellect merely
takes stable views-cuts made across the background of a continuous flux. Intellect shows us no change, but a sucthat Spencer, enmeshed in his mechanistic method, only got hold of the outward appearance of evolution. False discontinuous, fixed states, and by stringing them together end to end imagines that it thereby reconstructs the whole movement. But, as Bergson says: "It is not by dividing the evolved that we shall reach the principle of that which 
3I8 THE FIRST PRINCIPLES OF EVOLUTION

cession of states. "The Forms, which the mind isolates and stores up in concepts, are only snapshots of the changing reality." In order to restore life to the cinematograph picture, we must add movement by a rapid rolling off of the picture film ; similarly, in order " to instal ourselves in becoming," we must " see in duration the very life of things, the fundamental reality."

We cannot but admire Bergson's penetrative insight in dealing with the problem of life. He seems to go to the very heart of the matter, and certainly has revealed an aspect of evolution which is as startling as it is profound. If we have had before a science of evolution, Spencer's "If we have had before a science of evolution, Spencer's us for the first time a real " philosophy of change."

There is left one final question : Seeing that life transcends intellect, intellect being limited to a mere "instantaneous" view of life, how can we get at the real inwardness of its flowing reality? Bergson's answer is: By intuition; not by intuition in the sense of the exceptional gift of the seer, but, as C. Wildon Carr has expressed it, by " that sympathetic attitude to the reality without us that makes us seem to enter it, to be one with it, to live it... It is so identical with life itself that wherever there is life there identical with life itself that wherever there is life there
might also be that consciousness of living that is intuition." How far this solution is a real one is too speculative a point to be raised in its fulness at this juncture. We have, in a previous chapter, adverted to the fact that "sympathy " cannot explain instinct, to which it is supposed to pathy " cannot explain instinct, to which it is supposed to be akin ; and it must remain a moot point whether intuition is sufficient to illuminate life as a whole in order to bring more a matter for the philosophical student than for the cientist. Inded, Bergson's ingenious work has shown that a true theory of life and a theory of knowledge are in their fundamentals interdependent. It is in the field of metaphysics rather than that of biology that the riddle of evolution will have to find its final solution.

\section{LITERATURE*}

(Italics denote that the work has been previously mentioned in the List.)

COSMIC EVOLUTION.

Sir Robert BALl: The Earth's Beginning. London, 1909. G. E. HALE : The Study of Stellar Evolution. Chicago, 1908. Chamberlin and Salisbury: Geology, Vol. II. London, 1906. SIR N. LOCKYER : The Meteoritic Hypothesis. London, 1890.

GEOLOGICAL EVOLUTION.

Sir A. GeIKIE : Textbook of Geology. London, 1903. Chamberuin and Salisbury : Geology. 3 vols. London, 1906. W. J. Soltas: The Age of the Earth. New edition. London, I912.

\section{ATOMIC EVOLUTION.}

R. K. Duncan : The New Knowledge. London, 1907. SIR N. LOCKYER: Inorganic Evolution. London, 1900. F. SoDDY : The Interpretation of Radium. London, 1909. SIR J. J. ThомSоn: Electricity and Matter. London, 1904.

EVOLUTION OF LIFE.

MAX Verworn : General Physiology. London, 1899. MAX VeRWORN : General Mysiology. London, 1909. OLIVER LODGE. Life andion to Science, London, I9II. J. A. THOMSON : Introductig and Nature of Life. London, I9I 3

* The list of books is not exhaustive. It is intended merely as a first guide to the literature of each subject. 
320 THE FIRST PRINCIPLES OF EVOLUTION

\section{ORGANIC EVOLUTION.}

(General Books.)

Charles Darwin : The Origin of Species. Sixth edition. London, 1872.

A. R. WAllace: Darwinism. London, 1889.

Principles of Biology. New edition. London, 1898

RNST HAECKEL: Natural History of Creation. Fourth edition. London, 1899

. WeIsmann: The Evolution Theory. London, 1904

G. J. Romanes : Darwin and after Darwin. 3 vols. London, 1897

\section{MORPHOLOGY}

Charles Darwin : The Descent of Man. Second edition. London, 1896.

DARWIN : Origin of Species.

WEISMANN : Evolution Theory, Vol.

ROMANES : Darwin and after Darwin, Vol. I

\section{EMBRYOLOGY}

E. HAECKEL : The Evolution of Man. London, 1906. DARWIN : Origin of Species.

HAECKEL : History of Creation, Vol. I

Weismann : Evolution Theory, Vol. II.

Romanes : Darwin and after Darwin, Vol. I.

\section{CLASSIFICATION.}

J. A. Thomson : The Science of Life. London, 1899. DARWIN : Origin of Species.

SPENCER : Principles of Biology, Vol. I

HAECKEL : History of Creation, Vol. II.

RoManes : Darwin and after Darwin, Vol. I.

PALÆONTOLOGY.

DARWIN : Origin of Species.

WaLlace : Darwinism.

SPENCER : Principles of Biology, Vol. I.

RoManes : Darwin and after Darwin, Vol. I

\section{LITERATURE}

GEOGRAPHICAL DISTRIBUTION.

A. R. WALlace : Island-Life. London, 1880.

DARWIN : Origin of Species.

PPENCER : Principles of Biology, Vol. I.

ROMANES : Darwin and after Darwin, Vol. I.

HISTORY OF EVOLUTION.

H. F. OsBorn : From the Greeks to Darwin. New York, 189

HAECKEL: History of Creation, Vol. I.

TномSON : Science of Life.

\section{LAMARCKISM.}

A. S. PACKARD : Lamarck, his Life and Work. London, I901. G. HensLow : The Origin of Plant-Structures. London, 1895. G. HeNsLow : The Origin of Floral-Structures. London, I 888 .

NATURAL SELECTION.

DARWIN : Origin of Species.

WARWIN: Origin of Speci

WEISMANS : Evolution Theory, Vol I.

Romants: Darwin and after Darin, Vol. I.

PLANT-STRUCTURES.

DARWIN : Origin of Species.

WALLACE : Darwinism.

WeIsMann : Evolution Theory, Vol. I

Charles DarwiN : The various special works on plants. ANIMAL COLOURATION.

Wallace : Darwinism.

WEISMANN : Evolution Theory, Vol. I.

F. E. BEDDARD : Animal Coloration. London, 1892.

E. B. Poulton : The Colours of Animals. London, 1890 . INSTINCT.

DARWIN : Origin of Species.

DARWIN : Origin of Species.

WEISMANN : Evolution Theory, Vol. I.

ROMANES: Darwin and and Instinct. London, 1896. 
322 THE FIRST PRINCIPLES OF EVOLUTION

\section{HUMAN FACULTY.}

WALLACE : Darwinism.

Rarwin and after Darwin, Vol. II

A. R. WALlACE : Natural Selection and Tropical Nature. London,

1891.
A. WEISManN : Essays on Heredity (see Thoughts on Nature of Music). Oxford, 1891 .

\section{DEGENERATION.}

SiR E. R. LANKESTER : Degeneration. London, 1880.

SEXUAL SELECTION.

DARWIN : Descent of Man

WALLACE : Darwinism.

ROMANES: Darwin and after Darwin, Vol. I.

BEDDARD : Animal Coloration.

Poulton: Colours of Animals.

NEO-LAMARCKISM VERSUS NEO-DARWINISM.

V. L. KellogG: Darwinism To-Day. London, 1907. (With V. L. Ketroce: Daryinism

extensive bibliography.) Plate. Selectionsprinzip

1908 :

DARWIN : Origin of Species.

WALLACE : Darwinism.

etc.)

\section{PANMIXIA.}

A. Weismann : Essays on Heredity.

RoManes : Darwin and after Darwin, Vol. II

KellogG: Darwinism To-Day.

Plate : Selectionsprinzip.

\section{INTRA-SELECTION.}

W. Roux : Der Kampf der Teile im Organismus. Leipzig, 1881 WEISMANN : Evolution Theory.

KELLOGG : Darwinism To-Day.
GERMINAL SELECTION.

A. Weismann: On Germinal Selection. Chicago, 1896.

WeIsMann: Evolution Theory.

KELLoG : Darwinism To-Day.

Prate : Selectionsprinzip.

COINCIDENT SELECTION.

M. BALDwin : Development and Evolution. New York, 1902. LLOYD MORGAN : Habit and Instinct.

KELLOGG: Darwinism To-Day.

Plate: Selectionsprinzip.

ISOLATION.

WALLACE: Darwinism.

Dor. III.

WeIsMAN : Evolution Theory.

KELLOGG : Darwinism To-Day

PLATE : Selectionsprinzip. Iife and Intelligence.

LLOYD MoRGAN : Animal Life and Intelligence.

\section{HETEROGENESIS}

HUGO DE VRIES : Species and Varieties : their Origin by Mutation. Second edition. Chicago, 1906.

HUGO DE VRIES : The Mutation Theory. English edition. London,

I9IO.
TH. H. Morgan : Evolution and Adaptation. New York, 1908. KeLLOGG: Darwinism To-Day.

PLATE : Selectionsprinzip. London, 1894 W. BATESON : Material for the Study in Populationen und reinen

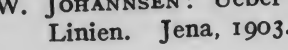

\section{ORTHOGENESIS.}

G. H. TH. Ermer : Organic Evolution. London, 1890 G. H. TH. Eimer : On Orthogenesis. Chicago, 1898. E. D. COPE : The Primary Factors of Organic Evolution. Chicago,

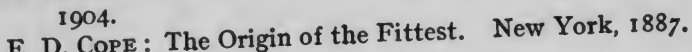


324 THE FIRST PRINCIPLES OF EVOLUTION

\section{VITALISM.}

OLIVER LODGE : Life and Matter.

H. Driesch: The Science and Philosophy of the Organism London, 1908.

GuStAV WOLFF: Mechanismus und Vitalismus. Leipzig, 1905.

A. PAULY: Darwinismus und Lamarckismus. Munich, 1905.

J. REINKE : Einleitung in die theoretische Biologie. Berlin, 191 I.

HenRi Bergson : Creative Evolution. London, 1911

MENTAL EVOLUTION.

Herbert Spencer :

The Principles of Psychology. Fourth edition. London, 1899.

J. LOEB : Der Heliotropismus der Tiere. Würzburg, 1890 . J. LOEB : Die Beipzig, 1909.

Leipzig, 1909.
H. JENnings: Behavior of the Lower Organisms. New York. 1906.

G. BoHN : La Naissance de l'Intelligence. Paris, 1910. G. Bond Behaviour. Second edition. London 1908

1908. Romanes: Mental Evolution in Animals. London, 1883.

G. J. Romanes: Mental Evolution in Man : London, 1888.

L. T. Новноuse : Mind in Evolution. London, 1901.

BERGSON : Creative Evolution.

MORAL EVOLUTION.

DARWIN : Descent of Man.

DARWIN : DESCent of The Principles of Ethics, London, 1897. A. Suthe Origin and Growth of the Moral Instinct. London, 1898.

LLOYD MOR, I8: Animal Behaviour.

A. TAYLOR: The Problem of Conduct. London, 1901.

A. Tondon, 1906.

. Tre London, 1906.

The Ethics. Fifth edition. Oxford 1906.

W. R. SorLEY: The Ethics of Naturalism. Second edition. London, 1904.

Tendencies in Ethics: London, 1904. TH. H. HUXLEY : Evolution and Ethics. London, 1894

\section{LITERATURE}

EVOLUTION OF MAN.

Darwin : Descent of Man.
TH. H. HuxLEY : Man's Place in Nature. London, 1897.

HAECKEL : History of Creation.

John LubBock : Prehistoric Times. London. New edition. 1912 .

A. H. Keane: Ethnology. Cambridge, 1909.

EVOLUTION OF MARRIAGE.

DARWIN : Descent of Man.

HERBERT Sociology, Vol. I. London,

I 893.
G. E. HOWARD : A History of Matrimonial Institutions. London, 1904. (With extensive bibliography.)

Sir H. S. MAINE : Ancient Law. London, 1861.

L. H. Morgan : Ancient Society. London, 1877. J. F. McLennan: Studies in Ancient History. New edition,

E. Wendon, 1886. The History of Human Marriage. London, I891. EVOLUTION OF THE STATE.

Herpert SPENCER : The Principles of Sociology. 3 vols. London,

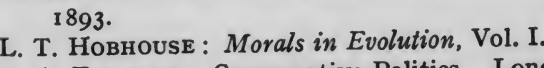

E. A. Freeman : Comparative Politics. London, 1874

E. JENKS : A History of Politics, London, 1900 .

A. SuTHERLAND: Origin and Growth of Moral Instinct.

FUSTEI DE Cout : Boston, 1874.

London, 1896.

H. W. Nondon, 1912.

\section{PRIMITIVE COMMUNISM.}

SIR H. S. MAINE : Ancient Law. SIR H. S. Marne: Village Communities in the East and West. Third edition. London, 1876

E. DE Laveleye : On Property and its Primitive Forms. London,

1878.
P. LAFARGUE : The Evolution of Property. Fifth edition. London. 1908 
326 THE FIRST PRINCIPLES OF EVOLUTION

B. H. BADEN-PowELL : Village Communities in India. London,

I899.
Fustel De Coulanges: The Origin of Property in Land. London. 1891 .

FEUDALISM.

SIR H. S. MAINE : Early History of Institutions.

SIR H. S. MAINE: Village Communities in the East and West.

P. LAFARGUE : Evolution of Property.

J. F. ABDY : Lectures on Feudalism. London, 1890

EVOLUTION OF RELIGION.

EdWARd Clodd : Animism. London, 1905.

E. B. TYLOR: Primitive Culture. London, 1871.

ERBERT SPENCER: The Principles of Sociology, Vols, I and III.

L. T. HoвHouse : Morals in Evolution, Vol. II.

J. G. Frazer : The Golden Bough. Second edition. London, 1900.

F. MAX MÜLLER : Natural Religion. London, 1889.

F. MAX MŨLLER : Physical Religion. Hondon, 1891. F. B. JEV.

W. Robertson SMrth : Lectures on the Religion of the Semites. London, 1894 .

ANDREW LANG: The Making of Religion. Second edition. London, 1900 .

E. CRAWLEY: The Tree of Life. London, 1905

EVOLUTION AND PROGRESS.

D. G. RITchIE : Darwinism and Politics. Second edition. London,

D. G. Ritchie : Studies in Political and Social Ethics. London, 1902.

T. HOBHousE : Social Evolution and Political Theory. London,

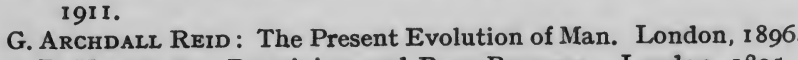
J. B. HAYCRAFT: Darwinism and Race-Progress. London, 1895. Sir Francis Galton: Essays in Eugenics. London, 1909.

PHILOSOPHY OF EVOLUTION.

Herbert Spencer : First Principles. Sixth edition. London, 1900. Henri Bergson: Creative Evolution.

H. WILDON CARR: Henri Bergson, The Philosophy of Change. London, I9I2.

\section{GLOSSARY}

[L. means derived from Latin; Gr. means derived from Greek. The pages refer to the context of the book, where the word is explained.]

Abiogenesis (Gr. a, negative; bios, life; genesis, birth) (p. 43).

ablo the born), relationship through the male line (p. 273)

gnostic (Gr. $a$, negative; gnosticos, good at knowing), pertaining to the belief that the essence of nature is unknown and perhaps unknowable.

(L. alga, sea-weed), a division of plants embracing sea-weeds. Aga (L. alga, sea-weed), a division of plants en not amenable to reason.

mixis (Gr, a negative; mixis, a mingling) (p. 199)

Amiria (Gr. $a$, negative, mixis, a minging) (p. Ig)) Amøoba (Gr. amabee, change),
stantly changing its form.

Aman single-celled animal.

Amobina (see Amœba), amœba-like single-celled animal. mphibian (Gr. amphi, both, bios, frogs, etc

both in water and, bo lancelet fish, pointed at both ends.

at both ends.

Analogous (Gr. ana, accort Angiosperms (Gr.

( closed spores.

Animism (L. anima, soul) (p. 289). Antenna (L. an

Anther (Gr. anthêros, flowery), the top of the stamens in a flower, (Gr. antheros, flowery)

chropoid (Gr. anthropos, man; eidos, form), man-like. Anthropom the 
328 THE FIRST PRINCIPLES OF EVOLUTION

Aphrodisian (Gr. Aphroditē, the goddess of love), devoted to sensual

love. having no placenta, and bringing forth immature youn

Apogamy (Gr. apo, away; gamos, marriage) (p. 200).

(pilless birc of New Zealand

Archæan (Gr. archaios, ancient) (p. 24)

Archøopteryx (Gr. archaios, ancient; pteryx, wing) (p. 94).

Archæesthetism (Gr. archos, first; aisthesis, perception)

Archebiosis (Gr. arche, beginning, bios, life) (p. 46)

. (Gr. arche, beginals with jointed feet, as insects, crabs, etc.

ilikenting, comparison.

Astrophysics (Gr. astron, star; physikos, natural), the study of the physical structure of the stars.

Atavistic (L. atavus, a great-grandfather), reverting to an ancestral type.

Atom, Atomic (Gr. a, negative; temnein, to cut) (p. 3o).

), a wasting.

atos, self; nomos, law), having its law within itself self-governing.

Bacteria (Gr. bakterion, a little stick), lowest single-celled plantorganisms.

Batrachians (Gr. batrachos, a frog), the order of reptilia which includes

the frogs, etc.
Biogenesis, Biogenetic (Gr. bios, life; genesis, birth) (p. 43 ).
. Biometrician (Gr. bios, life; metron, measure), a student of metrics, the statistical science of life.

Blastula (Gr. blastos, germ) (p. 73).

Cambrian (pertaining to Cambria-i.e., Wales), geological strata first found in Wales.

(arbohydrates (L. Carbo, coal; Gr. hydör, water), organic compound of carbon with oxygen and hydrogen in the proportion of water, as, e.g., sugar, starch, etc.

Woniferons (L. carbo, coal; ferre, to bear), producing coal.

Catastrophism (Gr. kata, down; strephein, to turn), the hypothesis of catastrophic or revolutionary changes in geology.

thode (Gr. kata, down; hodos, way) (p. 35).
GLOSSARY

Cenozoic (Gr. kainos, recent; zöon, animal) (p. 23).

Chemotropism (chemical and tropism) (p. 228).

Cilia (L cilium, an eyelash), hair-like lashes borne by cells.

Coccygeal (Gr. kokkyx, the cuckoo), relating to the lowest bone of the vertebral column.

Coelenterata (Gr. koilos, hollow enteron, intestine), a class of lowe many-celled animals.

Cœiom (Gr. koilos, hollow) (p. 73).

Coolomula (Gr. koilos, hollow) (p. 72)

Cognation (L. co-, together; natus, born), of the same family (p. 273).

Colloid (Gr. kolla, glue; eidos, form) (p. 44 ).

Communism, Compun the common ownership of the means of production, with common use products.

Concept, Conceptual (L, concipere, to conceive), an abstract idea.

Copulation (L. CO-, together: apere, to join), the process of sexul (

Corolla (L. diminutive of corona, a crown), the inner circle of the floral envelope, generally of bright colour.

Corpuscle (L. corpusculum, a little body) (p. 35)

Gretaceous (L. creta, chalk) (p. 27)

Crustace (L crusta, a crust), a large class of animals, includin lobsters, crabs, etc.

Cryptogams (Gr. kryptos, concealed; gamos, marriage), flowerles plants with concealed fructification.

Determinants (L. determinare, to determine) (p. 195).

Devonian (belonging to Devonshire), strata abounding in Devonshire.

Dicotyledon (Gr. di-, two; kôtylêton, cavity), a plant having two seed-lobes.

Dimorphic (Gr. di- twice; morphê, form), with double form.

Diphyceresl (Gr. diphyēs, of double nature; kerkos, tail) (p.

Dominant (L dominare, to be master), to be predominant (pe).

Dominant (L. dominare, to be master), to to predo

Dynamic (Gr. dynamikos, powerful), pertaining to force producin motion.

Echinodermata (Gr. echinos, a hedgehog; derma, skin), a class of lower animals having their skin covered with spines.

coderm (Gr. ebtos, outside; derma, skin), the external layer of the embryo.

Edentates (L. $e-$, out of; dens, tooth), an order of mammals having no teeth. 
330 THE FIRST PRINCIPLES OF EVOLUTION

Emanation (L. e-, out; manare, to flow) (p. 37)

Embryonic (Gr. embryon), the young organism in its earliest

stages of development.
Embryogenesis or Embryogeny (Gr. embryon; genesis, generation), the development of the embryo.

Embryology (Gr. embryon; logos, a discourse), the science of the development of the embryo.

Entelechy (Gr. en, in; telos, end; echein, to have) (p. 220).

Entoderm (Gr. entos, within; derma, skin).

Focene (Gr. ēos, dawn; kainos, new) (p. 27).

Eolith, Eolithic (Gr. êos, dawn; lithos, stone) (p. 26I)

Eugenics (Gr. eu, well; genēs, producing) (p. 304).

Dros (Gr. exos, out; gamos, marriage), marriage outside one's own tribe (p. 276).

Finalism (L. finis, end), the theory that the universe has a final

purpose.
Fission (L. findere, to cleave), division (p. 44).

Fisgellate (L. flagellum, a little whip), a single-celled organism.

Foetns (L. feuere, to bring forth), the young in the womb in its later

stages.
Foraminifera (L. foramen, hole; ferre, to bear), orders of lower animals generally perforated with pores.

Fungi (L. fungus, a mushroom), one of the lowest class of plantorganisms.

Gasteropod (Gr. gastêr, the belly ; pous, pod-, a foot), molluscs having a muscular disc under the belly, which serves them as feet.

Gastræaa (Gr. gastêr, the belly) (p. 75).

Gastrula (Gr. gastêr, the belly) (p. 73)

(Genepistasis (Gr. genēs, being born; epistasis, a standstill) (p. 217).

Genesis ( $\mathrm{Gr}$. a begetting), production.

Genesis (Gr. a begettic its centre.

Germinal (L. germen, a bud), pertaining to the germ-cells

Gestation (L. gestare, to bear), the bearing of the young in the womb. Gymnosperms (Gr. gymnos, naked; sperma, seed), plants with naked seeds.

Gymnospores (Gr. gymnos, naked; sporos, a seed), plants with naked spores.

\section{GLOSSARY}

$33 \mathrm{I}$

Meliotropism (Gr. helios, the sun; tropos, a turn), the tendency to turn towards the light (p. 228)

Henotheism (Gr. heis, hen-, one; theos, god) (p. 292).

Hetairism (Gr. hetaira, a female companion), concubinage.

Heterocer (Gr. heteros, different from; kerkos, tail) (p. 96).

Heterogeneity (Gr. heteros, different from; genos, kind), composition from different parts.

Heterogenesis (Gr. heteros, other; genesis, generation) (p. 206).

Heterostylism (Gr. heteros, other; stylos, a pillar) (p. I29).

Histonal (Gr. histos, a web), pertaining to tissues.

Homocercal (Gr. homos, the same; kerkos, tail) (p. 96)

Homocercal (Gr. homos, the same; kerkos, tail) (p. 96).

Homogeneity (Gr. homos, the same; genos, kind), composition from parts of the same kind.

Homologous (Gr. homos, the same; logos, ratio) (p. 52).

Hydrosphere (Gr. hydōr, water; sphaird, ball), the water surrounding the earth's surface.

Idealist (Gr. idøa, a general form or idea), pertaining to idealism, or the theory according to which the universe must be referred or the theory acco
to ideas only.

Ideational (Gr. idexa a general form or idea), referring to the formation of ideas.

Infusorian (L. in, into; fundere, to pour), protozoa found in stagnant nfusions of animal and vegetable matter.

Integration (L. integrare), to make whole (p. 307). Intra-uterine (L. intra, within; uterus, the womb), within the womb. Intuition, Intuitionist (L. in, into; ineri, to lok), immediate per-

Invertebrate (L. in, negative; vertebra, the bone of the spine), with
out a backbone. out a backbone.

Jurassic, geological strata well developed in the Jura Mountains.

Kinetogenesis (Gr. kinetos, movable; genesis, birth), origination of animal structure in animal movements.

Lepidoptera (Gr. lepis, a scale ; pteron, a wing), insects with four

Levirate (L. levir, a brother-in-law) (p. 276).

Lithosphere (Gr. lithos, a stone; sphaira, a ball), the crust of the earth.

Heliocentric (Gr. hellios, the sun; kentron, the centre), having the sun as a centre. 


\section{THE FIRST PRINCIPLES OF EVOLUTION}

Mamma (L.), breast.

(Limals having breasts and suckling their young.

Mandible (L. mandere, to chew), jawbone.

Marsupial (Gr. marsupion, a pouch), carrying young in a pouch, as the kangaroo.

Matriarchate, Matriarchal (Gr. mêtèr, mother; archos, a ruler), government by a mother (p. 274)

Maxilla, Maxillary (L.), jawbon

Megatherium (Gr. megas, large: thérion, wild beast), a gigantic extinct quadruped.

Mendelian, referring to Mendel, the founder of a theory of heredity (p. 189 ).

(p. 2 I I).

Mesozoic (Gr. mesos, middle; zōè, life) (p. 27).

to metabolism-i.e., the sum of chemical changes within the living organism.

the sur. meta, expressing change; morphè, form), transformation.

Metaphysical (Gr. meta, after; physika, physics), relating to metaphysics, the philosophy of first principles.

Mocene (Gr. meion, less; kainos, recent) (p. 27).

olecular (L. moles, mass), consisting of molecules, a molecule being the smallest chemical mass.

Molluscs (L. molluscus, softish), a large division of invertebrates, as snails, cuttle-fish, etc.

Monism (Gr. monos, alone), the philosophical theory that all being may ultimately be referred to one entity.

Ionocotyledons (Gr. monos, alone; kotylêdōn, cavity), plants having one seed-lobe.

Monogamian, Monogamous (Gr. monos, one; gamos, marriage), relating to monogamy, the marriage between one man and

one woman.
Monogenist (Gr. monos, one; genos, kind), believer in the descent of the whole human family from a single pair.

Monotheism (Gr. monos, one; theos, god), belief in only one

God.
Monotremata (Gr. monos, one; trêma, hole), the lowest order of mammals having a single opening for the genital and digestive organs.

Monotypic (Gr. monos, one; typos, type) (p. 189)

Morphology, Morphological (Gr. morphè, form; logos, discourse) the sience of organic forms.

Morula (L. morum, mulberry) (p. 72).
Motor nerves (L. movere, motus, to move), the nerves which move the

muscles of the body.
Mnlticellular (L. multus, many; cella, cell), consisting of many cells. Mutant, Mutation (L. mutare, to change) (p. 210 )

Neo-Darwinism (Gr. neos, new ; and Darwinism) (p. 178). Neo-Lamarckism (Gr. neos, new ; and Lamarckism) (p. I75)

Neolithic (Gr. neos, new; lithos, stone) (p. 26r).
Neo-vitalism, Neo-vitalist (Gr. neos, new; L. vita, life) (p. 219)

Neptunist (L. Neptunus, god of the sea) (p. I8).

Neural (Gr. neuron, nerve), pertaining to a nervous change.

Neurosis (Gr. neuron, nerve), a change in nerve-cells.

Vitrogenous (Gr. nitron, soda; gennain, to generate), possessing nitrogen, which is an essential constituent of living matter.

Non-placental (L. non, not; placenta, a flat cake), having no placenta, as the lower orders of mammals.

Notochord (Gr. notos, the back; chorde, string), a cellular rod forming the basis of the future spinal column.

Nuclens, Nuclelous (L. nux, a nut), a central mass, a special part of the cell (p. 70).

Oligocene (Gr. oligos, little; kainos, new) (p. 27).

Ontogeny, ontogenetic (Gr. on , ont-, being; genesis, generation), the individual development of an organism (p. 6r).

Orthogenesis (Gr. orthos, straight; genesis, generation) (p. 214).

Orthoplasy (Gr. orthos, straight; plasis, formation) (p. 183).

Orthoselection (Gr. orthos, straight; and selection) (p. 214 ;

Ovum (L.), egg (p. 70).

Palæolithic (Gr. palaios, ancient; lithos, stone) (p. 26r).

Paloniol ancient; onta, existences logos, discourse), the science of ancient life on earth.

lozoic (Gr, palaios, ancient; zōé, life) (p. 23).

Palooneny (Gr. palin, again; genesis, generation) (p. 79).

Panmixi (Gr. pan, all, mixis, mingling) (p. 186).

Partarition (L parturire, to bring forth), the act of bringing forth young.

Patriarchate, Patriarchal (Gr. patêr, father; archos, a ruler), government by the house-father (p. 272).

Permian pertaining to Perm, a province in Russia, where the strata are extensively developed.

are extens phallos, the male sex-organ), relating to the phallus.

Phan (Gr. phaneros, visible; gamos, marriage), plants having true flowers with stamens and pistils. 
334 THE FIRST PRINCIPLES OF EVOLUTION

Photochemical (Gr. phos, light; and chemical), pertaining to the chemical action of light.

Phyetic (Gr. phyle, tribe), pertaining to a tribe.

Phylogeny (Gr. phylon, race; genesis, generation), the development of the race.

Physiogenesis (Gr. physis, nature; genesis, generation) (p. 217).

Pistil (L. pistillum, a pestle), the female organ of a flower.

Placentals (L placenta, a flat cake), mammals having a placenta, by means of which the unborn young is nourished in the womb.

Planetesimal, Planetesimal (Gr. planêtēs, a wanderer), a body like a planet (p. 15)

Planetoid (Gr. planêtēs, a wanderer; eidos, form), a body like a planet (p. 15)

Pleistoceno (Gr. pleistos, most; kainos, recent) (p. 28).

Pliocene (Gr. pleiōn, more; kainos, recent) (p. 27).

Polsandey (Gr. polys, many: anēr, andr-, man), union of one woman with many husbands.

Polygamy (Gr. polys, many; gamos, marriage), the practice of having more than one wife at the same time.

Polggenist ( $\mathrm{Gr}$ poly, many; genos, kind), a believer in the multiple genesis of man.

Polvgyny (Gr. poly, many; gynê, woman), the union of one man with many women.

Poljo (Gr. polys, many; pous, foot), an animal like the fresh-wate hydra.

Polytheistic (Gr. polys, many; theos, god), relating to the belief in many gods.

Polytypic (Gr. polys, many; typos, type) (p. 189).

Precambrian (L. pres, before; and Cambrian) (p. 24).

Precambrian (Lrimus, first) (p. 85).

Promiscuity (L. pro, intensifying; miscěre, to mix), promiscuous sexual intercourse.

Proteid (Gr. prōtos, first; eidos, form), a body containing protein for (Gr. prolos, first; cidos, fhe basis af the most essal food formerly supposed to be

Proterozoic (Gr. proteros, fore; zōe, life) (p. 24).

Proto-metal (Gr. prôtos, first; and metal) (p. 33). substance formin living matter.

Protoro (G. protos, first, zōinn, animal), the lowest one-celle Protozoa $(G$.
animals.

Psychosis (Gr. psyche, the soul), a state of consciousness.

Ptolemæan, pertaining to Ptolemy (A.D. 139)

\section{GLOSSARY}

Recessive (L. recessus, a going back), receding (p. 189)

Reflex (L. re, back; flectere, bend) (p. 228)

s, to go), a decline. developed or dwindled part (p. 59).

Sacrum (L sacrum, sacred-namely, bone), the triangular bone situate at the lower part of the vertebral column.

leaping.

(p. 3II)

sertoring and motion.

Sensory nerves (L. sentive, to feel),

pressions made on the the ancient inhabitants of the south-eastern part of Wales (p. 25).

imian (L. simia, ape), like an ape.

Simian (L. simia, ape), like an ape.

Somatic (Gr. soma, body), perly (spectrum and Gr. skopsein, to see)

(p. ro).
Spectre, to see) (p. 9)

Spectrum (L. spectre, to see) (p. 9).

(p. 7r)

Sperm-cell (Gr. sperma, seed), the male sex-cell (p. 7I).

Stamen (L. stare, to stand), the male organs of the flower.

(Lta

Static (L. stare, to stand), pertaid tropos, a turn), the turning toward a solid (p. 229).

ama (Gr. stizein, to mark), the top of the female organ of a flower. Style (L. stilus, anything long), the middle portion of the pistil, leading from the stigma to the ovary.

Suture (L. suerre, to sew), the connections between the various bones of the skull.

symbiosis (Gr. syn, together; bios, life) (p. 154).

Syndasmian (Gr. syn, together; desmein, to bind) (p. 275)

(hy combination of separate elements into a whole.

Tarsal (Gr. tarsos, the flat part of the foot), relating to the tarsusi.e., the ankle.

Taronomic (Gr. tassein, to arrange; nomos, rule), referring to classification.

felology the doctrine of the final issue of things. 


\section{THE FIRST PRINCIPLES OF EVOLUTION}

Tibial (L. tibia, shinbone), relating to the shinbone.

Tort (L. tortus, twisted), a wrongful act (legal term)

Totemism (Algonquin, kitotem, the family-mark) (p. 293)

Triad (Gr. trias, union of three).

Triassic (Gr. trias, union of three), from the threefold grouping of this geological system.

(Gr. treis, three; morphē, form), with three distinct Tropism (Gr. tropos, a turn) (p. 228)

Ungulates (L. ungula, a hoof), hoofed animals. Uniformitarlan (L. unus, one; forma, form) (p. 18).

Urea (Gr. ouron, urine), a substance produced by the decompositio of proteid matter of the body, and carried off by the urine.

Usufruct (L. usus, use; fructus, fruit), the use and profit, but not the property, of a thing.

Ventral (L. venter, the belly), relating to the side of the belly.

Vermiform appendix (L. vermis, worm; forma, form; appendix, something appended) (p. 64)

Vertebrata, vertebral (L. vertebra, a bone of the spine), backboned animals. Villeinage (L. villanus, from villa, a village), the tenure of land by villein-i.e., menial services.

Vitalism, Vitalist (L. vita, life), belief in a special vital principle of life (p. 219).

Voluntarism (L. voluntas, will) (p. 220)

Volvocineso (L. volvere, to roll), an order of fresh-water alga. Vulcanism (L. Vulcan, the god of fire) (p. 18)

\section{N DEX}

ABIOGENESIS, 43, I07 cquired characters, inheritance of, $156,175,177,178$, $217,218,238,303$. See also tance

system, 232

(2) active, 177
between flowers and in sects, 129 sects, 129
colour-, 135

functional, 177

intellectual, 243

ontogenetic, 183

passive, $176,177,188$

of plants, $13 \mathrm{I}$

predetermined, 99 Esthetic standard, 169 . 70

Fsthetics, 246

Agassiz, 86

Alcoholism, 301

Altar, 29I

Amixia, 199

Anaximander, 10

Ancestor-worship, 293 nimals:

ir-breathing, 25 arctic, 135

balance butween, 31

colouration of eggs, 133

compound, 307

domestication, 28
Animals :

emotions, 254

frequenting trees, 133

fresh-water, 100

herbivorous, ' 12

higher, II $3,116,143,148$

I 50, 228, 237, 244, 25 I

o9. See also Ouadrupeds

mitating objects, 137

lower, I1 $3,116,164,227$

$237,242,251,307$

marine, 100

marking, I 35

multicellular, 73

one-celled, $75,228,230$.

See also Protozoa

terrestrial, IOO

unsociable, 252

Animism, 289, 293, 296, 297

See also Spirits

Ape-man, 28, 261, 26

Apogamy, 200

Archæan era, 24

Archæsthetism, 2

Archebiosis, 46

Archistotle, 43, 83, 10

Assimilation, 24I

Atavism, 79

Atom, 30, 31, 40, 43

Atomic theory, 30, 10

trophy, 61, I1 3, I95. See also 


\begin{tabular}{|c|c|}
\hline $\begin{array}{l}\text { Avebury, Lord, } 79 . \text { See also } \\
\text { Lubbock } \\
\text { Avoiding reaction, } 231\end{array}$ & $\begin{array}{l}\text { Bronze-age, 29. See also Metal- } \\
\text { age } \\
\text { Buckman, S. S., } 246 \\
\text { Buffon, I08 }\end{array}$ \\
\hline $\begin{array}{l}\text { Bachofen, J. J., 274, } 277 \\
\text { Baer, Von, } 86\end{array}$ & $\begin{array}{l}\text { Butterflies, } 52,56,79,128,133, \\
\text { 136 }\end{array}$ \\
\hline $\begin{array}{l}\text { M., I } 83 \\
271\end{array}$ & climatic variation, 116 \\
\hline $\begin{array}{l}\text { Barbari } \\
\text { Bates, }\end{array}$ & $\begin{array}{l}\text { geot } \\
\text { ined }\end{array}$ \\
\hline $\begin{array}{l}\text { Bates, } \\
\text { Bateso }\end{array}$ & $\begin{array}{l}\text { inedible, } 146, \\
\text { Kallima, I } 38\end{array}$ \\
\hline Bathmism, 217 & leaf-, I87 \\
\hline fort, 298 & $y, 148,152,164$ \\
\hline $\begin{array}{l}\text { Becquerel, Henri, } 34 \\
\text { Beddard, F. E., I 32, I } 34,147 \\
\text { Bell, I } 46\end{array}$ & $\begin{array}{l}\text { seasonal dimorphism, I35 } \\
\text { warning colouration, I46 }\end{array}$ \\
\hline $\begin{array}{l}\text { Bell, I46 } \\
\text { Bergson, Henri, 221, 222, } 235 \text {, }\end{array}$ & Cambriar \\
\hline $\begin{array}{l}239,240,298,315,316,317 \\
318\end{array}$ & Candolle, \\
\hline $\begin{array}{l}318 \\
\text { Biogenesis }\end{array}$ & $\begin{array}{l}\text { Capitalism, 303. See also In- } \\
\text { dustrialism }\end{array}$ \\
\hline $\begin{array}{l}\text { ww, } 69,74 \\
\text { s, } 213\end{array}$ & Carboniferous age, 25, 26 \\
\hline $\begin{array}{l}15,213 \\
\text { I, } 115\end{array}$ & $\begin{array}{l}1,318 \\
118\end{array}$ \\
\hline 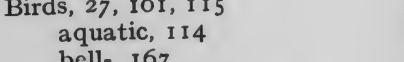 & Catchpool, 201 \\
\hline $\begin{array}{l}\text { bell-, } 167 \\
\text { colour of eggs, } 133\end{array}$ & Cave-age, 265 \\
\hline $\begin{array}{l}\text { colour of eggs, I } 33 \\
\text { cries, } 245\end{array}$ & $\begin{array}{l}\text { Cell colony, } 75 \\
\text { Cesnola, 179 }\end{array}$ \\
\hline $\begin{array}{l}\text { instincts, } 156 \\
\text { maternal, } 240\end{array}$ & $\begin{array}{l}\text { Chamberlin, Th. C., I4, 16, } 22 \\
\text { Change, philosophy of, } 3^{16}, 318\end{array}$ \\
\hline $\begin{array}{l}\text { parental, } 250 \\
\text { intelligence, } 24 \mathrm{I}\end{array}$ & $\begin{array}{l}\text { progressive, 50. See also } \\
\text { Evolution }\end{array}$ \\
\hline 133,141 & Chellian age, 265 \\
\hline $\begin{array}{l}\text { nous union, } 278 \\
166\end{array}$ & Chems \\
\hline $\begin{array}{l}\text { l } \\
\text { colour }\end{array}$ & $\begin{array}{l}\text { Chemotropism, 228, } 230 \\
\text { Citizenship, 284, 287 }\end{array}$ \\
\hline sex differences, 165 & City state, 283,285 \\
\hline sexual selection, 167,169 & Civilization, 271 \\
\hline $\begin{array}{l}\text { song, } 158,170 \\
\text { swimming, } 123\end{array}$ & $\begin{array}{l}\text { ication, } 83,87 \\
\text { E., } 289\end{array}$ \\
\hline 8 & Co-a \\
\hline $52,54,6 \mathrm{I}$ & s, 64 \\
\hline Blackwell, I 53 & \\
\hline $\begin{array}{l}\text { Blastula, } \\
\text { Blood-com }\end{array}$ & $\begin{array}{l}\text { Coelomula, } 75 \\
\text { Collective responsibility, } 288\end{array}$ \\
\hline $\begin{array}{l}\text { Blood-communion, } 29 \\
\text {-corpuscles, I } 95\end{array}$ & $\begin{array}{l}\text { Colour, I } 3 \mathrm{I} \\
\text { distincti }\end{array}$ \\
\hline & resemblance, variab \\
\hline Breeding, & Colouration, $13 \mathrm{I}$ \\
\hline 2 & \\
\hline
\end{tabular}

Colouration, protective, 132, Darwin, Charles, on-

$133,134,170$
warning, I 43,14 Communism, primitive, 280 Conduct, 252

human, 256

Constable, F. C., 159

Co-operation, $251,280,288,303$.

Cope, E. D., II5, I16, 214, 215 , 217,218

Copernicus, 7 4 1, 42, 43. See also Electron, negative Correlation, $183,184,188,198$ Crawley, E., 296, 297, 298 Creation of matter, 7

theory, I 7, 50, 58, 6I
Creative Evolution," 221, 31 5 316

Cretaceous epoch, 27

Croll, James, 28

Crookes, Sir William, 34, 35 Cross-sterilty, 199, 201. See Cunningham, Professor J. T I 33 3 Custom, 254, 282

Cuvier, 86, 109

Dalton, John, 30

Danger-signals, 143

Darwin, Charles, atrophy, 6I variations, 207

cross-fertilization, 128 geographical distribution, IOO, 101, 102, 104 geological time, 29 heterostylism, I 30, I3I human characteristics, I 58 249,267

infertility, 203

instinct, $153,154,238$

inter-relation of species, 80
Darwin, Charles, on-
laws of growth, 183

lunar function of woman, 47 monogamy, 278

moral faculty, 254, 257, 300

natural selection, 182,190

plant-adaptations, 1 25, I 26,

127. serial homologies, 56
sexual selection, 164, 168,

social instinct, 251

struggle for life, I 20

Darwin, Erasmus, 3, 109

Darwin, Francis, 234

Darwin, G. H., I I, I6, 19, 30

Darwinism, 3, 49, 106, I I 7 , I 22 , 124, I 1 $172,178,184,189$ winism

Dawkins, W. Boyd, 265

Death, 3I 2, 3I 3

Degeneration, I59, I6I, I85,

192, 194. See also Atrophy

and Rudimentation

Delbœuf, J., 189

"Democritus, 107 " Descent of Man," 63, 1 57, 249

Descent of Man,"

Determinants, 195

progressive, 50, 56, 90, 107. 157

social, 307
See also Evolution

Devonian system, 25

Differential sensibility, $23 \mathrm{I}$

Differentiation, progressive, 309 Dissipation, 306, 307. See also

Dissolution
Dissociation of elements, 32,33 ,

34,37
Dissolution, 305,313 . See also Dissipation

Dominants (of Mendel), I 89

(of Reinke), 220 
340 THE FIRST PRINCIPLES OF EVOLUTION

Driesch, Hans, 44, 220 Dubois, Dr. Eugène, 26I Duration, 316, 318

Ear, 68

Earth, 13, 17, 19, 20, 22, 313 Ectoderm, 73

Eimer, G. H. Th., 134, 192, 214 215, 224

Electron, 35,40

negative, $36,41,42$. See negative, 36,4
also Corpuscle positive, 41,42

Elements, 33, 40, 314

Emanation, 37, 38

Embryogeny (embryonic de velopment), 69, 7I, 77, 98, 194, 197, 250, 307

Embryology, 69

Empedocles, 107

Entelechy, 220

Environmental conditions, 112 II4. II 5. See also Lamarckism

Eocene period, 27

Eolithic age, 26I

Epicurus, 10

Equilibrium, 311, 312

radio-active, 38

Ethics, 4, 246, 247, 248, 256

See also Mora

Eugenics, 304

volution, 2, 49, 50, I6I, 316 velopment

atomic, 30

cosmic, 7

definition, 306

diagram, 174

divergent, 189

ethics, 247

geological, $17,306,308$

geological, $17,306,308$

Evolution of life, 43

limit, 311

mental, 226, 240

monotypic, 189

moral, 247,256

$223,307,308,310,312$

polytypic, 189,203

and progress, 298

of religion, 288

of science, 318

simple, 308

social, 226, 271, 297, 309,

313
stellar, II, 306, 308, 310

uperorganic, $157,225,307$

312
theory, 105, 205

Evolutionism, false, 315,316

Eye, $65,116,221$

Family, 250, 272, 273, 275, 279

Family, $250,272,273$

Faye, Professor, 13

Fertilization, 250 cross-, $127,128,129$
by insects, 127,128 by wind, 127

Feudalism, 284, 286

Feudalization, 285

Finalism, 222

"First Principles," 4, 305

Fittest not the best, 160, 162
Fluctuations, 2 10. See also

Variations, fluctuating

France, R. H., 220, 234

Fraunhofer, 9

lines, 9
arer, Professor J. G., 293

Frequency curves, 206

Galton, Sir Francis, 210

Gastrula, 73

Genepistasis, 21

Generation, spontaneous, 43
Genetic tree, 87
INDEX

$34 \mathrm{I}$

Geocentric theory,

eographical distribution, 99

Geotropism, 228, 230

Gill-arches, 78

Goethe, 109

Goethe, 109

Green, Thomas H., 247

Growth, 183, 214, 217

Gulick, J. T., 200

Gynocracy, 275

Habit, 114, 156, 162, 177, 238

Haeckel, Ernst, 37, 46, 69, 79, 86, III, 299

Heliocentric theory, 8

Heliotropism, 228

negative, 229

posative, 229,230

Helmholtz, 47

Henotheism, 292, 294

Henslow, G., II

Heraclitus, 107

Herschel, Sir William, 8

Heterogeneity, 308

Heterogenesis, 106, 205, 206, 207. See also Mutation theory Heterostylism, 129

(24I,

$499,301,244$

Homogeneous, transformation of the 31

Howard, G. E., 272

Huber, P., I 54, 236

Huggins, Sir William, 10

Human faculty, 157,196

Hutton, 18, 108, 109

Huxley, T. H., 46, II I 226, 257 ,

Hyatt, A., II 5, II6

Ice-age, $27,28,103$

Ideas, ethical, 25 practical, 24 mitation, 244 Industrialism, 309. Se also Capitalism Infant, 66, 237, 246, 249 Infanticide, 276

Infectious diseases, 301 203,278

Infertility, 201, 202,

See also Cross-sterility Insects, 43, IOI

colour of eggs, 133

communities, 251,271

instincts,

mimicry, 148

mouth-organs, 56

seasonal dimorphism, 135

stick-, 137
wingless, 62

Instinct, $152,153,155,156,229$, 235, 238, 318

and habit, 177

maternal, 240

moral, 247,238

prigin, 237,238

pure, 236,25

vital, 296

ntegration, 306, 307, 308

Intellect, 260,317

Intelligence, 238, 240, 24I, 244

Intercrossing, 198

Intra-selection, 193, 214

ron-age, 29. See also Metal-age Island life, $\mathrm{IO}_{3}$

5. 198, 199, 200,

James, Professor William, 314

315

Jean, J. H., 20

Jevons, F. B., 293
Johannsen, W., 213 
342 THE FIRST PRINCIPLES OF EVOLUTION

Jolly, J., 29
Jordan, D. S., 200

Judgment, conceptual, 245. See also Ideas

ethical, 248, 253. See also Morality

practical, 243, 245

Jurassic system, 27

Jurassic system 286

\section{Kant, 8, 9, 14}

Kant-La placean theory, 8

Keane, A. H., 265, 268

Keeler, Professor, 14

Kellogg, V. L., 194

Kelvin, Lord, 19, 29, 47

Kepler, 8

Kinetogenesis, 217

King's peace, 287

Koch, Robert, 43

Korschins

Kropotkin, Prince, 25

Laissez-faire, 299

Lake-dwellings, 270

Lamarck, 3, 106, 108, 111 , 113

I I 4, I 23, 177

Lamarckism, 106, III, I14, 123

129, I 56, I 59, 172, 173, 177

$178,180,185,190,215,220$

223,238 . See also Neo-

Lamarckism

Language, 1 58, 245, 246, 309

Language, 158, 245, 246,

Laplace, 8, 9, 14, 16

Law, 283 moral : 256. See also Mo-$$
\text { ralit }
$$

Leonardo da Vinci, 17,108

Levirate, 276

Lewes, G. H., 1 56, 238

Life, origin of, 46,47

Limbs, 54,58
Linnæus, 83, 108, 120, 208 Lockyer, Sir N., 16, 32, 33, 34, 36 Lodge, Sir Oliver, 44 Loeb, Professor J., 227, 228, 229 uubbock, 277. See also Avebury

Charles, 18 , 109

Madelenian art, 270

epoch, 265

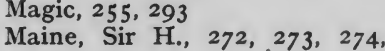

275

Malthus, I IO, I 20

feet and teeth, I I6

flying, 1 I 5

non-placental, 27

Man, 90, 93, 160, 235, 298

arm, 54

descent from monkey, 2

higher achievments, 3

faculties, $157,158,159$

172,226

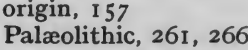

specifically human charac-

Mark, 28

ters, 158

arriage, 278

communal, 277

Matriarchal theory, 274

Matriarchate, 277

Mıtter, electronic theory of, 40 and life, 44, 22I

radiant, 35

Maurer, G. L. von, 28

Mayer, Professor, 4

McDougall, Professor William,

cLennan, J. F., 274, 276, 277 279
Mammals, 90, 141, 167, 250
INDEX

343

Mechanistic theory, 44, 214, 218, Mutation, 106, 185, 204, 209, $222,228,230,314,317$

Memory, 243

Mendelian 31 , 43 inheritance, 189, 204, 207, 211 Mesolithic age, 268

Mesozoic era, 27

Metal-age, 261, 270

Metamorphosis of insects, II6 of plants, 107

Meteoritic theory, I

Meyer, Lothar, 3

Migration, 100, 105, 199

Mimicry, I48, I 5 I, 240

Miocene epoch, 27, 261

Mitchell, Professor P. C., 46

Acquired characters

Monism, 44

Monogamous theory, 278

Monogamy, 279, 280

Monogenists, 266

Monotheism, 292, 294

Moral behaviour of animals, 249 faculty, 25

growth of child, 249

judgments, 253

progress, 247, 255, 257, 300 worth, 247,253

Morality, $116,247,248,255$ See also Ethics

, 274, 275,279

Morgan, Professor Lloyd 143,

I $53,156,169,171,179,192$ $198,226,235,237,238,246$, Morgan, Th. H., 209, 212

Morphology, 5

Mortillet, M. de, 26

Morula, 72

Mother-right, 274, 277, 279

Moulton, F. R., 13, 14, 15

Mousterian epoch, 265

Mïller, Max, 292, 295 .

Music, $58,159,196,309$
2 10. See also Variations, discontinuous theory, 190, 205, 207, 208 rogenesis

Naegeli, Carl von, 21

. $180,181,184,187,190,239$ Neo-Lamarckism, II

187. See also Lama 172,17 Neolithic-age, 26I, 268

Neo-vitalism, 219

Neptunists, 18

Newlands, John, 31

Obligation, 254, 255, 256

Oken, Lorenz, 109

Oligocene epoch, 27

Ontogeny, 69, 78

Organic compounds, 45

"Origin of Species," 3, 49, I09, 110,157

Aignal pairing, 278

Orthogenesis, 106, 205, 214, 215

218,224

Select, 183, 188. See also Orthostion,

Osborn, H. F., I I 5, I I 6, I 83

Packard, A. S. III II5, II6

Palæolithic age, 26

Palæontology, 89

Palingeny, 79

Panmixia, I86, I90, 191, I92, 195. See also Selection, natural, cessation of

Parasitism, I6I. See also Retrogression

Patriarchal theory, 272

Patriarchate, 273, 279, 282

Pealy, A., 220

Pearson, Professor Karl, 303 
344 THE FIRST PRINCIPLES OF EVOLUTION

Perrier, 156

Persistence of force, 311,314

Perthes, Boucher de, 260

Pflüger, $47,48,234$

Phylogeny, 69, 78

Physiogenesis, 217

Physiological units, 194

Pithecanthropus, 28, 261

Planetesimal hypothesis, 15,22

Plants, 27, I1 $3,115,120,22$ 234, 305

climbing, 125

Plate, Professor $1,17 \mathrm{I}, 178$

$182,187,189,190,193,200$

$202,204,213,218,219$

Pleistocene period, 28, 261

Polygamy, I68. See also Poly

gyny

Polygenists, 266

Polygyny, 277, 279. See also

Polygamy

Polytheism, 291, 294

Post-glacial period, 28

Poulton, Professor E. B., 133

134, 1 36, I 46, I 50, 179, 239

recambrian system, 24

Prefertic ae, 26I

Preyer, Professor W., 47

Progress, 299, 300

of science, 310
miscuity, $276,277,278,279$

Proterozoic era, 24

Prout, 31

Pure lines, 213

Quaternary era, 28, 26

Quatrefages, 267

Race decay, 313

-feeling, 202 $34,37,40,314$

Ramsay, Sir William, 36

Recessive, 189
Recognition marks, I43, 170, 203 Reflex, 228, 236

Reid, Dr. Archdall, 30

Reinke, J., 220, 22

Religion, 288, 298

evolution of, 289
Religious consciousness, 255 .

288,296
sacrifice, 291, 29

sacrifice, 291,

Revelation, 289, 295

Ritchie, D. G., 258, 300,304

Romanes, G. J 49, 50, I43, I78,

I8I, I86, I89, 190, 19I, $19^{2}$

199, 200, 20I, 227, 230, 236

257

Roux, W., 193, 194, 214

Rudimentary structures, 59

6I, I6I, 191, 192. See also Atrophy, Degeneration, Rudimentation, and Vestigia structures

Rudimentation, 192. See also

W., 36, 37

Sanders, 179

Savage, $158,254,255,271$

Scudder, W., 152

Seasonal dimorphism, I35

Segregation, 3I I

Seitz, Dr., 150

Selection, artificial, I 20, I 22

coincident, 183. 197

germinal, 184, 186, 190, 192

194, 196, 2 I4

natural, 106, $116,117,124$, 160,168 . See als

and animal colouration, 132, $133,134,138$ 163

auxiliary theories of, 190 See also Panmixia
INDEX

345

Selection, natural, and evolu- Spencer, Herbert: origin of martion, $172,173,178$ 189, 205, 209, 217 223 and origin of flowers, and

and instinct, 153,154

196 in man, 157,158

and mimicry, 152

and morality, 251 and sexual selection,

168,17

rational, 304

reversed, 186

exual, 106, $117,152,163$ $164,166,167,168,171$

ex-characters, secondary, 163 169, I70, I7I

Silurian system, 25

Smith, Professor W. Robertson 293

293 inheritance, I 59, 301

Sroe also Development, socia

Society, 225, 288, 307, 309

Soddy. Professor F., 36, 40

Solutrian age, 265

Sorley, Professor W. R., 247, 248

pecies, 2, 49, 50, 52, 86, 87, 124 I $72,180,208,292,307$

pectrum, 9, 10, 32, 33

Spencer Herbert, 3, 5, 6, 86, I IO, II $5,122,180,192$ 225

conduct, 252

dissolution, 313, 314, 315

formula, 305, 310, 3 II

instinct, 236, 237

and Lamarckism, 115,116 , I $59,187,188$ riage, 274, 277, 278,

f religion, 289, 29I

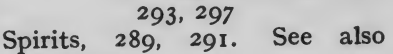

Animism

influx, 158

Sprengel, Christian K., 127

State, 280, 287

teno, 17, 108

tereotropism, 229

St. Hilaire, Geoffroy, 109

also Neolithic and Palæo-
also lithic ages

Professor, 245

Surnatural, the, 292, 293

(the fittest, I22, 180 , 257 , 302. See also Selection, natural

value, 223
therland, A.,

ymbiosis, A, 250, 257

Sympathy, 239, 249, 25I, 318 "Synthetic Philosophy," 4, 5 IIO, 305

Tayler, J. L., 183

Taylor, A., I70

Teleological interpretation, 122

1 59, 221,222

Thales, 107

Thomson, Professor J. A., 45

Thomson, Sir J. J., 4O, 4I, 42

Thorndike, Dr., 242, 244

Totemism, 293

Transmutation, 3, ro9. See also Change and Evolution

Treviranus, 109

Trial and error, 230, 23I, 240, 244

Triassic system, 2

ibal communitios

feeling, 254
Spiritual agencies, 172 
346 THE FIRST PRINCIPLES OF EVOLUTION

Tribal organization, 28I Tropism, 228, 230, 231
Tylor, Professor E. B., 289, 292

Uniformitarian doctrine, 18

Use-inheritance, $116,155,156$, 175, I78, 188, 238.
Acquired characters

Variability, 121, 180, 188, 206 ariations, $121,180,218$ 224. See also Species, elementary continuous, 182, 20 definite, 196

discontinuous, $185,205,207$ fluctuating, 182 , I97. See also Fluctuations germinal, $183,198,203$ individual, 182,213 single, 2 10

somatic, 206

Variation, law of, 170, 174

Verworn, Professor Max, 44

See See also Rudimentary struc-
tures tures

Viage community, 281, 28 instinct, 296 principle, $44,45,46$ See also Vitalism Vitalism, 47, 214, 218, 219, 220, 223,224
Voluntarism, 220

ries, Hugo de, 184, 185, 208 , 209, 210, 211, 212, 213

Wagner, Moritz, 199 Wallace, A. R., IO2, I10, 117 $122,141,143,151$ human faculty, 157,158 , infertility, 203, 204 Lamarckism, 159, 172, 178, 181

sexual selection, I70, I7I eismann, August: colouration, I 33, I 35

nal selection, I 86, I 89 , 190, 194, 195, 196, 197 . 214 histonal selection, 193 infertility, 203

musical faculty, 159 Neo-Darwinism, 172, 177 , $178,180,184,187$ panmixia, 190, 191, 192

Weldon, W. R. F., 214

Werner, 18

Westermarck, Professor E., 253 $274,278,279$

Wife-capture, 276

Wöhler, 45

Wolff, G., 219

Woman, periodic function of,

Wundt, Professor, I 56, 238

SOME PRESS OPINIONS OF

THE

FIRST PRINCIPLES OF HEREDITY

\author{
BY \\ S. HERBERT, M.D., M.R.C.S., L.R.C.P. \\ Large Crown 8vo. Cloth. Containing 75 Illustrations.
}

Price 5s. Net

(By Post 5s. 4d.)

" Dr. Herbert's book can be recommen Jed as a trustworthy 'first aid' in the study of a difficult subject. His style is lucid and concise, and he has provided a glossary which will be of service to many."-Atheneum.

“- First Principles of Heredity' gives a popularly written yet scientific account of all that the average educated reader may desire to know about heredity and kindred subjects, without assuming any knowledse of the subject on the reader's part."-Public Opinion.

"Dr. Herbert will be found a safe guide. He writes as clearly and as simply as may be upon a subject in which it is practically impossible to avoid ably adapted for the class for whom it is intended."-Westminster Gasette.

"We have only praise for the result of Dr. Herbert's attempt to provide us with a simple and brief, but at the same time scientific and comprehensive, survey of our present knowledge concerning the laws of heredity, their working and significance. Hitherto there has existed no book upon heredity whose bulk and technicality did not appal, weary, or distract a first enquirer. 'First Principles of Heredity' is designed for those without any previous knowledge of this difficult subject. And since 'social subjects' have never before occupied so great a share of men's thoughts; since, in fact, we have all 
become reformers under different names, it is a matter of supreme importance that as a foundation to our thinking we should possess an accurate knowledge of the laws of life. Particular mention must be made of the wealth of diagram the complety which will be much apreciad by many readers."-Eugenics Reviev.

"The appearance of this book should be welcomed. . . May be recom. mended to all anxious to follow the course of modern speculation in the realm of heredity."-Daily News.

"A sound little treatise which will be found valuable by those who have little preliminary scientific training. What is actually known is succinctly set forth, and then follows a fair and impartial account of the theories of Spencer Weismann, and Mendel, in which we should conjecture that the writer hasce more influenced by $\mathrm{Dr}$. J. A Thomson-and a very rood influence it is - than by any one else."-Nation.

“ Dr. Herbert has produced a book which we think will he widely read and will also serve its original purpose as a text-book for elementary students very usefully. The text is clearly written, without any superfluous wordiness, and conveniently divided into sections. The diagrams and illustrations adopted from various sources have been judiciously chosen, and do much to throw light on the difficulties which so often puzzle beginners; and the printing and page are very pleasant."-Manchester Guardian.

"This may be described as a text-book of the science of heredity. It has all the qualities of a rood text-book, orderly arrangement, clearness of exposition, apt illustrations and diagrams, without any straining at originality or a strong statement of the author's particular views."-Glasgow Herald.

" It is a book which any serious man or woman desirous of some introductory insight into these problems would profit by reading."-Aberdeen Free Press.

"Dr. Herbert's introductory manual can be confidently commended to all who are unacquainted with the subject. It is clear, and thorough, and fair, and it gives good descriptions and illustrations of the relevant groups of facts and the various theories advanced in regard to them. A glossary robs the dreadful jargon of the biologist of its terrors. The treatment of Biometrics, the statistical method developed by Galton and prosecuted by Pearson, is particularly enlightening."-Liverpool Courier. 
COLUMBIA UNIVERSITY LIBRARIES

This book is due on the date indicated below, or at the expiration of a definite period after the date of borrowing, as provided by the library rules or by special arrangement with the Librarian in charge.

\begin{tabular}{|c|c|c|c|}
\hline DATE BORROWED & date due & DATE BORROWED & DATE DUE \\
\hline & DEs 7 19/ & 5 & \\
\hline & & & \\
\hline & & & \\
\hline & & & \\
\hline & & & \\
\hline & & & \\
\hline & & & \\
\hline & & & \\
\hline & & & \\
\hline & & & \\
\hline & & & \\
\hline & & & \\
\hline & & & \\
\hline C281546)M25 & & & \\
\hline
\end{tabular}

Herbert

The first principles of evolution

$$
\text { d. Goomen }
$$

DEC it 965 


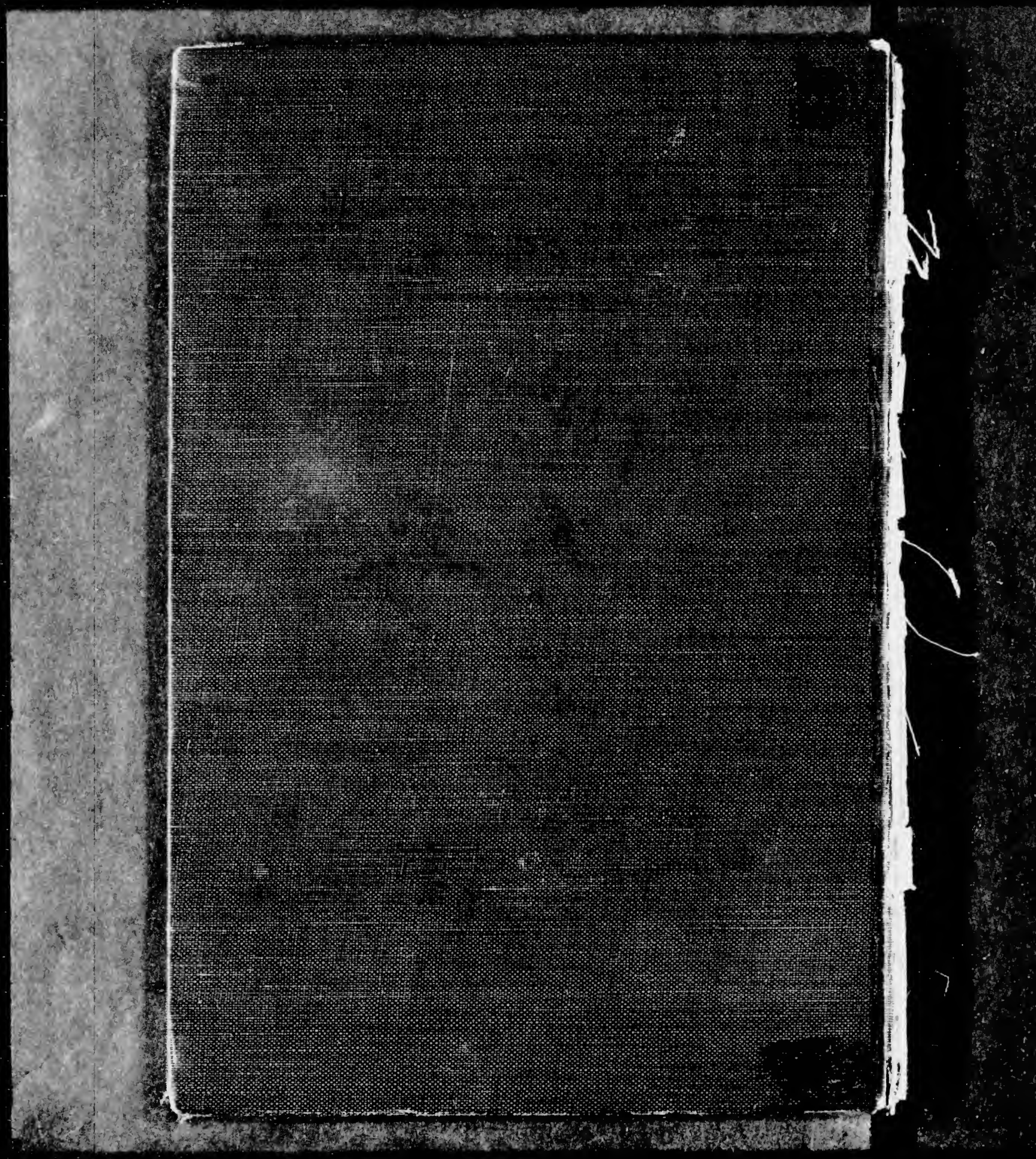

